

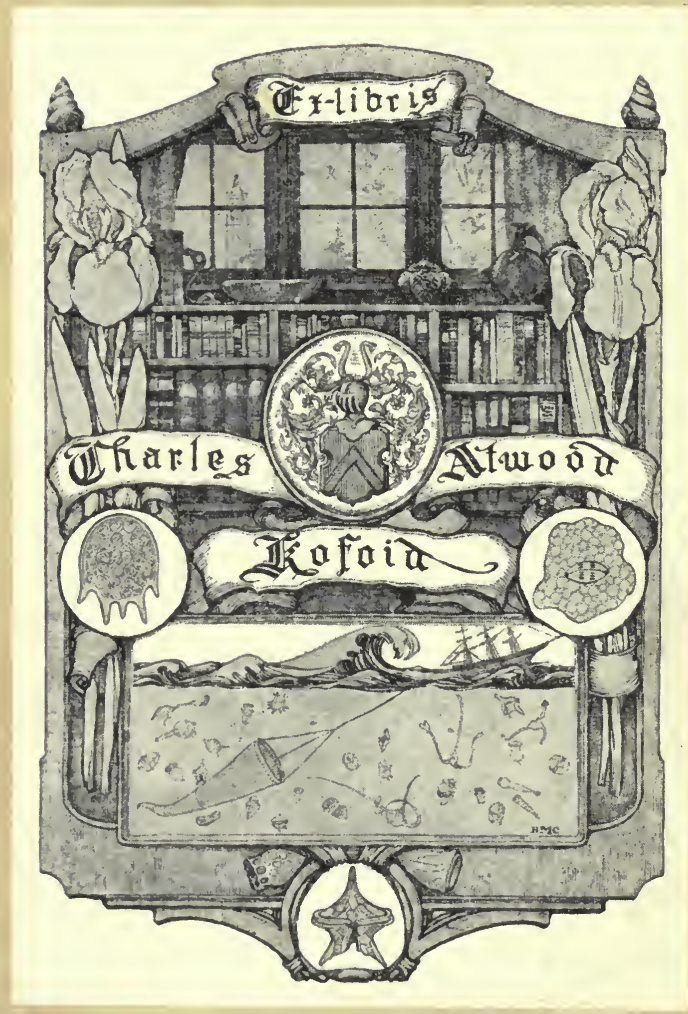




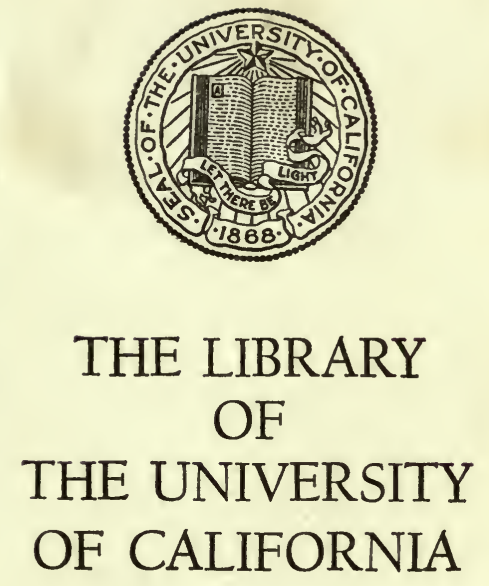

PRESENTED BY

PROF. CHARLES A. KOFOID AND MRS. PRUDENCE W. KOFOID 


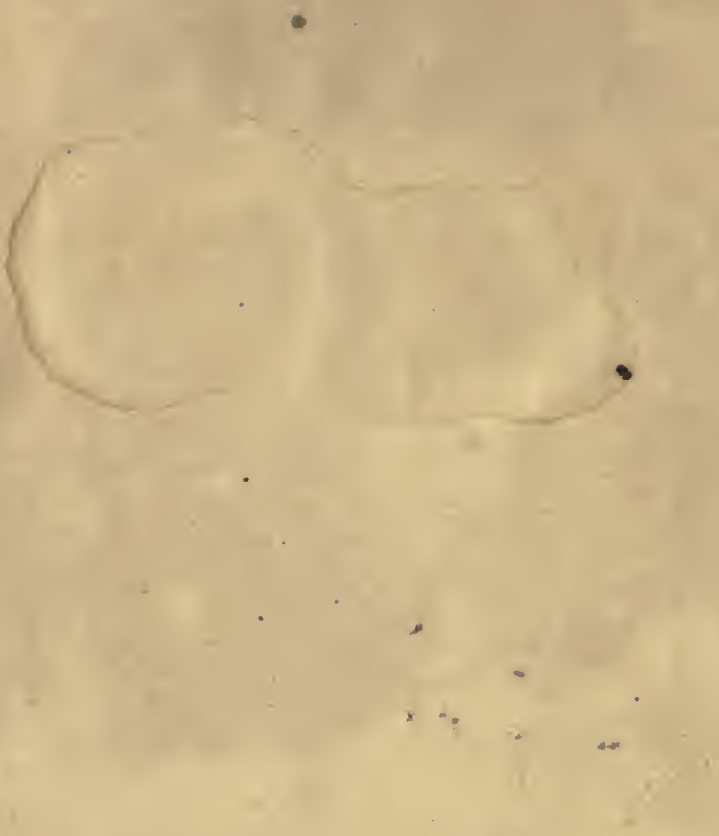

Unin Calit - Digitized by Microgoli at 



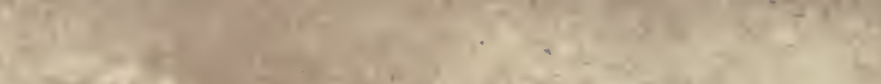

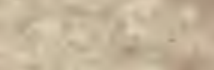

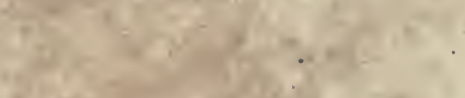

$\lim _{x \rightarrow 2}+20$

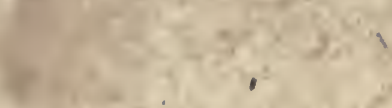

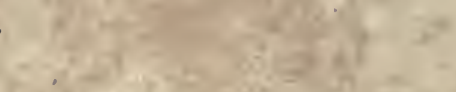

(1)

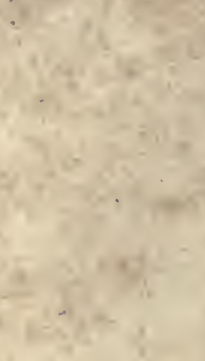

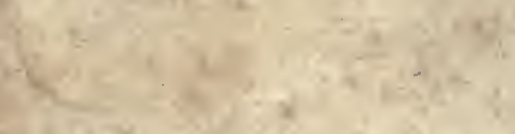

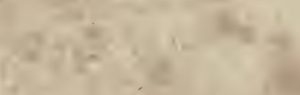

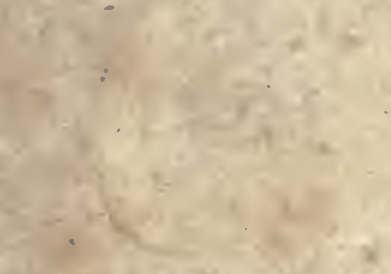

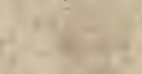

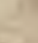

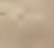

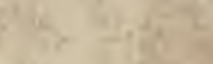
$-1$

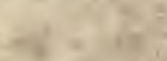

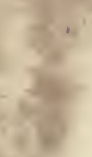

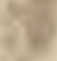

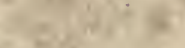

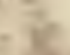

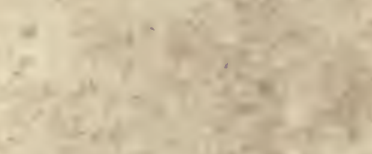

a.

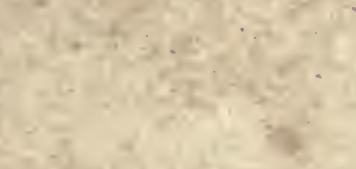

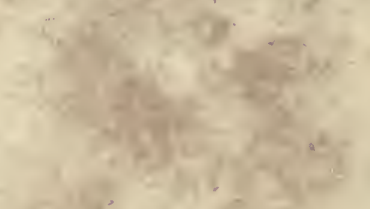

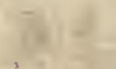

77

tr.

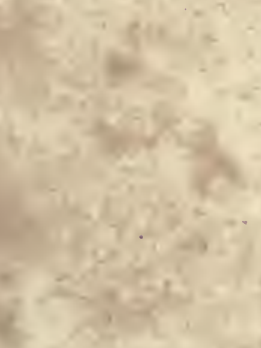

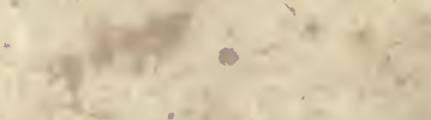

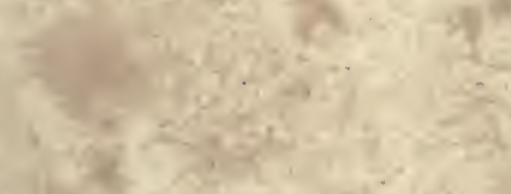

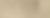


Digitized for Microsoft Corporation

by the Internet Archive in 2008.

From University of California Libraries.

May be used for non-commercial, personal, research, or educational purposes, or any fair use.

May not be indexed in a commercial service. 


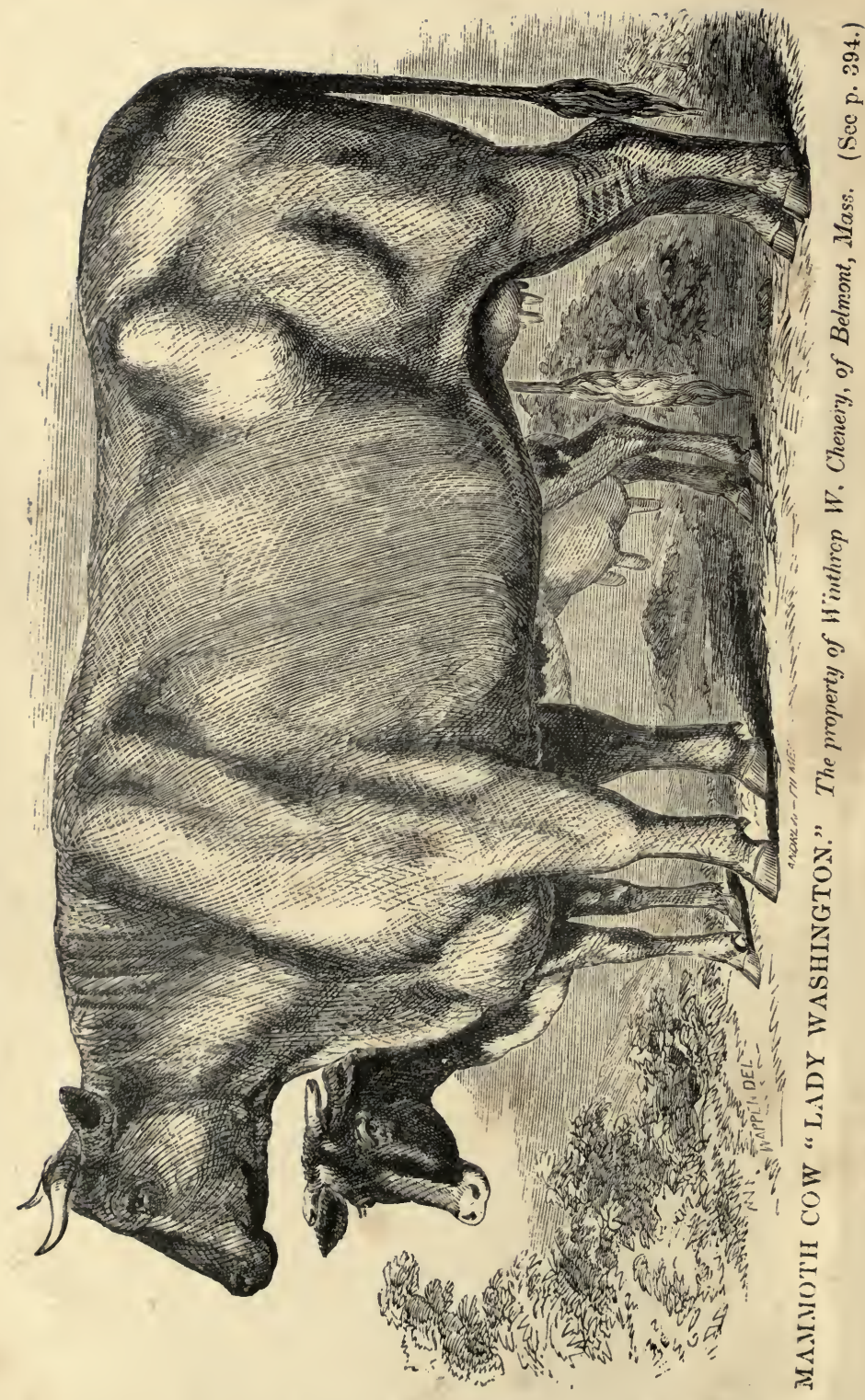




\section{A D D}

ON THE NATURE AND TREATMENT OF

\section{THE DISEASES OF CATTLE,}

WITH

DESCRIPTIONS AND ILLUSTRATIONS

of

VARIOUS ORGANS AND FUNCTIONS OF THE ANIMAL ECONOMY.

Containing also,

USEFUL AND PRACTICAL INFORMATION

ON BREEDING, VENTILATION, AND DIET,

\section{BY GEO. H. DADD,}

VETERINARY SURGEON.

Author of "Anatomy and Physiology of the Horse," "Modern Horse Doctor," etc., Lecturer on Veterinary Science at the Boston Veterinary School.

Those Physicians generally become the most eminent, who soonest emancipate themselves from the tyranny of the schools of physic. - RUSE.

\footnotetext{
THIRD THOÜAND.
}

B O T T O :

JOHN P. JEWETT AND COMPANY NEW YORK: C. M. SAXTON.

1859 . 
Entered according to Act of Congress, in the year 1859, by JOHN P. JEWETT AND COMPANY,

In the Clerk's Office of the District Court for the District of Massachusetts.

LITHOTYPED BY COWLES AND COMPANY,

17 WASHINGTON ST., BOSTON.

Printed by R M. Edwards. 


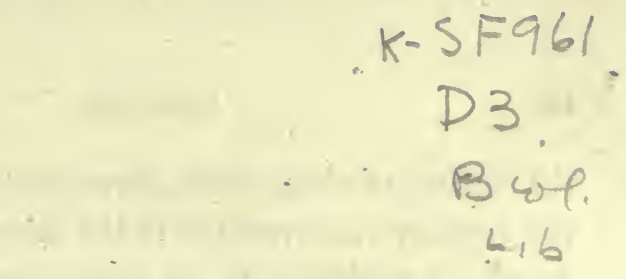

\section{PREFACE.}

During the past few years, American husbandmen have been, without regard to cost, extensively engaged in importing some of the finest specimens of neat stock that man ever beheld; and in consequence of these laudable enterprises, a very marked improvement in this description of live stock is continually occurring. Having great interests at stake in the ownership of more costly and valuable animals than have hitherto been found in this country, and great losses continually occurring in consequence of premature deaths, brought on by unnecessary diseases; the common inquiry among farmers and dairymen is, - How shall we protect our property against the ravages of disease? But a more important question, in my opinion, might be asked; viz., How shall diseases be prevented? If this country could only boast of a class of men highly educated in all that pertains to the veterinary art, and, provided such persons practised a rational system of medication, and had the necessary faith in the- powers of nature to cure disease; then, these questions might easily be solved.

Unfortunately for the interest of stock owners, and

\section{Univ Cali Ṁ̧ C502}


the welfare of their stock, there are but few persons in this country conversant with the theory and practice of veterinary medicine, in its application to cattle; and my object in writing this work is, to supply, to the best of my ability, a deficiency which all husbandmen have had occasion to lament.

This work is intended for men who are not expected to understand Latin; therefore, I have deviated from the accustomed mode of using the same, in all cases where it could be dispensed with; and knowing that most, if not all of my readers, will consult these pages more for practical than theoretical information, I have endeavored to be as practical as possible, and have given the reader the benefits of my past experience in as brief a manner as the various subjects can be presented.

The great superiority of the methods of treatment offered in the following pages is (in my opinion), to the candid mind, self-evident, and must eventually supercede the popular, yet false, theory which teaches that blood-letting and poisons cure disease. Blood-letting and poisons, which destroy health, can never be made to restore it, and in the course of many years, practice I have established these propositions in my own mind, beyond the shadow of a doubt. I now have more faith in the recuperative powers of nature, and in the exhibition of sanative agents, than in false theories of art, or the destructive agents so highly recommended and extensively used by those professing 
the orthodox veterinary faith ; having also, strong convictions of the soundness in doctrine, as inculcated by Dixon ; viz., "Nature is ever busy by the silent operation of her own forces in curing disease; her medicines are air, food, water, and rest," etc., I contend that in the treatment of any and every form of disease, the object should be to aid nature, and thus preserve the vitality of the system; this is to be accomplished by regulation of diet, ventilation, cleanliness, good nursing, which includes proper attention to the real necessities of the animal, medicinal agents properly selected of well-known sanative qualities, obtained from the laboratory of nature, concocted by the great chemist in the forest, and the field; and necessary surgical operations which have to be performed under the influence of sulphuric æther.

It is a fact well known and acknowledged by those who have emancipated themselves from the theory of the schools, that the heroic practice-meddlesome medication - has destroyed more animals than the epizoötic sword, and yet many physicians even in these enlightened times, will lull their consciences into an insane belief that the phlebotomizing, and heroic practice is the only legitimate, safe, and effectual method of eradicating disease; and they base their arguments on the untenable ground, that some animals thus treated recover; when the fact is, these supposed medical recoveries are so many lucky escapes from death, secundum artem. 
The intelligent reader is probably aware that some animals will survive the most frightful injuries, and reckless methods of practice; hence, if a poor, sick brute recovers its ordinary health, after having more than one-half of its blood abstracted, and the remaining portion poisoned by tartar emetic, corrosive sublimate, arsenic, or antimony, medicines in great repute among men who reverence science instead of nature, or nature's God. The inference to the rational mind is, - and on the strength of logical arguments which I might introduce, - that the supreme vital powers of the system successfully combatted both the disease and the outrageous treatment.

I am well aware that such real, matter-of-fact opinions conflict with those of many well-educated, and honest physicians; and it is a notorious fact, that the popular opinion of the non-medical world, who obtain their knowledge of veterinary science from the experience and writings of men more desirous of sustaining the rotten autocracy of science over nature, rather than to establish nature's autocracy, is somewhat against me; yet, as I have truth, reason, and experience to sustain me, I fear not the consequences of an impartial investigation.

The remedies recommended in the following pages, for the treatment of bovine afflictions, are selected in consequence of their well-known sanative effects; they are calculated to favor vital action, and remove ordinary obstructions wherever they exist; and if the reader 
comes to the honest conclusion that I have recommended any agent in the treatment of disease, which is known, or shall ultimately prove, inimical to the physiological action of any function or organ of the animated creature, then the fault is on my side, yet is purely accidental, in consequence of my lack of experience in being able to select suitable substitutes; but such do exist; and so soon as they shall be discovered they are to be marshalled in the list of physiological agents.

Husbandmen and others, who shall treat disease according to the principles recommended in the following pages, will have the satisfaction of knowing that, if their patients die, their deaths are not occasioned by a medicinal disease; and as the remedies are of a sanative character, a slight mistake in either quantity or kind will not prove injurious, unless it be recklessly administered.

There is nothing good in medicine, except that which is congenial to nature, or acts in harmony with the laws of life; and the same proposition is proverbially and experimentally true, both as regards food and fluids; neither the one nor the other are of any value, unless they contain elements of nutrition.

In the early history of medical science, or rather at the period when Hippocrates flourished, simple and safe medicines were prescribed, and the wonderful success which attended his mode of treatment, was due to the fact that he was skilled in the use of medicines 
furnished by nature. This was the man who rescued Athens from the most dreadful scourge that ever afflicted the human race. But so soon as the science of medicine was rendered technical, and also, incomprehensible by false theories and chemical speculations; then simple remedies were replaced by agents prepared in the chemist's laboratory, many of which are known to be highly injurious and poisonous; and others. no less noxious, were obtained from the vegetable world; these are the "heroic" medicines,_- "They deserve a considerable share of the praise of the Casars and Alexanderrs of the world; powerful to destroy, heroic in blood, havoc, and desolation."

But the days of heroic medicine, so far as it applies to the United States, are numbered. Intelligent men of the right stamp, are now engaged in testing the merits of the new system of practice recommended in the "Modern Horse Doctor," and in this work ; and it is gratifying to the author to know that his work on the horse has had a large circulation among the lovers of fine animals; and this work is now offered in the hope, that it may do good and advance the cause of medical reform.

George H. Dadd.

Boston, 1859. 


\section{CONTENTS.}

\section{Diseases of the Organs of Respiration.}

,, 15

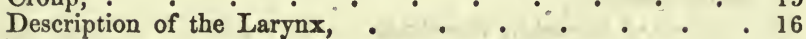

Laryngitis, . . . . . . . . . 17

Bronchitis, . . . . . . . . . 18

Inflammation of the Lungs, . . . . . . 19

Description of the Lugngs, Function, etc, . . . . 24

Catarrh, or Hoöze, . . . . . . . . 25

Epizoötic Catarrh, . . . . . . . . . 28

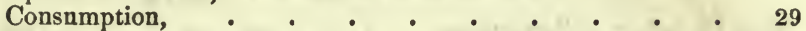

Pharyngitis, or Sore Throat, . . . . . . 31

Description of the Pharynx, . . . . . . 32

Pulmonary Apoplexy, . . . . . . . 33

Pleurisy and Description of the Pleura, . . . . 34

Pleuro-Pneumonia, . . . . . . . . 36

Epizoötic Pleuro-Pneumonia, . . . . . . 37

Inoculation for Pleuro-Pneumonia, . . . . . 43

Pneumatosis, or Windy Distention, . . . . . 55

The Gaseous Fluids of the living animal body, . . . . 46

Murrain, . . . . . . . . . . 56

Essay on Ventilation, . . . . . . . . 65

\section{Diseases of the Digestive Organs.}

Description of the Esophagus, . . . . 77

Foreign Bodies in the Gullet, . . . . . . 78

Csophagotomy, . . . . . . . . . 79

Laceration of the Esophagus, . . . . . 80

Apthæ, . . . . . . . . . . 85

Description of the Stomach, . . . . . . 86

Rumination, or Remastication, . - . . . 88

Sensible Phenomena of Rumination, . . . . . 91

Bloat, or Tympanites, . . . . . . . 100

Distention of the Rumen with Food, . . . . . 103

Gastro-Intestinal Inflammation, . . . . . . 104

Suspended Rumination, . . . . . . . 112

Inflammation of the Bowels, . . . . . . 115

Invagination of the Intestines, . . . . . . . 116

Diarrhœa, : . . . . . . . . . 118

Chronic Diarrhœa, . . . . . . . . . 119

Gut-Tie, . . . . . . . . . 119

On the Internal Ruptures of Oxen, ${ }^{-}+{ }^{-}+{ }^{-} 124$ 


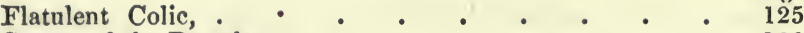

Spasm of the Bowels, . . . . . . . 126

Constipation of the Bowels, . . . . . . 127

The Pancreas and its Function, . . . . . . 128

Description of the Spleen, . . . . . . . 129

On Diet; . . . . . . . . . . 130

Variety of Food necessary, . . . . . . 130

Effects of various kinds of Food, . . . . . 135

As regards the quantity of Food required, . . . $\quad$. 137

Animals intended for fast work must not accumulate fat, . 138

As regards changes in Diet, . $\quad$. $\quad . \quad$. 142

\section{On the Principles of Breeding.}

In-and-in Breeding, . . . . . . . . 150

The objects of In-and-in Breeding, . . . . . 155

Animals become parents too early, . . . . . 156

Objections to In-and-in Breeding answered, . . . . 159

The advantages of In-and-in Breeding, . . . . 160

\section{Parturition, or Labor.}

Signs of Labor or Parturition, . . . . . 160

Natural and Unnatural Labor, . . . . . . 161

Fore Legs Presenting, . . . . . . . . 161

One Fore Leg Presenting, . . . . . . 162

Head Presenting without the Legs, . . . . 162

Extraction of a Calf on its back, hind legs presenting, . . 163

Breech Presentation, . . 165

Cleansing or Removal of the Afterbirth, . . . . 166

Back of the Calf presenting at the Brim of the Pelvis, . . '168

Uterine Hemorrhage, or Flooding, . . . . . 169

Birth of Twins and Triplets, . . . . . . 169

\section{Diseases of the Generative Organs.}

Constriction at the Neck of the Uterus, . . . . 171

Embryotomy, . . . . . . 172

Treatment of Cows during Pregnancy, . . . . 173

Symptoms of Pregnancy, . . . . . . . 175

Dropsy of the Womb, . . . . . . . . 175

Puerperal Fever, . . . . . . . . 176

Puerperal Fever mistaken for Horn-Ail, _ . . . 183

Inversion of the Uterus, . . . . . . . 185

Mammitis, or Garget, . . . . . . . . 189

Inflamed Udder, . . . . . . . 189

Stricture in Cows' Teats - Obstruction at the end of the Teats

- Obstruction in the Teats,. . . . . 191

Tumors within the Teats - Injured Teats-Sore Teats, . 192

Chapped Teats and Chafed Udder-Inversion of the Vagina, . 193

Iaceration of the Vagina, . . . . . . 194

Rupture of the Uterus, . . . . . . . . 195

Abortion in Cows, . . . . . - . . . 195

Inflammatory Affection of the Hind Limbs after Calving, . 201 


\section{Diseases of the Urinary Organs.}

Description of the Urinary System, Page.

The Uterus and Bladder, . . . . . . . 203

Urethra, . . . . . . . . . 204

Hæmaturia, . . . . . . . . . . 204

Inflammation of the Kidneys, . . . . . . 206

Urinary Calculi, ${ }^{\circ}$. . . . . . . $\quad 207$

Calculi in the Bladder, . . . . . . . 208

Black Water; . . . . . . . . . 209

Red Water, . . . . . . . . . . 210

The Heart-Its Function and Diseases.

Description of the Heart, . . . . . . . 214

The Heart's Function, . . . . . . . 217

Dilatation of the Heart, . . . . . . . 218

Pericarditis, ..$\quad$. . . . . . . 219

Hypertrophy of the Heart, . . . . . . 225

Endocarditis, . . . . . . . . . . 226

\section{Diseases of the Eye and its Membranes.}

Description of the Eye, . . . . . . . 227

Muscles of the Eyelids, . . . . . . . 230

Glass Eye, or gutta serena, . . . . . . . 233

Ophthalmia, . . . . . . . . . $\quad$. 235

Foreign Bodies in the Eye, . . . . . . 235

Specific or Periodical Ophthalmia, . . . . 236

Cancer, : . . . . . . . . . . 236

Ruptures.

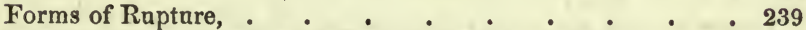

Inguinal Strangulated, and Ventral Hernia, or Rupture, . 240

\section{Diseases of the Bones.}

Bone Disorder, . . . . . . . . 244

Mechanism and Structure of Bones, - ${ }^{-}$- $\quad 249$

Dilatation of the Jaw Bones, . . . . . 250

Abscess beneath the Periosteum at the Angle of the Jaw, . 253

Exostosis or Deposit of Calcareous Matter on the Surface of

On Sympathy and the Sympathetic Relations which exist

Horn-Ail, in the Animal Economy, - Definition of Sympathy, . 255

Tail-Ail, $\bullet^{\circ} \cdot \bullet^{\circ} \cdot \bullet_{268}$

Rhumatism Acute and Chronic.

Acute Rhenmatism, . . . . . . : 272

Chronic Rheumatism, . . . . . . , 276

Causes of Rheumatism, . . . . . . . 277

Treatment of Chronic Rheumatism, . . . . 279 
The Liver and its Diseases.

Description of the Liver, . . . . . . . 280

Secretion of Bile, its uses, etc., . . . . . . . 281

Inflammation of the Liver, . . . . . . 282

Hydatids, . . . . . . . . . . 283

Jaundice or Yellows, . ‘ . . . . . . 290

\section{Diseases of the Brain.}

Inflammation of the Brain and its Membranes, . . . 293

Sturdy, or Cerebral Parasites, . . . . . . 294

Shaking Palsy, . . . . . . . . . 297

Hydrophobia, . . . . . . . . . 298

\section{Diseases of the Skin.}

Mange, . . . . . . . . . . . 301

Foul in the Foot, . . . . . - . . . 302

Warts, . . . . . . . . . 302

Gadflies, . . . . . . . . . 304

Yoke Galls, .

The Hair of Cattle is an Epidermic appendage, . . 306

Pemphigus, or Vesicular Eruption, • . . . 307

\section{Generalities.}

Dutch Cattle, their Introduction into Massachusetts, Valuable Qualities, etc., . . . . . . . . 311

Castration, . . . . . . 314

Enzoötic Milk-Sickness, or Trembles, . . . . 318

Watering Cattle and Farm Horses, . . . . . 326

Cracks in the Heels of Cattle, . . . . . . . 329

Parasites around and within the Globe of the Eye, . . 330

Improved Method of Milking, . . . . . . 331

Diseased Thymus Gland, . . . . . . . 332

Cords in Young Calves, . . . . . . . . 334

Steamed and Cooked Food for Stock, . . . . 335

Cheap Fodder for Cows, . . . . . . . 338

Chinese Sugar-Cane as Food for Stock, . . . $\quad 339$

The Value of Natural Food in contrast with Artifical Food, . 340

Black Leg, . . . . . . . . . 341

Black Tongue, . . . . . . . . . 347

Organic Composition of the Body, . . $\quad$ - $\quad$. 349

Fractured Bones, . . . . . . . . . 351

Light in Barns, . . . . . . . . . 353

Diarrhoea in Calves, . . . . . . . 354

Sprains or Strains, . . . . . . . . 355

Farcy, . . . . . . . . . . 356

Splenic Apoplexy, . . . . . . . . 357

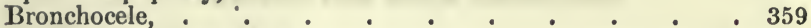

Analysis of Cows' Milk, . . . . . . . 361

Analysis of Woman's Milk, . . . . . . $\quad 362$

The Effects of Impure Milk, . . . . . . 362

The Composition of Milk at Various Times of the Day, . 364 
On Milk which does not Yield Butter,_and the Remedy, Pago.

Spaying Cows, . • • • • • •

Hair Balls, . . . . . . . . . . 375

Effects of Salt on Animals, . . . . . . 376

Fluid Extracts of Medicinal Preparations aseful in Cattle

Practice, . . . . . . . . . 379

Remarks on Clysters, . . . . . . . . 381

Formula of Clysters, . . . . . . . . 381

Miscellaneous Recipes, . . . . . . . . 385

Explanations of Illustrations, . . . . . . 391

\section{IL L USTRATIONS.}

Instruments used in Cattle Practice faces the Title Page.

Section of a Cow's Stomach, . . . . . . . 78

Representation of a Cow's Stomach, . . . . . 87

Intestines of a Cow, . . . . . . . . 105

Series of Cuts showing the process of dentition, and the age of

Cattle, by their teeth, . . . . . 108

Mode of operating on a Bullock for Gut-Tie, . - . . 123

Inversion of the Uterus, . . . . . . . 184

A View of the Mechanism of the Heart, . . . $~ 214$

Cut of Diseased Bones, . . . . . . . 245

A Section of the Scull and Horn, . . . . . 258

A View of the Superficial Muscles, . . . . . 271

Cut of the celebrated Bull, "Dutchman," . . . . 310

The Cow, "Purmer," . . . . . . . 315

The Mammoth Cow, "Lady Washington," . • . . . 312 


\section{THE DISEASES OF CATTLE.}

DISEASES OF THE ORGANS OF RESPIRATION.

\section{CROUP.}

THIs disease is generally supposed to occur among young animals, but Claude relates a case of false membranes in a nine - years old ox; young calves are frequently attacked with "laryngitis," and very many die from obstruction in the airpassages ; these, after death, are found to be occupied by semiorganized lymph ; such cases are known to veterinary surgeons as membraneous croup, and in the latter stages of the disease the false membranes are found to occupy the intestinal canal, as well as the air passages.

Symptoms of Croup. - The animal is observed to be in imminent danger of suffocation: there is some discharge of morbid matter from the nostrils; yet it is evident that the respiratory passages are fast filling up with the morbid secretion. The only chance of saving the animal is to perform the operation of tracheotomy; but this operation, in order to be successful, must be performed in the early stage of the disease, or when false membranes are confined above the point selected for the operation; for, when the obstruction exists at or about the lower end of the trachæ, in the vicinity of the bronchial tubes, the case is hopeless. The only medicine of any value, in the early stage of this affection, is :-

Glycerino 2 ounces.

Tincture of Lobelia 2 drachms.

A second dose may be given at an interval of two hours. If 
the patient does not improve, and the danger appears imminent, tracheotomy should be performed.

\section{DESCRIPTION OF THE LARYNX.}

The larynx is seated at the upper part of the windpipe, to which it is joined; it occupies that part known as the throat, between the broadest part of the angles of the jaw. It is composed of several cartilages, which are under the control of the laryngial muscles. These cartilages are so contrived as to be movable on each other, in various directions.

The first cartilage is named thyroid, or shieldlike. It forms the most extensive part of the larynx, and protects the other. parts from external injury.

The second cartilage is named cricoid, or ring-like cartilage. It overlaps the first ring of the trachea or windpipe, in the form of a helmet.

Thirdly, there are two ewer-shaped cartilages, termed arytenoid; they are found on the upper and back part of the trachea. They form a canal which leads to the glottis.

The fourth cartilage is named epiglottis, in consequence of being situated upon and over the glottis; it is the door-keeper of the larnyx, and every particle of food, or drop of water, which the animal swallows must pass over it; if it fail to perform its function, for a single moment, when the animal is either drinking or eating, death is sure to follow. But the $o x$ is rather more favored, in the mechanism of the epiglottis, than the horse. The epiglottis of the horse is just adapted to the calibre of the glottis, he being a non-ruminant; but in the case of the ox, the rough, unmasticated particles of food have to be returned to the mouth for a second mastication; this would peril the life of the animal if he had no other protection than that found in the larynx of horses. The fact is, the epiglottis of cattle; instead of being confined to the calibre of the rim of the of the glottis, overlaps it; and this securely protects the parts from the accidents which may occur in the process of remastication. 
The larynx is lined by a membrane very susceptible to irritation; it is abundantly supplied with excretory glands and orifices, for the emission of a secretion, peculiar to itself.

\section{LARYNGITIS.}

This disease often commences as an ordinary cold, but soon the throat becomes husky, followed by prolonged sonorous respiration; the respiration soon becomes quickened, and finally the patient may die of suffocation.

Laryngitis consists of an inflammatory affection of the submucous cellular membrane of the larynx, often ending in cedema, or effusion into the membrane; in such cases it is called oedematous laryngitis. This is one of the most dangerous of all diseases, for after œdema has once set in, the animal is liable to die of asphyxia (loss of pulse), at any moment.

Symptoms of Laryngitis. - Commencing, as it often does, as an ordinary cold or sore throat, it has some symptoms in common with the latter. The animal protrudes the nose, so that the head, instead of being pendulous, is thrust forward; the animal very rarely turns its head. sideways. The region of the throat is usually tumefied and tender, and pressure on the larynx occasions great distress. These symptoms, associated with the alarming character of the breathing, and livid appearance of the visible surfaces, will enable any one to determine the true nature of the disease.

Treatment. - The first object is to endeavor to prevent effusion; in this view I recommend that the patient be carefully drenched with the following:-

Nitrate of Potassa,$\ldots \ldots \ldots \ldots \ldots \ldots \ldots \ldots \ldots \ldots \ldots \ldots \ldots$ ounce.

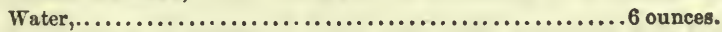

Fluid extract of Lobelia,.............................

At the end of three hours repeat the dose. In the mean time bathe the jaws and throat with a strong infusion of lobelia; then apply a cold water bandage around the jaws and throat. The body and limbs should be well rubbed with a wisp of straw, so as to keep up an active circulation on the surface of the body. An enema, composed of salt and water, may be 
thrown into the rectum. Should the symptoms become more alarming, the services of a veterinary surgeon will be required, to perform the operation of tracheotomy: which consists in taking a circular piece of cartilage out of the trachea, and inserting therein a common tracheotomy tube. If the disease be confined to the parts above the seat selected as the place of operation, the animal may yet be saved. When the disease passes into the chronic stage, we have a purulent discharge from the nostrils. This discharge may be accelerated by giving a few doses of the following:

Tincture of Matico,.................................2 ounces.

Syrup of Garlic,.................................... 8 ounces.

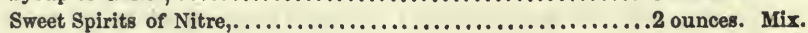

Dose - Two ounces, morning and evening.

The throat should be rubbed occasionally with a small quantity of tincture of bloodroot or vinegar. It often happens that chronic laryngitis ends in thickening, or altered structure, of parts within and around the larynx; should this be the case, the patient must be put on a course of iodine; twenty grains per day of iodide of potassium may be given, in a small quantity of water, and the region of the throat should be anointed every night with the following ointment :-

Powdered Iodide of Potassium, .......................2 drachms.

Simple ointment,...............................2 ounces. Mix.

\section{BRONCHITIS.}

Bronchitis is a disease of the bronchial mucous membrane ; in its early stage the term acute has been applied to it, this having subsided it assumes a chronic type. It is very rare that this is a primary affection, for it is generally preceded by cough or catarrh, or else is an accompaniment of an abnormal condition of contiguous tissues. Its existence may be demonstrated very readily by applying the ear to the trachea in the region of the point of the breast bone, the peculiar sound differing from that in any other part of the trachea, having what is termed a sibilant, or whistling sound. The treatment will 
be about the same as that recommended for common catarrh, with the addition of a counter irritant to the sides of the chest, a little mustard and vinegar will answer the purpose. A bronchial difficulty of a very alarming character, sometimes prevails as an epizoötic, and this must be treated the same as epizoötic catarrh.

Description of the bronchial tubes. - The bronchial tubes are a continuation of the trachea, it having entered the thorax, becomes forked or bifurcated; they are constituted of several pieces, making up so many segments of the circle, overlapping each other so as to admit of extension and contraction in the respiratory acts ; these are connected together and invested by an elastic cellular substance, which imparts to them both strength and elasticity. A further subdivision of the bronchial tubes takes place as they penetrate the substance of the lungs, so that they become very numerous; as they proceed onwards their calibre continually grows less, until they end in the extreme ramifications known as air cells. The bronchial tubes are lined by a membrane common to the trachea.

\section{INFLAMIMATION OF THE LUNGS.}

Inflammation of the lungs, known also as pneumonia, is not usually so prevalent among the bovine, as it proves to be in the equine species, excepting, however, milch cows located in unventilated milking establishments.

In such locations diseases of the lungs are often fearfully prevalent, raging at times as an enzoötic affection, which generally proves fatal when a large number of animals are confined in a small space.

Among horses this disease is often occasioned by laborious work and feats of speed, which produce rapid and sometimes distressing respiration. But among cattle, whose powers of speed and endurance are not often put to the test, we may reasonably infer that the exciting causes vary in their general character.

The stimulating and morbie action of an impure atmos- 
phere, may produce this disease, by first creating irritation on the lining membrane of the respiratory passages. It has also been noticed that this disease frequently appears among cattle that have been driven a long distance in tempestuous weather, and have also been compelled to go hungry and thirsty for many hours. Fortunately for the poor brute this disease is not so painful as bronchitis, pleurisy, and laryngitis; and after having passed through the acute stage, it assumes "a sort of mild, sub-acute, or chronic type, which apparently appears less dangerous than the acute kind, yet after all, is more so, as it is apt to terminate in altered structure, hepatization, induration and tubercles.

Pneumonia, now and then, terminates by metastasis, that is, by translation of the formidable lung difficulty to one equally formidable, which locates in the feet, known to veterinarians as laminitis - fever in the feet. Among cattle, however, this termination is rather rare, yet very frequent among horses. When the disease does not take this course it often ends in "resolution," which signifies a return to health without leaving any perceivable evidence of altered structure; so that after awhile, the animal may become sound as ever.

Pneumonia is divided into several forms or stages, but as they all have reference to its degree or intensity, it seems unnecessary to refer to them; it may, however, be proper to inform the reader that pneumonia may exist, either as a state of congestion, or of inflammation. Congestion signifies a distended or plethoric state of the blood-vessels of the parenchyma of the lungs, and slow motion of blood. Congestive pneumonia sometimes sets in as suddenly as that which is termed "inflammatory," and among cattle the former is most prevalent.

In the congestive stage the symptoms are those of embarrassment, the blood courses through its channels sluggishly, and there is not the activity of heart and lungs which is perceivable in pneumonia.

Symptoms of Inflammation of the Lungs. - The symptoms in the early stage are such as are generally observed at the 
commencement of any inflammatory affection; viz., coldness of extremities, and shivering fits; loss of appetite, labored respiration, quick pulse, slight cough, mouth hot and clammy. The animal will not lie down, and refuses to move; the head is extended, perhaps drooping, and the fore legs stand wide apart. As the disease progresses these symptoms vary, and the appearance of the membrane of the mouth, nose, and eyes vary also, from the color of bright scarlet to that of a leaden hue. In the congestive stage, the pulse is more voluminous, yet less active, and the visible surfaces are highly congested. A cough, slight or active, as the case may be, is usually noticed; it is a sort of deep-seated, half-suppressed cough, and sometimes is the first symptom which attracts the owner's attention to the ailing animal. -

Treatment of Pneumonia. - I have little faith in the heroic remedies, so highly recommended by Youatt, and others, and even by myself only a few years ago. I now have more faith in nature, and in regimenal means, and find that more cases are cured in this way than by the old method.

It is very important, at the commencement of the treatment, that the patient shall be placed in a clean, comfortable location where pure air abounds; for, under such circurnstances the conditions favorable to the operation of nature in the cure of the malady, are secured.

- Should the animal labor under accelerated respiration and full, strong pulse, I should administer one ounce of powdered nitre in a quart of cold water; after which, four ounces of the liquor acetate of ammonia, may be given every four hours; this agent also, should have a quart of cold water added to it at every dose. The brisket and sides may be rubbed with a portion of the following:-

$$
\begin{aligned}
& \text { Powdered Mustard, } \\
& \text { Strong Vinegar. } \\
& \left\{\begin{array}{l}
\text { Enough of each to } \\
\text { form a thin paste. }
\end{array}\right.
\end{aligned}
$$

When mixed, a small quantity of oil of cedar may be added. This application should be repeated two or three times in the course of twenty-four hours.

Nauseants are next administered in view of relaxing cap- 
illary and muscular constrictions, and this is desirable, as such conditions tend to equalize the circulation of the blood, and prevent an undue quantity accumulating in the pulmonary organs.

In cattle practice, and having a case of this character under treatment, I prefer to administer the nauseating remedies by the anus ; hence, a couple of quarts of infusion of lobelia, may occasionally be thrown into the rectum. Considerable of the active principle of lobelia will be absorbed within this gut, and, under the circumstances, it is much better to introduce the medicine into the system in this way than by the stomach. The proportions of the lobelia to the water are,-lobelia (herb) two ounces; boiling water, two quarts; when cool, strain, and it is fit for use.

It may be necessary to give a dose of medicine; if so, I should use the following :-

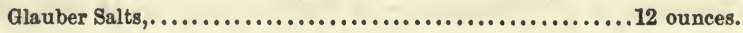

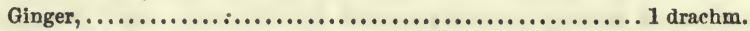

Warm Water, .....................................1 quart.

It should be known to all husbandmen that a disease of this character, located in such important organs as those of respiration, is very prostrating, and operates very unfavorably on the inherent vitality of parts. Hence, so soon as the activity of the morbid phenomena is somewhat subdued, all active medication should cease.

The affection is likely to continue for some days, and all we have to do, is to try to keep the patient alive while the disease is running its course; careful nursing, pure air, and light diet are the remedies.

After the first twenty-four hours I pay little attention to the pulse, but more to the patient, for I can conceive of but two conditions in this disease; one I call acute the other chronic, the very moment the acute condition subsides, it merges into the chronic, and requires life-sustaining agents.

After the first twenty-four hours, I generally resort to the following medicine :-

Glycerine, .8 ounces.

Powdered Bloodroot, 4 drachms.

"

Goldensea 1 ounce. Mix

Dose. - One tablespoonful to be smeared on the tongue night and morning. 
Management of the patient while under treatment. - As I have already intimated a full supply of pure air must be insured; for a practitioner would be more likely to save an animal in the open air (provided the weather was not too cold nor tempestuous), than in the unventilated cow-house. Should the limbs at any time be cold, they are to be hand rubbed and bandaged: the body being in the same condition, must also be clothed. I should also give the chilled patient some warm ginger tea or any other non-alcoholic stimulant or carminitive, in view of arousing the action of the heart and capillaries, by which means the red arterial and lifesustaining blood, would be forced to the external surface and extremities, imparting to them a genial warmth, and thus insuring an equilibrium of the circulating fluid.

The patient should be furnished constantly with a bucket of pure cold water; when morbid thirst prevails, the water must be acidulated with either lemon juice, cream of tartar, or acetic acid; any symptoms of debility or lassitude are to be opposed by a few doses of some vegetable tonic; tincture of goldenseal, or tincture of matico, in ounce doses, every. twelve hours, are the best remedies that I am acquainted with.

Finally.-My experience in the treatment of this formidable disease is, that in ninety-nine cases out of one hundred, the patient dies of a meddlesome medicinal disease; in fact, he dies secundem artem. 'In view of furnishing a logical argument to support this theory, I refer the reader to Youat, Percival, and others of the orthodox stamp, - very learned men, - who are apt to place too much confidence in art, to the exclusion of nature.

It is my opinion, after many years study and practice, that diseases are not cured by art, but art may so modify the diseased condition that the recuperative powers of the system can thereby induce salutary changes, without which they cannot, so readily, be effected. Thus art, when understandingly applied, may be said to aid nature. 


\section{DESCRIPTION OF THE LUNGS.}

The lungs are known, in common parlance, as the "lights," they may be considered as a double organ, separated from each other by that part of the pleural membrane known as the mediastinum; when distended by air, or inflated, they occupy the whole cavity of the chest, but the moment expiratory action ensues they are in a state of collapse, occupying not more than one-half the volume of the chest. The lungs are composed of arteries, absorbents, veins, and nerves, and ramifications of the bronchial tubes, known as air cells, connected together by a cellular substance, known as parenchyma. A healthy lung, when immersed in water, will float upon the surface; yet if the lungs as in the fotal state, have never been inflated, they sink like a stone.

\section{FUNCTION OF THE LUNGS.}

The principal function of the lungs, is to arterialize, or decarbonize the blood. This arterialization of the circulating fluid is more essential to vital integrity, than either food or water, for animals cán live many days, weeks, and even months, without a particle of extraneous food-hybernating animals for example - whereas, no creature having lungs, to expand and contract, can be expected to live more than a few seconds when deprived of the " breath of life."

The functional acts of respiration and expiration, must necessarily be divided into two parts; the acts are performed in the ratio of from fourteen to twenty times in a minute, it is more frequent during exercise, and under many states of disease. When an animal is located in a pure atmosphere, and the lungs are in good working order, all the impurities of the blood are brought into the presence of oxygen through the medium of the air cells; a change in the character and color of the blood is very soon effected which I shall notice. In the first place the venous blood as it appeared before aeration, was of a dark purple approaching a black color; by union with oxygen respired, it has changed its color for one of scarlet, 
it las parted with carbonic acid gas and vapor and has absorbed a sufficient quantity of oxygen, to vitalize it and rendered it fit for the renovation of tissues. It appears that carbon exists in venous blood, the lungs are the pulmonary furnaces; the air cells are flues or safety valves, one set are permeable to oxygen, others prevent the escape of carbonic acid gas. Pulmonary combustion, therefore bears some analogy to the combustion of carbon, or charcoal, in a common stove.

\section{CATARRH OR “HOOSE."}

Cattle as well as horses are subject to a catarrhal affection, known among English farmers as "hoose;" it consists of a defluxion from the nasal cavities, acompanied with cough, loss of appetite and flesh; in popular language it is nothing more than a common cold, induced by the ordinary causes, such as exposure, errors in diet, and management. It generally appears in the season of spring, or towards the latter part of autumn, when the temperature of the atmosphere undergoes the most sudden changes, and it generally selects its subjects; for many animals subjected to the ordinary causes of cold, enjoy immunity from the same; hence, I infer that a predisposition to this affection is hereditary, and manifests itself at periodical intervals, without the intervention of the common exciting causes, although they may prove operative in developing a. latent disease.

I conceive that it sometimes has an hereditary origin from the fact that some breeds are more subject to it than others, in some cases, however, this hereditariness exists only so far as the animal is of a peculiar temperament, so that when removed from a warm to a colder region, it is apt to contract catarrh, This is the case with many of the Alderney breed of cows imported into the northern region of the United States; ere they have been here long, they have an attack of catarrh, which often runs into the chronic stage and ends in consumption.

Symptoms of Catarrh. - The first symptom which the farmer will observe, is loss of appetite; succeeding this are 
febrile symptoms, such as quick pulse and respirations, heaving at the flanks, dry muzzle, glairy discharge from the nostrils; reddening of the visible surfaces; the limbs are generally colder than usual, the hair loses its glossiness and appears roughened; the animal will occasionally snort and discharge more or less of glairy mucus, and some soreness of throat may be observed. Such are the early and most noticeable symptoms of this disease, and this is the most proper period for the animal to receive attention, in order to prevent the malady running into the chronic form; for should it do so, ten chances to one if the case is not called "horn-ail," and thus the poor animal has to submit to a routine of barbarisms, such as boring horns, letting daylight, pepper, and turpentine into the frontal sinusses - much to the annoyance of a sick brute, and very significant of the ignorance of the itinerant cattle slayer.

Treatment of Catarrh. - The treatment depends somewhat on the condition of the patient, as regards the preponderance of fever or debility. A high-fed animal abounding in morbific material, and necessarily of a febrile diathesis, must have aperients : eight ounces of glauber salts, dissolved in warm water and sweetened with molasses, may without the least danger be administered, followed by a liberal supply of warm, sloppy, bran mashes; and should the pulse be voluminous and excessively active, thirty grains of powdered nitre may be -added to the above. which in all probability will reduce the action of the heart. In the mean time we keep the patient quiet; withhold all fat and muscle-making food, and allow the patient to breathe a pure and cool atmosphere; for a cool atmosphere is, perhaps, a better sedative than nitre, and certainly more requisite; and after the medicine shall have had time to traverse a portion of the intestinal surface, say a lapse of five or six hours, an enema of glauber salts may be given, in the proportion of half a pound to half a gallon of water.

In the early stage, and having a plethoric subject under treatment, it may by some persons be considered necessary to resort to the fleam, and some highly educated physicians decide this to be the best course; there may be cases occurring 
in pampered and stable-fed animals, which demand a prompt use of the above instrument; but the author has never seen a case of catarrh which, in his judgment, demanded the abstraction of blood. Bleed by the bowels if need there be of depletion: this is my doctrine. Catarrh, whether it be simple or epidemic, in one feature resembles influenza occurring among horses; it is a prostrating disease - induces debility. However I have no desire to force my opinions on any man; try glauber salts and nitre; should they fail to have the desired effect, the judicious practitioner has his remedy.

The bowels having responded to the above dose we have only to keep the patient alive, while the disease is running its course, and this is accomplished by means of "good nursing." There are a great many remedies that I might recommend in view of hastening convalescence, but "good nursing" supplants the whole.

A sore throat may accompany the malady, and if so, I recommend the following:-

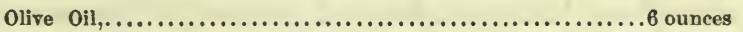

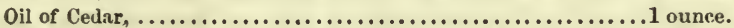

Spirit of Ammonia,................................

Tincture of Capsicum,...........................

$\Lambda$ pply a portion to the throat twice darly.

In order to promote a discharge from the nasal outlets I resort to vapor, which may be generated by dropping water or vinegar on a hot brick; and to insure the full effect of the same, I envelop the head with a cloth or blanket, so as to direct the current of vapor through the nasal passages. In view of promoting nasal discharge, a small quantity of bayberry bark pulverized may occasionally be blown up the nostrils from a quill or a hollow tube of paper. The after treatment will depend upon the observable symptoms; while a febrile diathesis continues we depend on sedatives and aperients. In the chronic stage tonics and alteratives, are indicated, and must be resorted to in view of warding off a chronic cough and its consequences. 


\section{EPIZOÖTIC CATARRH.}

Epizoötic catarrh is infectious, yet animals having once had an attack of the same may enjoy immunity from it thercafter. It usually appears and spreads over various parts of the country, when great variations in the weather are noticed; it generally appears in the spring, and disappears when the weather becomes warmer and more uniform.

Symptoms. - The symptoms of epizoötic catarrh in the early stage does not differ materially from those alluded to in the preceding article (common catarrh), in a very short time, however, the animal begins to grow very weak and becomes debilitated; tumors form in various parts of the body, emitting when pressed, a crackling sound; the glands in the region of the throat are enlarged; the neck stiff; the odor from the breath and fæces is very offensive, the animal loses flesh very fast, and unless relieved will surely die.

Causes of Epizoötic Catarrh. - The direct causes of this, like that of any other epizoötic and epidemic affections, are involved in obscurity; speculation is rife as regards the causes of cholera and the potato rot, which probably have analagous origins, but it is very difficult if not impossible at the present time, to define the precise character of the morbid germ, which, "like a little leaven," leavens the whole loaf.

Treatment. - The principal objects in the treatment of this malady are to sustain the vital powers, and thus guard against the subsequent prostration and decomposition which under the orthodox treatment is sure to occur.

The proper mode of treatment is as follows. Drench the animal with the following:-

Tincture of Matico, 1 ounce.

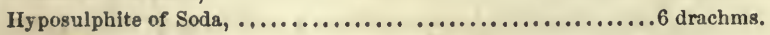

Powdered Goldenseal, ..............................2 drachms.

Warm Water, ................................... pint.

Having administered the above medicine, anoint the throat and all tumefied parts with a portion of the following counterirritant : - 
Oil of Cedar, .......................................1 ounce.

Oil of Sassafras, ...................................

Cod Liver 0il, ..................................6 ounces.

Mix, and apply by means of a small piece of sponge.

Should the breath become very fotid, and the odor from the evacuations almost intolerable, as is often the case, very powerful antiseptics will be needed, to arrest the morbid fermentation. The most efficient and valuable article for this purpose is pyroligneous acid; a couple of ounces of the sáme may be given in a quart of oatmeal gruel every four hours, until the odor is exterminated. The diet should consist of well-salted, scalded shorts, sliced carrots and parsnips. In the absence of rumination, give a drachm of powdered goldenseal, and half a krachm of carbonate of soda, twice in twenty-four hours.

\section{CONSUMPTION.}

This disease, as it appears among cattle, is supposed to be the sequel of other diseases of the respiratory apparatus, and some writers contend that phthisis is the termination of chronic disease of the lungs, characterized by the formation of tubercles within the substance of the lungs. The most notable symptoms are emaciation, debility, cough, ferer, and purulent expectoration. Expectoration, however, is a feature of this disease more marked in the human subject than among horses and cattle, yet in the last stages we occasionally observe nasal discharges of a purulent character.

In diagnosing this disease, it is necessary to make ourselves acquainted with the history of the case, and the physical conformation of the animal; for, if the patient be the subject of neglected catarrh, bronchitis, or any other pulmonic or pleuritic difficulty, we have the data for an intelligent diagnosis, provided the physical conformation of the animal corresponds to that which physiologists regard as susceptible of phthisis; viz., a lean, lank organization, associated with an active, nervous temperament. Referring to Percivall for evidence on the subject now under consideration, I find that he considers a colt having long legs, overgrowth, narrow chest, flat sides, pot belly, and an 
appearance of weakness and unthrivingness, a capital subject for phthisis. A cough occurring in such an animal, of a feeble, painful, hoarse, rattling, or gurgling character, shows conclusively that disorganization of the lungs has commenced. The cough will also be accompanied by a sound which gives us an idea that it is deep-seated.

Causes of Consumption. - Aside from the well-known direct hereditary causes, which are known to exist in breed, there are others, operating insidiously to produce disease, and altered structure in the lungs. The climate may be prejudicial. I have known this disease to make its appearance among cows unsuited to our New England climate; the Alderneys, for example. On the other hand, if cows be removed from a warm, comfortable location or barn, to a region involving a material difference in temperature, a derangement of the respiratory system is very apt to occur. It may appear at first under the guise of a simple bronchial affection, which insidiously steals on until the substance of the lungs is affected. Animals shut up in close and hot stables, as is the case at the "swill milk" establishments in New York, where they cannot obtain sufficient oxygen to vitalize or decarbonize the blood, are apt, after a short time, to die of tuberculated lungs, or perhaps a worse form of disease, known as infectuous pleuro-pneumonia, soon terminates their wretched existence. Impure air is at all times operative in exciting pulmonary affections ; the least deviation fiom purity may occasion very serious difficulties. Therefore, it should be the business of the farmer to see that his cattle have constantly an abundant supply of pure, uncontaminated air - the breath of life.

Treatment of Consumption. - In the first place the patient must be removed tó a comfortably warm and well-ventilated barn; should the weather be chilly, a blanket may be thrown over the body, and it will be expedient, also, to clothe the limbs up to the knces and hocks with strips of flannel; by this means we promote cutaneous and sub-cutaneous circulation, and every drop of blood invited and maintained, at the surface in the extreme vessels, tends to prevent internal congestions. Without proper attention to these matters, we might as foolishly 
attempt to raise a dead cow to life. Next, the patient, whose appetite is almost sure to be impaired, should be fed on that kind of food which contains more carbon and nitrogen than common hay; viz., oatmeal. In case of a complete suspension of rumination, - loss of cud, - a due proportion per diem of oatmeal gruel; sweetened with some sacharine matter, may be administered from a bottle. Every morning the patient should have four ounces of the best cod liver oil; this can be continued until its action is made manifest by purging. Every evening give the patient a dose of the following:

Powdered Phosphate of Lime (pure),.....................

" Bloodroot,..................................1 ounce.

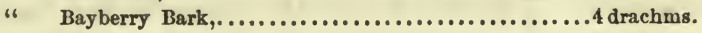

"Sassafras,..................................2 ounces. Mix.

Divide the mixture into sixteen parts.

The above is, according to my experience, the most rational method of treating this disease; but the farmer must not feel disappointed if he fails in arresting it, for it frequently baffles the most consummate skill.

\section{PHARYNGITIS. - (Sore Throat.)}

The term pharyngitis, signifies inflammation of the membrane lining in the pharyngial inlet, or funnel-like entrance into the œsophagus, or gullet. The diagnostic symptom of this affection is as follows; the subject is unable to swallow, and thus, the food taken into the mouth is apt to be returned by the nostrils. * On exploring the inferior region of the throat, from ear to ear, considerable swelling or tumefaction is encountered; yet the pharyngial muscles appear to be constricted. It generally appears among cattle as a simple local affection, yet it often accompanies other diseases of the respiratory eharacter, and whenever it does appear as a local malady, it is apt to merge into something else. It is a very distressing affection, and the animal gets but little relief until suppuration commences, then a free discharge takes place.

* This happens occasionally, although the passage of the nasal inlet is much smaller than it is horses. 
Causes of Pharyngitis. - In some cases it may arise in consequence of some morbid habit of body, in others it is evidently excited by cold or chilliness of the external surface; rough food, such as cornstalks, musty hay, and other irritating bodies are apt to induce it.

Treatment. - Let the animal's throat be rubbed twice daily with a portion of the following:-

oil of Cedar, ..................................... 1 ounce.

Cod Liver Oil,$\ldots \ldots \ldots \ldots \ldots \ldots \ldots \ldots \ldots \ldots \ldots \ldots \ldots \ldots$ ounces.

Spirits of Ammonia,..............................2 drachms. Mix.

Keep a sloppy bran mash before the patient, or some flaxseed tea, into which stir a small quantity of powdered nitre and liquorice. This will relieve the cough, if any be present, and tend to lessen irritation of the lining membrane of the pharynx. When the patient begins to expectorate, or has the least discharge from the nose, give the following:-

Balsam of Tolú,................................2 ounces.

Sweet Spirits of Nitre, ..............................3 ounces.

Mucilage of Gum Arabic,.......................... 8 ounces. Mix

Dose. - One wineglassful, twice daily.

\section{DESCRIPTION OF THE PHARYNX.}

The pharynx is the commencement of the tube known as the oesophagus or "gullet;" it is a funnel-shaped cavity, lodged between the mouth, gullet, and windpipe. The pharynx is composed of muscular and membraneous tissues; the most important muscles which enter into the composition of the pharynx are the constrictors, they give the membrane, forming the funnel-shaped sac, a complete covering, and their function is to force the food, beyond the action of the tongue, into the cosophagus. The pharynx is divided from the mouth by the soft palate and the epiglottis; therefore, except in the act of swallowing, or coughing, there is no direct communication. The interior of the pharynx is lined by a membrane having within its structure, a vast number of minute glands, with excretory ducts, from which a viscid or lubricating fluid issues; this lubricates the pellets of food, so that by this process, their passage into the cosophagus is insured without the casualty of friction. 


\section{PULMONARY APOPLEXY.}

This disease occasionally appears among cattle in the Western States. It attacks animals irrespective of age, sex, or condition. It is generally sudden in its attacks, and death frequently ensues in the course of a few hours. The causes of this disease are involved in obscurity, therefore $\mathrm{I}$ shall not trouble the reader with any speculations on the subject, but proceed to describe the symptoms.

Symptoms. - The pulse and respirations are very much accelerated, the former sometimes running as high as 110, an augmented salivary secretion is observed to run from the mouth; the tongue is much swollen, so also are the eyelids, and tears run down each side of the face; various parts of the body are swollen and congested; the stomach is distended with gas, and the evacuations are profuse and watery.

Post mortem examinations revea? a highly congested state of the.lungs, in fact they are engorged with blood, and the muscles in the region of the tumefied parts are in a similar engorged condition.

Treatment. - No time should be lost in administering the following drench, for it will preserve the tissues against decomposition and perhaps save the animal. Take

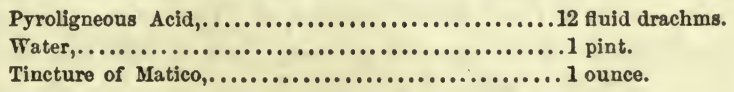

Repeat the dose after a lapse of six hours.

The tumefactions, externally, should be rubbed occasionally with a portion of the following:-

Oil of Cedar, .1 ounce.

Tincture of Capsicum, $\ldots \ldots \ldots \ldots \ldots \ldots \ldots \ldots \ldots \ldots \ldots \ldots . .2$ ounces.

Tincture of Bayberry Bark,..........................

It appears that in this disease there is a morbid impulse directed to various parts, which results in local accumulations rendering the parts turgid; then the blood is thrown out of the capillary vessels, and sometimes they suffer a rupture, which accounts for the engorgement and extravasation.

As there is generally some effusion present in this malady 
some good may be accomplished in acting slightly on the kidneys, yet as the pulse and respirations are both accelerated, the ordinary diuretic - sweet spirits of nitre - is not admissible, for the simple reason that it is too stimulating, therefore I recommend the use of common nitre - half an ounce, every four hours, to be given in a little water.

The tumefied tongue should be rubbed often with table salt. The animal does not require any kind of food until amendment takes place. The best drink for the patient, is cold water, to which a little table salt may be added.

\section{PLEURISY AND DESCRIPTION OF THE PLEURA.}

The delicate, transparent membrane, which lines the cavity of the thorax or chest, is duplicated as an external tunic on the lungs, and forms a partition called mediastinum, which divides the cavity of the chest into two equal parts, termed right and left cavities of the thorax, It is, therefore, a reflected membrane. That portion which gives a lining to the chest is termed pleura costalis, and that which invests the lungs is called pleura pulmonalis, although at all points they are precisely similar in structure and function. 'The pleura is called a serous membrane; it is dense, shining, and transparent; its texture is penetrated by blood-vessels, nerves, absorbents, and exhalents. The minute ramifications of the arteries give origin to a vast number of exhalents; and these furnish a serous or watery vapor, which is distributed over every part of the pleura, and thus all friction and irritation is prevented. In the disease known as hydrothorax, dropsy of the chest, the effused fluid found in the cavity of the thorax comes from the exhalents. The absorbents play a very different part ; their function is to absorb or drink up any superabundant serum or blood that may be found in the chest. The functions of these vessels, however, are limited, for when, in consequence of disease, augmented serous secretion takes place, the absorbents are unequal to the task imposed on them, consequently the subject of hydrothorax often dies with his chest loaded with water. 
Symptoms of Pleurisy. - This disease is generally ushered in, like other febrile affections, by fever and trembling of the fore extremities. The cough accompanying pleurisy is painful, and the animal tries to suppress it as much as possible; the breathing is not laborious, but short, the intercostal muscles not admitting of their usual extension and contraction without intense pain; the diaphragm has to perform the respiratory morement, without the aid of the former muscles. If slight pressure be made on the intercostal spaces, between the ribs, the animal will erince symptoms of intense pain; if a person attempts to back the patient, the latter will moan or grunt, and be very unwilling to move. The patient stands with his fore legs wide apart, and seldom, if ever, lies down.

On applying the ear to the sides of the chest, a slight sound, resembling that of friction, is discernible; this is probably occasioned by the presence of effused lymph on the pleural surfaces. The pulse is generally quick, tense, and small. These are the principal symptoms of pleurisy in its early stage; they will vary as the disease progresses, or become complicated. The minor symptoms, such as "loss of cud," etc., are not worth noticing, as they are present in various other forms of disease.

Treatment of Pleurisy. - All the orthodox veterinary works recommend bleeding and purging for this affection, but the author advises his readers not to pay the least attention to such false and fatal doctrine; the practice has killed more than it ever cured. Instead of abstracting blood, I usually administer nauseants and diaphoretics. Let the animal be drenched with the following:-

Fluid extract of Lobelia,..............................1 drachm.

Liquor Acetate of Ammonia,........................ ounces.

Hot Water,.....................................

Repeat the dose at the end of four hours. In the meantime let a mustard poultice be applied to both sides of the chest; should it not be convenient to do this, smear the sides with a paste composed of mustard, vinegar, and salt. After the exhibition of the above medicine, let the patient have a few doses of powdered nitre; this may be dissolved in flax-seed tea, or thin 
gruel; provided the animal will not imbibe, the nitre may be given in a drench, to the amount of two ounces per day. In view of mitigating the cough which may be present, and of relieving pain, the patient may be made to inhale an ounce or so of sulphuric ether from a sponge; the latter being merely covered with a towel, except that part which comes in contact with the nostrils. It would not be proper to completely etherize the animal, but merely to stupify him for a time; this will have an anti-spasmodic effect, and may be repeated, or not, at intervals of four hours, according to the nature of the effects produced.

In cases of this character which have come under the author's treatment, it has been found that when the lobelia was used freely in the early stage, the patient generally recovered.

It will be proper to administer an occasional enema, and this should be of an anti-spasmodic character ; therefore, an infusion of lobelia is recommended. The very moment the animal appears to be relieved of urgent symptoms, the treatment should not proceed on the same principles. The intention should be to guard against debility and hydrothorax, two mortal enemies to the bovine species. Goldenseal and matico are the best remedies to prevent the one and guard against the consequences of latter. They may be given in the following proportions :-

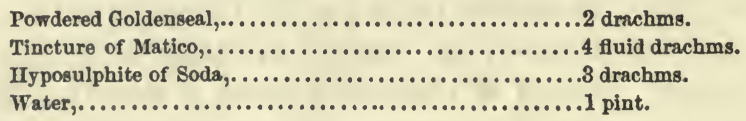

This quantity is sufficient for a period of twenty-four hours. The animal appearing much better will be the signal to discontinue all medical treatment.

\section{PLEURO-PNEUMONIA.}

Pleuro-Pneumonia, signifies inflammation of the lungs and pleura, and merely indicates that both lung and pleuræ are diseased; the disease probably commences in the lungs and finally involves the pleuræ so that the disease in its compound form, may be considered as an aggravated form of inflammation 
of the lungs, the terminations of which are, altered structure, and hydrothorax, hence it differs from the disease termed epizoötic Pleuro-Pneumonia, from the fact that it is not infectious nor contagious, but sometimes endemic. The treatment of this compound disease, if it can be so called, must be nearly the same as that recommended for acute inflammation of the lungs, with the addition, of " broken doses of nitrate-potassa in water."

\section{EPIZOOOTIC PLEURO-PNEUMONIA.}

This disease, which has at certain periods, prevailed so alarmingly in the old world, is of rather rare occurence in this section of the United States, the only cases that have come under the author's notice, occured among some animals owned by the Hon. D. Webster, some three years prior to the death of the Sage of Marshfield; he about this period, lost some very fine cattle, and in order to secure himself pecuniarily, he sent a number to Brighton market, which were sold at current beef prices, although some of them were really worth their weight in gold. From the intelligent description Mr. Webster gave me of the mode of attack, primary symptoms, duration of the disease, and its termination, - and at the same time having a couple of subjects laboring under the same difficulty, - I had a fine opportunity to compare notes, and make a correct diagnosis. On expressing my doubts to Mr. W., of the genuineness of the disease, he immediately quoted from the "Farmers Dictionary," Youatt, several German and French authors, to sustain his position, and contrary to the experience of our American vets, I was compelled to "knock under," as the saying is, and coincide with him, that the cases, as they occurred, were of a purely pleuro-pneumonic character, and since which period my opinion has remained unchanged. In view of furnishing the reader with reliable matter on the subject now under consideration, a selection from the pen of Findley Dun, V.S., "A prize essay," is offered.

"The causes of the disease, both immediate and remote, are subjects full of interest and importance; and a knowledge 
of them not only aids in the prevention of disease, but also leads the practitioner to form a more correct diagnosis, and to pursue the most approved course of treatment. It is, however, unfortunate that the causes of pleuro-pneumonia have not as yet been satisfactorily explained. No department of the listory of the disease is less understood, or more involved in doubt and obscurity. But in this respect pleuro-pneumonia is not peculiar : it is but one of an extensive class which embraces most epidemic and epizoötic diseases. And if the causes which produce influenza, fevers, and cholera, were clearly explained, those which produce pleuro-pneumonia would, in all probability be easy of solution.

"Viewing the wide-spread and similar effects of pleuropneumonia we may surmise that they are referable to some common cause. And although much difference of opinion exists upon this subject, it cannot be denied that contagion is a most active cause in the diffusion of the disease. Indeed, a due consideration of the history and spread of pleuro-pneumonia over all parts of the land will be sufficient to show that in certain stages of the disease, it possesses the power of infecting animals apparently in a sound and healthy condition, and otherwise unexposed to the action of any exciting cause. The peculiarity of the progress of this disease, from the time that it first appeared in England, is of itself no small evidence of its contagious nature. Its slow and gradual progress is eminently characteristic of diffusion by contagion; and nct only were the earlier cases which occurred in this island distinctly proved to have arisen from contact with the Irish droves, but also subsequent cases, even up to the present day, show numerous examples in which contagion is clearly and unequivocally traceable. . . . Although pleuro-pneumonia is not produced by the action of any one of these circumstances alone [referring to noxious effluvia, etc.], yet many of them must be considered as predisposing to the disease; and although not its immediate exciting causes, yet, by depressing the physical powers, they render the system more liable to disease, and less able to withstand its assaults. De- 
ficient ventilation, filth, insufficient and bad food, may indeed predispose to the disease, concentrate the animal effluvia, and become the matrix and nidus of the organic poison; but still, not one, alone, of these circumstances, or even all of them combined, can produce the disease in question. There must be the subtle poison to call them into operation, the specific influence to generate the disease.

"On the other hand, it appears probable that the exciting cause, whether it be contagion, or whatever else, cannot, of itself, generate the disease ; but that certain conditions or predisposing causes are necessary to its existence, and without which its specific effects cannot be produced. But although these remote or predisposing causes are very numerous, they are often difficult of detection; nay, it is sometimes impossible to tell to what the disease is referable, or upon what weak point the exciting cause has fixed itself. A source of perplexity results from the fact. . . The predisposing causes of the disease admit of many divisions and subdivisions; they may, however, be considered under two general heads hereditary and acquired.

"With reference to the former, we know that good points and properties of an animal are transmitted from one generation to another; so also are faults, and the tendencies to particular diseases, As in the same families there is a similarity of external form, so there is an internal likeness, which accounts for the common nature of their constitution, modified however, by difference of age, sex, etc.

"Among the acquired predisposing causes of pleuro-pneumonia may be enumerated general debility, local weakness, resulting from previous disease, irritants and stimulants, exposure to cold, damp, or sudden changes of temperature, the want of cleanliness, the breathing of an atmosphere vitiated by the decomposition of animal or vegetable matters, or laden with any other impurity. In short, under this head may be included every thing which tends to lower the health and vigor of the system, and consequently to increase the susceptibility to disease. 
"The primary symptoms of pleuro-pneumonia are generally obscure, and too often excite but little attention or anxiety. As the disease steals on, the animal becomes dull and dejected, and, if in the field, separates itself from its fellows. It becomes uneasy, ceases to ruminate, and the respirations are a little hurried. If it be a milch cow, the lacteal secretion is diminished, and the udder is hot and tender. The eyes are dull, the head is lowered, the nose protruded, and the nostrils expanded. The urine generally becomes scanty and high-colored. It is seldom thought that much is the matter with the animal until it ceases to eat; but this criterion does not hold good in most cases of the disease, for the animal at the outset still takes its food, and continues to do so until the blood becomes impoverished and poisoned; it is then that the system becomes deranged, the digestive process impaired, and fever established. The skin adheres to the ribs, and there is tenderness along the spine. Manipulation of the trachea, and percussion applied to the sides, causes the animal to evince pain. Although the beast may have been ill only three days, the number of pulsations are generally about seventy per minute; but they are sometimes eighty, and even more. In the first stage, the artery under the jaw feels full and large; but as the disease runs on, the pulse rapidly becomes smaller, quicker, and more oppressed. The breathing is labored, and goes on accelerating as the local inflammation increases. The fore extremities are planted wide apart, with the elbows turned out in order to areh the ribs, and form fixed points for the action of those muscles which the animal brings into operation to assist the respiratory process. In pleuro-pneumonia, the hot stage of fever is never of long duration [simply because there is not enough vitality in the system to keep up a continued fever]. 'The state of collapse quickly ensues, when the surface heat again decreases, and the pulse becomes small and less distinet. We have now that low typhoid fever so much to be dreaded, and which characterizes the disease in common with epizoötics,

". . The horse laboring under pleuro-pneumonia, or, indeed, any pulmonory disease will not lie down; but, in the 
same circumstances, cattle do so as readily as in health. They do not however, lie upon their side, but couch upon the sternum, which is broad and flat, and covered by a quantity of fibro-cellular substance, which serves as a cushion; while the articulation between the lower extremities of the ribs admits of lateral expansion of the chest. In this position cattle generally lie towards the side principally affected, thus relieving the sounder side, and enabling it to act more freely. There is sometimes a shivering and general tremor, which may exist throughout the whole course of the disease. (This is owing to a loss of equilibrum between the nerves of nutrition and the circulation.) . . . As the case advances in severity, and runs on to an unfavorable termination, the pulse loses its strength and becomes quicker. Respiration is in most cases attended by a grunt at the commencement of expiration - a symptom, however, not observable in the horse. The expired air is cold, and of a noisome odor. The animal crouches. There is sometimes an apparent knuckling over at the fetlocks, caused by pain in the joints. This symptom is mostly observable in cases when the pleura and pericardium are affected. The animal grinds its teeth. The appetite has now entirely failed, and the emaciation becomes extreme. The muscles, especially those employed in respiration, become wasted; the belly is tucked, and the flanks heave; the oppressive uneasiness is excessive; the strength fails, under the convulsive efforts attendant upon respiration, and the poor animal dies.

"In using means to prevent the occurrence of the disease, we should endeavor to maintain in a sound and healthy tone the physical powers of the stock, and to avoid whatever tends to depress the vital force. Exposure to the influence of contagion (and infection) must be guarded against, and, on the appearance of the disease, every precaution must be used to prevent the healthy having communication with the sick. By a steady pursuance, on the part of the stock proprietor, of these precautionary measures, and by the exercise of care, prudence, and attention, the virulence of the disease will, we are sure, be much abated, and its progress checked." 
As the reader could not be benefited by our detailing the system of medication pursued in England, - at least we should judge not, when we take into consideration the great loss that attends their best efforts, - we shall therefore proceed to inform the reader how the disease should be treated in this country.

If a "sound and healthy tone of the physical powers of neat stock," is the best preventive against this formidable malady, it follows, that a course of medication and management, calculated to restore the lost heallihy tone, is the most rational. In the first place, the patient should be removed from its associates, into a loose barn or shed; the diet must be light and nutritious; should, however, the animal be plethoric, the attendant would of course dip a lighter hand into the meal-bag. The general indications of cure are as follows: Restore the suppressed evacuations, secretions, and excretions ; provided either are interrupted, and relieve all urgent symptoms.

In view of fulfilling the above indications the following recipe is submitted :-

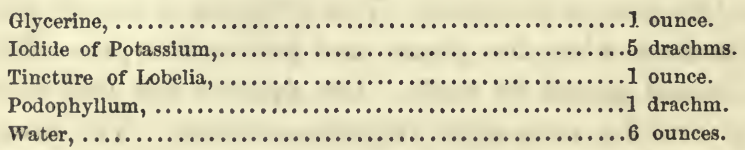

Mix, and give one-sixth of this quantity morning and evening. Should peristaltic action of the intestines appear to be tardy or inefficient, a relaxing and stimulating enema may be administered in the following proportions :-

Pulverized Lobelia seeds,..........................1 ounce.

Pulverized Ginger, ...............................4 drachms.

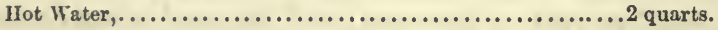

Mix, and inject.

It is a woeful error to resort to blood-letting in this malady, for in the first place all epizoötic diseases are of a very prossrating character, and in a brief space of time generally commit the most fearful ravages, so that all the blood in the economy is needed; some of it goes to repair the mischief occurring in the organs of respiration and elsewhere ; and another quantum is needed to carry on the vital operations; in fact there 
is no blood to spare. In the next place blood under all the stages of this malady is highly earbonized. Now it seems to be more necessary to decarbonize it than to abstract it; it can be decarbonized by administering repeated doses of ammonia with much better prospects of success, than by the former process.

Ammonia is always indicated in debilitating diseases, and in congestions of the lungs; it stimulates the circulatory apparatus to increased activity, and thus induces a more equal distribution of the blood; in this way congestions are relieved.

'The dose of aqua ammonia, as a diffusable stimulant, decarbonizer and antiseptic, is from two to four drachms; it should be largely diluted with water or gruel, for if given alone it will act as a vesicant and irritant, and thus do more harm than good. It may be given often, provided it is well diluted, as it does not accumulate in the system, but is generally excreted from the same through the common excretory outlets.

Ungent symptoms may be thus relieved, for example: should the animal have a bad cough, a dram of Tilden's or Thayer's fluid extract of lobelia may be given occasionally, in a draught of water, and after the exhibition of ammonia, should the pulse indicate a sedative, half an ounce of powdered nitre, may be given at intervals of two hours until the pulse become softer and less frequent.

The best purgative should such an agent be indicated, is chloride of sodium, - common salt. Dose, eight or twelve ounces dissolved in water.

Should the animal be feverish, which may be discovered by the unnatural heat of the external surface, dry state of the mouth, accompanied by excessive thirst, scanty urine, etc., a few doses of the solution of the acetate of ammonia may be given. Dose, three ounces diluted with water.

INOCULATION FOR CONTAGIOUS PLEURO-PNEUMONIA.

It appears, from reports made by French and German veterinary surgeons, that inoculation for the above disease must come into general practice, and finally will prove of great 
value in mitigating the form and intensity of this dreadful malady.' Prof. Simmonds of the London Veterinary College, who was commissioned, a short time ago, to visit the locations of the "rinderpest," reports unfavorably on inoculation for the same, but this will not affect the general issue, "time, which proves all things," must elapse ere inoculation becomes popular. Vaccination, when first practised by Jenner, met with great opposition, in fact, for a long time it got the cold shoulder of public opinion, and a great number of professional men who were directly interested in the success of so great a boon to suffering humanity also opposed it.

The want of success in a new experiment of this kind, is probably in a majority of cases, owing to a lack of knowledge on the part of experimenters, regarding the conditions necessary to a successful issue. Inoculation has been tried in the "swill-milk" establishments in New York, the results have proved unsatisfactory, and there are reasons for these failures, which I shall briefly allude to. In the first place, the matter used for innoculation was taken from the lungs of dead subjects after having died the most horrid of all deaths, in an atmosphere and region too beastly to contemplate. Now it is well known that absorption of morbid matter from a dead subject is almost sure to occasion death. It is well known that many eminent physicians have iost their lives in this way, and millions of men and animals have sunk into the arms of death in consequence of absorbing septic poisons. In my opinion, there is not the remotest chance of success in inoculation, when putrid matter from the lungs of a deal subject is used. It is understood that a great number of animals in the swill-milk establishments loose their tails, the greatest wonder is, that their bodies should survive the tails.

In the next place, the location selected for the insertion of the virus is not a good one; it is too remote from the central organs of circulation, so that if any damage occurs to the tissues of the tail by the introduction of the virus, the reparative process will not be so active as in other parts situated nearer the heart. Even a simple wound, made in the tail, does 
not always heal so readily as it would in some other parts of the body. The fact is, the tail is a very useful, yet active member of the body, and it is this very activity that I complain of, for it is unfavorable to the healing of the parts. Every one knows, also, that in crowded hospitals, in filthy, unventilated dungeons and stables, even simple wounds often acquire a malignancy. which very much retards the healing process. Then again, very few persons (in this country) understand the modus operandi of inoculation; as it is now practised in New York, viz., by making an incision, there is little hopes of any benefit to the animal, profit to the owner, nor, under the circumstances, will the operation ever become popular.

To those persons who wish to try the experiment of inoculation, I offer the following suggestions :-

1st. The animal to be experimented upon should be placed in a clean comfortable location, separated from the infected animals.

2d. The virus should be collected from the nasal cavities of a living, yet affected animal, at a period when the disease has about attained its height, as the saying is. The exudation may be obtained after an act of coughing, or it may be gath ered or scraped from the nasal membrane, by means of a teaspoon; but, probably, the matter expelled in the act of coughing, will answer the purpose best. This, as soon as collected, should be placed in a ground stopped bottle, ready for use.

3 d. The virus may be inserted at the inside of the fore arm, three or four inches below the point of the elbow; then make a slight puncture with a common lancet, then dip the same into the virus (contained in the bottle), and thoroughly smear the orifice and insinuate some under the epidermis; the very smallest particle, properly introduced, will suffice; a single germ or cell is all we require to "leaven the whole loaf."

\section{PNEUMATOSIS OR WINDY DISTENSIONS.}

The states of various tissues and organs of the body, known as windy distention, - emphysema, - are of such common oc- 
currence among live stock, that it "stands us in hand," as the saying is, to inquire into the why and wherefore of the same. I had prepared an article on the above subject; but, fortunately for the reader, and luckily for me, I have been permitted to furnish a very valuable document, which throws mine completely into the shade, saves my credit, and amply repays the reader for the patience he must necessarily possess in order to read and appreciate the following lengthy article. It emanates from the brain, and is chronicled by the pen of M. Rainard, in the Journal de Medicine Veterinaire de Lyon. The translation here introduced is furnished by the Veterinarian.

The subject is introduced in four parts, The first treats of a combination of healthy and diseased gases found to pervade the animal body during life. The second refers to pulmonary pneumatosis or emphysema of the lungs. The third lucidly explains pneumatosis of the alimentary canal, called tympanitis. The fourth investigates cellular pneumatosis or external emphysema.

The remedies used for the treatment of pneumatosis are tonics, stimulants, and antiseptics. The following will serve as an example : -

Hyposulphite of Soda, ...........................1 ounce.

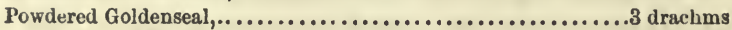

" Ginger,$\ldots \ldots \ldots \ldots \ldots \ldots \ldots \ldots \ldots \ldots \ldots \ldots . \ldots 2$ drachms.

Mix with water and drench the patient; this dose may be repeated at the end of six hours, if necessary.

ON THE GASEOUS FLUIDS OF A LIVING ANIMAL BODY, CONSIDERED IN THE LIGHT OF GENERAT PIIYSIOLOGY AND PATHOLOGY.

"M. Dumas, by a learned deduction from scientific facts, establishes on proofs furnished by the chemistry of organic bodies, that the primitive materials of organization are derived from the atmosphere. According to him, plants, like animals, spring from air, - are real dependents of the atmosphere.

"The vegetable kingdom, adds this learned chemist, is the grand elaboratory of organic life. Therein is it that vegetable and animal matters are produced at the expense of the air, and 
by a transmutation no less true than surprising, these matters, ready formed, pass from vegetable to herbivorous animals, and then to carnivora, which either consume or preserve them, according to their wants. Lastly, either during the life of such animals, or after their death, these organic matters, in the ratio in which they become consumed, return to the atmosphere whence they are derived; and thus is formed the organic circle of organic life upon the surface of our globe.

"The air contains or generates certain oxyde productions, carbonic acid, water, azotic acid, oxyde of ammonia. Plants, the veritable decomposers of these, absorb their bases, carbon, hydrogen, azote, and ammonia, with which elements they compound the whole of the matters, organic and organizable, yielded to animals. These veritable apparatus for combustion, in their turn, reproduce carbonic acid, water, oxyde of ammonia, and azotic acid, which once more depart into the air, in order to regenerate afresh, through endless ages, the same phenomena.

"To this picture, striking no less by its simplicity than its grandeur, we must add the undeniable influence of solar light, which alone can set in action this immense apparatus of the vegetable kingdom, whence is effected the reduction of the oxyde ingredients of the air to scrve the purposes of the formation and repair of organization.

"So that modern chemistry has traced, with admirable profundity, the important part performed by the air, the grand agent, this immense reservoir, which, by itself, or through the agency of the substances contained in it, furnishes the primary elements of regetable organization. Here, then, is the primary form of the constituent elements of living bodies (to wit) the gascous state. It is likewise through the same state that comes their end.

"But it is not only at their formation, or at their decay, that their immediate principles become resolved into gas; the same thing happens in the course of their lifetime. Even in their very tissues gas becomes developed, and commonly as the product of secretion; only such products are not generated in any 
continuous or permanent manner, like carbonic acid gas exhaled by the green parts of vegetables; they form, but under certain conditions and for certain uses, which we shall now consider.

"M. de Blainville, in his General Physiology (rol ii, p. 124), is of opinion that there are two kinds of principal gases; one to be accounted elementary, composing the integrant part of the organism, which exists constantly and normally; the other, as I have just remarked, secreted or exhaled by the tissues.

"The elementary gases, observes this learned physiologist, enter into the composition of the body, are found in the cells of the tissues, and through them distributed over every part of the body. The physical characters of these elements become confounded with the anatomical character of the tissues, so that they are only to be found in the component solids of organization; we may add, or in liquids, since it is beyond all doubt that the blood contains among its molecules particles of aeriform fluid.

"And gaseous products are, like other products of the body according to the same author, substances differing in nature, disposed about the organism, oftenest upon the surface of the body (meaning by surface not only the skin, but the different mucous inlets, all corresponding to the exterior as well), but sometimes likewise within certain cavities and cells, without, in fact, composing part of their organism, and with many without disturbing them, be extracted from them, or may be rejected by them.

"Gaseous products appear to be the result of secretions analogous to those producing fluids. Like as the skin furnishes the perspirable matter, it produces likewise carbonic acid gas; and the mucous passages of the bronchii give issue to not only carbonic acid gas, but likewise to azote and to water. Glands also, it is probable, secrete gas with their habitual fluids; and the cellular tissue itself generates gas in the case of emphysema, as well as serosity, and so likewise do serous surfaces.

"These general positions established, without stopping to in- 
quire into the distinction prescribed by M. de Blainville, the order I propose to observe is this :-

"In the first paragraph I shall exhibit the parts of the body in which gases are found, and this paragraph I shall divide according as they are met with; viz. : -

"(A.) In the Blood.

"(B.) In the Cellular Tissue.

"(C.) In the Serous Membranes.

"(D.) In the Mucous Membranes.

"(E.) In the Skin.

"In a second paragraph I shall treat of the physical and chemical characters of the gas.

"In a third of the physiological conditions of the production of gases, either as elements of the body or as products. 1st. of respiration; $2 \mathrm{~d}$, of nutrition; $3 \mathrm{~d}$, of digestion ; $4 \mathrm{th}$, of absorption; 5th, and lastly, of the secretions.

"In a fourth paragraph, of the gases belonging to the diseased state; of the morbid conditions under the influence of which gases are generated, and of the nature of disorders which they beget.

"In a fifth and last paragraph, I shall offer some general considerations on the therapeutics of flatulent disorders.

\section{Of the Parts of the Body where Gases are found.}

"The existence of gas has been demonstrated in the blood, in the cellular tissue, in the serous cavities, upon the surfaces of the mucous membranes, and upon that of the skin.

"(A.) Of Gases contained in Vessels, mixed or circulating with the Blood.

"Venous blood admits gases, as may be plainly proved, and in health too, and we know that they become accidentally introduced into it.

"Commencing with animals occupying a low station in the scale of animal existence, the tench, for example, we ascertain by opening the body of the animal under water, that there ex- 
ists in its veins a notable quantity of æriform fluid. And without a question, pulmonary absorption, in other animals, introduces gases into the venous system; and chemistry has taught us, that the blood flowing through this system is most greedy of it. Magnus, the Berlin chemist, has established, by his researches, that the blood has the power of dissolving a certain quantity of all gases in contact with it; but that, whenever this liquid, already charged with gas, comes to absorb another, it can only do so by giving out a certain portion of the one first taken up; so that, when venous blood is agitated with hydrogen, a portion of this gas is dissolved, and a corresponding quantity of carbonic acid already existing in the liquid is disengaged; and when, instead of hydrogen, oxygen is made use of, an analogous result is obtained. The venous blood ab-sorbs a certain quantity of gas, and liberates a quantity of carbonic acid nearly equivalent thereto.

"Persons engaged in dissection know full well that it is by no means an uncommon thing to meet with gaseous globules in the veins of animals slaughtered in a state of health.

" We also know that the insufflation of air into the jugular vein of a horse does not always produce ill consequences, much less death. Under these circumstances, without doubt, the air introduced becomes absorbed by the blood.

"Is gas likewise present in arterial blood? Chemists think so, and M. Lassingen assures us positively of the fact. According to him, arterial blood, though in less quantity than venous blood, both contains acid gas and azote.

"Brummer has proved the existence of gas in arteries by the following experiment: After having produced a slow circulation by means of foxglove on a dog, he seized the aorta and by means of a couple of ligatures dammed up the blood flowing through it, closing the farther ligature first, instantly after the contraction of the ventricle. On opening after a little while this imprisoned portion of trunk, he discovered an aeriform fluid in it, of which we shall anon ascertain the composition.

"We are told that every time we take a large quantity of 
blood away from an animal, we find gas in the arteries, introduced there to fill the void left by the flow of blood; a roid which is not suffered to pervade the arterial parietes, on account of their not returning with sufficient rapidity to their natural calibre.

"For a very long time it has been known that, after death, aeriform fluids occupy the place of the blood in the arteries, which has been propelled into the venous system. It was, indeed, from this discovery of Erudistratus that the arteries received the name they bear to this day.

"The presence of gases in the sanguiferous system, and in the interstices of tissues, is never observed, according to M. de Blainville, in the foetus, before it has respired. He assures us he has never seen globules of air escape from the body of the fœtuses, which he has opened under water. Notwithstanding this imposing authority, however, one is tempted to doubt the correctness of the assertion, when one knows that the blood of the mother and the waters of the amnion both contain gas.

\section{"(B.) Of the Gases of the Generative Cellular Tissue.}

"The presence of gas in the cellular tissue is abundantly roved by the formation of emphysema, at times very considsrable.

"We find them within the cellular tissue entering into the somposition of organs, as well as in that which forms the adherent surface of serous and ligamentary membranes.

"Underneath the skin, emplyssema, in some cases, makes its appearance spontaneously, or without any appreciable cause: at then seems to be the result of a particular and entirely ocal secretion of this tissue. More commonly, however, the accumulation of sub-cutaneous gases depends upon some internal morbid condition, of which it is but the effect or a symptom. Fevers called adynamic and typhoid, and typhus ever, and the introduction through the skin of certain poisons, urnish examples of this.

"But the presence of aeriform fluids underneath the skin, 
constituting emphysema, is at times purely accidental; it may depend upon a solution of continuity of the skin, permitting the introduction of atmospheric air into the subjacent cellular tissue.

"As for the gas discovered within the parenchyma of organs, especially of the lungs, it no doubt owes its presence to respiration, which escapes through some laceration or perforation of some of the air-cells, previously dilated and softened by the action of inflammation.

"It is the same with the gases found in the sub-pleural cellular tissue, and within the abdomen, in the peritoneal cellular tissue, as the consequence of rupture or perforation of the stomach and intestines.

"(C) The Reservoirs and Sacs formed by Serous Membranes are in some cases, normally or from morbid causes, the Seat of Gaseous Collections.

"Everybody knows that certain fish, such as carp and perch, are provided with a reservoir called a swimming-bladder, placed at the posterior part of the visceral mass. This reservoir contains an aeriform fluid, which remains within it, and distends it, and thus serves divers purposes to the animal. It is well known that this gaseous fluid is not directly derived from the lung. M. de Blainville assures us that the swimming-bladder has no communication with the buccal cavity. He has never been able to empty it through this passage, nor to force the gas out through the respiratory channels. Indeed, the analysis made of it by Messrs. Rumboldt, Provençal, and Delaroche, has shown that it is not directly furnished by the air of respiration, but must be the product of a particular secretion.

"The feathers of birds are, likewise, another example of air reservoirs having no communication with the respiratory passages; the air appearing to be introduced into them through absorption, at the period when the gelatinous matters disappear, which up to that time had filled the tubes.

"We know that the air of respiration gains admission into the 
osseous system of birds of high flight. We also know that in insects, which, like birds, have need of great specific lightness, here exists plenty of air, brought by the trachea, and afterwards distributed through the different parts of the animal, to p'ace it in relation with the molecules designed for its assimilation.

"Among fish, shell-fish enjoy the faculty, which to them proves a source of health, of filling their stumachs with air, and so of considerably augmenting the volume of their body, and, through an extension of their'skin, facilitating the erection of the scales by which it is covered, and which remain depressed so long as the skin continues in inaction. It is likewise the atmospheric air which enables that frolicsome animal known by the name of dolphin to render himself light enough to swim upon the surface of the sea. - Blainville's Physiologie Generale.

"Not even vegetables are without reservoirs containing air. Chemists have demonstrated that it is the fluid found in certain plants of the leguminous family, that fills and swells the pericarp at the period of maturity; and Gaspard has assured himself, in opening under water many sceds of the same family, regarded by physicians as full of wind, that they contain in their tissues a large quantity of atmospheric air.

"In regard to collections of gas within the serous cavities, such as the peritoneum, the pleura, and even the pericardium, they are attributed, and with reason, to two different sources, to the atmospheric air, and to an exhalation from these membranes. It is thus that we account for peritoneal tympanitis when there exists no mechanical lesion; viz., through the effect of physiological operation; but in a much greater number of cases they proceed from rupture of the stomach or intestine.

"Pneumatosis of the pleura depends, most commonly, upon these two latter circumstances, either proceeding from rupture of some air-cell near the surface, as in the case of emphysema; or else from the perforation of the pulmonary pleura, as the sequel of the softening of the tubercles in communication with the bronchii. In this last state, the air proceeding from 
the lungs is constantly mingled with purulent and other matters.

\section{"(D) Of the Gases of the Mucous Surfaces or Internal} Tegumentary Tissues.

"Although we are assured of the existence of gaseous col- . lections in all organs lined with mucous membrane, such as the Eustachian pouches, the lung, the alimentary canal, the uterus, and the bladder, it is more particularly within the lungs and alimentary canal that they are frequently observed. We give the name of pulmonary emphysema to the collection of air within the lung; to that within the alimentary canal the name of abdominal pneumatosis or tympanitis. As for the Eustachian pouches, it is the same with them as with the air-cells, it being only when their orifices are obstructed through some morbid condition that gaseous fluids remain in them. We then find them mingled with muco-purulent matter, furnished by the lining of the reservoir, and commonly collected within the reservoir.

"In the normal state, the stomach and intestines contain variable quantities of aeriform fluids; and it is their accumulation in any considerable quantity that constitutes the flatulent or pneumatose condition.

" "Gases spring from various sources. Some are the product of an exhalation going on from the free surface of the lining membrane; others are introduced through deglutition along with the food, to which they in a manner adhere; and there are some which are even contained in the alimentary matters, and which become disengaged during the process of digestion.

"The fact of the exhalation of gas from the internal surface of the intestine has been placed beyond doubt by experimentation. Messrs. Majendie and Girardin, having caused a portion of the intestinal canal of an animal to protrude from its abdomen, containing nothing, and secured it with ligature before and behind, they liave found shortly afterwards the imprisoned portion of gut filled with gas; and all the while the mucous lining perfectly healthy. Bernard Gaspard, who has made the 
same remark, informs us that this gaseous exhalation is even more active than at the time of digestion.

"It is generally beliered that this fluid is of use in continually preserving the form and dimensions of the intestines. If it be true that the body of the fotus prior to birth does not admit any gas into the cells of its tissues, as M. de Blainville has asserted, it is no less certain that we have witnessed in the fotus of several animals, while as yet in utero, a certain quantity of gas within the intestines. And M. Baumes (in his Traite des Maladies Venteuses), assures us of having made the same remark in the human fotus; whence he concludes gases to be a product of exhalation of the intestinal mucous membrane.

"As to the gaseous fluids which find their way from without into the gastro-intestinal passages, they necessarily derive their source from the atmosphere, or from the food. It is evident that every time men and animals eat and drink, they must take into their alimentary canals a certain quantity of air mingled with the saliva. It is likewise evident that the aliments themselres introduce into the same passages a certain quantity of atmospheric air, adhering to the particles of food, or penetrating them while under mastication. Lastly, some aliments there are which contain by nature, within their interstices, aeriform fluids, as the experiments of Gaspard show. These are especially the vegetables belonging to the family legumina and crucifera, recognized commonly as being of a ventose nature.

"Aliments of this description introduced into the alimentary" canal, into the vast stomachs of ruminants, and the capacious intestines of horses, give escape to such an abundance of gas that, through their accumulation and their expansion from the heat of the situation, they are capable even of occasioning death from the impediment they cause to the respiratory and circulatory functions. The presence of gas, and its accumulation within the cavity of the uterus, in human medicine characterized by the name of physometra, is most rare with domestic females. The only cases in which we have been.able to trace the presence of gaseous fluid in this reservoir are those named, mal à propos, uterine dropsy. We know that in this 
sort of cases evacuations take place from time to time of mucopurulent matters, which occasion remarkable sounds, caused by the presence of gases found mixed with them, and in which we very distinctly detect air-globules after their escapes.

\section{"(E.) Of Gases furnished by the Skin.}

"The skin is also the seat of the continual exhalation of gas. With some animals, the frog especially, it is so abundant, according to Edwards, that it exceeds that which proceeds in the same animal from the surface of the lungs. We may be convinced of this by placing the living animal in water underneath the glass of an air-pump. As soon as exhaustion is effected, there escapes a certain quantity of aeriform fluid.

"The body of a man placed in a bath and exposed to the solar light, becomes covered with a multitude of aerial bubbles, as do the leaves of vegetables under certain circumstances.

"But M. de Blainville has remarked that we must not confound the gases of the skin with the matter of perspiration reduced to the state of vapor by the heat either of the body or of the atmosphere. Neither must we confound them with the atmospheric air, of which a thin layer reposes upon, adherent to the surface of the skin, disengaging itself in the form of bubbles whenever the body is plunged into water.

"However it may be, gases exhaled from the skin are never retained upon its surface, like those of the intestines. We have no means of obtaining them save through artificial means."

\section{MURRAIN.}

The husbandmen in this country have great reason to rejoice that their flocks and herds have, up to the present period, enjoyed comparative immunity from the awful and devastating pest, or pests, simulating or known as murrain, which, since the period of the almost total destruction of the Egyptian cattle, as recorded in the "good book," has to a certain extent prevailed, more or less, arnong the bovines; the property of the husbandmen of the old world.

J) uring my residence in this country I lave never scen a 
case of pure murrain; nor are the records of the sudden decease of cattle, deer, sheep or swine, as chronicled in the agricultural literature of the United States, at all conclusive on the subject of cattle pest - murrain. In view, therefore, of throwing a ray of light on a dark subject, I propose first, to consult authorities. The following article is an extract from a report made by the "Imperial Agricultural Society of Vienna," translated for the London Times:-

"The murrain, termed also cattle plague, stomach distemper, overbile, and putrid fever, is known, partially, in some districts, as cattle dysentery, on account of the presence of alvine defluxions, continued to the end of the disease. The contagious and infectious character of the murrain is such, that the disease, having made its appearance in one animal, is immediately communicated to all others in its vicinity which are not, without delay, separated from it. On the contrary, an animal which has once had the disease is not liable to a second attack. In consequence of this contagious and infectious nature of murrain, the animal first attacked by it must immediately be separated from the bealthy stock; it must also have its own attendant, and be provided with its own distinct fodder and drinking arrangements, apart from the other cattle. Cases, indeed, have occurred in which healthy cattle, tended by servants who have been in communication with diseased or dead animals, sickened of the murrain in the second, third, and fourth week. Also, the carcass should be buried with the excrements; and as the skins of the animals remain in a contagious and infectious state, they should, when not also buried, be steeped for a considerable time in water and sprinkled with quick-lime. In the Esurgo district, the carcases were indeed buried, but the excrements being thrown into the dung-pit along with the other manure, constantly exposed to the action of the air, and not allowed to come into contact with the cattle, no evil consequences were the result. The skins were immediately fetched away by the leather dresser, to be at once put in hand, and steeped in lime-water. The opinion that dogs, 
cats, flies, or insects continually communicate the contagion of the disease from one animal to another, appears to be an ultra idea, according to which, on the outbreak of murrain, no single animal of a district could escape, as all insulation of the diseased from the sound stock would be ineffective and fruitless. Previously to the introduction of healthy cattle into houses where diseased ones have been kept up, the fodder racks and mangers, as well as the brick or plaster work, ought to be well scoured with hot water; and the whole interior of the places, with closed doors and windows, be well fumigated with the vapor of chlorine; produced in the following manner : -

"In iron pans, placed in several parts of the cattle-house, put a tea-spoonful of finely powdered oxide of manganese, well mixed with the same quantity of common salt, and the whole moistened with water; then add oil of vitriol in small quantities. These vapors from manganese are not only cheaper but stronger than those produced by pouring oil of vitriol over chloride of lime. They must, however, be employed with moderation, otherwise they will inflict injury on the lungs. Such of the herdsmen's clothes, also, as are not washed with chloride of lime water, should be fumigated.

"For the purpose of preserving sound cattle from the murrain, Dr. Pessina rejects all venesections and purges, as well as all strong stimulating medicines, and even setons. The preservative means, by which the Esurgo herds have been so well protected from the murrain, consists in a separation of the sound from the diseased stock, a daily weak fumigation of the cattle houses with chlorine, wholesome food and water, and clean airy houses, rather cool than hot, and not crowded with stock. -In the animals which died of the disease, the fourth stomach and the intestines were corroded and inflamed, the gall-bladder unusually large, and preternaturally distended with an accumulation of green watery bile; the mass of blood throughout the system was in a corrupt confluent condition; and in many cases particular internal portions were in a state of decomposition, all evincing an inflamed, corroded, or mortifying condition of the body. 
"The following three conditions in the administration of muriatic acid for the cure of murrain, are essential :-

" 1 . The acid must be given early at the commencement of the disease, for the farther the symptoms are advanced, the more difficult will become the cure; and should internal mortification have already sét in, it will be too late to attempt it.

" 2 . The acid must be given in strong doses, at short intervals of time, according to the prescription about to be recommended; and the greater the intensity of the murrain, the stronger the doses must be.

" 3 . The acid must be unadulterated, strong, and fuming, and if of a weaker strength, it must be given in proportionately increased doses.

"Dr. Pessina recommends the iron-impregnated muriatic acid, in preference to the simple acid: the former, however, requires certain indispensable conditions to be attended to in its admil.istration.

"SYMPTOMS.

"1. Period of Sickening. - The animal gradually ceases to chew the cud or take food. It becomes melancholy, languid, and indifferent, frequently shaking its head, while its ears and horns become alternately hot and cold. The pulse is small and quick; in many cases there is a cough, the dung is sparing, and usually dry; the urine is, in all cases, turbid and reddish in color.

" 2. Period of Development. - the fever and faintness increase; the animal sinks into a stupid apathy, even in the case of those which previously were the most frolicsome of the herd, but which now become insensible to objects around them, and heedless to their herdsman's call. There is frequently a rising at the stomach, and rejection of its contents, the eyes sink inward, the animal begins to shiver, has pains in the under part of the body and spine, and unwillingly submits to have the back stroked; a yellow mucus commonly flows from the nostrils. The animal continues to refuse the smallest amount 
of food, and lies down upon the straw, where it heaves and snorts, while it breathes heavily, quickly and painfully.

"3. Period of last Struggle. - The respiration becomes more heary, and the breath more fetid, very warm, and even hot. The animal is constantly on the stare, has often a violent thirst, and groans much. The under belly becomes distended, and then generally ensues billious watery secretions from the bowels, of a very offensive character, and frequently tinged with blood, after which the paunch collapses. The animal suffers, in general, from the commencement of the disease, only four or five days, seldom more than six or seven, till death, and in the last struggle breathes or rattles in the throat, with wideset open mouth.

"Administration of Muriatic Acid. - The fuming, unadulterated muriatic acid, is at the beginning of the disease, so certain a remedy, that of twenty head of sick cattle, scarcely one is lost. Also, in the second period of disease, more than onehalf of them are saved. But in the third period, its use becomes less decided, at the same time that many animals are saved, even in the last extremity, by the administration of strong doses, and the acid is found preferable to every other remedy. Cows far gone in calf, can only be cured in the first period of the disease. As soon, therefore, as the symptoms of murrain, in any case, make their appearance, the cure must immediately be attempted. In case, however, one or more animals in the same house have already been attacked, the others may be assumed to have caught the disease as soon as they lose their appetite or cease to chew the cud, and steps may be taken with these accordingly, without waiting for further symptoms. The muriatic acid must be given within short intervals, and in strong doses, diluted with a proper quantity of water, a difference being made according to the character of the murrain, the degree of disease, the violence of the attack, and the strength and age of the animal. Even the season and the state of the weather must be attended to, in reference both to the degree of murrain and the curative influences. 
“The Esurgo farmers, following Dr. Pessina's prescription, gave a drench regularly every hour to each sick animal.

"1. Strong Oxen. - Fifteen to twenty drenches, each composed of two quarts of water and three-quarters of an ounce of muriatic acid.

"2. Strong Cows. - The same drenches, but with only half an ounce of muriatic acid.

"3. Two-year-old Cattle.-Ten to twelve drenches, two quarts of water, with half an ounce of muriatic acid.

"4. Year-old Calves. - Eight to ten drenches, one quart of water, with a quarter of an ounce of muriatic acid.

"5. Sucking Calves. - Eight to ten drenches, one pint of water, with half a quarter of an ounce of the acid.

"These drenches, given neither cold nor hot, but in a lukewarm state, will effect the whole cure of the disease, if only at its commencement, or not too far gone, provided they be given continuously, hour by hour, either through the day or the night. The more ill-conditioned the form of the murrain, the stronger will the dose be required to combat the evil.

"After administering the foregoing amount of drenches, nothing further is to be given for the succeeding twenty-four hours than gruel-drinks, and the more the animal can then take of these the more certain is their recovery, as an animal never dies of the disease, when, after the muriatic acid drenches, it begins to take drink."

The "Times," also publishes letters from Mr. Redcliffe who speaks of the pulmonary complaint with typhoid symptoms. Mr. Gamgee describes the true rinderpest - contagious typhus or murrain of the steppe; Dr. Greenhow speaks of the murrain as "lung disease," but the probability is, that there are not three kinds of murrain, but three different stages in which it has been seen by as many different persons, at various times.

In the early stage, it probably constitutes a caturrhal affection of the membrane lining the respiratory passages, accompanied by febrile symptoms, and the usual prostration which always occurs in diseases of epizoötic origin. By proper treatment in this stage, - when the lungs are not 
supposed to be involved, - the disease, in many cases, might be arrested, but so long as phyiscians consider it as an inflammatory affection, and treat it as such, by administering agents which reduce the vitality of the system, there is no hope for the patient; the disease will run into the typhoid stage. The treatment I recommend as the most rational, is as follows: Let the infected animal be removed from its associates, to a comfortable, clean location. The body and limbs, if they are chilly, should be well rubbed with wisps of straw, and afterwards clothed if necessary. The medicine to be administered consists of, -

Balsam Copaiba,.....................................4 ounces.

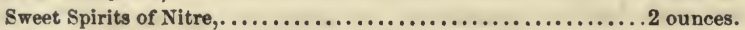

Mucilage of Gum Arabic,...........................12 ounces.

Tincture of Matico,............................... 3 ounces. Mix.

Dose. - Three ounces, morning and evening.

A superabundant discharge of urine will be the signal to stop the medicine. The drink should consist of warm mucilage of slippery elm ; and the food, if the animal is disposed to eat, should consist of ground oats, and green vegetables, if they can be obtained.

When the fœcal discharges become liquid and profuse, pulverized charcoal, at the rate of six ounces per day, may be given, at the same time I should offer the patient a liberal supply of sliced carrots; I use this vegetable in preference to all others because it contains an agent, capable of gelatinizing the contents of the abdominal viscera; viz., pectec acid.

Notwithstanding the above treatment, should the alvine discharges continue liquid and profuse, I should give a few doses of infusion of bayberry bark, and feed on good hay and ground oatmeal. If the patient is thirsty, I should prescribe hay-tea acidulated with lemon-juice, or a few bruised cranberries. If, after the above treatment, a lung difficulty, or typhoid symptoms set in, there is very little hope for the animal; the principles of veterinary theory and practice exercised with the most consummate skill, may fail in arresting the malady; still, however the animal should not be sacrificed until some means such as $\mathrm{I}$ have recomended have been tried. 
When the lungs become involved and the disease is passing into the typhoid stage, the symptoms vary and intensify, as the various tissues of the body become secondarily affected. Those that have paid the most attention to the prevailing symptoms, record the following:-

"The 'lung disease,' combined with typhus, may be divided into three periods. The symptoms of the first period, during which there is no fever, are, - sadness and prostration of strength ; second, drooping head and pendulous ears; third, eyes fixed without loss either of lustre or of color (in vigorous animals the eyes are often red and fiery, but dry); fourth, the skin of the nostrils pale, and the inside of the mouth 'slimy;' fiftl, temperature of the body low, with horns, ears, and feet cool ; sixth, skin dry and tense [stretched], the hair lustreless, rough, and bristly, and erected along the spine; seventh, breathing difficult. The first period sometimes lasts a fortnight or three weeks ; the second, or feverish period lasts three or four days. The symptoms are those above described, with feverish movements. The diseased animal has fits of shivering, considerable exacerbation in the evening, and remission of fever towards the middle of the day. After the cold, or aguish fits are over, the reaction is much less violent than in other inflammatory complaints. Each paroxysm of fever is accompanied by an acceleration of the respiration, which is audible, and often accompanied by a moaning sound. The weakness and exhrustion of the animal are very great; the temperature of the ears, liorns, and legs change continually - now warm and now cold; the skin is dry and rough, and looks as if dust were strewn on it; the hair is erect, and the eyes which are opened wide, are projecting, dry, shining, and fixed. The pupil is dilated. The nostrils are covered with a slimy secretion, which the suffering animal removes with its tongue; the teeth are loose; the loins are so sensitive that the pressure of the hand cannot be borne without shrinking, and the pain in the chest increases. The animal lies down but seldom, and when it does so, it is on the side on which the lung is affected. If both lungs are diseased, 
the animal rests on its breast-bone, with its legs under its body, and its head and neck stretched out. The alvine secretion is often either entirely suppressed, or very scanty. The urine is dark in color, and pungent in smell. During the third period, which commonly ends in death, the uneasiness and agitation of the animal are extreme. It continually changes its position, and draws back from the crib to the length of its tether. The eyes sink and become glazed, and the lids fall, as if the animal were about to sleep. The horns, ears, and nose are cold; the mouth is filled with offensive phlegm and saliva, and an ill-colored secretion flows from the nostrils. The animal gnashes its teeth, which are loose and shaky, the hair becomes more and more bristly, and the emaciation is rapid. At this period of the disease the pulse is often above one hundred a minute."

Treatment of Murrain when the lungs are involved. - I should give about two drachms of aromatic tincture of sulphuric acid in a pint of water, every three hours; the whole of the back, and region of the chest is to be well rubbed with a portion of oil of cedar, and linseed oil - equal parts. Should the animal rapidly lose strength, tonic remedies must be employed; two drachms of goldenseal and one of ginger, may be given thrice, in the course of twenty-four hours. If it be necessary to evacuate the contents of the rectum, I should throw in occasional clysters; composed of two quarts of water, three ounces of table salt, and one ounce of goldenseal.

In the typhoid stage, the following medicine should be given :-

Powdered Charcoal,.................................12 ounces.

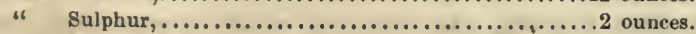

" Goldenseal,................................. 3 ounces.

Table Salt, .......................................

Divide the mass into six equal parts, one of which is to be given every four hours, in a pint of milk. The back and remions of the chest are to be rubbed occasionally with tincture of capiscum. If the patient has a troublesome cough, a mucilagenous drink of slippery elm should be given. Should an improvement take place, the quantity of medicine is 
to be reduced, and finally suspended altogether. If on the contrary the animal grows worse it should be slaughtered and buried.

\section{ON VENTILATION.}

Pure air is one of the forces of nature, in constant operation, to preserve the integrity of animal life; therefore, impure air must necessarily occasion various forms of disease.

In the course of fourteen years' practice, the author of this work has had ample opportunities of investigating the causes of disease, and has satisfied himself, beyond a reasonable doubt, that a very great proportion of the diseases occurring among live stock, owe their origin, either directly or indirectly, to a vitiated atmosphere; and that other maladies, having various origins, are aggravated, and restoration is often tardy, sometimes impossible, in consequence of the morbid action of impure air.

The author's intention, in offering the following article, is 10 benefit both the superior and inferior orders of creation; hence the attention of the reader is craved to some matters which do not directly apply to cattle, yet may prove of great value to owners of the same. A pure atmosphere is the "breath of life."

The science of ventilatior has never received that attention which its importance to the. well-being of man, and the welfare of the inferior orders of creation demands ; in fact, everybody professes to be somewhat acquainted with the wants of the animal economy, as regards food, fluids, rest, and exercise, yet, in reference to the necessary amount of aerial food, - the breath of life, - very few persons ever give the subject more than a passing thought. A pure and uncontaminated atmosphere is absolutely necessary for physiological respiration; any deviation from purity (whether the man or animal be diseased or not), is sure, sooner or later, to end in ill health. A cow, or, indeed, any other animal, can survive the deprivation of both food and water for many days, without incurring any thing like the same amount of danger encountered when breathing, for a 
few hours only, a contaminated atmosphere, such, for example, as pervades swill milk establishments, and filthy barns, where the principles of both ventilation and cleanliness are almost entirely disregarded.

The object of ventilation is to secure a current of pure air at ali times, by which means the vitiated is replaced, and a constant supply of the pure material is kept up. 'This neutralizes the morbid effects which follow the re-respiration of a pent-up atmosphere.

Pure air is that immense mass of elastic fluid which surrounds the globe we inhabit. It is capable of varying its dimensions under the influence of heat and cold; heat expands or rarifies it, and cold contracts or condenses it. It is transparent, so as to be invisible, except by the blue color it reflects when in large mass, as seen in the regions of space. It is without odor, except that of electricity, which it very frequently manifests, and, like other gases, it is capable of holding in solution, or receiving an admixture of vapor. For example, it absorbs water in considerable quantities, without decrease in its own specific gravity; it is supposed, however, that the air suspends vapor, not really by absorption, but by separating its particles, and thus preventing their condensation.

Pure air almost always contains vapor; for the rain and dew, which attract our attention, as well as the clouds and fogs, all deposit moisture, and even when the atmosphere appears perfectly transparent, water can be extracted from it. The usual process of demonstration is as follows: Take one ounce of sulphuric acid (which has an extraordinary affinity for water, more than any other acid), and expose it in a shallow vessel, subject to the free action of pure air, and in a short time it is converted into a dilute acid; its weight having increased in the ratio of one hundred per cent. The vapor or water, thus absorbed, ean again be separated by distillation, showing conclusively that watery vapor is always present in pure air. Everybody knows that iron and steel, when exposed to the atmosphere, will corrode; that lime will slake; salt and sugar will imbibe moisture; consequently the theory needs no further 
illustration. Water seems to be almost as essential for the purposes of respiration as that of nutrition; and when we realize the fact, that the animal frame is composed of 75 per cent of water; that three-fourths of the wondrous and complicated mechanism of man and his congeneric flocks and herds is composed of the "dew-drops ;" that the vital current which courses the arteries of each, and gives vitality, health, and beauty to the animal mechanism, is in the same ratio, we must come to the conclusion that water plays a very essential part in the animal economy, both as regards respiration and nutrition.

Chemistry has demonstrated that pure air, which I contend is absolutely necessary for the purpose of physiological respiration, is not composed of a single element, as some suppose, but is a unity of three gases, termed oxygen, nitrogen, and carbonic acid. These unite in the following equivalents: Oxygen, 21 per cent; nitrogen, 75 per cent; carbonic acid, one per cent. These equivalents are persistent; they never unite in any other form; hence we know, from inductive evidence, that the elementary basis of a pure atmosphere rests on the above proposition, so that the elementary constituents of pure air are the same all over the world.

Oxygen. - This gas does not exist in a free state, but in combination, it is universally dispersed throughout nature. It unites with light and heat, as well as air, and to bodies in a state of combustion, and so intense is its own caloric power, that if it could be set free throughout nature, a universal conflagration might be expected; the hardest rocks would crumble to dust, and even the diamond, considered as indestructible, would melt as with "fervent heat." This gas has neither taste nor odor, and like common air is capable of indefinite expansion and compression. It is indispensable to respiration, and gencrates animal heat.

The estimated weight of oxygen respired by a healthy man in 24 hours, is $21-4$ pounds. This, in a gaseous state, occupies a volume of 48,000 cubic inches. It unites with the carbon of, the blood, and in the course of 24 hours liberates from the lungs 48,000 cubic inches of carbonic acid gas. 
Having briefly alluded to the use and properties of oxyge $u_{\text {, }}$ nitrogen next engages our attention.

Nitrogen. - This gas possesses all the physical properties of common air. It is distinguished for its repugnance to enter into chemical combinations. Its principal use seems to be, to neutralize the effect which might result from the action of pure oxygen on the animal tissues. It is a non-supporter of vitality, yet there appears to be a continual absorption of it by the blood. In fact, the blood, and all the organized tissues contain about 17 per cent of nitrogen.

Carbonic Acid Gas. - This gas is supposed to possess greater density than common air, and therefore is generally found to occupy a space next the earth, or floors of unventilated stables and dwelling houses, or such situations as contain the materials, which generate it by decomposition. The miners have given it the name of "choke damp." It is often present in the stomach and intestines of animals, generated by putrefaction, and often causes death by distension. It is an invisible fluid, of pungent odor.

Some persons are disposed to believe that carbonic acid gas is so dense as to occupy no other space than beneath the common atmosphere, in close proximity with the earth, and floors of cellars and stables. This is not the case, for it has been discovered at the greatest heights which the industry of man has been able to penetrate. Saussure found this gas at the summit of Mount Blane, a point of the earth mantled with perpetual snow; and Humbolt has recently demonstrated the presence of this gas, in air brought by M. Garnerin, from a height not less than 4,280 feet above the earth's surface, to which height he had arisen in an air balloon. From these facts we are led to infer that, notwithstanding the current opinion regarding the great density of carbonic acid gas anil the affinity that seems to exist between it and the earth's surface, it must enter into combination with the atmosphere, therefore is chemically combined, or artificially mixed, with the same. The following anecdote settles the point :-

Not long ago the king of Naples had a very fine elephant 
of enormous proportions, who, in a fit of rage, killed his keeper. The king ordered a charcoal fire to be kindled in the den of the enraged animal, by which means a large quantity of carbonic acid gas was generated, and the monarch of the world soon "bit the dust." This is the mode by which carbonic acid gas is artificially mixed with air.

Carbonic acid gas, like many other deleterious valpors, has, in my opinion, less affinity for pure than impure air, hence, in order to render them wholly innocuous, we have only to secure a uniform current of air within the barn and stable.

The atmosphere of a crowded barn or stable, is rendered unfit for respiration in various ways : 1 st, by non-ventilation; $2 \mathrm{~d}$, by the cutaneous exhalation; $3 \mathrm{~d}$, by re-respiration of air not purified; 4 th, by emanations from the excrements.

In our crowded cities, where land, comparatively speaking, is worth its weight in gold, it is impossible to institute complete sanitary regulations; yet, we have an "anchor of hope," in view of preserving the health of the habitats of these "dismal swamps," by a system of thorough ventilation.

Carbonic acid gas is formed at the expense of the oxygen of a given atmosphere, and under certain circumstances is again decomposed and forms oxygen gas. In view of illustrating this point, I introduce the record of an experiment made by a French chemist. He mixed twenty cubic feet of carbonic acid gas with the atmosphere of an air-tight room, and yet, strange to relate, thirty-five minutes afterwards he could not discover the least trace of the same.

It is evident, therefore, that the intent of nature is to establish an equilibrium between the above processes; that is to say, all the carbonic acid gas formed by combustion in the lungs of animals is decomposed, and results in oxygen. This is in accordance with the economical law of nature, which never suffers any thing to be wasted.

The process of pulmonary combustion in the lungs is somewhat analogous to the consumption of charcoal in a stove. The lungs may be compared to the stove. Carbon, or charcoal, is furnished by venous blood. 'The oxygen which is necessary to 
insure combustion in the lungs, passes through the delicate lining texture of the pulmonary cells, exhausts the carbon and eliminates carbonic acid gas. The venous blood is thus deprived of its defiling elements and becomes oxygenizedacquires an arterial hue. This is precisely what takes place in the common stove when charcoal is used as fuel. Charcoal in its crude state may be compared to venous blood, unfit to impart heat or vitality, until ignited or brought in contact with oxygen, then carbonic acid gas is evolved. 'The burning carbon acquires a red appearance, like arterial blood, radiating its life principle, oxygen, to surrounding bodies, while its deleterious properties, like those evolved from the lungs, mingle with the atmosphere and render it unfit for the purpose of respiration. Here lies the "bane;" the "antidote" is simple consisting of nothing more than pure air.

Now, suppose for example, we rate the number of respirations in a healthy horse at 17 per minute, and the consumption of air every time the lungs are inflated, at 80 inches; it requires 1360 cubic inches of air to vitalize the blood. So that in the course of an hour one pair of lungs will, at this low estimate, vitiate an immense volume of atmospheric air.

The fatal effects of breathing such an objectionable atmosphere, as is too often found within our barns and stables, may be made the subject of a very simple yet convincing experiment. 'Take, for example, a glass jar of about two quarts, capacity, turn it mouth downwards, and place within it a live bird or mouse. At first the imprisoned animal experiences little inconvenience, but in proportion as the consumption of oxygen and liberation of carbonic acid gas proceeds, the creature begins to show symptoms of uneasiness; the respirations become accelerated, and in the course of a short time it dies as if drowned or strangulated. Now it requires no great stretch of the imagination to liken a tight barn or stable, having nc provision for the exit of impure nor admission of pure air, to the glass jar; the air-tight barn is to the cow, just what the jar proves to be to the bird or mouse. The latter die quicker, and thus endeth their sufferings; but the pon swill- 
stable cow has to linger and die by inches. It must be evident therefore, that if the results followirg an extreme vitiation of a local atmosphere be so destructive, then those arising from every minor degree, are no less certain, ultimately, to impair an animal's health.

The most important matter to be borne in mind, whatever mode of ventilation we adopt, is, "air once respired should not again come within the sphere of respiration, but should be made to pass off, or be replenished with a fresh supply introduced into the stable by a steady current. In a ventilated stable, we find that the air which has just been expired, is lighter than the surrounding medium, consequently ascends, and before a second inspiration commences, the impure air is out of reach of the nostrils.

In order to secure a current of pure air, it is only necessary to make openings in the ceiling, introduce square or circular chimneys with caps, and make provision for the admission of pure air in the vicinity of the floor, which can be done by cutting square holes in the wall, and inserting into them a wooden frame, covered on the outside with a wire grating. A harness room or stable office may be ventilated by making a circular hole into a disused chimney, the upper edge of the hole being on a level with the ceiling; the foul air naturally ascends, and having the benefit of the draught of the chimney, is readily carried upwards; fresh air is admitted through the doorway in summer, and beneath it in winter, so that it is an easy matter to get rid of the unpleasant atmosphere, which almost invariably pervades such places, and with which arrangement so many persons who labor in, and visit the same, have occasion to find fault.

- Prof. Wyman, in his work on ventilation, informs us that this simple plan of ventilation, is carried out in two of the largest printing establishments in the city of London, in which, for several years previous, the workmen employed had been exposed to the full influence of vitiated air, which was so sickening and oppressive (just like that of some harness rooms), that they were continually the subject of disease, but so soon 
as this simple plan of ventilation was adopted, the lealth of the men improved.

Vitiated air, under the above conditions, has an upward tendency, still if we wish to diverge from the common mode, we can give it a downward current, and thus effectually prevent all expired air from again re-entering the pulmonary cells. The act of expiration, through the nasal cavities of cattle, is in a downward direction, and a current in this direction can be secured when sufficient spaces near the ceiling are left open. This plan was adopted by Mr. Bigelow, in the construction of a barn and stable at West Cambridge. It is so constructed that a current of pure air free from dust, is admitted under the eaves all round the building, and there are loopholes in various parts within a few feet of the floor; these are furnished with slides, which serve as regulators of the temperature of the atmosphere within. To insure a free downward current, it is only necessary to open the slides, and if a still purer and cooler atmosphere is desirable the doors may be opened also. A warm atmosphere is secured by closing the slides and doors, for then the current of air is interrupted.

The only adrantage, however, of this mode of ventilation over the ordinary one which insures an upward current, is, the air reaches the lungs uncontaminated by dust, or the exhalent vapors of the body.

In some stables in this city we observe a large hole in a partition, or wall, right in the face and eyes of the animal. This, in most cases, is objectionable, for, should the horse face to the eastward, he has to contend against the acknowledged depressing influence of an east wind, and facing otherways he may encounter dust, vapor and rain. In view of all the facts connected with the subject of ventilation, I contend that the theory of an upward current is the most feasible and economical. This was the opinion of Sir Humphrey Davy, who, in a letter to Lord Liverpool, in the year 1811, proposed to ventilate the House of Lords. His plan was (and it is suggestive to those about building new barns and stables), to construct flues, and admit fresh air by numerous openings in, or near, the 
floor. This plan is a simple one, and the great chemist realized that all the operations of nature in this direction were conducted on an apparently grand, yet simple scheme, that of motion. He contemplated the benefits derived from the gentle zephyr, and the more refreshing breeze, and periodical currents of wind from region to region, and he was led to exclaim, that a fixed atmosphere, or ane without motion, was the bane of vitality. Hence we are to understand that in order to purify the atmosphere of our dwellings, houses, barns, and stables, we must give it motion. for without motion, it will become filthy, like a puddle of stagnant water. The world's progress and man's ambition have rendered the means of ventilation more complicated and costly, yet the principles are the same and ever will be.

I contend that every dollar spent in insuring a thorough system of ventilation in barns and stables, "pays ;" it is an investment which tends to keep animals healthy, for it is a bulwark of defence against many forms of pulmonary diseases; it keeps the eattle and spontaneous pneumonia separate: it curtails doctors' bills, and puts a stop to the barbarisms known as horn-boring and tail-docking, and at the same time, should the cow have an accidental cough, pure, cool air, is the best cough medicine in the world, and as it costs but little, it is worth a fair trial.

I intimated at the commencement of this article that my intentions were to offer some suggestions, which might, possibly, benefit the husbandman, - the autocrat of the destinies of the domesticated animal, - and in view of accomplishing some good in this direction, with an intention of showing, to a certain extent, how a sound mind can be secured in a healthy constitution, $I$ crave the reader's indulgence while $I$ introduce a few paragraphs, rather foreign to cattle practice.

A house, barn, or stable, not ventilated should be considered as untenantable as the notorious "black hole" of Calcutta; no intelligent, hard-worked, over-burdened, or over-milked animal should ever be permitted to drag out a miserable existence in a fashionable air-tight swamp; which, however, might an- 
swer as. a depot for the deposit of exotic vegetation. their fragrance and beauty depending more on the absorption of nitrogen and carbonic acid gases; but it is a great mistake to compel the precious buds of our race to respire the noxious vapors of an air-tight dwelling, for instead of promoting health, strength, beauty of form, and soundness of intellect, we are adopting the sure means to produce a reverse effect.

Parents look on, and in agony witness the sufferings of their loved ones just on the verge of an early grave; they observe the mandate of death written in unmistakable characters on the pale cheek and attenuated form of their " $i d o l s$," and they can also, with what some persons have termed "Christian fortitude," submit to the irreparable losses which are constantly occurring, under a false conviction that it is the "dispensation of a wise Providence;" but we seriously urge such persons to abandon this injurious doctrine, and inquire of themselves if they have fulfilled the obligations which the laws of physiology impose on all ; and if they have failed to perform their duty in this matter. what hath Providence to do with it? "God helps those who help themselves;" hence, if people trifle with vitality, and prove recreant to the laws of their being, they must expect to suffer. The so-called "dispensations of Providence" are nothing more than the results of our own ignorance and failures. to perform necessary duties (see article on breeding). Long life, when not hereditary, is the result of an intelligent use of the various organs and functions of the body, by keeping every one of them in as perfect a state as possible, we promote health, secure length of days, and thus guard against unnecessary diseases, and premature deaths. It is a matter of importance, therefore, that every house and sleeping apartment should be thoroughly ventilated, and parents should see, as a matter of duty incumbent on them, that their tender buds of promise are bountifully supplied with the "breath of life" - a pure atmosphere. A celebrated physiologist propounded the following grave question: "Can any thing be imagined more at variance with the fundamental laws of life than the repeated respiration of a local atmosphere, where the principles of 
ventilation lave been entirely disregarded? In this respect some of our citizens are more humane to the inferior orders of creation, for in the construction of some of their stables they have inaugurated a thorough system of ventilation."

An impure atmosphere not only interrupts the normal action of the lungs, but in a majority of cases the digestive organs become first affected. Medical men endorse the fact that dyspeptic symptoms are the first indications of disease germinated in an impure atmosphere, and that the lungs suffer only after the digestive system has been for a time disordered. It is physiologically impossible for human beings in a sound and healthy state of body and mind to exist in the midst of a close, ill-ventilated atmosphere. An individual possessing a strong constitution may withstand the bad consequences of occasionally. breathing an impure atmosphere, but even he will suffer for a time.

"A healthy man will not experience the same amount of mischief in the respiration of impure air as the invalid, but will. be perfectly conscious of a temporary feeling of discomfort, the very purpose of which is, like pain from a burn, to impel him to shun the danger, and seek relief in a purer air. The comparative harmlessness of a single exposure is the circumstance which blinds us to the magnitude of the ultimate result, and makes us fancy ourselves safe and prudent when every day is surely, though imperceptibly, adding to the sum of the mischief. But let any one who doubts the importance of this condition of health, watch the dyspeptic, the pulmonary, or the nervous invalid, through a season devoted to attendance on crowded parties and public amusements, and he will find the frequency of headaches, colds, and other fits of illness, increase in exact proportion to the accumulated exposure, till, at the end of spring, a general debility has been induced, which imperatively demands a cessation of festivity, and a change of scene and air. This debility is often erroneously ascribed to the unwholesome influence of spring, - a season extolled by the poets, not as a cause of relaxation and feebleness, but as the dispenser of renovated life and vigor to all created beings." 
The effects of impure air are more strikingly manifested in infancy. A few facts will illustrate this: About a century ago, the workhouses of London presented the awful result of twentythree deaths in every twenty-four infants under the age of one year ; and this frightful devastation was allowed as beyond the reach of human remedy. But finally the buildings were ventilated, and a better system of management adopted, and the deaths were speedily reduced from twenty-six hundred to four hundred and fifty per annum. Here, then, was a total of two thousand one hundred and fifty deaths occurring yearly in a single institution, chargeable, not on Providence, but against the ignorance, indifference and cruelty of man. At the end of the last century, during the space of - twenty-one years, out of ten thousand two hundred and seventy-two sick children sent to the Infirmary, only one thousand seven hundred and twelve recovered. Deficient ventilation was not the only cause, but it was one of the chief causes of the dire calamity. And even now, in this country, it is said that every tenth infant-perishes within a month of its birth. Striking as these facts are, and others which I could quote, many are still blind to the instructions of experience, and the warning of outraged nature. But they go on constructing churches, schools, dwelling-houses and other buildings, without bestowing a thought on the physical wants of man.

- Let us then hope for a better state of things - not only hope, but labor to produce a reform. This is the age of improvement. It seems that the genius of man is just emerging from darkness to rejoice in the meridian brightness of perfection in the arts and sciences, and while discoveries are leaping upon discoveries in such rapid succession, we must not overlook so important a matter as ventilation. In view of further illustrating the bad effects arising from repeated respiration of a local atmosphere, I quote the following paragraph selected from Dr. Arnot's work. He informs us that,-

"Twenty or thirty young women, engaged in the manufacture of lace, in the city of London, tried the experiment of keeping themselves warm in a small room, by making it air 
tight, and depending on the heat given off from their lungs and bodies in lieu of fuel, which they could not afford to buy. In the course of a few weeks their countenances became of a deathlike paleness; at the end of a couple of months death visited these unfortunates, and carried off nearly half their number, and several others were only reserved to die a more lingering death of typhus fever."

These unfortunates were to be pitied; but what shall we say of those who know the evil and have the means to guard against it, as that mean economy or thoughtlessness which is to be observed in the construction " of dwelling-houses, lecturerooms, public places of amusement, and houses of worship?

\section{DISEASES OF THE DIGESTIVE ORGANS.}

\section{DESCRIPTION OF THE CESOPHAGUS.}

The œesophagus or gullet, extends from the mouth to the stomach; it passes down the left side of the neck, outside the windpipe, between the two first ribs, and then runs backwards along the upper part of the thorax, until it reaches the midriff or diaphragm ; having passed through the latter, it terminates in the digestive canal.

The cesophagus is composed of three coats; the outer one is made up of cellular substance, which admits of considerable distention; the middle coat is muscular, and is composed of two layers, arranged spirally, and running in opposite directions; that is to say, the fibres wind round the gullet, in contrary directions; this allows or aids the food which has been masticated to pass down the tube into the first compartment of the stomach ; viz., the paunch, and by a reverse action of the other set of spiral muscular fibres, the pellet-cud-ascends into the mouth for remastication.

The inner or third coat is similar in structure to the pharyn- 
gial membrane, or that which lines the pharynx, jet it is so arranged as to admit of considerable distention.
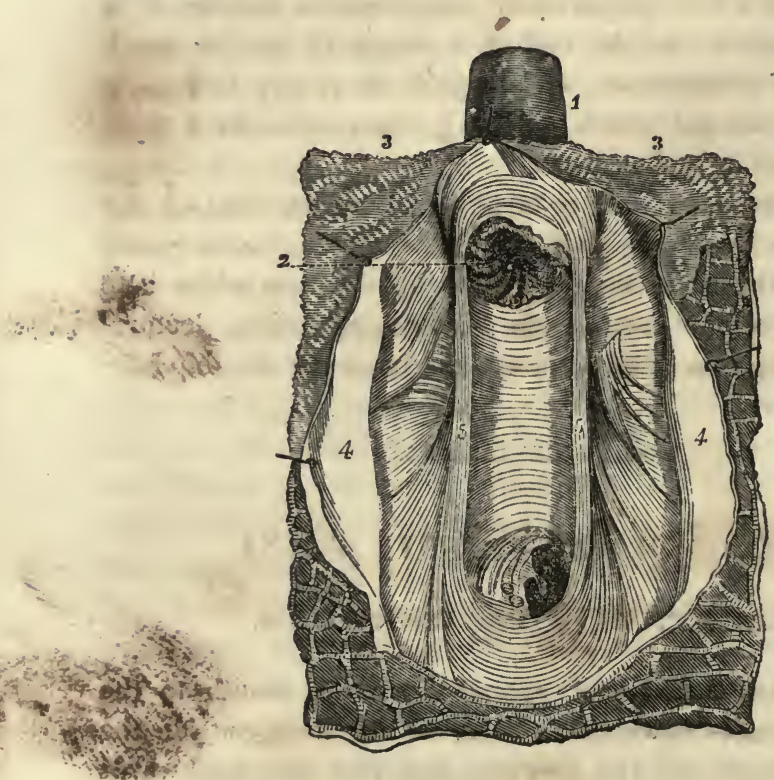

SECTION OF A COW'S STOMACH.

Explanation. - 1. A portion of the cesophagus, or gullet. 2. The terminating portion of the gullet. 3,3 . Lining membrane of the first compartment of the stomach. 4,4. Portions of the mucous membrane of the second compartment of the stomach, dissected and raised, so as to show the muscular mechanism beneath it. 5,5 . The lips of the demi-canal, which are the boundaries of the groove. At the lower part is the entrance into the third compartment of the stomach, termed "many-plies."

\section{FOREIGN BODIES IN THE GULLET.}

When an animal attempts to swallow a substance too large for the calibre of the csophagus, it becomes impacted in the same, and the creature is said to be choked, and on examining the left side of the neck the foreign body can be both seen and felt. When an accident of this character occurs, half a pint of olive oil should immediately be administered; this will lubricate 
the internal surface of the œsophagus, and aid us when attempting to force the impacted material towards the stomach. Before any attempts are made to introduce the probang (see eut of instruments), some efforts should be made to manipulate the obstruction, and thus force it downwards; if it can be felt yet cannot be moved by external manipulation, there is very little chance for the animal; yet we are not without resource. The probang is our remedy. This is to be introduced through the mouth-piece into the œsophagus; some slight degree of force may be used to push the obstruction downwards; if that fail, no time should be lost in futile efforts; an operation must be performed termed œsophagotomy.

\section{GESOPHAGOTOMY.}

This operation is performed as follows: Place the animal in the trevis or cast, and etherize him; then make an incision over the region of the obstruction, through the skin and subcellular tissues; the œsophagus will then be seen. The only vessels in this location that are of any consequence, are the jugular vein and common carotid artery; but there is no danger of wounding them when the œsophagus is distended. The obstruction having been found, an incision is to be made through the coats of the gullet sufficiently large to admit of the extraction of the incarcerated body; so soon as this desirable object is effected, the edges of the gullet may be closed by sutures or stitches, one end of which should be cut off close to the knot, and the other left long enough to hang out of the external wound. The integuments are then to be brought together by another set of stitches, taking care to leave a small orifice at the lower part of the neck, for the escape of any morbid matter. The wound, with the exception of this orifice, should be well coated with collodion or liquid cuticle. For a few days after the operation, the patient should be kept on a light, sloppy diet, sufficiently seasoned with common salt to prevent fermentation. In the course of a fortnight the wound will be quite healed. 


\section{LACERATION OF THE CESOPHAGUS.}

This accident very frequently occurs from the objectionable practice of attempting to force a foreign body, such as an apple, potato, or turnip, that the animal has greedily attempted to swallow, down the œsophagus into a more dilated part of the digestive aparatus, by means of such rude instruments as a whipstock or common stick, in lieu of a proper instrument, known as a probang. The operator sometimes succeeds in removing the obstruction, but soon a swelling is observed in the region of the neck; the animal evinces signs of pain, and symptoms of suffocation ensue; in such cases it is evident that the œsophagus is ruptured. The following from the author's case book is introduced in view of showing the folly of forcibly removing such obstructions.

Oct. 10th, 1855. - Saw a cow, at Feltonville, the property of Mr. Welch and others. The animal had calved about ten days previous, and done well; two days after parturition she was purchased by another man for the above party, and driven to her new home. On the way thither she "picked up an apple and got choked;" the apple was-discovered in the upper half of the œsophagus. The attendant tried to manipulate it either one way or the other, but failing in this, he procured a whipstock, and forced the foreign body towards the rumen. This induced convulsions, and the subject threw herself violently down, with the whipstock in her throat. This feat she repeated several times, to the imminent danger of limb and life. She shortly, however, recovered and appeared to do well, and the next day, I believe, was received by the above firm. After a brief space she appeared to be "ailing," and the owners, thinking the apple was the cause of the same, gave her a full dose of oil. Soon afterwards, inverted peristaltic action took place, and whenever she attempted to swallow fluids or solids, vomiting, or regurgitation, took place. This was her condition at the time I saw her-ten days after the first attack. I prescribed alkalies and counter irritation; next 
day she appeared better - that is, the romiting had ceased. She was then drenched with glauber salts and spearmint, and during the next day received several alkaline injections, and such other treatment as the urgency of the case seemed to require. Notwithstanding this, she died on the third day from my first visit. The owner, in accordance with my request, notified me of the death, and I made an autopsy. The heart, lungs, liver, spleen, panereas, kidneys, stomach, and bowels, all appeared in a healthy state; they presented, however, evidences of debility, in the condensation and pale aspect of their tissues. The omentum-caul was exceedingly dense, scarcely thicker than a piece of writing paper. Tracing the œsophagus internally from the mouth to its termination, or base, there were no symptoms of laceration or inflammation; but in the dilated portion of the same, which is contiguous, and receives food after primary mastication, I found a mass of juvenile cornstalks, about the size of a man's fist, and twice the length of the same - seven inches. This part being considered as the termination of the œsophagus, and commencing link of the stomach, was distended beyond its ordinary capacity and in a high state of gangrene - mortification - and particles of cornstalk were protruding through its disorganized and lacerated tissues. This accounts for the death, but the reader will, probably, want to know something about the cause, and may, possibly, say that the whipstock was the exciting one. This would appear, on first thought, as a rational conclusion; because many valuable animals, both in this and the mother country (as records show) have been destroyed by lacerating the œsophagus, with the above, or some such instrument; and we might reasonably assign the cause of death to the same, and thus terminate this article. But my readers, I opine, desire the truth, and nothing but the truth. I am satisfied that the whipstock, however injurious it may have been in other cases (and it is in most cases an objectionable remedy), was inoperative in this - that is, so far as the vitality of the animal was concerned. Now for the proof. The seat of the disease proved to be, by careful measurement, forty-three inches from 
the tip of the lips. The whipstock was three feet six inches in length, and, according to the testimony of the operator and others, six or eight inches of the same never entered the mouth; eomputing the medium at seven inches, the reader will perceive that the diseased location was just seven inches beyond the reach of the instrument.

How, then, are we to account for the death of the animal?

I shall try to satisfy the reader on this point. 'The animal, at the time of purchase, had not recovered from the pain, labor, and excitement of parturition; she was an invalid; in the same condition, yet less well provided for than her lordly mistress, who has the advantages of science, skill, and sympathy, to alleviate her woes, and mitigate her pains. The poor brute was compelled to perform a journey, when she ought to have been kept at rest, and kindly cared for. The common sympathies of our race ought to have been extended to her; she ought to have been dosed with groaning cordial, instead of cornstalks; and, instead of performing a journey through apple orchards, she ought to have been kept at home until health and strength re-appeared.

Changes in food, location, and barn management, are at times, and under certain circumstances, operative in inducing disease, especially when the subject be in a weak or delicate condition. Cornstalks, therefore, being very indigestible, tend to overtax and irritate the stomach, and the oil, probably, induced nausea. In efforts at vomiting, the rough particles of food found a lodgment at the point indicated, where they accumulated, produced irritation, inflammation, and, finally, mortification. The direct cause of death, therefore, was obstruction within the gullet; the morbid appearances were the consequence of the same.

The best instrument I know of for the accident of choking, or obstruction within the gullet, is a flexible probang: but, as that instrument is not always to be obtained, every farmer should be provided with the next best instrument, which consists of a piece of smooth, flexible rattan, about five feet in length, armed at one end with an oblong ivory ball, which must be securely 
fastened. If much force be used, laceration of the œsophagus is apt to occur ; therefore, if the foreign body will not yield to gentle pressure, I should pour down a little olive oil; wait awhile, and then try the probang again. If, however, the foreign body can be detected, and the probang fails to remove it, we should immediately perform the operation of osophagotomy, which consists of making an opening into the gullet large enough to remove the former, and then bringing the divided edges together again by means of sutures - stitches.

Cases like the above (when the medical man is not called on until after the lapse of several days from the time of the accident), do not admit of the introduction of a probang.

The following case, which occurred in the practice of $\mathrm{W}$. Sanders, Student Royal Veterinary College, goes to show that an animal should never be consigned to death until the skill of a qualified person proves unavailing. "In the month of March a young Alderney cow became choked with a Swede turnip, which was found to be impacted about the termination of the third of the cervical portion of the œsophagus. The owner immediately sent for a person whom he had been in the habit of employing, but who, not having a proper probang, substituted a common ash stick. After some difficulty, the obstruction in this way was removed. In the course of a fortnight the neck was found much swollen, and the animal not only evinced a great deal of pain, but sometimes, as I was informed, appeared as though threatened with suffocation. It was supposed that the œsophagus must be ruptured, in consequence of, as it appeared, a considerable portion of food having protruded between the muscles of the neck, just anterior to the sternum. A small orifice was made through the skin, and a portion of the food (for food it proved to be) removed. The cow continued to get worse for several days, and putrefaction had apparently commenced. The attendant now advised the owner to have the cow slaughtered; but as her condition precluded the prospect of selling her advantageously, it was deemed expedient to risk the chances of recovery, especially as she was young and in calf. Under these circumstances, my brother, who resides in 
that locality, was consulted. On his arrival he gave but little hopes of recovery, seeing she was to so great a degree debilitated. A stimulant was administered, and an incision, about seven inches in length, was made in the most depending part of the swelling, through which more than a quarter of a peck of food was removed from between the muscles. The wound being now held open, and a candle placed in front, the rupture of the œsophagus became quite apparent. It proved full three inches in length. 'The wound was cleaned. A common sidesaddle was placed upon her back, and fastened on with a girth in the usual manner; a small-sized piece of ash-wood was shaved so as to render it pliable at one end. The large end was then tied to the crupper-loop of the saddle, and passed then between the pummels, which kept it in its place, and elevated it half way along the neck. The œsophagus at this part being rather deep seated within the loose fleshy part of the dewlap, it was not convenient to pass sutures through the edges of the laceration. A pledget of tow dipped in some digestive was put into the wound, and pressed against the ruptured part. A pad of flannel was then placed over the outside, and a broad bandage, with some thin but flat pieces of wood sown to it, to prevent its becoming too narrow. This was carried round and over the stick above the neck, which, being pliable, acted as a spring, that kept a moderate but equal pressure as she moved her head up and down. She was mainly supported upon gruel made of barley and bean and wheat flour; but in addition, occasionally, was allowed a little green food. Tonics and stimulants were administered. Any food that accumulated in the wound was removed, and it was regularly dressed twice a day. Three weeks after she calved a live calf ; but, from the weakness before parturition, she became so reduced as to require assistence to get up for a short time. I went home from college on the 6 th of May. On the 8 th I saw her myself. There was then a small circular opening, leading into the œsophagus, sufficiently large to admit the finger, which was prevented healing by the frequent escape of food. The edges of the wound were thickened, and apparently healed over. They were occasionally 
scarified, with the view of promoting cicatrization; for it was my opinion that, should the wound heal, it would leave a stricture in that part of the tube, and consequently render the animal susceptible of becoming again choked. The food continued to pass more or less through the opening, until the beginning of June, when the wound became entirely closed. Since then she has become again in calf, and from that has continued to go on well; nor has she ever, that I am aware, again shown any symptoms of choking, although she has taken her chance as to the nature of her food. She is still in the same person's possession; consequently I know, from the information I have received, that she continues up to the present time apparently as well as ever she was; and it is now eight months since the wound healed over."

\section{APTHж.}

This disease is commonly known as "thrush," or sore mouth. It appears as a vesicular eruption on the tongue, gums, and on the buccal and palatine membrane. When the disease is mild, and confined to the above parts, it is easily cured by daily applications of a portion of the following:-

Powdered Goldenseal, ...............................2 ounces.

Tincture of Matico, ................................

Honey, ....................................... ounces.

Mix, and apply by means of a swab or sponge.

When the disease is violent and of long standing, it is apt to extend through the whole course of the alimentary canal, from the mouth to the anus. If this be the case the animal will purge, as if a powerful cathartic had been administered, and will be otherwise unwell. The methodis medendi in this event is, to prescribe tonics and astringents. The remedies are tincture of matico, goldenseal, and sulphur, in the following proportions : -

Tincture of Matico,.............................. drachms.

Powdered Goldenseal,..................................2 "

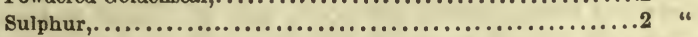

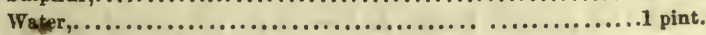

Mix and administer. 
The patient's diet should consist of oatmeal gruel, slightly alkalized with hyposulphite of soda.

In a late number of the Veterinarian I find the following article upon epizoötic aphthr :-

"Epizoötic Aphtho, commonly known as foot and mouth complaint, is a febrile, very contagious, and panzoötic affection i.e., readily communicable from one species to another - met with in the horse, goat, pig, fowl, hare, etc., but most commonly in the ox and sheep, in which last two mentioned animals it consists of vesicles breaking out on the mouth, gums, lips, teats, and around the coronary surface of the foot between the skin and the hoof. It is an Epizoötic affection, spreading over large tracts of country, interfering very seriously with the capability of the ox to put on fat ' whilst preparing for the butcher,' and in the milch cow rendering the supply of milk small, if not altogether suspending it.

"In this disease the ox exhibits the following symptoms:Suspension of rumination, constipation, sometimes, though rarely, diarrhoa, great flow of saliva from the mouth, and severe lameness.

"Milk taken from cows affected with this disease should never be drank, as it will most readily produce aphthre in man. To prove this fact, Professor Hertwig, together with two medical men, Mann and Vilion, drank the warm milk of an aphthous cow, and the result was that each became the subjects of severe inflammation of the throat, associated with the vesicular eruptions mentioned above as indicative of this malady.

"Professor Simonds also gave the warm milk of an aphthous cow to pigs, with a similar result."

\section{DESCRIPTION OF THE STOMACH.}

The stomach of a ruminating animal presents a very complex arrangement, of which the purpose seems to be to favor the mechanical reduction of the food, and its impregnation by the salivial and gastric fluids, before it is subjected to the action of the biliary and pancreatic juices. 
The stomach of an ox is suldivided into four distinct cavities named as follows:-

First compartment, Rumen, or paunch.

$\begin{array}{lll}\text { Second } & \text { " } & \text { Reticulum. } \\ \text { Third } & \text { " } & \text { Manyplus, or Omasum. } \\ \text { Fourth } & \text { Abomasum. }\end{array}$

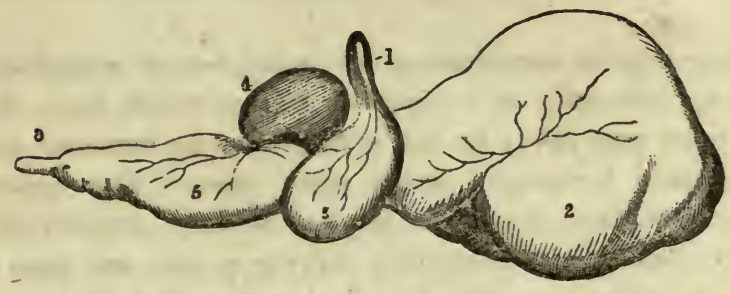

REPRESENTATION OF A COW'S STOMACH.

Explanation. - 1. A part of the œesophagus. 2. The paunch. 3. The second stomach, commonly known as the "honey comb." 4 . The third compartment of the stomach, known as the "many-plus," or " many-plies." 5. The fourth compartment, known as the abomasum. 6. The pylorus, and commencement of the dnodenum.

The compartment known as the abomasum, 5 , is the seat of the true process of digestion, and this is that part of the calf"s stomach that the "rennet" is taken from, which possesses the power of coagulating milk. ТЋ coagulation, or "curdling" of milk, in the manufacture of cheese, is accomplished by means of the organic acid contained in the "rennet."

The rumen, like the œsophagus, is composed of three coats; the internal one is studded with numerous papillæ, which incline in the direction that the food takes; they are erectile, and by inclining in different directions, they can, to a certain extent, favor or oppose the passage of food.

The openings into the rumen are two. One at the base of the œsophagus, through which the food and fluids pass; the other is below this. It is much larger, and communicates with the second stomach. The paunch is not so highly organized as some other parts of the stomach. This compartment is capable of extraordinary distention, and in some cases of tympanites, becomes so distended as to produce suffocation by pressure on the diaphragm and lungs. 
The reticulum, or second stomach, sometimes called the -honeycomb, presents a very irregular surface, consisting of open cells, varying in size and depth, looking very much like a piece of honeycomb on a large scale. There are two openings into this stomach: one through the floor of the gullet, the other into the paunch. The pellet of food to be returned for remastieation, is thrown into the esophagean canal by the reticulum.

The manyplus, sometimes called manyplies or manyfolds, is made up internally of laminæ, or leaves, which hang down from every part of it; by this arrangement an immense digestive surface is crowded into a small space. The cuticular covering of these leaves or laminæ is very singular; it is thickly studded, with eminences, varying in size and form; in some places they resemble little hooks, others look like papillæ; some are soft, others are hard and durable like horn. The function of the laminæ and papillæ is to comminute, and properly prepare the food ere it enters the fourth compartment.

The abomasum, is the true digestive stomach; its function is to secrete the gastric juice, at least the gastric juice is secreted by small glandular bodies, having duets which terminate on the villous membrane which lines the abomasum. The lower orifice of this part of the stomach is termed pylorus; it is guarded by a projecting body which answers the purpose of a sphincter muscle, to guard against regurgitation from the duodenum.

\section{RUMINATION OR REMASTICATION, AND' INGESTION OF FOOD.}

'The ox, a member of the group Ruminantia, has four compartments in the stomach, yet two of them are nothing more than dilitations of the œsophagus.

The food having been gathered by the lips, tongue, and teeth within the mouth, it undergoes a grinding process between the molars, and receives the admixture of salivial fluids secreted by the submaxillary, parotid, thyroid, and sublingual glands; ، then passes down the cesophagus into the paunch; the char- 
acter of the food, however, regulates its passage into the various compartments; if the pellet of tood be solid, the paunch receives it; if it be semi-fluids, it goes beyond the paunch to the second and perhaps third compartment. This is the case with a sucking calf; the milk which forms its nutriment, requires no remastication, and therefore passes directly inio the true digestive cavity - the fourth compartment.

It appears, therefore, that the functions of digestion and remastication are involuntary, and are governed by the same sort of power which causes the heart to pulsate, expands the lungs, secretes the bile, pancreatic juice, etc., without the aid or consent of the animal. We may, however, to a certain extent, increase or decrease these functions; by artificial means; but their primary operations are uncontrollable, simply because they are involuntary. Some persons have doubted the fact of rumination, and if any of my readers be skeptical on this subject, let them satisfy themselves by experiment. The best subjects for demonstrating the acts of rumination, are animals with lean necks. For example : let a person stand on the left side of the animal, in the region of the neck (supposing the latter to be in the ruminating mood). He perceives the cud re-ascend through the gullet, and re-descend again into the . stomacl. At the period of re-ascension, place the ear in the region of the gullet, and a gurgling sound will be heard, different from that accompanying re-decension. The action has been described as undulating, alternate, coming and going, like the motion of a ship; but this is regulated by the respiratory movements and different attitudes of the body. We can, however, at the moment of re-ascent, perceive a flank movement, deep inspiration, succeeded by a rapid expiration, showing conclusively that a powerful nervous concurrent force involuntary - controls the action of rumination.

Finally, the cud can be made to ascend or descend, in the following manner; we perceive the cud descend, now grasp the gullet firmly, and it re-ascends into the mouth. We next perceive the cud ascending; arrest it by compressing the gul- 
let, and it rapidly descends again into the stomach; hence the phenomenon of remastication can readily be demonstrated.

The solid food, when once in the paunch, receives the admixture of fluid secreted from its walls; after maceration for a short time, the more solid parts are returned to the mouth, where they undergo another mastication, and are again saturated with the salivial fluids and swallowed; if properly masticated it reaches the third stomach - manyplus or omasum here it undergoes a further reduction, becomes quite pulpy, after which it enters the fourth stomach.

Carpenter thus describes the phenomena of rumination: "The direction of the food into one or the other of the digestive cavities, appears to be affected without any voluntary effort on the part of the animal itself, but to result simply from the very peculiar endowments of the lower part of the œsophagus. This does not entirely terminate at its opening into the first stomach or paunch, but it is continued onwards as a deep groove with two lips; by the closure of these lips it is made to form a tube, which serves to convey the food onward into the third stomach; but when they separate the food is allowed to pass either into the first or second stomach. When the food is first swallowed, it has undergone but very little mastication; it is consequently firm in consistence, and is brought down to the termination of the œsophagus in dry bulky masses; these : separate the lips of the groove or demi-canal, and pass into the first and second stomachs. After they have been macerated in the fluids of these cavities, they are returned to the mouth by a reverse peristaltic action of the œsophagus; this return takes place in a very regular manner, the food being shaped into globular pellets by compression within a sort of mould formed by the ends of the demi-canal, drawn together, and these being conveyed to the mouth at regular intervals, apparently by a rhythmical movement of the œsophagus. After its second mastication, it is again swallowed in a pulpy semi-fluid state; it now passes along the groove which forms the continuation of the œsophagus, without opening its lips; and is thus conveyed into the third stomach, whence it passes to the fourth." 
ON THE SENSIBLE PHENOMENA OF-RUMINATION.

This subject is one of great importance to persons desirous of practising veterinary medicine ; and husbapdmen, no doubt, will be glad to become better acquainted with matters that have hitherto, in this country, been shrouded, in comparative darkness. In view of furnishing reliable information on this subject, the author has selected a communication by M. Colin, translated by Mr. Percivall.

"The following comprises the substance of the report of a paper on this subject, read before the National and Central Society of Veterinary Medicine of France :-

"Under the heading of 'Sensible Phenomena of Rumination,' M. Colin includes 'all the external and appreciable acts of this function, every thing, in fact, one can make out of acts in a great measure concealed, having for their object the return of the aliment from the stomach into the mouth, and its remodification within the latter cavity.'

"These acts are -

" 1 st, The return or rejection of the alimentary cud.

" $2 d$, The mastication of the cud, wherein are to be observed, the direction of the motions of the lower jaw, the rapidity or tardiness of their succession, their number and regularity.

" $3 \mathrm{~d}$, The deglutition of the ruminated cud.

"The return of the aliment into the mouth, M. Colin regards as a sort'of inverse or anti-peristaltic or deglutition, called by $M$. Flourens, rejecton. In it are two distinct acts :-

" 1 st, The operation by which the cud is formed, seized, and held by the cardiac orifice of the cesophagus.

" $2 \mathrm{~d}$, The transmission of the cud from the stomach into the buccal cavity.

"The first of these acts it is that is involved in the greatest obscurity, owing to its being the least accessible of any of the phenomena of rumination: the last act is simple, sensible, and appreciable enough.

"At every return of the aliment from the rumen to the 
mouth, there is observable a deeper drawing of the flank than at ordinary times. In the eyes of many, this is no more than a respiratory heave - a deep inspiration; while others contend it is expiration. M. Girard, senior, thought that, through the contracted condition of the diaphragm in inspiration, as well as that of the abdominal muscles, rumination was set in action by the stomach, thus having added to its own motions a powerful concurrent force. M. Colin, however, is of a different opinion. He argues, that, at the moment of repulsion, a brisk movement takes place in the flank, caused by rather a deep inspiration momentarily succeeded by a rapid expiration; a movement which must precede the arrival of the cud within the cervical portion of the œsophagus. This theory reconciles the partisans both of inspiration and expiration.

"Our own inquiries into this matter, however, embracing both the sensible and insensible phenomena of rumination, contradict this opinion, since nothing like it have we discovered.

"The rational mode of proceeding to us has appeared to be, to class the agents of rumination into two orders, - an extrinsic - and intrinsic order. In the first category we have examined into the agency of the diaphragm, the abdominal muscles, the pression of the intestinal mass, the different movements and attitudes of the body. In the second place, we have endeavored to ascertain whether contractions of the stomach were to be felt at any part of the abdomen, and, if so, to take this into account.

"When the cud has once entered the œsophagus it rapidly travels through the canal, it being by the action of the fibres of the tube (described by Stenon and Peyer) that it ascends into the mouth. And in effecting this ascent of the cud, the action of the fibres is not, like that of the intestines, an undulating or vermiform movement, but alternate with every act of rumination, by an action that comes and goes like the motion of a ship, and this is continued through the entire process.

"In all ruminants these operations may be demonstrated, though it is most apparent in such as are in lean condition and have long necks, such as the lama, the giraffe, and the camel; 
and, owing to the course of the csophagus, it is more conspicuous on the left than on the right side of the neck, though it may likewise be seen on the latter : in the dromedary it is even more visible in the lower part of the neck, along the median line.

"Many authors have asserted that there takes place an elongation of the neck; that it becomes stretched out, and the head protruded forward, at the time the aliment is passing out of the rumen into the œsophagus. These conditions, however, are by no means constant, nor are they essential, since, if the neck be flexed either to the left or to the right at the time of rumination, the phenomena continues uninterruptedly, the aliments uniformly ascending and descending. This M. Colin has not noticed.

"But he was desirous of determining the quantity of alimentary matter collected in the mouth; with which intention he forcibly applied his hands upon each side of the jugular furrow in the neck, so as sharply to compress the osophagus, while, at the same time, he had the mouth opened, and thus obtained a soft mass weighing from three or four ounces. He likewise informs us, that the rejected cud was not always a globular mass consisting of solid matters exclusively ; for oftentimes, cast up $7 \mathrm{~h}$ the solids, were parcels of herbacious matters, along with a goodly proportion of fluid. From this M. Colin makes an arithmetical calculation. He supposes the daily ration to amount to from twenty-five to thirty pounds; and this to be dry provender, reckons the operations of rumination, the time its reproduction will occupy, calling to mind M. Lassaigne's experiments, to which his calculations bear but too distant analogy, and arrives at the conclusions, that thirty pounds of hay acquire within the stomach a weight equal to nearly 150 pounds; and that 500 parcels, of from three to four ounces each, require, in order to be submitted to a second mastication, seven hours thirteen minutes.

"Now for this calculation, to which we have no inclination to revert, to be correct, the liquid aliments should have been taken into the account; and likewise allowance ought to be 
made for a notable quantity of aliment, for that especially which has been sufficiently attenuated, not being returned to the moutl. In what proportion does M. Colin make these enter into his calculation? For this we look in vain : though this detail it is which constitutes the veritable secret of rumination.

"And, after all, what does such calculation prove? Hay is not the exclusive provender of the bovine race. Their food is either dry, or very dry, or green, or pulpous, or mealy, or liquid, all which variations M. Colin's calculation has left out of consideration. And besides, were his estimate true, that an ox required more than a quarter of the day for the operation of rumination, he could no longer be employed as a substitute for - the horse in certain mountainous countries where the latter is unavailable. But the fact is, that the ox's food is not often hay alone.

"The author (M. Colin) confirms the fact of the aliments, after detention in the rumen being known to become acid, though, after return into the mouth and mastication for some seconds, they evince alkaline reaction; tumeric paper recovering its blue but very tardily.

"Mastication being the most tangible act of the operation of rumination, we are enabled concerning it to speak sith more confidence. M. Colin has used the word merycique to denote this process. The more simple treatment of the subject, however, appears to be to consider mastication as preparatory and ruminatory.

"MI. Colin has divided rumination into unilateral and its varieties, and alternate and its, varieties. In this, however, he appears to commit a grand mistake. There may be such distinctions made in mastication, though we would rather call them preparatory and ruminatory, and say the grand act of rumination is an intermediate process. To make rumination consist in the action of the jaws is to confound the accessory with the principal act, the sensible operations with the insensible ones. Therefore, instead of saying unilateral and alternate rumination, we would say unilateral and alternate mastication. 
"As to unilateral mastication, the jaw, like other parts of the body, is not symmetrical in its operation ; its action, owing to various causes, may be more energetic on one side than cn the other. Nor need we say that mastication will be prolonged by certain kinds of food, by age, etc., or that it will be comparatively tardy or rapid at one time to what it is at another, owing to similar obvious causes. It may likewise be interrupted by any thing alarming the animal, or provoking his attention during the act; and whenever he finds it impossible to continue mastication, with an effort he swallows the cud. We have seen the cud re-ascend into the gullet, and no sooner become lodged there than redescend again into the stomach; as though the contractile force which has caused its ascent so far had become expended at that spot. And we have reproduced the same phenomenon by counteracting, by vigorously seizing hold of the œsophagus with the hand, the contractile force which caused the cud to ascend, and this has been followed by its redescent. But where to? Into the rumen, the reticulum, or the manyplus? We can answer only by hypothesis. It is probable that such aliment as had not received sufficient attrition should fall back into the first two compartments, such parts as contained the most fluid passing into the reticulum, those the most solid into the rumen.

"The deglutition of rumination is attended with a remarkable phenomenon. While it is going on, and the aliment is being subjected to the action of the jaws, a motion is perceptible along the œesophagus. M. Colin asks the reason for this? In our opinion it is owing to the involuntary deglutition of liquid matters left in the back of the throat by the passage of the cud. In proof whereof comes the shortness of the interval between the commencement of mastication and this perceptible motion. At the time the aliment is re-ascending into the mouth, there is to be heard along the œsophagus a gurgling sort of noise ; in some cases it amounts to a kind of eructation. The cud no sooner reaches the œsophagus than there comes to be seen, after a slight catch (soubresant), a fresh cud re-ascending to the mouth with a speed nearly equal to that with which the other 
descended. These intermediate deglutitions going on without any cessation of mastication, we have shown that they commence immediately the cud has entered the mouth, and are involuntary, their number varying from two to three, rarely being four. One or two happen consecutively; but it is rarely we reckon four during the mastication of the cud. If at this time the ear be applied to the left side of the pharynx, borborysm is heard at the time deglutition takes place, when the cud arrives in the mouth, at the very moment even that it is passing over the isthmus of the throat. In general, the quantity of fluid which ascends along with the cud, in order to facilitate its passage and prove effective for ruminatory mastication, is considerable, especially when animals are fed on green forage or roots.

"M. Colin asserts that no more than four or five seconds elapse between the deglutition and rejection of the cud, but does not inform us how such calculation is arrived at. To properly estimate the time, we should reckon the number of seconds intervening between the cessation of mastication at the moment of voluntary deglutition, and the return of a fresh cud into the mouth to be masticated. And short as is this interval, yet it is divisible into three acts: the descent of the chewed cud; the formation of a fresh cud; and the ascent of the last.

"We can understand its being necessary that the swallowed cud should pass first throngh the osophagus to have the passage free for the new cud; in the course of which passage it is that the latter obtains its formation. To say that the cud is seized and rejected by the osophagus, is to convey false notions. There is in operation, in all the parts concerned, a continuity of contraction which sets aside all notion of independent action; which successive contractile force now and then becomes expended, as we have seen in the stoppage of the cud in the middle of the neck; whence it again, instead of passing upward, descends. We can, as we have likewise seen, should the cud remain in arrest, by pressure, cause its re-descent; but when once it has become sufficiently masticated, give what pressure we may, we cannot force the cud in the reverse direction, upward, towards 
the mouth. On the contrary, indeed, the moment such pressure is resumed, it will redescend.

"We concur with M. Colin that the cud which is returned to the mouth requires being soaked in fluid to render its passage easy; but we do not hold with him that such fluid is furnished by the rumen or by the reticulum. It cannot come from the rumen, because fluid never exists there in any quantity. And as for the water within the receptacle, fluid there not only mechanically facilitates the displacement of the alimentary matters, but plays a most important part in the insensible operations of rumination.

"A certain quantity of ingesta becomes requisite for the contraction of the rumen : it being rendered inert either by being surcharged with aliment or through emptiness. While for the due execution of rumination is required a proportionality between the aliment taken in and the aliment under rumination. But the food may not be in excess within the rumen, and yet the organ suffer from distention, from the disengagement within it of a quantity of gas; while which state continues, rumination ceases. In a state of vacuity the rumen lacks the point d'addui requisite for contraction; the same as is sometimes seen in the uterus in which no water is collected, stifling, as it were, the stimulating and provocative pains within it. The impossibility of rumination under vacuity of rumen seems to prove to us, that the abdominal muscles play but a feeble part in the act of rumination. We also think that the cessation of the act, after paralysis being effected through section of the spinal marrow in the dorsal region, in M. Flouren's experiment, was occasioned by the weakening of the constrictive force of the abdominal parietes, which, in the natural condition, operates as a counteractive to the weight of the viscera.

"After taking in a sufficiency of food, the animal seeks repose for a longer or shorter time, during which are elaborating the matters afterwards to become subjected to rumination. A silent, shady retreat is sought after by the timid beast, flying from all molestation, avoiding every thing, in fact, that might interrupt comfortable rumination. As soon as the act commences, various 
postures are assumed, the most usual one being lying down. The camel under such circumstances will often gather his fore limbs underneath his body, and lie down upon his breast as an ostrich does. M. Colin asserts that in the stable animals will ruminate without intermission for half an hour or an hour, or longer. But this we cannot confirm; for our own part, we should say intermissions are much more frequent.

"Cessation of rumination is a grave affair. In disease, in fact, if we do not succeed in re-establishing this primordial act of digestion, though it be but in an irregular manner, the consequences may be serious, while the disease itself increases in danger. And while cessation of rumination must be accounted unfavorable, its return may be hailed as favorable. These reflections teach us that the diet in cases of sickness should neither even be unrestricted or forbidden, since vacuity of rumen (no less than that of repletion) could not fail to injure digestion.

"Imperfect as the foregoing sketch of rumination must be acknowledged to be, still, from the nature of the subject, we could hardly expect more. There are certain sensible phenomena which cannot by the imagination even be descried when we consider how digestion enters into every act of it. To give one example of this: At the time that rumination is in its fullest activity, if the back of the hand be thurst into the left flank so as to press against the rumen, the contractions and displacements taking place in it are to be plainly felt : even the eye can discover these undulatory motions connected with rumination. And yet these motions have escaped the notice of all who have seen in the motion of the flank nothing beyond the general effect. Although in this general motion, in unity with the act of respiration, is concealed an evolution of the rumen observable by the attentive eye alone. This is a plenomenon of which we have had additional evidence afforded us by placing animals in a stable facing the north, in such position that the rays of light impinged upon them at an angle of about $45^{\circ}$. By this simple means, a shadow has been produced which, descending upon the transverse vertebral procesics 
of the loins, so crossed the left flank, that, while the entire movement of it which made the shadow general showed the act of respiration, the creeping and gradual encroachment of it upon the lower part of the flank indicated the contractions of the rumen.

"It has struck us as being possible to carry our investigations further by inquires per rectum. With this view we have introduced our arm into the rectum of the cow at the time of feeding, and carrying it towards the left flank have perceived the same movements as were visible to us in the palpitation of the flank externally. We have endeavored to make the same inquiries during rumination, but no sooner had this been attempted than almost immediately has the act ceased. If the ear be applied to the cardiac region, extraordinary agitation is heard in the great gastric cavities: a sound beomes very distinguishable resembling a noise made by an oar splashing in the water, and that of the water afterwards dropping from it when raised. At the same time gaseous sounds are heard. If it be true that the salivary gland be remarked to be swollen at the time of rumination, it could not fail to interest us to know if such turgescence be greater during preparatcry mastication than while ruminating. We have pervailed on M. Clement, chef de service of chemistry, to make for us an analysis of the ruminatory cud obtained through compression of the œesophagus; and the following is the result :-

\section{"Ruminatory Cud.}

“ Water, ..........................93.21

Organic matter, .................... 5.25

Soluble alkaline salts, ................. 0.22

Insoluble salts, ........................ 1.2

100.00

"By the way of sequel to the above, we collected from the reticulum of a bullock, about to be slaughtered, some of the fluid contained in it, which likewise M. Clement has had the kindness to analyze. 
"Water of the Reticulum.

"Water, .. .........................94.08

Organic matter,......................46

Soluble alkaline salts, ................... 0.24

Insoluble salts, ... ................... 0.22

100.00

BLOAT, HOVEN, OR TYMPANITES.

The term "bloat" has long been discarded by Veterinarians, as an indefinite term, signifying a state of turgescence, dilation, inflation, or puffiness, which is merely indicative of changes in the form and condition of parts, without regard to the actual seat or nature of the difficulty. For example, a horse is bloated when he becomes the subject of subcellular emphysema, ${ }^{*}$ or œdema, $\uparrow$ etc., etc. However, as every farmer appears to be somewhat conversant with the condition of the animal known as "bloat," or "hoven," we shall not offer any remarks calculated to mystify him, but, merely suggest that the term, tympanites be substituted for "bloat," Tympanites intestinalis, signifies a distension of the intestines, with wind or gas, accompanied by an elastic distension of the abdomen; the latter when struck or sounded by a blow, sounds like a drum, and indicates a windy distension of the abdominal viscera, $\ddagger$ commonly known as fatulent colic.

Tympanites rumenites, signifies distension of the rumen, in the bovine species, - the ox and cow, — and in the phraseology of the grazier, is known as bloat or hoven,

Causes of Bloat, or tympanites. - The direct cause of flatulency and windy distension, is imperfect digestion; in such cases the food, instead of undergoing the normal process of digestion, whereby it is converted into chyme and chyle, ferments and evolves gasses, either carbonic acid, or sulphuretted hydrogen, and, as " a little leaven leavens the whole loaf," so

* Distension of the cellular membrane beneath the skin, with gas.

$\dagger$ Dropsical tumefaction.

$\ddagger$ Viscera. - $\mathrm{A}$ bowel or organ within the body. 
the fermentation, once commenced in the stomach, goes on until the food is in a state of putrefaction, or up to the period when all its gaseous material has been extracted; ere this takes place, it frequently happens that the animal dies, either by rupture of the rumen, or some portion of the abdominal viscera. In some cases, unrelieved, the distension is so great that the animal dies in a state of suffocation, occasioned by the pressure on the diaphragm, and other important parts and organs.

Imperfect indigestion may be occasioned by a deranged condition of the digestive organs, induced by various causes, such as give rise to the same phenomena in man, viz., errors in diet; sudden changes in the same; thus, if stall-fed animals be turned into a field of clover, or into a luxuriant pasture, they not only eat greedily and create an undue distension of the stomach, but they partake of food containing a large amount of aqueous matter, which every one knows is more indigestible than dry food, and such a sudden change of diet is not always to be tolerated. There can be no dispute about the causes of bloat, hoven or tympanites; it evidently is occasioned by imperfect digestion. As a general proposition, therefore we may çontend that all indigestible matter may directly or indirectly produce a tympany of the abdominal viscera, and we may also contend that an animal may occasionally become tympanic, under the most intelligent management, owing to some inherent idiosyncrasy* in the local organs, honestly inherited from sire or dam, or their ancestors. Hence, the reader will infer that this dyspepsia, or indigestion, is like various other diseases which seem to appear without any direct cause, transmissible not always, directly, but by predisposition to this and other maladies, which is said "to lurk in breed and conformation" over which we have but little control, other than palliative.

Treatment of Bloat, Hoven, or Tympanites. - Supposing the abdomen to be distended to its utmost capacity, by the extricated gas, and the animal is oppressed and distressed in the act of ireathing, there is no time to be lost; it is useless to

* Singularity of Constitutıon. 
resort to drug medication, - the case is imminent. The gas must be evacuated immediately, and we therefore puncture the flank on the left side, in its most salient region, by means of the trocar and canula; * immediate escape of the gas is the result, and the patient is soon relieved; now we may resort to medication, and that medicine is the best which is calculated to arouse the action of the stomach and arrest fermentation; with these objects in view, I recommend the following: Hyposulphite of soda, 4 drachms ; tincture of ginger, 2 ounces; water, one pint. Dissolve the hyposulphite in the water, and then add the tincture of ginger. Drench the animal with the same. If the tincture of ginger cannot be obtained, then substitute 4 drachms of the pulverized root. If the case be curable, the above treatment is almost sure to afford relief. The medicine, however may be repeated at the end of four hours, if necessary.

Remarks on the Introduction of the Trocar. - Having ascertained that the animal is in a dangerous condition, owing to the great quantity of gas present within the rumen, the most prominent point of the left flank should then be selected. Here make an incision through the integument, sufficiently large to admit the instrument; then draw the skin upward, and puncture the abdomen; in this way we make an indirect opening, so that when the trocar is withdrawn, the integument covers the orifice made last. The trocar must be kept very sharp or keen, so that it may, without using much force, penetrate the peritoneum, and lastly, the rumen ; once within the latter, all resistance ceases; the trocar is now withdrawn, and the canula remains, for the passage of the gas. In bad cases, the moment the cutting instrument is withdrawn from its sheath, the gas will escapc, with a noise resembling a steam whistle, which conveys to us the idea that we are in the presence of a living locomotive, issuing a blast of warning to keep out of smelling distance, for ofttimes the odor is intolerable.

It is best to let the tube remain in the stomach or paunch, until the abdomen is reduced to about its natural size; the in-

* An instrument somewhat similar to that used for tapping the chest. 
strument must occasionally, be drawn forth a little or pushed forward, as the case requires, and when it becomes obstructed with any portion of the contents of the stomach, a quill or straw may be used to clear the obstruction, and as the gas escapes and the paunch or bowels recede, the canula, which is about six inches in length, must be pushed forward as far as it will go.

Relief may sometimes be obtained by passing the probang (see cut of instruments) into the stomach, and I should advise' its use in such cases as those attended by eructation of wind by the mouth, from the stomach.

\section{DISTENTION OF THE RUMEN WITH FOOD.}

It occasionally happens that the function of the stomach, as a whole, or a part of the şame, become impaired; the food is then very apt to accumulate in the rumen; or it may happen that an animal has partaken voraciously of meal or corn, which becoming saturated with the fluid found in the paunch, swells to such an extent that there is danger of its bursting.

Symptoms. - At first the animal is noticed to be uneasy and frequently shifts its position; occasionally moans; the left flank is swollen and hard. This swelling may be determined by a person taking a position directly behind the animal; he will immediately perceive the enlargement. On striking the part with the hand, it has no drum-like - tympanitic - sound, as in hoven or bloat, but has a solid sound, showing that the distinction is owing to the presence of a quantity of solid food. Should the medicinal preparations fail to relieve the animal, rumination then ceases, the symptoms become aggravated, the brain sympathizes, unconsciousness and convulsions occur, which soon end in death.

Treatment. - In cases of extreme distention, it is all folly to waste time in administering medicine; an incision, about five inches in length should be made through the left flank into the stomach ; then by means of the hand the indigestible mass is to be removed; this should be done carefully so as to prevent the food falling into the abdominal cavity. The incision made 
into the rumen is then to be stitched, or sutured; and lastly, the integuments are brought together in the same way. It may be proper to apply a little incture of matico, or tincture of aloes, to the wound. Having finished the operation, the next object is to arouse the action of the stomach, for which purpose I recommend the following:-

Powdered Goldenseal,............................... 3 drachms.

Hyposulphite of Soda, ........................... drachms.

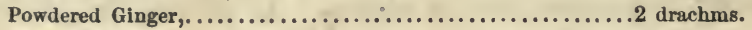

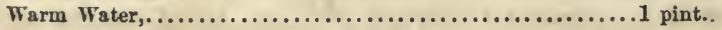

Mix, and drench from a bottle.

The patient had better be kept hungry the first twenty-four hours after the operation, then an occasional bran mash well seasoned with table salt may be allowed.

Many cases of very considerable severity have been relieved by the above treatment. There is very little danger attending an operation of this kind for the rumen is not very highly organized with either blood vessels or nerves. I have known several instances in which this operation has been performed in the rudest possible manner, with a common jackknife, and yet the animals operated on recovered.

The intelligent husbandman, however, will if possible, secure the services of a surgeon for the performance of all operations requiring skill and good judgment.

Removal of the Sutures or Strtches. - The incision into the rumen having been secured by very fine yet strong thread, and the ends cut off, needs none of our attention. The external sutures, however, will have to be removed in the course of a week or ten days; we merely cut the knot and withdraw the suture.

\section{GASTRO-INTESTINAL INFLAMMATION.}

Gastro-intestinal inflammation of the stomach and bowels is frequently occasioned by the presence of concretions and hair balls, or some other foreign bodies. There are many plants, such as hemlock, crowfoot, henbane, wild poppy, etc., which act as poisons, and induce an inflammatory condition of the stomach and intestines. An animal may feed on substances which 
are too dry and fibrous; they accumulate and distend the stomach beyond its normal capacity; or the manyplus may contract spasmodically and imprison the food; in either case an inflammatory condition is the result.

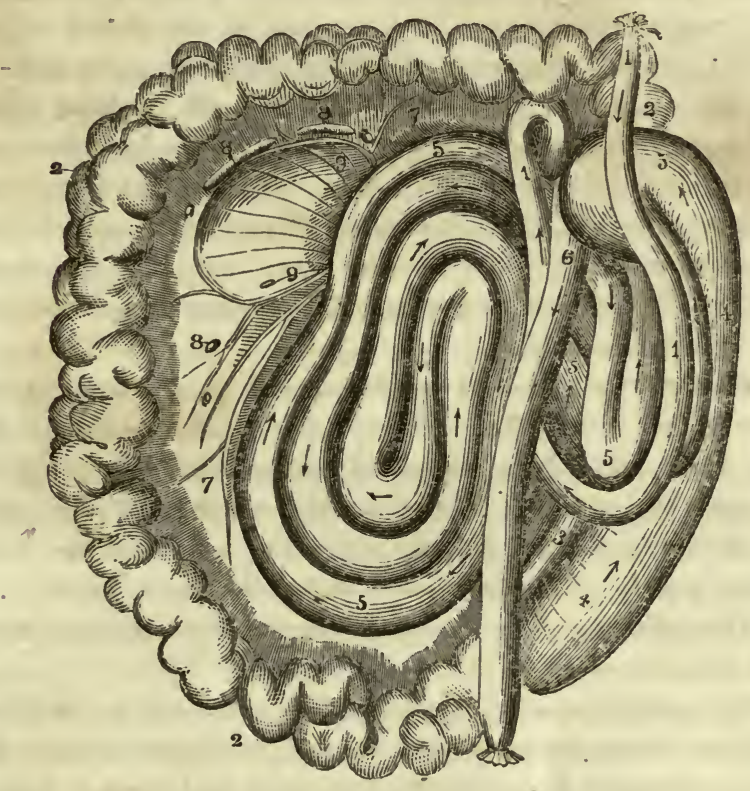

THE INTESTINES OF A COW.

Explanations. - 1. The duodenum. 2. The jejunum. 3. The ileum. 4. The cæcum, or blind gut. 5. The colon. 6. The rectum. 7. The messentery. 8. Messenteric glands. 9. The bloodvessels of the abdominal viscera.

The length of the intestines of an $o x$ are about one hundred and twenty feet, or about twenty-one times the length of his body.

The treatment of a disease of this character is very unsatisfactory, and it is very difficult, if not impossible, to write out any directions that shall meet the emergencies in cases of the above character.

The following case communicated for the Veterinarian, by 
surgeon Redwood, will give the reader a better idea of this malady than the author can furnish; his experience being rather limited in treatment of this affection:-

"I have forwarded to you a jar containing portions of the abomasum of a cow that I have had slaughtered, seeing that further treatment was altogether useless. You will perceive a large gangrenous spot on the inner coat of the above viscus, which I consider was the cause of the symptoms presented. I have also sent you portions of the ilium and jejunum, which will afford you some idea of the intensity of the spasmodic action with which these intestines were affected. The whole of the small intestines presented the most marked spasmodic condition; in fact they were like so many muscular cylindrical cords, and impervious to any body larger than that of an ordinary sized goose-quill.

"Now, all the diseased conditions are enumerated in the above brief description. Every other organ-except the liver, which had a little deposit of earthy matter in a few of its larger biliary tubes, a very common condition of the gland - both in the thorax and the abdomen, presented the most healthy aspect. The animal was ill but thirty-six hours.

"The following were the symptoms observed and the treatment adopted :-

"The patient was a dairy-cow, five years old, in excellent condition, living on straw alone for the last fourteen days, five months advanced in pregnancy, and never had been ill before, being bred on the farm.

"When I first visited her she evinced all the symptoms of hoven, and that to a great extent, so much so, that at one time I was about to introduce the trocar, for the purpose of affording relief, yet knowing the animal could not have had access to succulent diet, I came to the conclusion that this was the effect of the chemical laws acting on vegetable matter, over which the stomachs had in some degree lost their vital influence. The poor animal was in great agony, shown by loud groaning, though rarely lying down; eyes sunk in their orbits; pulse 
quick and irritable, but not such as to indicate or warrant depletion. Occasionally a quantity of the fluid contents of the rumen were regurgitated through the nose and mouth; almost, it would appear, involuntarily. She also, at intervals, voided a small quantity of commingled aqueous and mucous fluid per anum ; although, as before remarked, from the moment she was observed to be ill, not the smallest portion of ingesta passed the abomasum, which, together with all the other stomachs, was partially filled with food in a pultaceous state.

"It appeared to me evident that the obstruction to the passage was caused by spasmodic action of the pyloric orifice, the action extending throughout the greater portion, or all, of the small intestines.

"Will you favor me with your opinion as to the cause of the circumscribed and intense inflammation of the villous coat of the true stomach, and say if you think it arose from any chemical irritant?

"The treatment consisted in the exhibition of spt. ammonix aromatic with the carbonate; aperients, and at last the chlorides, but all proved inert, no benefit whatever accruing therefrom. Had I suspected spasm to such a marked extent, I should certainly have given large doses of ext. belladonnæ and hyosciami, both in the form of enema and by the moutl. As it was, my treatment was directed solely to the symptoms evinced; and when I found that all the usual remedies were of no avail, as the animal was in high condition, I thought it best to have her destroyed.

"[The lining membrane of that portion of the alimentary canal forwarded by Mr. Redwood, was throughout in a state of congestion, presenting here and there depressed or cuplike patches, which apparently resulted from ulceration, commencing in the sub-mucous tissue. The ulceration had also penetrated, in spots, the substance of the mucous membrane. This condition of parts is somewhat singular, and might have had its origin in the existence of some local irritant.]" 


\section{DENTITION OF CATTLE.}

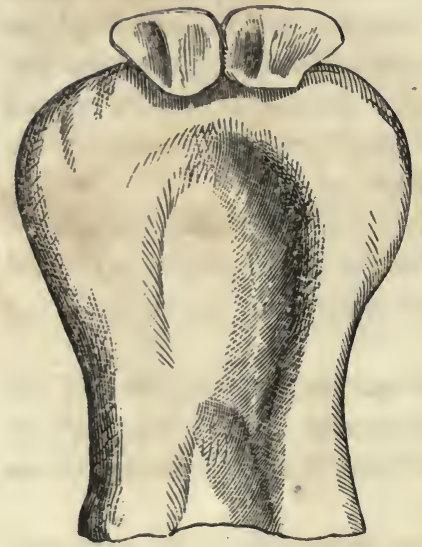

Appearance of the temporary incisors at birth.

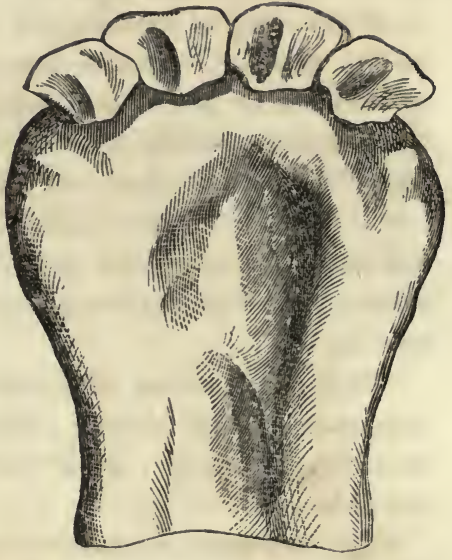

Appearance of the temporary incisors about one week after birth.

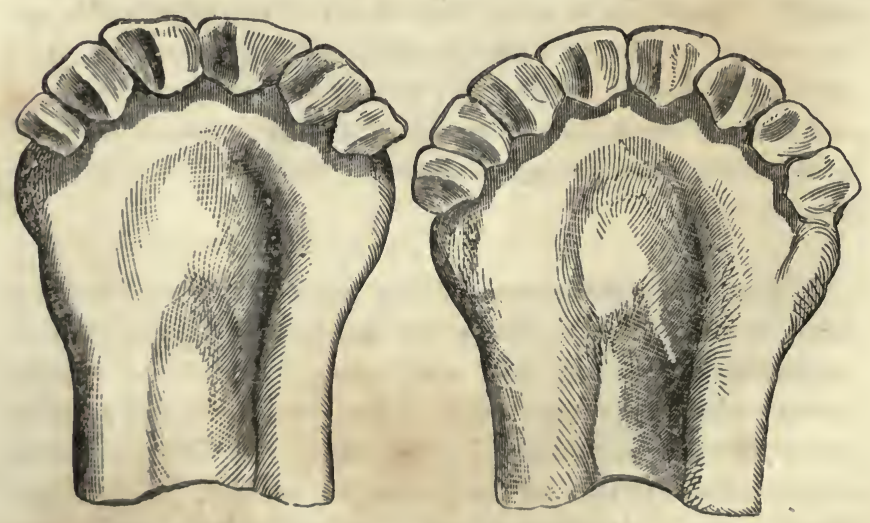

Appearance of the temporary incisors about two weeks after birth.

Appearance of the temporary incisors about three weeks or a month after birth. 


\section{DENTITION OF CATTLE.}

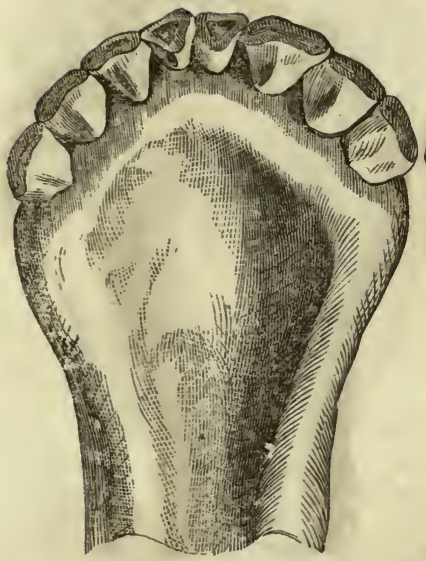

Appearance of the temporary incisors at the age of eight or nine months.

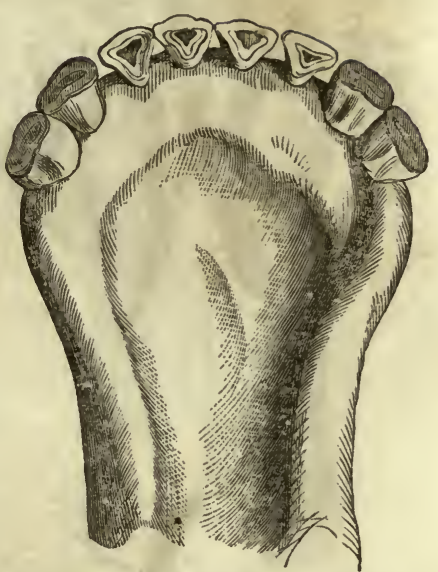

Appearance of the temporary incisors at the ages of ten or eleven months.

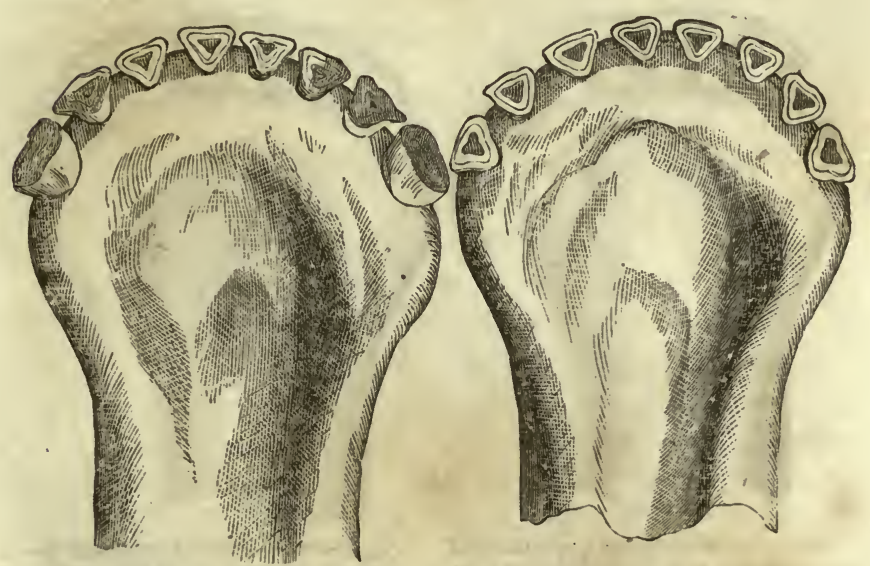

Appearance of the temporary incisors at the age of fifteen or sixteell months.
Appearance of the temporary incisors at the age of eighteen or nineteen months. 


\section{DENTITION OF CATTLE.}

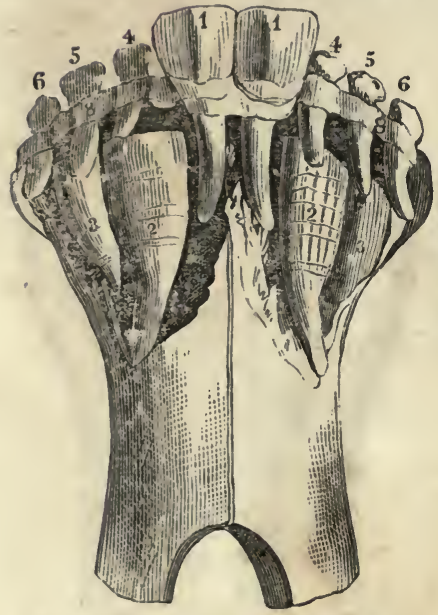

Appearance of the teinporary and permanent incisors at the age of about two years.

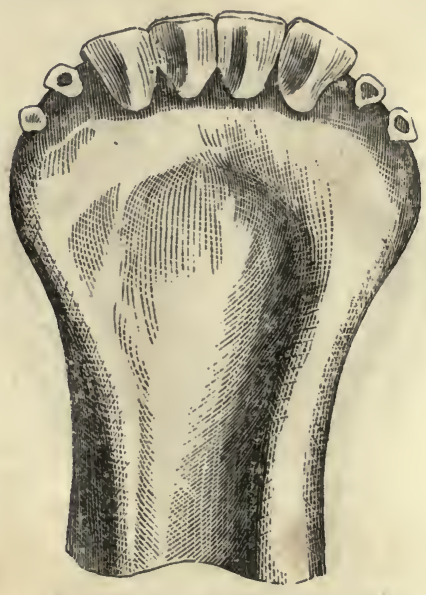

Appearance of the temporary and permanent incisors at the age of three years.

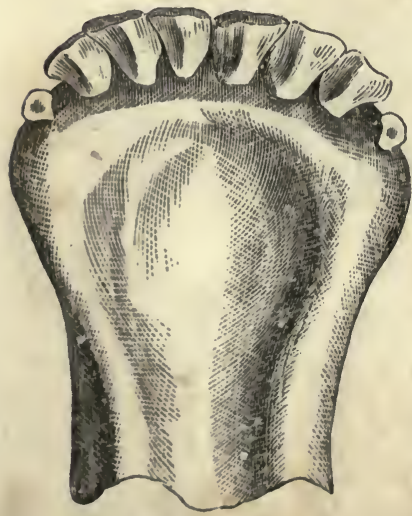

Appearance of the six permanent incisors, and two temporary, at the age of four.

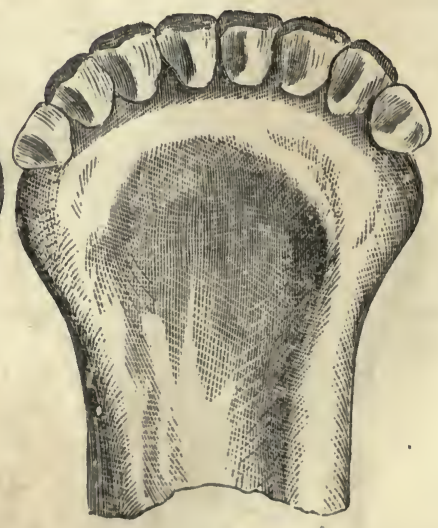

Appearance of the permanent incisors at the age of five, or between the fifth and sixth years. The animal is now said to have a full mouth. 
DENTITION OF CATTLE.

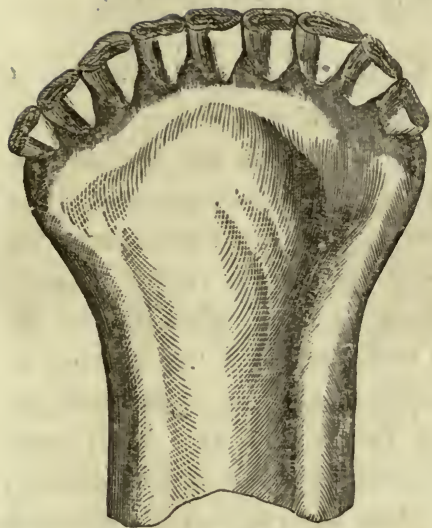

Appearance of the permanent incisors at the age of about six years.

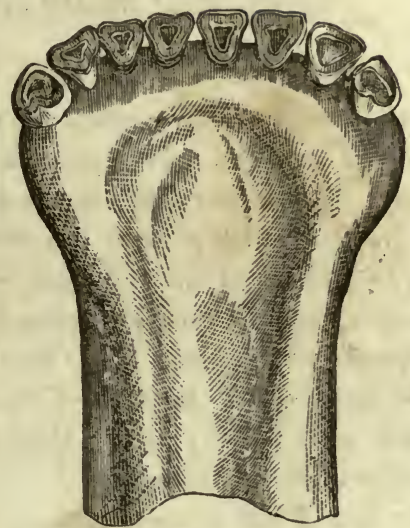

Appearance of the permanent incisors at the age of about ten years.

\section{SYNOPSIS OF DENTITION.}

INCISORS.

Temporary incisors all prominent at the end of one month.

The two central permanent incisors appear in from twenty to twenty-four months.

The two inner middle permanent incisors appear at about the age of three.

The two outer middle permanent incisors appear at about the age of four.

The corner permanent incisors appear between the ages of five and six.

MOLARS, OR GRINDERS.

Temporary molars, three in each jaw above, and below, on both sides, are prominent at birth or within four weeks of that period.

Fourth temporary molars are cut at the age of six months.

Fifth temporary molars are cut at the age of fifteen months.

Sixth temporary molars are cut at the age of from two years to thirty months.

The first and second permanent molars are cut at.the age of -about two years.

The third molar is cut at about the age of three; the fourth appears at the age of four; the fifth at the age of five; and the sixth at the age of six. 


\section{SUSPENDED RUMINATION OR LOSS OF CUD.}

Some people, who are in the habit of prescribing for loss of cud, more properly termed "cessation of rumination," suppose that if they can only restore the lost function the trouble wils end. This is certainly very desirable, for an improvement in the appetite of sick animals is a sure sign of rapid recovery; yet a restoration of the cud alone will not always insure a cure; neither are the remedies prescribed by some, calculated to accomplish this object. One man recommends a red herring to be thrust down the throat; another a portion of the quid, or cud, of a healthy cow. Others recommend raw beef, pork, pepper, etc. This results from mistaking symptoms for disease, for loss of cud is nothing more than a symptom of deranged digestive function, or that of other organs sympathetically associated with it. Those who have the care of cattle; and prescribe for them when sick, are not supposed to be able to trace loss of cud to derangement of one or a class of organs, unless they shall have had the advantages of a medical education, which is not often the case. They are not acquainted with the various sympathetic relations that exist in the animal economy, neither can they understand why an abnormal condition of one organ produces a corresponding effect in one or a class of organs remotely situated; nevertheless, such are the facts. Many a poor cow has been thus forced to swallow down a red herring (bones and all) or "another cow's quid" (not of tobacco, for none other than two-legged animals chew quids of this description), and we can readily conceive that such articles may, for the time being, arouse the digestive organs, and create an unnatural appetite in animals of such refined taste and nice discrimination as the cow. A red herring, either whole or comminuted by the grinders, and then swallowed, only creates irritation on the mucous surfaces of the various compartments of the stomach; an unusual abundance of blood flows into the walls of that organ, the circulation of that fluid is quickened, the gastric juice flows more readily, and the digestive function is exalted. A reputition of the practice enfeebles the power 
of the stomach, its action is quickened at expenditure of power, for all unnatural excitement of a natural function is followed by a corresponding depression.

A stimulant, and red herring may be classed as such, creates a desire for food; but then the animal may be laboring under an acute disease of some organ, when food would be inadmissible, or the stomach may be overburdened and unable to digest what is already there, and therefore requires rest, as any other organ would after long-continued action.

The stomach is one of the most important organs, and performs some of the most delicate operations in the animal economy ; its functions may be suspended from various causes, and it is the province of the practitioner to learn and understand the why and wherefore of its derangement. In many cases the stomach craves no food because it cannot digest it; and merely creating an appetite by stimulants, is worse than useless, for whatever is then eaten cannot be converted into chyme, nor can the lacteals take it up, and apply it to the purposes of nutrition.

Whenever an animal is suffering from disease, pain, or excitement, there will often be absence of appetite (loss of cud), and this function is suspended because the animal is drawn. from it by his sufferings.

The real seat of sensation of hunger is in the brain, not in the stomach alone; as some suppose; the latter may first communicate some such sensation to the brain, yet if that organ be in a deranged condition, unable to recognize the want, then we must impart bealthy action to it, and establish an equilibrium between the nervous and general system, in order to produce a natural appetite. Do you wish to know how to do this? If so, study the veterinary art. That the appetite is affected by the state of health, both of the body and mind, is certain. Human practitioners realize that. "In fever, pain, and in certain dyspeptic states, the stomach craves little or no food. So in mental distress, in times of great fear, or sorrow, or extreme anxiety, the appetite fails. Even in a single moment 
the appetite may be suspended by any sudden mental affection or emotion." Animals are known to manifest mental emotion when separated from their offspring, or from those with whom they have been accustomed to work or associate, and many cases are on record showing that animals, when deprived of the society of their fellows, refuse their food, and die of grief; so that in this particular the brute does not differ from his master. Is it not a matter of importance then, to ascertain the cause of loss of cud (appetite) before we prescribe red herrings, etc.?

- "Loss of cud," says Mr. Youatt, "is more a symptom of disease than a disease of itself. It accompanies most inflammatory complaints, and is often connected with those of debility. It will be the duty of the practitioner to ascertain the cause of this suspension of second mastication, and to adapt his mode of treatment to the nature of that cause. A dose of physic, with a small portion of aromatic medicine, will be indicated if any fever can be detected; more than the usual quantity of aromatic should be added in the absence of fever, and still more, with tonic and alterative medicine, if general debility is indicated. The caraway and ginger powder are the best aromatics, and will supersede every other; the gentian and ginger, with epsom salts, will prove a very useful tonic and alterative, in cases of loss of cud, that cannot be traced to any particular diseased state of the animal." A word to the farmer, and I have done. If you have permitted your animals to subsist on innutritious diet, so their digestive powers have been overtaxed, and that function is paralyzed, then the blame rests with you. On the other hand, have you been preparing them for market, piling on the fat, at the same time depriving them of pure air and exercise? if so, you are equally blamable. Is your barn and dairy management consistent with the received opinion of those who are the best judges in these matters? if not, make them so, and depend upon it, your cattle will thrive and be blessed with a natural appetite; for disease in nine cases out of ten, results from violating the laws of nature. 


\section{INFLAMMATION OF THE BOWELS. - Enteritis.}

This disease occurring in any of the divisions of the intestines is one of frequent occurrence; yet among cattle, it is not liable to become so suddenly fatal as among horses.

This disease, bears some analogy to colic, in the suddenness of its attack; a healthy animal is all at once attacked with abdominal pain; gets down, and moans from incessant or persistent pain. The pulse generally ranges from 60 to 70 ; rumination has ceased, and the fæces is hard, covered with slime or streaked with blood; the flanks heave (as the saying is), the limbs are tremulous, and the animal has a staggering gait; the visible surfaces of the eye, mouth, and nostrils are reddened; pressure upon the abdominal region, - which is generally tucked up, elicits symptoms of pain; as the disease proceeds these symptoms are aggravated, and intestinal hemorrhage or mortification, terminates the sufferings of the animal. The post mortem examination generally reveals engorgement of the blood-vessels of the intestines, with highly carbonized and coagulated blood; the lining membrane is of a dark velvet color, and the large intestines are more or less, inflamed or gangrenous.

Treatment. - The principle objects in the treatment of this disease are to lubricate the interior of the stomach and intestines with mucilage of slippery elm, and to equalize the circulation and nervous action over the general system; the remedies are as follows:-

The above dose may be repeated at the expiration of eight hours, in the mean time apply a mustard poultice to a part of the abdomen, and excite the circulation on the surface of the body and extremities, by friction with wisps of straw.

An occasional anti-spasmodic enema should be thrown into the rectum; two quarts of hot water, to one ounce of powered lobelia, are about the proper proportions. Should the patient appear to suffer from distention of the intestines with gas, 
then give one ounce of hyposulphite of soda, two drachms of powdered goldenseal, and one pint of water.

Animals in the above condition cannot bear cathartics, yet cases now and then occur, which require a gentle aperient, merely to aid in the removal of fæcal accumulations. When such remedy is indicated, I recommend the following:-

Glauber Salts, .............................. 8 ounces.

Warm Water,................................

Molasses, .................................. $\frac{1}{2}$ gill.

Powdered Ginger,......................... 1 tablespoonful. Mix.

Drench the animal with the same.

\section{INVAGINATION OF INTESTINE.}

Invagination of intestine signifies, a portion of intestine drawn within another, there becoming strangulated. This difficulty does occasionally occur, and the symptoms do not differ materially from those attending strangulation, occasioned by the cord, or vas deferens. The symptoms are, that the animal passes nothing from the rectum, but a small quantity of blood; suffers incessant pain, is very uneasy and rumination is suspended; he will occasionally anxiously regard the flanks and moan. This trouble is generally, preceded by flatulency. The best plan of relieving the animal is to etherize him, for it often happens that during etherization a relaxation of the muscular tissues takes place, and such condition is favorable to the return of the bowel. It may be proper, while the animal is down and under the influence of ether to introduce a hand into the rectum and try what can be done by manipulation and traction. The small intestines in which the difficulty occurs, can be seized through the wall of the rectum, and perhaps by some slight traction or movement, the difficulty may be remedied. It is impossible to tell what is the result of our efforts, until the animal is relieved and has had time to recover from the effects of the ether. This having taken place, without improvement, I should immediately perform the right flank operation, search for the seat of the difficulty and 
reduce the invagination. This operation may appear to some as a very formidable affaír, very dangerous and painful. But a skilful surgeon, armed with the great godsend - ether, can perform the same without the least danger. I have opened the abdominal cavity sereral times, in cases of sterility, merely to explore the uterus and ovaries, and never met with any accident, and to encourage those who have never had any experience in the performance of this operation, I relate the following incident. I was requested a short time ago to visit a very valuable Durham cow, the property of Mr. G. Clarke of Hyde Hall Otsego County, N. Y., which had been purchased of Lord Ducie, accompanied by a warranty of pregnancy, by one of the best bulls in England. Time revealed the fact, that she was not pregnant; she had afterwards, several connections, with the opposite sex, yet could not be impregnated. The object in securing my services was to solve the problem of her sterility. Now comes the pith of the matter. I cast her and explored the vagina, it appeared that there was a sort of hour-glass contraction in the vagina, so that the hand could not be introduced more than six inches; at this point there appeared to exist a mechanical obstruction to further penetration, this was sufficient evidence of incapacity of the sexual congress, yet having travelled a long distance, at great expense to the owner, and there being some prospect of litigation in the matter, I was determined to remove all doubts. I therefore performed the flank operation, and explored the uterus and ovaries; the whole were in a state of atrophy, except the right ovary which was as large as the kidney of an ox ; being desirous of ascertaining what the character of the enlargement was, I put my thumb and finger into it, by so doing I ruptured a vessel which bled very profusely; my immediate impressions were, that the animal must die of internal hemorrhage. It was a matter of impossibilty to secure the bleeding vessel, so I sutured the incision expecting that the animal would die in the course of a few hours; but contrary to my expectations she got well, so; nil desperandum. 


\section{DIARRHCEA.}

Diarrhœa consists of an increased number of alvine discharges, augmented peristaltic motion of the bowels, irritability of the same, and a too rapid propulsion of the secretions.

Diarrhœa is sometimes salutary - an effort of nature to rid the system of morbific matter; it frequently occurs at the commencement of various forms of disease, and is scarcely, if ever, an isolated affection. Gallup, in his "Institutes of Medicine," contends that the muco-intestinal discharges are portions of the centrifugal circulations, which probably have their functions accelerated by the force of the heart and arteries, above that of the centripetal series. A fluid, quite similar to the cold sweat of the skin, and by a similar process, is forced out in abundance, and produces the diarrhœe.

A moderate diarrhœa, occurring in a plethoric animal, is often salutary; for it relieves the relative plethora of the vascular system, which occurs at the onset of acute disease.

When the discharges are of a yellow or greenish color, there is, generally, functional derangement of the liver. When an abundance of mucous material is observed, it goes to show that the mucous membrane is congested. Sometimes an excess of serous fluid is observed, this occurs more particularly in dropsical affections.

There is also a alvinous variety of diarrhœa, caused by an abnormal secretion or exudation of coagulable lymph; it frequently comes away in shreds or detached pieces from various portions of the intestinal canal.

Treatment of Diarrhoa. - Almost any form of this affection, except the chronic kind, can be checked, and perhaps cured, by administering a few doses of charcoal and lime water I use these agents in the following proportions:-

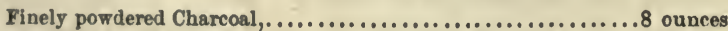

Lime Water,....................................4 ounces

Tincture of Matica,................................2 ounces.

Water,........................................... Mint.

One-fourth of the above is a dose for an ox or cow, which may be repeated every four hours. The same remedy answers 
for calves, only they require a smaller quantity. The astringent properties of the above mixture can be augmented by increasing the quantity of matico, or by adding a small quantity of powdered bayberry bark.

In all cases of diarrhoea, I usually order a change of diet, for in some cases the food is operative in producing the diffculty; if it occur while at grass, the animal should be taken to the barn for a short time, and allowed a few moderate meals of ground oat meal.

When suckling calves are under treatment for diarrhœa, the mother should also have a few doses of the above remedy; for it often happens, that she is ailing at the time, and her milk has a morbid tendency on the calf.

In the advanced stages, when the facal discharges emit a bad odor, and rumination is suspended, the patient should have a few quarts of milk porridge per day. Scalded milk alone will sustain and benefit the calf.

\section{CHRONIC DLARRHEEA.}

Chronic diarrhœa is usually accompanied by loss of condition; the coat stares, and although the animal is allowed the very best kind of food, still it thrives not, the skin and ribs seem to have entered into permanent relationship. In a case of this character, I recommend the following:-

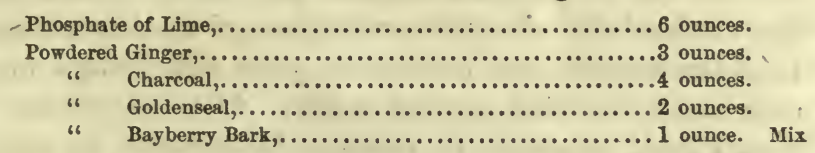

Divide the mass into eight equal parts, and mix one of them in the food night and morning. This will generally have the desired effect; should it fail, I would increase the quantity of bayberry bark to three ounces.

\section{"GUT-TIE."}

It would seem that an apology is due the reader, from the 
author, for introducing such an apparently vulgar term as the above; but the fact is, this term has a meaning; perhaps better understood than any other that can be introduced at the present time.

It would appear that "gut-tie" is often occasioned by a faulty method of castration, this is the testimony of experts; but it is my opinion, that gut-tie, often occurs more accidentally than otherwise; for animals have been known to die of gut-tie, after being castrated in the best possible manner. I once operated on an animal for this mechanical trouble, and am satisfied that the castrator was as well qualified to perform the operation, as the best of the craft; yet, the cord had retracted into the abdomen, formed a false tissue and had also a large bulbous extremity, which no skill nor foresight could have possibly guarded against. The animal operated on, presented the following symptoms: Pulse small and quick; respirations hurried; animal very uneasy (all the time), down and up again very often; rectum empty, yet coated with slime; the, patient refused both food and water, and had not ruminated nor passed any frece, for several hours. I proposed an operation with the intention of exploring the abdominal cavity, to which the owner consented. The patient was cast on the near or left side, and etherized; an incision five inches in length was then made through the integuments of the right flank, midway between the last rib and anterior part of the ilium, about three inches below the transverse spines of the lumbar vertebræ; the muscles and peritoneum were also divided in the same manner as when spaying a cow. After introducing my hand $I$ found a portion of intestine incarcerated by the remains of the spermatic cord, which seemed, together with some false membrane, to have entangled the intestine; after liberating the latter, the divided muscles were closed by suture, one end of which was left long enough to hang out of the wound ; the integuments were then sutured, and dressed with tincture of aloes.

The patient staggered a little when he got up, but soon commenced eating. I did not see him afterwards, but a fortnight 
from the time of the operation was informed that the animal experienced immediate relief from the difficulty, and was then well.

Up to the present time there appears to be no information afloat, in this country, regarding the cause and remedy of this singular difficulty, hence I presume that some reliable account from other sources may be acceptable to the reader of this work. The following account of "gut-tie" is from the pen of Surgeon Crowhurst, published in the London Veterinarian:-

"I was requested, on the 15 th of last month, to attend a two-year-old steer, the property of W. W. Daws, Esq., of Ewhurst, which was taken ill the day previously, but it being late when the illness was observed, and my residence nine miles distant, some aperient medicine was administered, and orders given to send for me the next morning.

"When I arrived, the steer was lying down in a shed, but soon got up and walked across the yard. His back was arched, and the abdomen tucked up.

" He was somewhat excited at first, but soon began to tremble, and to step in a backward direction by putting one hind leg directly behind the other. Occasionally he turned his head towards his side, and would kick at his belly, and now and then stretch himself out, and curve his loins to a considerable extent. After being in the yard for a short time he returned into the shed and lay down again, doing this in a very careful manner. He soon got up a second time, and stepped backwards as before, seemingly for the purpose of getting his hind quarters against some resisting body. The man in charge of the animal explained that the symptoms had undergone but very little change since he was taken ill, and that he had not eaten any thing nor voided any fæces. There were, however, several evacuations of mucus lying about the yard, which had been expelled from the bowels.

Having procured a wagon-rope, and obtained the assistance of two or three men, I had the animal cast, and examined him per rectum. There were no fæces present, but on passing my hand onward I readily detected a band, which was drawn 11 
tightly round the bowel. It appeared to pass from behind forwards, and under the rectum. By pulling at this the animal struggled from pain. Finding this state of things, I at once decided upon operating, as I could not see the patient any more that day, having many pressing professional engagements.

"I first cut off the hair from the right side, which I prefer to do while the animal is standing, that I may know better where to commence my incision when he is cast. I will here describe my plan of casting the animal, that should any person have a preferable one, I may put it in requisition in my afterproceedings. I first fastened one end of a rope to the off fore leg, then passed it in front and around the near fore leg, and afterwards under the part of the rope between the legs, so as to pull them close together. Next, it was carried between the hind legs and round the near one, and then under that part which passed from the fore to the hind legs. By then bringing the end of the rope over the bullock's back I was enabled to throw him on his near side, and prevent his rising by drawing the near hind leg forwards, and fixing it between the fore legs. As the off hind leg was still at liberty, it was secured by drawing it backwards and fastening it by another rope to a crowbar fixed in the ground. A man was then placed on the animal's neck to keep his head down, and prevent his rising. Every thing being ready, I commenced the operation by cutting through the common integument and abdominal muscles midway between the antero-inferior spinous process of the ilium and the last rib, a short distance below the transverse processes of the lumbar vertebræ, so as to avoid the arteries of the part. The peritoneum was then broken through with the fingers, and afterwards the left hand was introduced into the abdomen in a direction towards the pelvis. I experienced no difficulty in finding the band, which consisted of the vas deferens, and which formed a semicircular projection in the abdomen from the intestines passing behind it, or from below upwards, as the steer lay on his side. It was drawn quite tight, and had produced strangulation of the intestines. I was soon enabled to liberate the intestines, after which I drew the vas deferens toward the opening in the 
muscles and divided it, excising a portion to the extent of about three or four inches. The part cut through retracted, and was left floating free in the abdomen. The operation was completed by passing some interrupted sutures of wide tape through the common integument only. After the animal was released, I gave him some aperient medicine, and ordered gruel to be administered at regular intervals.

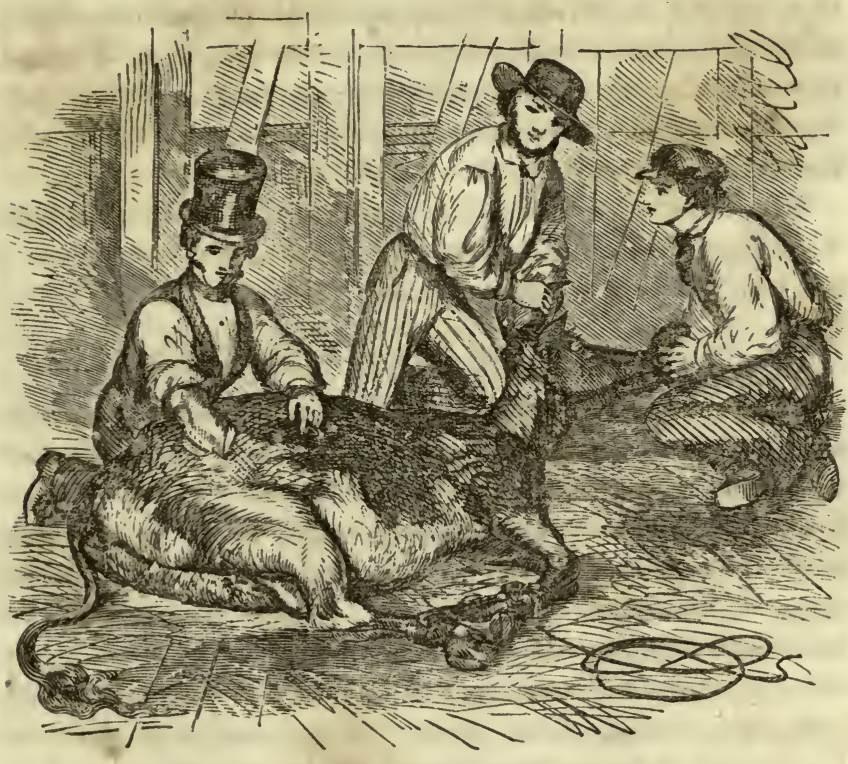

MODE OF OPERATING FOR GUT-TIE.

"Before I was a student at the college, I attended a postmortem examination of an old Welch runt, which my father ordered to be killed, as the proprietor neglected sending soon enough for him to be of any service. In this ease there were about six inches of the small intestines strangulated, and quite black in color.

"The question arises, Is this affection produced from any particular mode of castration? My father has castrated ani- 
mals in the same way as taught him by his father for forty-five years, and has never had one case among those he has operated upon, although he has been called to several which had been operated upon by other persons.

"The calf which I have alluded to was not castrated by him, nor was the two-year-old steer, the subject of this communication, by either of us, which tends to prove that castration has to do with its production, these cases having occurred in our district. I had, until recently, supposed that the spermatic artery, on being drawn at until it ruptures, in the operation of castration, might recede into the abdomen, and hanging loose, afterwards strangulate the intestines by getting around them, but I feel convinced this is not the cause."

The following, which lately appeared in the Edinburgh Veterinary Review, is offered for the reader's instruction; it is a translation from Gierer, by Mr. Gamgee.

\section{"ON THE INTERNAL RUPTURES IN OXEN.}

"Gierer alludes to the fact, that all author's agree as to the nature of the internal or peritoneal ruptures, termed ' ueberwurf:' by the Germans - 'gut-tie' by the English. There is a separation of the atrophied spermatic cord from the sides of the pelvis, and, under peculiar circumstances, the peritoneum is lacerated, a portion of intestine slips downwards and backwards, and the cord is entwined round it, so as to constrict it, obstruct the passage of excrement, and inflamation, with other consequences, result. Gierer especially describes his method of discovering the seat of the constriction, and his plan of operating. He says that it is not always so easy to find the spermatic cord, and to discover precisely which intestine is incarcerated. Most cases occur in oxen from a year and a half to four years old. When symptoms of colic, and no discharge of fæces induce him to suspect ' gut-tie,' he examines per rectum, and, by careful manipulation, can always detect the spermatic cord and imprisoned intestine. Gierer lias never seen this strangulation relieved spontaneously; and there are two methods of cure to adopt, - the one palliative 
and the other radical. The first consists in the return of the intestine through the fissure in the spermatic cord, by quickly driving an ox or raising his hind quarters in a stall; this should be tried soon after the first appearance of the disease; when this does not answer, the normal condition of the parts must be restored by the taxis effected through the rectum.

"Very often there may be a relapse, from the loose spermatic cord and fissure of the peritoneum remaining in statu quo. There are two methods of radical cure; one by the introduction of the hand through an incision through the abdominal walls, and the other by the rectum. Gierer always operates by the rectum, and his method consists in the simple return of the spermatic cord in contact with its natural point of attachment against the abdominal wall. To effect this a limited, successive, and slightly outdrawing traction, forwards, or from behind forwards, of the intestine is effected; and, having accomplished this, the soft part of the thumb of the right hand, which is used from the beginning of the operation, is applied through the coats of the rectum in the lower and posterior part of the cord ; and, with a jerk, or forward movement, the operation is completed.

"Gierer says, that the introduction of the hand in the abdomen is only needed when, from the amount of intestine imprisoned, it is difficult to feel the rudimentary spermatic cord; but, under these circumstances, inflammation and gangrene would have ensued already, and the operation would therefore be useless, and it is many years since he had occasion to perform it."

\section{FLATULENT COLIC.}

This disease is generally occasioned by some derangement of the digestive organs, whereby the food, instead of bring properly digested, undergoes fermentation, and thus carbonic acid gas, or sulphuretted hydrogen is evolved. It is attended by considerable pain; the animal will be very restless, continually lying down and getting up again; discharges gas from the anus; strikes the belly occasionally with the hind feet, and the abdomen is enlarged. 
This species of colic can generally be relieved as follows: Take one ounce of hyposulphite of soda, dissolve the same in a quart of water; then add tincture of ginger and tincture of goldenseal, of each, one ounce. Drench the animal with the same. Clysters of soap suds, to which a little salt may be added, should be thrown into the rectum occasionally. The belly should be well rubbed with coarse straw, and in severe cases, I should rub some mustard, moistened with vinegar, on the lower part of the abdomen. After a lapse of two hours, should the patient appear unrelieved, a second dose of the colic drench may be given; generally, however, one dose is sufficient.

\section{SPASM OF THE BOWELS.}

Spasm of the bowels, generally termed spasmodic colic, is occasioned by contraction of the longitudinal and circular fibres of the muscular tunic of the intestines. In this disease, nearly the same symptoms are observed as those alluded to in flatulent colic, with the exception of flatulency. The patient, however, is more irritable and dangerous to handle than in flatulent colic, and he has periods of relaxation from pain which return at intervals with increased violence. It is supposed that this affection is caused by the presence of irritating matters in the intestinal canal either-in the form of bad food, poisonous plants, or water impregnated, with lead. As the muscles of the intestines belong to that class known as involuntary, it follows that the state of spasin is the result of some excitability or deranged condition of the nerves of involuntary motion; hence antispasmodics are indicated.

In view of relieving the spasm, I recommend the following:-

Powdered Assafoetida,.......................... drachm,

Sulphuric Ether, .............................. 2 drachms.

Thin Gruel, ................................. 1 pint.

Mix.

And drench, then administer occasionally an antispasmodic clyster, composed of warm water and a small quantity of powdered lobelia.

Failing to relieve the animal by the above means, I should 
get him under the influence of sulphuric ether, to be applied to the nostrils by means of a sponge. There is no necessity for fully etherizing the animal, for if kept in a partial state of stupefaction for about twenty minutes, the spasm will relax; after which, let the patient be kept on bran mashes for a day or more.

\section{CONSTIPATION OF THE BOWELS.}

Constipation is generally the result of impaired digestion, yet now and then it is the precursor of some definite malady. The old method of resorting to powerful cathartics generally aggravates the symptoms, and the animal dies unrelieved of the constipation.

The best method of treating this affection is to administer, with an aperient, stimulants and bitters; in this way we arouse the action of the digestive organs, and create a lax state of the bowels. Let the following drench be given:.12 ounces.

Powdered Goldenseal, 3 drachms.

Dissolve the glauber salts in one quart of tepid water, then add the other ingredients. After a lapse of eight hours the animal should be walked about; have its belly rubbed, and an occasional clyster of warm soap-suds may be thrown into the rectum. Should the medicine not operate at the expected time, administer two drachms of powdered mandrake, the same quantity of goldenseal, and half an ounce of hyposulphite of soda, in about a quart of water.

To prevent a recurrence of the constipation, let the animal have half an ounce of equal parts of goldenseal and carbonate of soda daily, which may be mixed in the food. It is important, also, in view of guarding against constipation, to make some change in the diet; thus, if the animal has been long fed on meal, some coarser material — shorts — should be substituted, for a brief period at least. 


\section{THE PANCREAS AND ITS FUNCTION.}

The pancreas is of light red color, composed of a vast number of glandular bodies, each having a duct or outlet, which finally unites with the biliary duct, and with it enters the duodenum. The fluid secreted by the pancreas is a colorless, limpid fluid; it forms an emulsion of fat, hence it dissolves the fatty matters of the food, and is an active agent in the preparation of chyle. That the pancreatic juice possesses the property of emulsifying fat is proved from the fact that when the pancreas is destroyed, and the animal be fed on food containing fatty matter, the latter passes with the fæces, just like fat in an unchanged state. Mr. Gamgee says:-

"The pancreatic juice has another important use which remains to be spoken of ; and that is, a peculiar action on nitrogenized substances. If raw meat be placed in some of the juice, the meat speedily softens and putrefies. The same occurs with albumen or casein, in the-raw state; but if the azotized principles are previously boiled or acted upon by the gastric juice, then they are absolutely dissolved by the secretion of the pancreas. The pancreatic juice, therefore, serves many purposes, and acts on every kind of aliment.

"Circumstances affecting the digestive function in general have a special influence on the pancreas, and modify its secretion; such is not the case with the salivary glands and their products. The pancreatic juice may, like every other secretion, be found to contain adventitious substances that have accidentally entered the blood. Thus, iodide of potassium may be eliminated from the system by the pancreas. It is not so with every salt, the prussiate of potash, for example, never being seen in the pancreatic juice.

"The pancreatic secretion is formed during infra-uterine life, but we are at a loss to account for its uses then. It is difficult to determine what nervous influences affect its production; a dose of ether excites it, and pressure on the abdominal viscera likewise tends to its increase ; the efforts of vomiting stop it."

The pancreas is subject to several forms of disease, and oc- 
casionally attains an enormous size, but in the present state of our knowledge on cattle pathology, I am induced to believe that it would be almost impossible to furnish symptoms which shall clearly indicate the presence of disease in the pancreas.

\section{DESCRIPTION OF THE SPLEEN.}

The spleen is commonly known as the "melt," it is a lengthy dark colored gland, situated on the left side, attached to the anterior part of the rumen. It is composed of a congeries of bloodvessels united together by cellular tisşue; its artery is derived from the coeliac axis, and is termed splenic artery, and the veins of the spleen terminate in the vena portæ - the great vein of the liver. Very little is known of the function of this gland, except that through its extraordinary distensibility it serves as a diverticulum, to relieve the liver when it is congested or when an obstruction to the flow of blood through the liver, heart, or digestive viscera exists.

Carpenter says, that the spleen has been repeatedly removed without obviously injurious consequences ; whenever it appears, either that its function is not of vital importance, or (which is more likely) that it is discharged by some other organ in its stead. In some instances in which animals have been allowed to survive after removal of the spleen, the lymphatic glands of the neighborhood have been found greatly enlarged and clustered together, so as nearly to equal the original spleen in volume; and hence it appears, that the function of the spleen corresponds to that of -the lymphatic glands.

The spleen is subject to various diseases, known as imflammation, hypertrophy, ossification, hydatids etc; but the symptoms are of such an obscure character that it would not be worth while in a work like this to discuss them.

"Prevention is cheaper than cure;" as the disease is obscure, the skill of the practitioner can be of little avail, therefore the husbandman should endeavor to prevent a malady which is apt to end in death. Inflammation and engorgement of the spleen, generally occurs in cattle that have been highly fed, a 
forcing system of feeding therefore is the principle cause of this affection.

\section{ON DIET}

Variety in food necessary - Effects of certain kinds of foodAs regards the requisite quantity, etc.

It is admitted by medical men, and the experience of my readers may possibly have confirmed the fact, that a great proportion of the diseases occurring among live stock are produced, either directly or indirectly, by errors in diet; consequently the.means of prevention are within the reach of every husbandman, and should be used accordingly.

No special form of diet, can for any great length of time, preserve the integrity of the animal machine; and in order to substantiate this proposition I shall show the effect of simple elementary principles on the system of man; considering what is known to be a fact, that the same is true of his servants, horses, and cattle.

Some of my readers have heard of the experiment made by Napoleon Bonaparte: which was that of trying to supply the nutritive wants of his system by living on a concentrated preparation of beef, in the form of jelly. He gave it a fair trial, yet came very near starving on the same, and he was led to remark, that the stomach was a sort of scavenger, hence required a given amount of rubbish to sort from, and select the necessary elements for renovating the tissues. He probably selected jelly because it is highly nutritious, containing more of the flesh-making principle, than most articles of food. It was rich, not only in nitrogen, but also in oxygen, hydrogen, and carbon, four of the principal elements which compose the animal fabric.

The fact is, no single article of diet, let it be ever so rich in the elements of organized tissues, can long support life. A nation of men subsisting long on a simple form of diet, without variety, would soon become emaciated, and die of innutrition. Let the Grahamites abstain from milk, and live on bread and water, and they would soon exterminate themselves. Milk is a highly 
nutritious compound and furnishes their systems with the equivalents that we obtain from beef and mutton. The inhabitants of the "Celestial Empire" - Chinese - are great consumers of rice; it is the principal article of diet.among the poorer classes many of whom are lank and lean, and would make very respectable walking lanterns (if a candle was placed within their abdominal cavity and lighted), only they happen to catch, occasionally, a stray dog or pig; such furnish not only a savory meal, but a supply of material for the formation of muscle and fat.

Alluding to dogs reminds me of an experiment made by Majendie. He proved beyond the shadow of a doubt, that such an animal could not live more than forty days on any single article of diet, let it be ever so nutritious.

The staple article of food among Irish peasants in the bogs, is potatoes; those people are subject to diseases of a low typhoid type, and all that saves them from disease, or perhaps premature death, is buttermilk, red herrings, and occasionally a drop of whiskey.'

The Scotch peasants are great consumers of oatmeal; this article is not inferior to wheat in the flesh-making principle, and we might naturally infer that an article of diet so valuable and palatable, ought to promote health and cater to longevity. This is not the case. The great oatmeal consumers are the notorious subjects of intestinal concretions, and in the Edinburgh Anatomical Museum are to be seen a vast and valuable collection of intestinal calculi, most of which proved death warrants to confirmed oatmeal consumers.

"What is one man's food is another's poison."

Dr. Carpenter, an eminent physiologist, says, that " no fact in dietetics is better established than that concerning the impossibility of long sustaining health and life on a single alimentary principle. Neither pure albumen, fibrine, gelatine, gum, sugar, starch, fat, nor oil, taken alone, can serve for the due nutrition of the body. This is partly due to their 
failing in supplying the waste of the tissues, and partly to the fact that single alimentary substances, long continued, excite such a feeling of disgust, that the animals experimented on seem to perfer the endurance of starvation to the ingestion of the same."

Our readers are aware that when a person be long confined to any particular article of diet, a craving for something else is experienced, which very few persons can resist. This teaches us that in order to preserve the health of live stock, we must vary the diet, and are not to be over-particular in selecting the most nutritious articles. But we want, as Napoleon says, a little rubbish-coarse rubbish. The internal surface of the stomach and bowels require to be irritated once in awhile, and this probably was the idea which Graham had, when he first recommended coarse food. The stomach must be made to labor hard occasionally, or its function will deteriorate. Persons who complain of weak stomachs and dyspepsia, are those who live on dainty viands, and seldom, if ever, distend that organ to a healthy capacity with coarse material.

Consider for a moment the condition of Spanish and Italian peasants ; they know nothing of our national disease, dyspepsia. Their bread has the appearance of being composed of sawdust ; the very sight of the same would disgust our effeminate stomachs; yet, with the addition of a little oil, wine, and a few vegetables, they can endure greater hardships, and often carry a heavier burden, with less fatigue, than the advocates of roast beef and fine flour.

We may distend the stomach with coarse food, and perhaps not impair its function; but if we overburden it with fine meal or any other highly nitrogenized article which the digestive apparatus can assimulate very readily, until repletion takes place, then there is danger. The best food for distending the stomach of a horse is sweet hay, cut straw, Swedish turnips, carrots, squash, apples, and potatoes. As an illustration of what working horses can subsist on, I present the following bill of fare, on which some English farm horses live, and grow fat:- 
1. $1 \frac{1}{2}$ bushels of (good) Oats,

2. $1 \frac{3}{4}$ cwt. of cut Straw,

3. 42 lbs. Swedish Turnips.

A week's allowance.

Many animals are fed on this kind of diet for thirteen weeks, until the work of spring commences; then the food becomes more nutritious, in the form of beans and pollard.

American horsemen would call this hard fare, small potato diet, but nevertheless, some of the English horses consume in the course of 24 hours, 37 pounds of cut straw, and thrive, like Jehu, on the same.

The stomach must be made to work for a living once in awhile ; hard work agrees with it ; coarse fodder stimulates and develops its latent powers, and augments the gastric secretion, which is the active solvent of the food.

Labor operates on the stomach in the same manner, and in the same ratio, that it does on the brain or muscles - increases their capacity. Compare, for example, the brawny arm of the mechanic with that of the counting-house clerk, or the powerful muscles of the truck and farm horse with those of the pet saddle-horse; this comes of work, hard work. See the king of birds, the eagle, towering above and beyond the sight and ken of man, darting with almost lightning speed from mountain to valley, buffeting the rude shocks of heaven's artillery; - he acquires strength of muscle and wing, by extraordinary exertion and desperate feats of flight. After the same fashion we develop the mental faculties and augment them; protracted mental labor, close thought and study, light up the intellectual nature of man, and develop the latent powers of his brain, and the more his mind acquires the greater are its powers.

It must be borne in mind, however, that the various functions of the body require periods of rest; for, should a cow be permitted to stand up to a full crib, and spend the greater part of the day and night in cramming her stomach, disease, sooner or later, must surely occur. The same is true as regards man. Let an individual gormandize during the day, and then indulge in a late supper, and continue the practice, he soon acquires a 
sympathetic headache, or the stomach grows refractory, and casts up the burden, for the simple reason that its function is overtaxed. It must have rest. The same rule applies to the muscular and mental natures. If, therefore, hard labor develops the function of either, rest, at suitable intervals, preserves their integrity, and therefore must not be disregarded.

In selecting food for working animals, we must remember that they require certain inorganic equivalents, which seem to be as necessary for the support of the system as nutriment.

Salt, for example, is not nutritious, yet neither man nor brute can long exist without it. Common salt, chloride of sodium, is decomposed in the stomach, and is there found in the form of muriatic acid and soda; the former is supposed to aid digestion, and the latter eliminates bile.

Neither is phosphorus (found in straw) nutritious, yet that article is actually necessary for the support of life. It is an element of both regetable and animal organization, the former absorb it from the soil, and in turn, yield it to animals for the promotion of their health and longevity. It serves to develop bone, muscle, and nerve. Animals require phosphorus just as much as they do meal and oats; the former is decidedly nutritious, yet deficient in phosphoric acid.

Meal, oats, and beans, are nitrogenous compounds, flesh-making equivalents, yet they furnish only one part in a thousand of the article we need, - phosphorus, - while cut straw, potatoes and several other "inferior" vegetables contain more than double the quantity of the same. So that an animal must eat such rubbish as straw, potatoes, carrots, beets, and "stubble" in order to supply the necessary material.

Then consider that sulphur, iron, chlorine, lime, potassium, magnesium, and several other mineral substances, not in the least nutritious, are alike necessary for the support and integrity of the living organism, and therefore, should be the elements of food. Some articles furnish the needful in abundance, in others there is a deficiency. This furnishes another argument in favor of variations in diet.

A lecturer on physiology has remarked, that "there exists 
a peculiar analogy between vegetable productions and living animals. Animal and vegetable fibrine-albumen of eggs and the gluten of wheat contain about 15 per cent of nitrogen, so that they are somewhat identical. If you take 100 pounds of flour and wash it in water, frequently changing the same, you get 15 pounds of gluten.

"This is the flesh-making principle, and represents 15 pounds of the albumen of flesh. The gluten of flour, casein of cheese and peas, albumen of eggs and the flesh of an animal, contain ulso a relative amount of carbon, hydrogen and oxygen. So that the flesh of animals is already prepared for them in the vegetable world. The digestive organs of animals merely change the mechanical form and condition. of the former, their chemical composition remain about the same."

\section{EFFECT OF VARIOUS KINDS OF FOOD.}

It is customary in some stables in Massachusetts to feed horses and cows all the year round on what is termed cut feed; composed of cut hay, fine meal, shorts, a small quantity of salt, and considerable water; the whole being mixed together, is served out, ad lilitum. This kind of food might (and sometimes does) agree with animals, but it is not right to feed them year after year on the same, for the reason just set forth. Another reason for objecting to this food is, that in the stables alluded to, we hear of a great many cases of tympanitis and flatulent cholic (diseases somewhat identical), arising, no doubt, from the presence of so large a quantity of water as some. persons are in the habit of using; it saturates the food and retards digestion. Not only this, but when dry food, highly charged with water, enters the stomach, the temperature of the latter causes the food to swell, - increase in bulk, — and distends that organ, and also favors fermentation instead of digestion; hence arises flatulency. I do not, however, mean to contend that such food is at all times the direct cause of indigestion, colic, etc., because many New England stablers are ready to testify that they have fed the same for many years without any apparent 
inconvenience to their horses; but $I$ contend that it acts indirectly in the manner alluded to; and although some horses may "get used to it," and others, having wonderful digestive organs, assimilate it, yet the day of reckoning may not be far off.

I contend that water taken with food, always retards digestion. The proper solvents of the food are the gastric fluids, and the cow has abundant facilities for supplying the requisite quantity. An ordinary cow is said to secrete (while feeding) fluid, of salivial and gastric characters, at the rate of one gallon per hour, - enough, we should judge, to saturate a common meal, - therefore the water is not needed. I urge no objection against the more rational custom of merely sprinkling the food with salted water, in view of absorbing dust which often abounds in inferior hay; but I seriously object to the above hydropathic method of preparing food.

From experiments made on the human subject, it has been ascertained that parsnips, carrots, turnips, and cabbage, which contain from 80 to 90 per cent of water, require over twice as much time to digest as solid food does. Cabbage for example, requires twenty, and broiled beefsteak only eight hours to digest.

Turn a cow into a luxuriant pasture of grass or clover, and after partaking of one or the other, she is liable to become "blown or hoven" - tympanitic; the abdomen becomes enormously distended with gas (either carbonic acid gas or sulphuretted hydrogen), and unless the same be condensed or evacuated, rupture and death are sure to follow. This imperfect digestion and consequent generation of gas is due to the presence of -vegetable fluids found in green fodder. Therefore, animals having weak digestive organs - predisposed to flatulency should have the privilege of watering their own food with salivial fluid. The best diet for such an animal would be " $d r y$ feed," composed of ground oats, cracked corn, "fine feed," and a small quantity of sweet hay. On the other hand, a constipated state of the bowels always indicates coarse food; and in this view the English use chopped straw and coarse bran with 
decided advantage. Animals should never be watered immediately before, nor after, meals, but after the lapse of an hour from feeding time is the best.

\section{AS REGARDS THE QUANTITY OF FOOD REQUIRED.}

The adult animal does not require so much of the fleshmaking principle as the young and growing, but he seems to require a greater variety. The adult merely requires enough to replace the waste - the wear and tear of his system. If he obtains more than this, the surplus is either excreted from the body, or else stored up within the same in the form of fat; and everybody knows that a fat horse or a fat man, are not best adapted for a race, nor hard labor; but of all others (except those in a state of debility), they are most subject to acute disease. With the young and growing animal the case is different. Here we require bone, muscle, and nerve. Oats, corn, and pollard furnish the same. The colt and calf obtain from their mother's milk all the elements of their own organization in a concentrated form - all that seems necessary for developing bodily proportions and hereditary traits; therefore, when weaned, the young must be furnished with the same equivalents in the form of fodder; ground oats, wheat bran, and meal furnish the same.

It is the young and growing animal that requires our greatest attention. If my readers desire to raise animals that shall remunerate them for the trouble and expense incurred, they must feed the same, during their minority, with a liberal hand. Any. neglect at this period can never be made up in after life; the subject will always remain lank and lean, - living monuments of their master's folly or ignorance, as the case may be. In addition to the food required for the calf's growth, we must also furnish enough to supply the waste incurred by expenditure of muscular power. We all know that the young are very active and playful. Every muscular movement involves an expenditure of vital force, and thus exhausts the system; therefore, in piew of developing their full proportions, and promoting the $12 *$ 
integrity of the living mechanism, they must have nutritious food and plenty of it. They are not, however, to have a large quantity at a time, but little and often; their stomach is small, not larger than that of a man. Should it be over-distended with coarse and innutritious food, the organs of respiration and circulation become embarrassed, and the blood loaded with carbon. They require food often, because the digestive organs are very active, and soon dispose of an ordinary meal; then comes the sensation of hunger, which every one knows is hard to bear.

\section{ANIMALS INTENDED FOR FAST WORK MUST NOT BE ALLOWED TO ACCUMULATE FAT.}

The adult horse or ox should neither lose nor gain flesh from day to day; this is the case with a full-grown man in the physiological condition. The amount of food should be in proportion to the amount of labor performed, so that waste and nourishment may be equally balanced and readily adjusted. A large amount of food requires a relative amount of work. An animal fed liberally, and kept in the barn, must accumulate fat, and consequently becomes dull, stupid, and "sleepy."

The city of Boston own and employ some 150 or 200 horses in removing street sweepings and offal. These animals are seldom urged beyond a walk, and large, powerful horses as they are, their labor is comparatively light. Such are fed with a liberal hand, out of the city crib, abounding in the best kind of fodder. They have comfortable quarters at night, and the stables are celebrated for cleanliness and good ventilation. Under such circumstances the reader will not be surprised when I inform him that the recipients of City Stable bounty are as fat as aldermen, and some of them clumsy as elephants. And it almost invariably happens that when such are attacked by acute disease, death is the result. Contrast the condition of these animals with that of the Roxbury omnibus horses; the latter are equally well fed and cared for, yet they seldom accumulate fat; this is due to the laborious nature of their work, which requires quick respiratory and muscular movements, in 
the performance of which feats the carbon of the food is in ratio to the oxygen inspired. Now note the difference : should the latter be attacked with acute disease, it generally yields under proper medical treatment. This teaches us that if we want horses capable of enduring fatigue, under rapid muscular action, we must not allow the fat to accumulate, but the moment a horse increases in bulk or weight, - beyond what may be considered fair condition, - that moment the daily allowance of food must be diminished, or he must be compelled to work harder, and thus exhaust the superabundant carbon. It will be seen, therefore, that it is a matter of impossibility to lay down any dietary rules that shall meet the wants of all animals, for their wants are subject to considerable modification, and the quantity of food suitable for one animal might be too great or small for others. Age, sex, climate, constitution, condition of life, state of health, kind of work, etc., are the modifying circumstances.

Under a state of rest cattle are more prone to accumulate fat than horses. The working ox should never be allowed to acquire much fat, for he will not only be lazy like the "fat boy," but he will also feel uncomfortable, and actually suffer in hot weather. It has lately been discovered that almost all fat animals are subject to enlargement of the heart, and this enlargement is occasioned by the substitution of fat for muscle, and this leads not only to distortion of form, but the cavities of the heart contract, and thus circulation is defective. The. moment this occurs the animal is liable to become diseased, and like the horse, is liable when diseased to die suddenly. Therefore, I advise farmers, in view of guarding against sickness and death, to feed their animals lighter, and give them an occasional meal of straw, for considerable farinaceous aliment can be obtained from it.

"The attention of agriculturists in France has been recently directed to the discovery of a method of converting straw into a kind of bran. The discovery has been claimed by two individuals. The first is a miller, near Dijon, who, it is said, on trying the mill-stone of a new mill, discovered the possibility 
of converting straw into a nourishing food. The second, $\mathbf{M}$. Jos. Maitre, of Vilotte, near Chatillon.

"This distinguished agriculturist, known for the purity and perfection of his breeds of sheep, conceived the idea of converting into farina not only the straw of wheat and other grains, but of hay, trefoil, lucerne, sanfoin, etc. His efforts are said to have been perfectly successful, and his discovery arrived at, not by chance, but by long experiment and research. The aliment which he has produced is said to be a complete substitute for bran. It is given to sheep and lambs, who consume it with avidity, and may be given to all other graminivorous animals as a grateful and substantial food. We know in this country that the mere chopping of straw adds greatly to its powers by facilitating mastication and digestion. We may believe that a more perfect comminution of its parts will produce a corresponding effect, and extend very widely the uses of straw and other fodder as a means of feeding our domestic animals."

The climate or temperature of the surrounding atmosphere has a wonderful effect on the animal machine. Let two horses be located in different stables, one of which shall be like " Jack Straw's" house-neither wind-tight nor water-proof; the other is built on the air-tight principle, the occupant of the former will require more food than he of the latter, because cold air has a depressing influence on the body, exhausting superficial heat. Our readers are probably aware that if a hot brick be placed in contact with a cold one, the caloric radiated from the first, is absorbed by the latter, until a sort of equilibrium be established. The same is true as regards the body of a horse, he being in an atmosphere many degrees less than that of his own body, gives off the heat of the same to the surrounding medium. The heat thus given off, has to be replaced by food, which is the combustible material. But it often happens that the digestive organs are deranged - incapable of assimulating a sufficiency of carbonaceous material to maintain even the normal temperature of the body, The consequences are loss of flesh and health. On the other hand, a fat animal can endure the depressing influences of a cold atmosphere, because he 
has within the body a vast generator and non-conductor of heat in the form of adipose matter. It has been proved that the immediate cause of death in warm blooded animals, when food has been withheld, was their inability to keep up that temperature necessary for the integrity of vital operations. The animal located in an air-tight stable is, probably, surrounded by an atmosphere almost equal in temperature to that of his own body, and consequently he does not require so much food as the former. Hence, the amount of food necessary in the one case might be too much for another, and consequently operate injuriously.

A cold, bracing wind is said to "sharpen the appetite." The inhabitants of northern regions require more food than those of the southern. A horse, therefore, of weak, muscular organization, the subject of debility, requires a comfortable stable, and food that will develop muscles. Now it has been ascertained that horse-beans contain more of the nitro-albuminous principles, than any other article of diet. English horses are very partial to the same, and in such, the development of muscle is very remarkable; consequently, a fat horse requires less of the nitro-albuminous principle, and more of the aqueous in the form of carrots, potatoes, and beets.

It must never be forgotten that some horses will keep in fair working order on a moderate supply of aliment ; in such cases, we infer that the digestive organs, are in a state of activity, capable of extracting all the nutrient properties from the same. On the other hand, a horse performs less work than the former; consumes twice as much food: yet actually loses flesh. The digestive organs are then at fault. A horse however may lose flesh, become weak in his legs, etc., in consequence of the laborious nature of his employment. Therefore, any derangement occasioned in this way, prevents the food from being converted into healthy chyme, chyle, or blood, and thus the necessary deposit of new matter is prevented.

Most voracious feeders are dyspeptic, and such are almost never free from intestinal worms; their breath becomes fœtid; saliva thirk and tenacious; excrement slimy; and should the 
subjec: be fed on oats, the same would be found, after traversing the alimentary canal, unmasticated. The principal remedy for indigestion, is change in det : sometimes it may be proper to allow scalded oats, although cooking does not add to their nutritive quality, yet, more or less, completes the destruction of organization, and better prepares them for the action of weak solvents.

Changes in diet will sometimes work wonders in the restoration of a dyspeptic; yet he will require also, medicines, possessing stimulating, tonic, and antiseptic properties, such as gentian, ginger, and salt. In the following proportions :-

Powdered Gentian,..................................2 ounces.

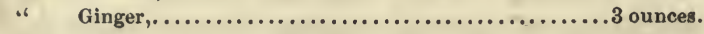

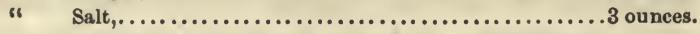

Mix. Divide the mass into eleven parts, and mix one with the food daily.

\section{AS REgARDS CHANGES IN DIET,}

I do not recommend sudden changes. For example: should an animal have been previously fed on corn, meal, or oats, I am not in favor of his being turned out to pasture to shift for himself, as the saying is, and depend entirely on grass for a living. Grass acts on animals unaccustomed to it as an aperient - scours them; and such is a debilitating process. Grass may improve the health of a fat, lazy, or humory animal - reduce flesh and purify his blood; but the emaciated one requires, in addition, a daily feed of oats or cracked corn, to make up for the deficiency of carbon in the former. For these and other reasons, that we might urge, the reader will perceive that changes in diet can only be made valuable in proportion to our knowledge of the wants of the animal economy.

A great proportion of our animals are too well fed, - obtain more food than they require. In this land of plenty, most of our valuable stock are overfed, and more especially does this happen among animals owned by wealthy and liberal individuals. The impression I wish to convey to the mind of the reader is, that the food of such is not proportioned to labor; 
in other words, there exists a disproportion between the amount of carbon taken in the form of food, and the oxygen received in the process of respiration. Now to illustrate this, we will suppose that a man engaged in mercantile pursuits owns one or more horses, he has not the time nor inclination to give the one or the other the necessary amount of exercise; they stand up to a full crib, from day to day, enjoying, or rather, gorging, themselves with a certain amount of fodder, over and above what they actually require, and much more than they really need; the surplus is often stored up in the form of fat, and this induces acute diseases, and they die of too much food and care. It is very rare that we have occasion to recommend a man to feed his horse more liberally; but almost always the reverse. Starvation is said to be the cause for many equine diseases, but so far as my experience goes, such cases are, in this country, very rare. We conceive the term starvation to be a libel upon cirilization; and so infrequent is its application among a nation of husbandmen, that it is omitted in our dictionaries. A man on a barren rock, or an animal in the deserts of Arabia, might probably starve, but the idea of the latter starving in the vicinity of a well-stocked barn, or stable, within striking distance of a land of plenty, seems to be a very absurd conclusion.

There are enough animals to be found dressed up in the garb of starvation; having tight skins, prominent ribs, and a cadaverous countenance, living, yet half dead. But they know nothing of the "Famine in Egypt;" they get enough, but too much of the same kind. They probably require a change in diet, or else they are confirmed dyspeptics, laboring under a chronic form of indigestion, and if such should be the case, quantity is objectionable, and good quality more desirable; the stomach, however, is not at fault, its function being deranged. Or they probably get enough, and perhaps too much for a weak stomach, hence loss of flesh, etc.

Some men are in the liabit of bleeding their animals every spring; this is done in view of reducing fat and flesh, the subjects being humory, plethoric; their systems abounding in 
highly carbonized blood; and this is proof positive that the same have been overfed. The racer, before he can perform a feat of speed, must be prepared, as the saying is ; this implies bleeding and physicing. Some works on farriery lay down regular rules for putting a horse in racing condition, and the remedies are fleam, physic, and bran, proof positive that such animals have had too bounteous a supply of nutriment.

Some horses, and the same is true of man, grow poor in consequence of having to carry about a juvenile restaurant, within their digestive organs, they probably become exhausted, or plethoric, as the case may be, in consequence of an over-burdened stomach. A stomach over-burdened, reacts on the nervous system, deranges the physiological condition of the subject, and lays the foundation for hypertrophy (which is an abnormal increase of fat or tissue), or the opposite, which condition is known as atrophy - a wasting of the same. But most frequently an over-burdened stomach induces diseases known as staggers, cerebral congestion, softening of brain, etc., etc.

Many persons are continually devising means to excite the appetite of their animals, in order to get as much food as possible into their stomachs; they seem to think that an error in this direction can never occur, and should the same refuse to consume the abundance placed before them, the liberal individual complains that his cow has a poor appetite, and does not eat "worth a cent." Now it were far better for both man and cow, if the former would only experiment in the opposite direction, and ascertain how small a quantity both may subsist, on. A small quantity of good food, well digested, answers the purpose of nutrition much better than a large quantity, imperfectly so. It is very interesting to contemplate how efficient a little food proves, for the promotion of health and longevity. For example, a little barley and coarse fodder, will suffice for the "Courser of the Desert." Shetland and Welch ponies will live and grow fat on the mere vestiges of vegetation. The best cow in the world, the property of J. H. Kelly, of Cleveland, Ohio, weighing 1,350 pounds is fed 
exclusively on hay and straw - very poor fodder some many exclaim, yet in the course of ten months the same creature yielded 4,921 quarts of milk; and during a single month, after calving, she gave 620 quarts, and the least she gave during the winter months was 562 quarts.

A pig will grow fat on small quantities of various kinds of food and still lose flesh when allowed to gorge himself with the same. Many swine in the vicinity of coal mines, consume both coal and charcoal, and little else, yet they grow fat.

Evidences can be furnished to show that both the superior and inferior orders of creation might subsist on a very small quantity of food without danger. Shipwrecked mariners have been known to subsist several weeks without food; and there is a man now residing in this State who during a period of 32 days never tasted food. The sleeping man of Rochester, is another example; and a case is recorded in one of our medical journals showing that an individual once lived for several months on nothing but pure water.

As regards cattle they form no exception to this peculiarity; we might introduce evidence convincing and positive of their ability to endure the privations of hunger, and at the same time show that they suffer very little from its effects. A single case will serve to illustrate this. I once treated a case of tetanas, lock-jaw. The subject never tasted food during a period of 16 days; on the seventeeth, the masseters relaxed and the faculty of swallowing returned. At this period we might suppose him to be "hungry as a bear," yet on offering him a few oats, he did not appear to be very ravenous, and partook of food subsequently offered him as if nothing had happened.

These are extreme cases, yet they go to show that there is no cause for alarm because an animal happens to be "off his feed," once in a while. Such condition may ultimately prove salutary, affording the stomach and its associate organs, time to rest from their lierculean labors.

The fact that most of our adult animals, get more food than they need, las been demonstrated by analysis of their excrement; which has been found to contain a large amount of 
nutritious material, over and above what the animals actually need.

We can develop the gormandizing powers of very many creatures by placing before them, from day to day, more than they require, their appetites, like some of ours, are not proof against temptation, and the digestive organs may be trained to dispose of twice the quantity of food, actually needed, and the habit at first acquired, becomes permanent, and the creature is known as a voracious feeder - a glutton. Hence, through indiscretions of this character, we can augment both function and capacity of stomach. I remember examining the stomach of a horse, the property of a baker, who was in the habit of feeding the former on brown bread. The animal died of chronic indigestion, and his stomach exceeded in capacity that of two ordinary horses.

Great care, therefore, is requisite in regard to the proper feeding of all animals, for in their domesticated state, they have lost those natural instincts which serve to inform the untamed animal of the necessary amount of food which his system needs, and they are in the condition of a thoughtless child that will eat all day, and on retiring to bed will crave and cry for more.

My readers have probably heard of the gormadizing propensities of natives in the arctic regions; some of them think nothing of bolting down 20 pounds of meat and oil per day, and making a good supper on tallow candles. A case is related, by Captain Cochrane, of a Russian who eat, in the course of twenty-four hours, the hindquarter of an ox, twenty pounds of fat and diank a quantity of melted butter. He also states that he has seen three gluttons consuine a deer at one meal. But we need not go beyond our immediate vicinity to prove that the gormandizing powers of both men and horses are equally extraordinary. 'The corn dealer's bill furnishes one illustration; and the lengthened meal which some of our young men indulge in, commencing in the morning and only ending at night, completes the evidence.

Hence with these facts before us, we may safely conclude: that errors in diet are constantly occurring, and consequently, 
a great many unnecessary diseases arise in consequence; therefore I recommend the reader to make an experiment in the opposite direction, and ascertain how small a quantity of good food will answer the purpose of nutrition.

Should the quantity be insufficient for the animal's wants, we shall soon be made aware of the fact, by loss of flesh and other unmistakable signs. On the other hand, the error alluded to is not so easily corrected, for the animal may die overburdened with fat, of an acute disease, before we can reduce his system.

\section{ON THE PRINCIPLES OF BREEDING.}

Ir is a law of nature that peculiarities of form, size, color, etc., shall be transmitted by parents to offspring - "like begets like," - although under certain circumstances a modification of this law is to be expected. If, for example, we liberate an animal from domestication and its influences which are known to operate very markedly on animal organizations and habits, the creature thus liberated loses its acquirements, and in successive generations gradually returns to the original type; this is a modification of the above law, and supposing our pecuniary interests are the object of the experiment, it will be an improvement in the wrong direction.

On the other hand, take a wild animal; bring him under the influences of domestication, and he gradually loses all his distinctive characteristics of size, form and instinct, and in popular language becomes a new creature; improved or not, as the case may be; under the direction of his lord and master. So that the inferior orders of creation, are really the creatures of circumstances, - these changes are the result of man's experience, or non-experience. These are general propositions which "precede beauty and symmetry."

Beauty and Symmetry. - If we examine into the methods pursued by some of the most successful raisers of live stock, 
we shall see that they paid particular attention to the selection of "well-formed, beautiful animals." 'They very naturally supposed that external conformation was transmissible: that if they happened to obtain a good calf or foal, from inferior, diseased, or mal-formed parents, it was purely accidental and out of the ordinary course of nature. In selecting beautiful animals they naturally excluded those of narrow chest; which peculiarity is indicative of predisposition to pulmonary affections, and founder (the latter term signifying a worthless or ruined condition, which in the eye of the law renders them actually unsound), because they have that about them which may impair their future usefulness; hence for more reasons than one, such are unfit for breeding purposes, unless, however, the morbid phenomena be neutralized by blood, in one of the parents, of a superior order; free from taint as it appears in the other.

In my adventures in search of the beautiful, I should pass by all animals having any peculiarity of conformation, general or local, which experience teaches me are sure to re-appear, either directly or indirectly, in future progeny. This appears to be the proper course to pursue; yet many, otherwise intelligent men, will invest their money in the purchase of defective animals, merely because they can be bought cheap, when every body knows, or ought to know, that cheap cows, like cheap watches, cost more in the end for repairs, etc., than a commodity of more real value.

The same rule applies to horses; some men if they happen to be in possession of a broken-down mare, unable from faults, defects, old age, and disease, to perform ordinary horse duties, they commence a speculation in a different enterprise; the reproductive organs must be exercised; just at this time some shrewd cent-and-dollar-calculating jockey, advertises and exhibits a well-fed, prancing steed, bearing a popular name; but his whole carcase is redolent of faults and defects, which the owner is not expected to know any thing about, and if he does it is not for his interest to point them out; the price of copula- . tion is dirt cheap, and the foolish speculator expects to obtain a 
smart colt, that will, eventually, command a high price. But alas for sucl milk-and-water calculations! The expected specimen of equine animality, inlerits and exhibits its parental infirmities and deformities, and ultimately becomes a living monument of the folly of its owner.

There is no beauty in the faults and defects which must necessarily occur through the sexual congress of faulty and defective animals; neither can there be grace in the motions of an overfed or ill-conditioned animal; beauty, symmetry, grace and soundness, are defunct in the ill-conditioned creature, $\mathrm{ol}^{\circ}$ otherwise defective one - a mere apology for the handiwork of nature. The muscular system of a horse, or cow, may in some regions of the body be well developed; but should their limbs be unnaturally curved, or any part of their system be out of proportion to the other parts of the body, then beauty has never seated itself on their thrones; yet we can improve the appearance of such animals by artificial means and costly adornments; this artificial kind of beauty is what most men seek after, and at a high price to their sorrow obtain it; whereas, the real beauty of form and endowments which practical husbandmen really require, must originate unartificially, in the living citadel; must be the work of nature and not of art.

It is a fact well known to many men, that animals of faultless form - having symmetrical proportions, are exempt from many diseases which are the heritage of faulty and inferior animals, and insurance companies take advantage of this knowledge and insure the former at less rates than the latter. As an illustration of the above, I may be permitted to remark that the "Arabian Courser," English "blood horse," American "Black Hawk," and pure "Devon" cow, - all remarkable for good points, beauty and endurance, - are exempt from many of the common and unnecessary diseases and abortions. Beauty and symmetrical proportions contribute to health; because there is a certain degree of relationship between external and internal organs and functions. For example, a finc exierior, good depth of chest, well-proportioned muscles and grace$13 *$ 
ful limbs are generally co-existent with good "wind anc bottom;" and the subjects of course possess active respiratory organs, a finely balanced circulation, and a digestive apparatus that can digest every article in the shape of fodder. In selecting the beautiful, we therefore obtain material for perpetuating health, long life, and valuable offspring.

One of Blakewell's great secrets was "breed from the beautiful." I allude to him because he was the most successful "breeder" that England ever boasted of. At the onset he paid great attention to "beauty of form ;" having developed a fine exterior, he engrafted on it the useful. He was well aware that beauty and utility were not always combined, but being in possession of the former, he could produce the latter to "order;" and he accomplished his object in the following manner. He required cows that would yield a large quantity of milk; consequently he selected those whose dams had long been celebrated for their excellent milking qualities, and from among such he chose the very best female of the family, and united her with a beautiful male. Having, in the production of offspring through the above union, accomplished his object, he then paid less attention to beauty, and more to the milking qualities, so as to render the latter permanent in the breed; still, in all his experiments le rejected uncouth, unthrifty, and defective animals.

I am aware, however, that the evils of domestication are operative, to a certain extent, on all animals. Still I contend that the "well bred" animal can resist the insidious encroachments of disease, and survive longer under its depressing influence than "ill" favored creatures. Illustrations are not wanting to prove the correctness of Blakewell's theory, therefore, I advise the reader to follow the example of one who has been styled the "Napoleon of breeders."

\section{IN-AND-IN BREEDING,}

We now inquire, What is breeding in-and-in? I answer, it implies consanguinity; breeding from animals of the same blood, or propagating in a close degree of relationship. 
Some persons have an idea that this system is pernicious, and leads to degeneracy and premature decay. But that is a matter of argument, and does, as I shall attempt to prove, depend on the skill of the "breeder," and his ability to make wise selections. The human race - the sons and daughters of "Adam and Eve," - afford a stupendous illustration of the practicability of "in-and-in breeding." The millions terrestrial, all originated (so the good book informs us) from our "common" parents, and consequently we are all "blood" relations. And this fact goes to show that in-and-in breeding is in accordance with the laws of physiology, and does not conflict with the intentions of "Him who doeth all things well." It is a part of the great scheme of creation - a physiological law - the problem of life, to solve which God has endowed us with reason, "God-like reason," the exercise of which puts us in possession of the fruit of the "tree of knowledge;" the nonexercise of the same furnishes us with forbidden fruit.

Ill-assorted marriages - "consumption mating with consumption," and scrofula with scrofula, seeks at the "altar" an introduction to an early grave. The same is true of animals; bad selections thwart the intentions of the Creator, mar his handiwork, and, if a friendly epizoötic sweeps them from the face of the earth, it is more of a blessing than a curse.

From the great human family I select a "branch" (to illustrate this principle), and I choose to refer to the Jews; so long as they are so in faith and practice - marrying their own kindred - they are a living illustration of the alove principle. Have they degenerated? No. The distinctive characteristics of the race are just as remarkable as they ever were; the vicious and defective find an early grave, but the "race" remains pure.

Now as regards horses and cows, the same is true; they all had a common origin. The different varieties that now exist are the work of time, circumstances, and the art of man. The famous horses mentioned by Mahomet in the "Koran," resulted from in-and-in breeding; they have existed and multiplied for three thousand years without the slightest intermixture of 
foreign blood, and from the time of Solomon up to the present day their pedigree has been watched and chronicled with great care, so that no doubt exists as regards their consanguinity. Their fine form, splendid action, endurance, spirit, speed, and docility, can only be retained by preserving the race pure, and this is an argument in favor of in-and-in breeding.

No breed can be preserved pure unless the in-and-in system be pursued. Take the Suffolk pig, for example; so long as we put "Suffolk to Suffolk" we get "pure" Suffolk; and if proper selections have been made, "good Suffolks" are the result; hut deviate from direct lineage, and the breed degenerates, for better or worse, as the case may be, and they lose their permanency of type, and cease to become pure bloods:-

"From the brave descend the brave."

The Suffolks in this country are notorious for a cutaneous disease simulating scrofula; and many suppose that this arises in consequence of the in-and-in system of breeding; this I think is an error. It results from the evils of domestication, and ohr want of knowledge in making proper selections. There often is one or more animals in a litter, incapacitated by fault, defect, or debility, to perpetuate the stamina and remarkable points of the breed; these are to be rejected. If we fail to do so, the next generation, or the next to that, furnish more convineing proof of error, which I contend exists in making " bad" selections, and not in the above system.

Turn for a moment to the history of the French Merino, and we shall find that Victor Gilbert - a name familiar to America's most successful sheep raisers - practised no other than the in-and-in system of breeding. A lot of Merinos were sent in 1786, by the Queen of Spain to the King of France; the latter, in order to benefit the agricultural community, sent half of them to Rambouillet, and the other halt to Croissy. The climate happened to suit them, and they were considered superior to the existing breeds in France. In the year 1800, Victor Gilbert bought at Croissy a four-year-old ram and eight ewes. He bred from those animals during a 
period of ten years; occasionally, however, "renewing the stock," as he termed it, by purchasing annually from two to four sheep. In 1821 he purchased some of the Rambouillet stock, and asserts that "from a union of the same he obtained great advantages." Now the reader will perceive that here was an alliance of blood; the two flocks were of the same lineal descent, belonged to the same "family," and of course the system of breeding was on the in-and-in principle.

Now as regards French Merinos obtained from the above source, and imported into this country, we have only to refer the reader to "Taintor, of Hartford, DeForrest, of New York, Sanford, of Vermont, Parker and Howard, of Ohio," and many others, who are ready and willing, we presume, to testify as regards the prosperity of the above breed in this country, the result of in-and-in breeding. S. W. Jewett, of Vermont, has purchased, up to the present time, over three hundred bucks and ewes; the offspring of the Croissy and Rambouillet breed, and this is proof positive of the correctness of our theory. Now as regards the advantages of in-and-in breeding, what are they?

When Victor Gilbert purchased the first ram, he carried but 9 pounds of wool; he finally realized 24 pounds from the rams, and from the ewes 18 pounds; a tangible illustration of the advantages. A very fine French Merino, originating from the above source, was very recently exhibited at a sheep-shearing in Wisconsin; the animal weighed 325 pounds, and carried 40 pounds of wool. Now the originals, as I have already shown, carried but " nine pounds ;" so that the standard, as regards a particular quality, has been raised, and that is what we understand by "improvement."

Mr. V. Barford of England has demonstrated the propriety of in-and-in breeding; he is a man, however, of superior judgment, and he culls and casts out, from his flocks and herds, all animals showing the least predisposition to any defect. $\mathbf{\Lambda}$ writer in the Mark Lane Express, considers Mr. Valentine Barford " one of the most successful in-and-in breeders of sheep in the kingdom; for he has bred from the pure Blakewell blood 
for sixty-five years, without the aid of any other sort or kind, and bred from his own flock for upwards of fifty years, maintaining size, weight, and constitution."

"I have known [continues the writer] Mr. Barford's flock for upwards of half a century, and they appear as strong in their stamina as when I first saw them.

"Mr. B. does not use a ram unless he has a wide loin, a large breast and collar, and very wide between the fore legs: all of which points denote $a^{\star}$ hale constitution. Although inand-in breeding has beat thousands to a stand, Mr. Barford still shines in it."

Therefore I contend that great advantages are derived from preserving the breed pure and in making proper selections. I have been very much pleased in perusing some remarks made by Sanford Howard, at the State House last winter, and published in the New England Farmer, and as they happen to have a direct bearing on our subject, I shall re-present them to the reader. "What is breeding in-and-in? While some apply the term only to animals distantly related, he conceived the only true idea of the matter to be, that it applied to creatures of the same blood. The consequences of breeding in-and-in, he believed might be either good or bad, and depended wholly on the skill of the breeder. As proof that breeding in-and-in was not contrary to nature, he referred to birds, the buffalo, etc., in a wild state. It is known that they breed in-and-in constantly, and yet no deterioration takes place. He had known geese to be propagated in this way for forty years, and not the slightest depreciation in size, quality or feather was visible in them. Still cases could be cited where breeding in-and-in had produced bad results; yet these might be attributed to imperfections in the parent stock. It is only necessary to select perfect specimens."

Having now attempted to show that in-and-in breeding is in accordance with the law of nature, and that the birth of inferior and defective animals, under this rule, resulted from the breeder's ignorance or neglect, in making proper selections. I shall next introduce some remarks of a general character. 


\section{THE OBJECTS OF IN-AND-IN BREEDING.}

Permanent Varieties. - In-and-in breeding should be practiced in view of some specific object ; viz., perpetuating species, capable of constantly and permanently transmitting characteristic peculiarities; such as may be observed in any particular, permanent, variety; as an illustration of the same, we offer the French Merino sheep; Black Hawk horse and Devon bull. These are permanent varieties; the type of each having been established by a long course of in-and-in breeding.

We are told, however, that many of the imported French Merinos (so called), have produced offspring scarcely worth the trouble of raising - far inferior to our common vative stock. The principal reason is, many sub-races of merinos existing in France, and elsewhere, are the result of cross-breeding; they are nothing else than mongrels; destitute of that permanency of type indicative of pure blood. But there are other causes for the deterioration complained of which will be noticed hereafter. By preserving the race pure, through a certain period, we thus obtain the requisite permanency of type, which can then be transmitted indefinitely.

Let us see, now, if we understand what is meant by a permanent variety, and inquire if such do really transmit their permanent peculiarities. A permanent variety (Black Hawk breed, or Devon cow, for example), are animals whose peculiarities were not coeval with the tribe, but have arisen, or been engrafted on the same, subsequent to the advent of their existence; and therefore what some may term distinct species, are in reality, nothing more than permanent varieties. The Shetland poney, therefore, is a permanent variety; circumstances have made him just what he is. He being an inhabitant of a stormy, tempestuous region, comparatively destitute of shelter and artificial food, is left, in many instances, like the cattle of Norway (whose diminutive size is notorious), to seek such food as the country affords; and owing to their being secluded from other horses, frequent intercourse among them- 
selves have rendered their small and peculiar forms permanent in the race; and with unerring precision, "like begets like."

The permanent varieties that now exist among the cattle of the British Isles, is due to local circumstances and the art of man ; most of the fine breeds now owned by English husbandmen, are named after the location in which they are said to originate; these are permanent varieties, yet the most of them, in fact all except importations, are descendants of the "Wild, or White, Forest breed." Hence the Highland breed, dispersed over the mountains of North Britain; the Alderney, of the Norman Isles; and the Devon from the Bristol Channel, etc., etc., are all permanent varieties, originally of the White Forest breed.

Yorkshire is celebrated for the production of a permanent variety of horses know as "Clevelands;" they are an ancient and unmixed race; their bodies have peculiar markings, and if a foal should be born without them the owner would give orders for its immediate destruction. I presume it is now understood what is meant by permanent variety.

ANIMALS BECOME PARENTS TOO EARLY.

Victor Gilbert never allowed ewes to have lambs until they had passed their third year; and the bucks were never used until they had arrived at full maturity. IIe, as well as many other sagacious stock raisers, that I might name, are probably conversant with the fact, that during the period of growth and development, up to maturity, the reproductive organs are dormant, while at the same time the nutritive function was wholly engaged in elaborating chyle and blood for the development of bone, muscle, and nerve; and that by calling into requisition the reproductive or generative organs, before the animal had attained full growth, must necessarily divert the elements .of matter intended for nutrition, from their legitimate channel and direct them to the reproductive organs. This is precisely what takes place. A too early use of the purely animal functions induces weakness and stunted growth.

The author remembers that in his schoolboy days, it was 
customary so soon as a boy had accumulated a few pence, to invest the same in a rabbit (a favorite animal at that period), consequently we had a community of juvenile rabbit raisers, and from the results of past experience, as observed by the older boys, a rule was adopted among us that the doe should not be put to the buck until she had attained full maturity. The reason assigned for this rule was, "Early breeding prevented the doe from growing;" the facts were evident, still we knew not the why, nor wherefore, but acted on the spur of experience. Physiologists have assigned the above as the true cause, and have in their writings pointed out the woeful results which often follow a too early use of the purely animal functions and organs. I seriously urge farmers to give this subject that attention which it evidently demands; by so doing they will prevent many of the unnecessary abortions which are almost constantly occurring.

Among the higher orders of creation the same law holds good ; in fact, there can be no deviation from it without incurring the hazard of paying the penalty.

Heifers should never be put to the bull until they have attained the age of three or four years; at this period they are in their prime. If they happen to have acquired too much fat, their daily allowance must be reduced.

Human growth, according to the best authority ceases between the ages of twenty and twenty-five; in very warm regions, however, where development and decay are universally allowed to be more rapid, the inhabitants come to maturity much earlier. A superior class of human beings can only be produced by selections and exclusions similar to those so successfully employed in rearing the inferior orders; we may rejoice in a Fulton, Franklin, or Webster, occasionally (by mere accident), the parents of such being absolutely ignorant of the first principles of physiology. But in the breeder's language, such are in possession of the "prerequisites." In the first place, they had not entered the marriage relationship prior to the age of reason; the parents, if we mistake not, were full grown men and women - not boys nor girls; they possibly possessed a sound mind, and healthy constitution, free from 14 
hereditary defect of mind and body which, stunted growth, aided by artificial modes of life, are almost sure to entail. Until within a few years, a wise and salutary law was in operation in the British Isles, which interdicted marriage until the candidates had arrived at the age of twenty-one; that law has been set aside, and consequently the mass of the population of the present day will not bear comparison with that of the past.

One safeguard, therefore, against stunted growth and illhealth is to avoid a too early use of the reproductive function. And herein we are not safe, unless proper selections have been made, and faulty animals or persons rejected.

I am persuaded that if husbandmen of these United States could all view this important matter in its right light, a very decided improvement would soon be the result; the subject will, however, eventually command the attention of all.

Many persons urge that the offspring of blood relatives are weak, nervous, deficient in intellect, complete idiots, etc., etc.; and that further intercourse in the same direction only makes bad worse; these are facts which cannot be controverted, yet the weakness, nervousness, etc., does not occur from the relationship which exists between the parties, but is the result of their defective constitutions. Many of the " cousin " marriages are entered into without the least regard to the rational theory of selection and rejection; the question is one of interest not of utility. These blood connections are consummated merely to retain property in families, and to satisfy the caprices of doating parents, superannuated uncles, and disappointed maiden aunts; and thus many an idiotic, or emaciated sprig of aristocracy, unites his destinies with a fashionable cousin the very counterpart of himself, both inheriting family defects of precisely similar character. Should they be blessed (cursed rather) with offspring, may we not expect a miniature of the originals? "Without due attention to avoiding disease, it" will increase in the progeny."

Among the human species, therefore, where the objects are of such immense importance to present and future generations, the principles of selection and rejection are entirely overlooked; 
we pay more attention to the principles of breeding in eattle than we do to those applicable also to their lord and master. Hence the faults and defects alluded to, are not the result of close affinities, but result from our indifference, or ignorance, of the laws of life.

\section{OBJECTIONS TO IN-AND-IN BREEDING ANSWERED.}

The two preceding paragraphs are brief answers to the objections against the sexual congress of blood-relations; yet as other evidence than my own, and of a more general character may be demanded by the reader, I have thought it best to introduce other testimony. The following quotations are from the pen of P. S. Humbrickson, of Ohio, published as a "prize essay:"

"Many object to what has been termed in-and-in breeding. Indeed, with most of those who do so, their objections assume the form of a very strong prejudice. This is attributable to a certain confusion in their minds, by which reasons, wherein there is no proper connection, are made with the aid of imagination to assume a form of mutual dependence and coherence in support of their theory. In the human family, marriages within the Levitical degree, or, as they are also called, incestuous marriages, are forbidden. But the prohibition rests exclusively upon moral, and not at all upon natural or physical reasons. Yet the direct physical calamities are imagined to pursue the infringement of that law. Now, it would seem, that where the moral reasons in favor of an enactment are sufficient not only to justify, but to demand it, no more should be required. And this is in accordance with the soundest rules of philosophizing. Moreover, if no such moral reason existed, the authority of the Lawgiver, in the case of the divine law, is a sufficient foundation and warrant for it ; and the human law is bound by, and but follows, the divine. Shall we then take the step beyond, and apply to the inferior animal the rule that. was intended for rational, accountable man? We know that, if left to his own observation and experience, and being himself the judge, the 
objector must avouch the fact that, in the state of nature, there. is no restraint, and that such connections are and must be continnally taking placc."

\section{THE ADVANTAGES OF IN-AND-IN BREEDING.}

"And, if there are advantages arising from the having placed in the line of the direct ancestry, near and remote, of our Hocks, a great number of approved individuals, both male and female, as has been seen, it follows that there must be far greater advantages arising from the having the same one individual - if he be of marked superiority - placed in that line the greatest possible number of times. "This is done by "in-and-in breeding," and is the object of it. Now it is easier to find this one unsurpassed individual than to find many ; for, in the many, there will most certainly be one to be preferred to all the rest. Then, under the operation or the principle of atavism, the chances that the resemblance of such unequalled ancestor will be obtained, must be in the ratio of the number of times that he occurs in the ascending lines. Hence, greater uniformity and greater excellence in all the progeny. An apt illustration of this is found in the frequent occurrence of the Godolphin Arabian, in the pedigrees of all our best blonded horses carried back to him as their founder."

\section{PARTURITION.}

\section{SIGNS OF LABOR OR PARTURITION.}

Ar the end of 270 days from the period of a cow's impregnation, some enlargement of the udder will be perceived, and the labii pudendi (external parts of the genital organs), are relaxed, and appear tumefied, and a sort of glistening discharge issues from the same. The animal is also restless, and appears desirous of avoiding the society of other cows ; her respirations are somewhat quickened; she becomes nervous and irritable, and labor pains set in, occurring at stated periods, until at last 
the neck of the uterus dilates, the foetal membranes present themselves in the form of a watery tumor, and the parts admit of the delivery of the foetus.

\section{NATURAL LABOR.}

Natural labor consists of the presentation of the placental membranes, enclosed fluid, with the head and two fore feet of the fotus. In the act of natural expulsion the membranes become ruptured, and the liquor amnii (water) escapes. This lubricates the parts, and greatly facilitates the birth of the fœtus. After delivery a few after pains occur, by which means the placenta or after-birth is expelled; this completes the painful routine of natural labor.

\section{UNNATURAL LABOR.}

A cow failing to give birth after the fashion described in the preceding article, and being in a state of parturition, having regular uterine pains, increasing in severity as they successively occur, yet no appearance of the fotus, is probably the subject of false presentation. The character of this presentation must be ascertained, and our efforts then directed to the replacement of the part to its natural position.

The person who intends to render assistance to the parturient cow, should be clad in suitable garments; his arms must be bared to the shoulders, and in view of guarding against the absorption of morbid virus, the person's arms should be lubricated with glycerine or olive oil.

The instruments required are : embryotomy knife, embryot:my hooks, and slip-nooses. (See cut of instruments).

\section{FORE LEGS PRESENTING.}

The most common false presentation is that when the two fore legs are advanced into the vagina, sometimes beyond it, and the head turned upon the fœetal body. This is occasioned by the muzzle having caught at the brim of the pelvis. The delivery cannot be effected until the position is changed, with- 
out danger to the mother, and certain destruction to the calf. The best plan is to attach a cord, or the slip-nooses, to each fore leg, which are then to be forced back into the uterus; the head must then be sought for and constant pressure exerted on the same until it is sent forward far enough to enable the operator to release it from the brim of the pelvis, and guide it into the vaginal outlet; a noose may then be slipped over the lower jaw, then traction on it, and those of the fore legs will accomplish the delivery.

If the calf is dead I should use the embryotomy hook in preference to the noose, but in view of saving the calf the latter is the safest; some care, however, is necessary in drawing out the fore feet, lest the points of the hoofs lacerate the vagina.

While the assistants are drawing steadily on the cords, the operator should give them a lateral action, from side to side, and upwards and downwards; this is far better than pulling persistently in one direction, for it tends to loosen and alter the position of impacted parts.

\section{ONE FORE LEG PRESENTING.}

This is also a common occurrence, and if seen early, the delivery may be safely effected by attaching the noose to the protruded leg, this is to be pushed back, the other sought for and secured in the same manner, and again to be returned; the head must then be properly placed, the legs drawn outwards, and the delivery may be accomplished with every prospect of bringing forth a live calf.

\section{HEAD PRESENTING WITHOUT THE LEGS.}

In a case of this character, it is evident that the legs are doubled up within the vagina and uterus; and unless attended to early, the calf will be dead; therefore, in order to save time and trouble, I should decapitate the calf, which is done as follows: Make a circular incision around the neck through the integuments, then cut down in a region between the first and second cervical vertabrx and sever the capsular ligaments 
and spinal marrow; a person not expert in these matters will probably succeed better in detaching the head at this point than at the base of the cranium. Before the neck is returned, the embryotomy hooks should be inserted into it, and the blades secured by tying the cord which passes through them. Having pushed back the neck, I run my hand along one limb at a time, and find the hoofs, these are brought forward and noosed; traction now being made on the three cords, the delivery is secured.

Supposing the calf to be alive, I proceed as follows: A noose is affixed to the lower jaw, the head is then pushed back as far as it can be got; the fore legs are then to be brought into position as above described, after which, the calf is readily brought away; some difficulty may be experienced in extracting the hind parts; if they require much force in extraction, the probabilities are that the pelvis of the foetus is impacted in that of the cow; the long diameter of the pelvis is crosswise of the body, so that if the calf be in a position that opposes its long pelvic diameter to the short one of the mother, it must be pushed back a few inches, and turned, so that its feet shall be downwards, in a line with the cow's limbs.

It is very important that the calf should be in the right position as regards the diameter of the pelvis, for many valuable cows are ruined by the violent means used in the extraction of the hind parts when in a faulty position; $\dot{x}$ little tact in securing a right position for the exit of the calf, would save a vast amount of unnecessary and cruel traction, which in our rural districts, where veterinary surgeons are not to be found, is too often employed.

\section{EXTRACTION OF A CAIJ ON ITS BACK, HIND LEGS PRESENTING.}

Some persons have an idea that when a wrong presentation of this kind takes place, the calf may be turned; this is an impossibility, and it is only a waste of time, and a feat of ignorance to even attempt it. The calf must be extracted in the manner of presentation; the traction, however, should be made 
in a direction towards the bones of the coccygis, or tail. In the early stages of this kind of parturition, the back rests on the belly of the mother, and the feet come in contact with her spine; if my services were sought at this early period, I should endeavor to bring the feet down, one at a time, and noose them, and proceed to deliver without making any futile attempts to change the position of the calf.

In a case of this character which occurred in my practice a short time ago, I found it impossible (the cow being down) to dislodge the feet from the spinal region; I therefore procured a double and single block tackle, and fastened it to a beam which ran across the barn; the hind extremities were then attached to the single block by means of straps, and in this way, the posterior parts were elevated; the consequence was, that the whole fotal aparatus receded into the abdominal cavity, the feet were dislodged from the spine, and I had the satisfaction of delivering the animal of a live calf.

The following case is related by Surgeon Cartwright, in the Veterinarian:

"On the 30th of April, 1850, Mr._- came for me to see a cow, four years old, that could not calve. As in a former instance, another celebrated man at such work had been in attendance on her, but from the state of the os uteri, he was fairly frightened from making an attempt to remove it; as, he said, 'an operation' must be performed on it. I found her well off at the hips, and about the vulva, well relaxed. On introducing my hand into the vagina, I ascertained that the os uteri was dilated to about five inches in diameter, in an apparent rigid state. On passing my hand through the os uteri, I found that the calf lay on its back. The hind feet could be felt, but they were doubled up at the fetlocks, and pressed against the rectum and inside of the upper portion of the os uteri. In consequence of the calf lying on its back, and its feet being doubled up, the latter was not forced into the os uteri ; from which cause the os uteri could not be dilated for the cow to calve. I immediately got one of the legs straight, and brought it forward into the vagina and passed a cord around it, 
and then served the other the same; afterwards we used gradual traction to the feet until the os uteri was fully dilated, and in the course of an hour, we removed a live calf, which, together with the cow, did well. I fear such cases as these may induce persons to divide the os uteri, thinking it in a scirrhous state.

"In a fortnight after, this person had an exactly similiar case; but from using gross force, they burst open the pelvis somewhere, and the consequence was, the cow was obliged to be destroyed."

\section{BREECH PRESENTATION.}

A presentation of this kind is generally attended with difficulty and danger, the difficulties depend however, somewhat on the length of time which has elapsed since the commencment of the labor; if it be recent, there is some hope for both mother and calf, but in a protracted case there is little hope for the mother, and one reason is, the vagina or uterus is often injured or ruptured by the struggles of the fotus in trying to free itself from its uncomfortable position. Then again, the uterus has contracted upon the fotus so as almost to imprison it, at least forcing and impacting it within the cavity of the pelvis, so that the little animal is almost immovable. Let a person unacquainted with bovine midwifery introduce his hand and arm in a case of this character, and he will be astonished at the amount of force it will require to thread his hand between the fotus and pelvis, and after accomplishing his object, the hand and arm become so benumbed, by the pressure, that he cannot accomplish much if any thing until he can succeed in forcing the fotus forward; which in some cases, when uterine action is strong, cannot be effected without elevating the posterior parts of the cow by means a hoisting tackle, It requires a person with a long arm to be of much service in a case of this kind, for the limbs are extended a long distance into the abdomen. A breach presentation is very readily detected by the presence of the calf's tail which occasionally hangs out of the vagina. 
The mode of extracting the foctus when the breach presents is as follows: Pressure must be made upon the buttocks of calf in the interim of labor pains; having succeeded in pushing the calf forwards the hocks may possibly be reached, afterwards the feet; these are to be brought into the vaginal passage ; then by traction, and altering the position of the calf if necessary, the delivery is completed.

Should it be found impossible to push the fotus forwards, I should lose no time in raising the hind quarters of the cow by means of hoisting apparatus which most farmers have on hand. In order to avoid hurting or injuring the cow's limbs, when hoisting the hind parts from the ground, I encircle the legs just above the fetlock, with some old gunny bag or something of the sort, then affix a strap to each leg into which the tackle must be hooked; the cow is, of course, raised from the floor belly upwards.

CLEANSING, OR REMOVAL OF THE AFTER-BIRTH.

After the delivery, the after-birth should be detached, if possible, for if it be allowed to occupy the uterus, the latter contracts upon it, and there it may remain for a week or more, and at last come away a mass of putridity, not however, before the cow has suffered some derangement of health.

So soon as the calf is born I introduce may liand, and pull in various directions on the umbilical cord, failing to bring the placenta away, I introduce my whole arm and carefully detach the now foreign body, from the cotyledons of the uterus. The uterus shortly afterwards contracts, and thus effectually prevents uterine hemorrhage.

It has been my universal custom of late to remove the placenta immediately after the birth of the calf, and I do so because I consider it unwise to allow it to remain, for the labor is not then completed. No practitioner of midwifery in human medicine would ever deem it proper to leave his patient until the "after-birth" was removed, for it would most undoubtedly endanger the mother's life if it were left to rot away, as is too often the case with the poon, uncomplaining cow. 
In the removal of the placenta, I am careful not to pull too hard on the umbilical cord, lest inversion of the uterus ensue; a little tact and patience, will often acomplish wonders. The placenta may be detached from the cotyledons and yet it cannot be drawn away, the probability is that some irregular contraction of the uterus retains it, now we must exercise a little patience, and then intwoduce the arm and feel for the seat of contraction, this can probably be dilated by the fingers, then the placenta can easily be removed.

In cases of protractell labor, when the cow is much exhausted, the placenta may remain in the uncontracted uterus for want of muscular power in the same to expel it. In such a case I should give the cow about a quart of ginger tea and if any tympany of the intestines exist, I should add a small quantity of carbonate of soda.

The absurd practice of attaching a weight to the membranes or rolling them on a stick as heretofore recommended, is not in accordance with my views of an enlightened system of practice. To say the least, it is unscientific, and presents an unsightly appearance; the odor which arises from the putrid mass in the course of a few days is enough to sicken a dog, and no doubt it does sicken pregnant cows, and may induce abortion. The membranes must be removed.

The abominable practice of allowing the cow to devour the after-birth is much to be deplored. I know the custom has the sanction of long usage, but that in my opinion, is no argument in its favor, the cow is not a cannibal nor a carniverous animal, yet for the sake of getting rid of an unsightly and filthy mass of carrion which ought to have been removed from her sight, she is tempted, and finally, does devour it; she may however, sometimes be led to devour the placenta and fœtal membranes through the promptings of a morbid appetite. The best and safest way to dispose of the after-birth is to burn it, for the odor arising from it under the process of decomposition, has a bad effect on pregnant cows of a highly imaginative and nervous temperament, and the odoriferous morbid germ is more active in warm than cold weather. 


\section{BACK OF THE CALF PRESENTING AT THE BRIM OF THE PELVIS.}

This unfortunate presentation is one of rare occurrence, $I$ never saw but one case, and that I now propose to introduce for the instruction of my readers. I was called a short time ago to visit a cow the property of Mr. R., of Winchester; the animal had been in labor, with strong parturient pains, for twelve hours, in the mean time several persons had tried their skill on the poor brute without doing the least good. At the time of my visit, she was in a deplorable condition, her ears, horns, and extremities, were icy cold; she was delirious, throwing her head about in a reckless manner, as if in convulsions; the vaginal lips were very much tumefied, their lining membrane highly inflamed.

I immediately gave her a goōd drench of stimulating medicine, which appeared to have a good effect in restoring warmth on the external surface, and in the extremities. On making an examination I discovered that the back or spinal column of the foctus, was firmly impacted within the brim of the pelvis, consequently every uterine effort to expel the same was only making matters worse. I employed all the usual means to cliange the position of the calf to no purpose; finally I proposed an operation, to which the owner consented. I now etherized the cow, turned her on her left side, and made an incision through the right flank, beginning at a point two inches beneath the transverse processes of the lumbar vertebræ, middistance of the last rib and anterior spine of the pelvis; the - length of the incision was about ten inches. I then divided the muscles in this region known as the transversalis, external, and internal oblique; having thus exposed the peritoneum, I punctured it, and by means of a probe-pointed bistoury dilated it to the extent of the external incision. I then made an incision through the uterus, disembowelled the calf so as to reduce its bulk, arid finally removed the heart and lungs; yet I could not extract the carcase (which was of extraordinary size). I therefore made a section of the spinal column, and removed the 
fœetus in halves, then took away the placenta and removed all fluids by means of a sponge. The incision was properly sutured, and after a short period the cow got up and partook of a bran mash. Twenty-four hours after the operation, the cow died; this probably occurred from the exhausted condition of the animal at the period of operating. When nothing except an operation of this kind can save the mother, I recommend that it be performed early, so that there shall be vitality enough in the system to bear up against it.

\section{UTERINE HEMORRHAGE.}

Uterine hemorrhage is known in common parlance as floading from the womb; occasionally it does occur as a sequel of forcible extraction of the calf, followed by an unwarrantable harshness in extracting the placenta and its membranes from the uterine cotylodens.

The best plan of arresting this kind of hemorrhage is to drench the cow with two ounces of tincture of matico, and then encircle the body in the region of the small of the back with a cold water bandage; the object in a case of this kind is to induce contraction of the uterus, for when once contracted the flooding will soon cease.

\section{BIRTH OF TWINS.}

There are many cases on record of cows giving birth to twins, and even triplets, without manual assistance, yet occasionally in consequence of two presenting in the passage at once, some assistance is needed.

When called to a case of this character the object should be to ascertain if the parts presenting belong to one or two calves; if the latter be the case, one must be pushed back, and the other advanced, for they cannot both be born at once, without perilling the life of the mother.

\section{TRIPLETS.}

Three years ago I visited Keene, N. H., on the occasion of the State Fair, and saw a cow of native breed, the property of 15 
Mr. Aldrich. I learned that at two previous births she had brought forth twins, and now was the mother of three at one birth ; these were milk-white, and a perfect counterpart of each other.

I understood Mr. Aldrich to say that the cow had never been bred to the same bull, so that the plural and triple births were the result of a peculiarity of constitution on the part of the cow. This remarkable peculiarity seems to favor the hypothesis of Pythagoras and Aristotle, who maintained that the female parent affords all the materials necessary for the formation of the offspring, the office of the male being merely to awaken the dormant formative powers residing in the female ovaducts. 'The "ovists" farther assume, that the fœtal germs already exist, with all their organs in some part of the female organs of generation, and that the action of the male is merely that of exciting and endowing the fœtus with vitality. These theories, lowever, appear irreconcilable with the phenomena of the offspring inheriting the faults and defects of the male.

The cow alluded to never required any assistance in labor; this may be accounted for from the fact that the mother had a large pelvis, and her offspring at the time of birth were all small.

But here are two other remarkable cases.

"The subject of this notice had been delivered of her first calf in January, 1857, when two years old, a fine heifer of the Brittany breed, and of medium size.

"Soon after she was served (only once) by a bull of the district, and becarne impregnated. During gestation the animal was healthy, walked easily, and her belly presented no uncommon appearance as regards size.

"On December 26, her term of gestation having closed with little pain or expulsive efforts, she gave birth, in a very few minutes, to two calves (male and female, the first being in the normal position; the last having the posterior limbs presented first. At the same time the fotal envelopes of the calves came away.

"During delivery the cow showed no suffering, and would 
eat and drink as usual. Shortly after, the attendants perceived, between the lips of the vulva, two white soft tumors, which they cook for inverted uterus, and at once hastened for the cow doctor. Meanwhile, a neighbor thinking he recognized in them the water bags, pricked them, and on the escape of the water another calf was seen, with a natural presentation, which was soon delivered by the efforts of the mother. This was immediately followed by a fourth, which was also easily expelled. These two last, the first a female, the last a male, died in a few seconds; though doubtless, had the liquor amnii been at once evacuated, both might have survived, as they were even stronger than the two first. They were very fat, and weighed, when given to the butcher, 25 killogrammes each. - "The cow which has shown such remarkable fecundity (five calves in one year) has all along preserved the most perfect health." - Translations by Mr. Gamgee.

Remarkable Fecundation in a Cow. - Mr. M. B. Forbes sent the London (Eng.) Veterinarian the following particulars relating to the birth of five calves at one time: "A cow of the short-horned breed, six years old, the property of Mr. Richard Knight, farmer, Santon, about a mile from Ryegate, was safely delivered on Monday morning, the 21st of February, three weeks before her time, of five calves - four bulls and one cow. Three of the calves died a few hours after birth, but the fourth survived until Tuesday, and the fifth until the following day, Wednesday." Mr. Forbes saw the cow on the $23 \mathrm{~d}$, and found her going on well. It was her third calving.

\section{DISEASES OF THE GENERATIVE URGANS.}

\section{CONSTRICTION AT THE NECK OF THE UTERUS.}

OWING to some abnormal condition of the neck of the uterus, it is occasionslly the seat of constriction; the difficulty can only be determined by introducing the hand into the vagina, 
then by bringing the fingers in contact with the mouth of tr womb, it is found in an undilated, and indurated or hardened state. Should the labor pains be quite strong, and no signs of relaxation appearing, I should then introduce a probe-pointed bistoury, or the embryotomy knife into the neck of the uterus, and dilate the stricture, by making incisions, into the inner border of the strictured or hardened mass; this will allow of some slight dilitation, large enough for a bladder of fotal membrane to gain enterance; after this takes place the labor will gradually progress and if every thing goes right, as the saying . is, a live calf may soon be expected to make its appearance, and the cow may also be expected to survive the operation.

EMBRYOTOMY.

This operation known among medical men as embryotomy, signifies dismemberment of the calf within the vagina and uterus. I presume no man except he be acquainted with the anatomy of the parts, would dare to attempt the dismemberment and disembowelment of a fotus. It is an operation, however, which has to be performed very often, and it has saved the lives of very many valuable cows, therefore I shall try to "post" the reader on the subject. The instrument used for this purpose is called an embryotomy knife (see cut of instruments), and is introduced into the uterine cavity, concealed in the hand so that its cutting edge shall not injure the genital organs of the cow.

Mode of operation. - Having introduced the knife within the uterine cavity, I run my hand along the fotal limb to the top of the shoulder, if possible, and there turn the knife and send its beak point through the integument, and slit the same to the region of the knee; here I make a circular incision of the integument around the knee; a slip-noose is affixed to the fetlock and while an assistant is making steady traction on the same, I loosen the integmuent from the limb, then by a little dexterity in the use of the knife at the top of the shoulder, and elsewhere, the whole leg is drawn away. "After amputating the shoulder, I make an incision through the cartilages of the ribs, 
this exposes the whole of the thoracic viscera, which I remove. If the bulk of the calf appears to be sufficiently reduced to insure its extraction, I affix a noose to the remaining fore leg and by traction remove the carcase; the only difficulty in the way of a prompt extraction occurs, ofttimes, in consequence of the foetal head being bent round on the opposite side of the chest; but under ordinary circumstances the calf can be extracted without proceeding to disembowel it, or decapitate it. If however, either of the latter operations, will facilitate the birth of the calf I should certainly perform one or the other or both.

Having extracted the whole of the fotus, I next remove the placenta and membranes, and then drench the cow with fluid extract of ginger, half an ounce ; tincture of matico, one ounce; warm water, one quart; this will improve the condition of the prostrate animal and insure contraction of the uterus.

The uterine expulsive power, so favorable to the liberation of the calf, if dormant, can readily be aroused by administering a stimulating drench.

\section{TREATMENT OF COWS DURING PREGNANCY.}

The cow is the only animal with which I am acquainted, that yields milk regularly, during the trying and prostrating probation of pregnancy; she has not only to yield milk for the profit of her owner, but she must also furnish an identical preparation for the nourishment of the fotus in utero. Then again, the integrity of her own system requires that her digestive organs shall furnish enough of chyme and chyle for the manufacture of good rich blood, to repair incidental and extraordinary wear and tear of her system; therefore she should be well fed, and cared for; any stinting or miserly economy in the feeding of pregnant cows is very poor policy, and is a sort of starvation procedure, which can never be expected to pay.

It is impossible for the cow to discharge these treble duties unless she be generously fed on nutrimental agents, containing the necessary equivalents. I am aware that most cows are too well fed (see article on "feeding"), hence milk fever and other $15 *$ 
inflammatory affections; yet the food given to some cows in this region, such as swill, brewer's grains, cornstalks, coarse damaged hay, etc., is not suitable for pregnant cows; they should have a mess of roots occasionally, and about a quart ot meal night and morning, which may be stirred in a bucket of water, to which add a teaspoonful of salt; a reasonable quantity of good sweet hay should be allowed daily; this will not only keep the stomach distended to a healthy capacity, but will also furnish matter for remastication, by which process a large amount of saliva is secreted, and passes into the stomach, where it operates on the food therein contained, as a powerful digestor.

A pregnant cow should never be confined to the cow-house, for want of proper exercise induces plethora, and a plethoric condition of the system retards the development of the fœtus; hence the cow is very apt to go over her time.

The pregnant animal needs, and must have, exercise ; it aids in the circulation of blood through her system; it brings the blood oftener in contact with aeriating surfaces, and thus invigorates it; in short, the whole animal economy is benefited by exercise in the open air.

If the season of the year admits, the cow should be sent to pasture; here under the advantages arising from pure air, natural food, etc., she will get in fine condition, so that when the period of calving arrives, she will be strong and vigorous, and can bring forth a healthy calf.

It must be borne in mind, however, that the petted, stall-fed cow, is not a safe subject to leave in the pasture at night; the cold, damp, ground and air, are apt to derange her health, therefore she should be housed at night and on stormy days.

As regards milking the animal during pregnancy, it must depend on circumstances; a cow in good condition may be milked longer than a poor one, and the poor, overmilked animal, must "go dry," as the saying is, for a couple of months prior to calving.

Should a pregnant animal yield milk up to within a fortnight of calving, she should have a few bran mashes, and the daily 
quantity of food and drink must be diminished. She should also have free access to salt, and occasionally a tablespoonful or so of phosphate of lime, may be sprinkled over her fodder.

\section{SYMPTOMS OF PREGNANCY.}

A cow in healthy condition will be in heat (a state of menstruation), about once a month, this lasts for a period of four days more or less.

About three or four months after conception has taken place, the belly is enlarged, and on making pressure on the right flank the motions of a live foetus can be distinctly felt. Pregnancy may be determined earlier than this by auscultation (the art of diagnosis by listening to the sounds of the heart), the beating of the foetal heart can be distinctly heard; the ear should be applied to the right flank.

\section{DROPSY OF THE WOMB.}

This affection generally prevails among aged cows in the latter period of pregnancy; the causes of it are, perhaps, obscure; yet it may be attributable, like other dropsies, 'to a debilitated condition of the system, and an impoverished state of the blood.

The symptoms noticed in this affection are as follows. An unhealthy and debilitated state of the animal; visible membranes, pale and watery; a pendulous and much enlarged condition of the abdomen; spinal column curved in a downward direction; and the animal when down is observed to rise with difficulty.

It often happens that in dropsy of the uterus, the walls of the abdomen are ruptured and the fluid escapes into the cellular tissue beneath the common integuments; this is readily detected by an unnatural tumefaction or swelling in some part of the abdominal region. My usual practice in a case of this charàcter is to puncture the integument, and allow the fluid to escape. I then direct that the animal have a few doses of the following:- 
Tineture of Matico

Sweet Spirits of Nitre, Equal parts.

Dose. - IIalf an ounce of each in one pint of water. The animal to have the privilege of barnyard or pasture exercise.

Dropsy confined to the uterus is a formidable affection, because it requires the services of an experienced surgeon, who will, probably, tap the dropsical membranes through the vagina; yet the operation is not always advisable, for it frequently results in premature parturition.

\section{PUERPERAL FEVER.}

During the past few years, very many valuable cows have died of "milk fever"-puerperal fever-puerperal convulsions, etc.

It is a remarkable fact, that this disease almost always attacks cows in high condition; hence, in view of prevention, we şhould endeavor to guard against the accumulation of fat; and this can be done by withholding meal and substituting shorts, and also by allowing considerable quantities of roots, and grass, when they can be had.

Puerperal fever is a disease of an inflammatory type. The state of plethora, which is observed among fine cows owned by wealthy individuals, who dispense provender liberally, because they hate to see a "pool" cow, is more likely to occur in a cow when pregnant, and stall-fed (from the fat of the crib), than otherwise, because, under such management, she does not get exercise enough to make away with the carbonaceous material, and therefore it increases from day to day, and is liarvested into the cell reservoirs, proving in its bulk detrimental to full and free circulation, respiration, and intestinal peristaltic action.

The warm and impure atmosphere which the stall-fed animal is compelled to respire, is decidedly operative in bringing about that condition known as plethora; therefore, our object should be to secure a current of cool and pure air throughout the cow stable. Pure and cool air is a very potent physiological, sedative, contra-stimulant, and as the fat animal is in a morbid 
state of excitation from the stimulus of the food, as well as artificial atmosphere, the suffering creature will surely be benefited by inhaling the requisite amount of an uncontaminated atmosphere.

The principal causes of puerperal fever in women are said to be misplaced benevolence, which benevolently! furnishes her with choice viands, rich caudles, and stimulants, in view of obviating debility, and insuring hilarity of mind. Now the condition of the pregnant female being one of increased susceptibility, it fully demonstrates the incompatibility of using even what may be considered as the ordinary stimulations of health. Therefore, in the case of the cow, stimulating food and an unnecessary amount of the same given daily after the cow has "come to her growth," as the saying is, may be termed misplaced benevolence; whereas, if the cow has not attained her full growth, the practice of feeding liberally is not objectionable, for she requires a large amount of nutriment to develop the various parts of her organism, and promote the integrity of the same, and also to nourish the fotus in utero, and lastly, for the purpose of furnishing the necessary material for the lacteal secretion. It has been noticed that great milkers, as well as fat animals, are often the subjects of peurperal fever, and probably the suppression of the milk secretion, in the advanced stage of pregnancy, may be an exciting cause of the difficulty, yet not in all cases; for we are pretty certain that some cows, owing to a peculiarity of constitution, are predisposed to puerperal hysteritis.

In view, therefore, of guarding against the consequences which may occur when the animal is suddenly "dried up," we should be careful to diminish the daily allowance of food, and also feed lightly from this period up to that of parturition.

Milking the cow before calving, in view of preventing puerperal fever, is very mischevious, for it is apt to excite premature parturition; many of the cows I have attended for the above complaint, had been so treated. Occasionally the udder becomes distended to a painful degree so that it is necessary to practice moderate milking, otherwise the practice is injurious. 
It is generally supposed that this disease first manifests itself in some part of the tissues entering into the composition of the reproductive organs; or, in other language, primary congestion and irritation of the womb, ending in cerebral congestion and convulsions. The cerebral congestion, however, is not always the cause of convulsions, for we have many cases on record in which phlebotomy was practised on the heroic plan - an incredible amount of blood having been abstracted without arresting the convulsions. Hence, in such cases congestion is the result, not the cause of convulsions. A very eminent physician (Dr. Logan) has stated, as the result of observation, that puerperal convulsions were generally found in females of highly organized nervous systems, and who were peculiarly susceptible to irritation of that system, yet our experience in this country, in cattle practice, confirms what we have written in the preceeding part of this article; viz., that puerperal convulsions are more frequent among fat animals than in those of lean condition. The theory of Dr. Logan may in the main be correct, for a lean animal (nervous temperament), can, by artificial means, be brought into the condition known as plethora.

Youatt contends that "cows in high condition are most subject to an attack of puerperal fever. Their excess of condition, or state of plethora, disposes them to affections of an inflammatory character, at all times and under all circumstances."

If it shall prove to be the case, that puerperal fever is the result of uterine inflammation, we should diagnose the case as puerperal hysteritis and treat accordingly. Puerperal hysteritis may, however, occur at any period of pregnacy.

Symptoms. - The early symptoms attending a disease of this character, are such as is found to prevail in disease of a febrile character; viz., loss of appetite, accelerated pulse and respiration, the latter attended with strong but quick abdominal flank movements. The tongue slightly coated; the mouth hot and clammy; muzzle dry. There is also a sort of wildness about the eyes; the animal is nervous, and some unusual spasmodis twitchings of the muscles will generally be observed. 
Soon the animal grates her teeth, foams at the mouth, dashes her head recklessly on the floor (for she is now on the floor); examine the eye at this stage, and the pupil will be found in an amaurotic state. The udder becomes swollen, hot and tender, and the lacteal secretion is partly suspended.

The disease generally appears within a fortnight after calving, and it may occur within a very few hours; its duration is very brief, both the curable and incurable cases terminate either one way or the other, in a short time, and if violent convulsions set in, we generally find that the patient has but little time to live, especially is this the case when paraplegia be present, or paralysis in any form. The principal symptoms in which the diagnosis.must be founded, are as follows We first ascertain whether or no the animal has, within the period of a fortnight, given birth to a calf, if so, and she manifests the usual symptoms of convulsions, refuses to notice her calf, and has lost the use, more or less, of her limbs; the eyes presenting a wild stare, the pupils being dilated, and the udder swollen, we may then safely conclude that we have a case of milk fever to deal with.

Treatment. - The professional man treats the disease according to its indications, and the non-professional, if he attempt to treat a case of this character, must endeavor to do likewise. I cannot possibly commit to paper all the necessary information, but shall merely lay down a few simple rules for the management of such cases, at the same time I would advise the owner of the sick cow to secure, if possible, the services of some competent veterinarian.

Some practitioners recommend the abstraction of blood from the jugular vein, but my practice is to bleed from the bowels, by administering purgative medicine; in this way the animal can be depleted with greater safety than by blood-letting.

The cathartic is as follows :-

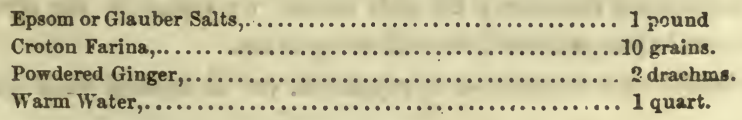


Directions. - First dissolve the salts in the above amount of water, then add the croton and ginger. Drench the animal by means of a quart bottle; take time to pour it down the œsophagus, and the more speedily will it act. If I have no faith in blood-letting, I may be said to have great faith in purgation, for as Percivall very truly observes, in regard to the treatment of staggers in horses, "purge a horse and you cure him," so I say in regard to the treatment of puerperal fever, purge a cow and she shall be cured; the bowels must be made to liberate their contents. After having administered the medicine, the

- patient must be watched, and when she lays down let her.have a comfortable bed of hay, and the attendant should occasionally sponge her head with cold water. When down, a good stimulating alkaline enema may be thrown into the rectum, composed of warm water, two quarts; ginger, half an ounce; fine salt, two ounces.

Supposing that, after a lapse of six or eight hours, the bowels fail to respond to the purgative, half the quantity just recommended may be given, and perhaps it may. be proper, in view of creating a vaccuum in the rectum, to repeat the enema; for purgation once established, our patient is safe; yet, in view of producing this very desirable result, it is not a rational procedure to convert the stomach into an apothecary's shop, and gorge it with useless drugs, as is, unfortunately, too often the case; for, by this means, a medicinal disease is created, which is generally more uncontrollable than the original one.

In curable cases it is very rare for the above medicine to fail in exciting catharsis; however, such remedy is not always at hand (I mean the salts); the next best remedy is common table salt, to be substituted for the glauber or epsom salts.

Other indications to be fulfilled in the treatment of this disease. - The palsied limbs require attention. Let them be diligently rubbed with tincture of capsicum - hot drops - in view of producing reaction; by this means we equalize the circulation, and thus relieve internal congestion.

Should the bowels be tympanitic, or distended with gas, a 
quart of ginger tea may be given, and it may do more good if a small quantity of carbonate of soda be added to the same.

Should the animal be thirsty, a small quantity of powdered nitre may be dissolved in water or thin gruel, and offered to her.

After the bowels have operated, the danger passed, a few doses of alterative medicine may be given. This is composed of -

Powdered Goldenseal,................................2 ounces.

" Ginger,...................................1 ounce.

" Sulphur,................................2 onces.

Mix, divide into eight parts, and give one, daily, in the food or by drench.

The following case, from the author's note-book, is here introduced to illustrate a new mode of treatment:-

The case to which the following remarks allude, occurred in a five-years-old cow, the property of Mr. G., Malden, Mass. The animal gave birth, without assistance, to a healthy male calf; the birth took place during the night-time, at pasture, the weather being rather tempestuous. Three days after parturition, the cow showed symptoms of failing health, and the owner, like a sensible man, instead of boring the animal's horns, at the suggestions of the neighbors, preferred to seek advice; hence my services were secured.

Recorded Symptoms. - Patient, down on left side; pupils amaurotic; pulse scarcely perceptible; respiration of a stertorous character, and accelerated; surface of the body comfortably warm, visible surfaces, of a leaden hue; abdomen slightly tympanitic. The animal occasionally turns its head towards the costal region, and returns it recklessly to the floor; mamma tumefied and hot ; internal surface of the labia pudendi inflamed. The patient takes no notice of its offspring.

Treatment. - Applied counter-irritants to the spinal and pectoral regions, and then applied sulphuric ether to the nostrils. The object in administering sulphuric ether was to diminish the reflex excitability of the nervous system, and so cut short the convulsive paroxysms. 
The ether appeared to prove invaluable; for, soon after its administration, the animal appeared calm, tranquil, and rational, and soon began to take notice of its offspring. I then administered table salt, eight ounces; water, one pint.

Flannels saturated with infusion of hops were now applied to the mamma, and renewed occasionally. In the course of thirty-six hours after the administration of the ether, the patient was standing up, nursing her offspring, and at the same time partook of a bran mash. The following three days the patient got two drachms of fluid extract of chamomile flowers per diem, and was then turned out to grass, and "done well," as the saying is.

Remarks on the Preceding Case. - The treatment of puerperal fever, in by-gone days, is a disgrace to what has been considered as a "learned profession." It is a very unfortunate circumstance that such learned men as Ramsbotham, Churchill, Meigs, and other equally distinguished midwifarians, should contend that "the lancet is our sheet anchor in puerperal convulsions." They inform the world of medical-non-thinkers, that the daring use of "the lancet is demanded ;" that the "lancet is our sheet anchor;" that "blood must be taken largely." Yet a great proportion of their patients thus treated, prematurely pay the debt of nature "secundum artem." What a libel on a "learned profession" is this state of affairs! and, unfortunately the distinguished French surgeon, Cazeaux, has endorsed the reckless tactics of England's universal wretched practice; viz., "sanguine emissions." Now I contend that the routine practice of the acknowledged authorities, will not stand the test of modern medical logic; that it is contrary to all demonstrative experience, and therefore should receive the seal of oblivious antiquity, never to be re-acted or countenanced by sensible men. The old school heretics are great sticklers for the support of their tottering fabric; viz., "that fever and inflammation must be subdued;" and they commit outrages on the physiological laws of animality, by instituting a series of manipulations redolent of the aroma acceptable to the god of pathology, whom they worship with the spontaneous faith of a new convert. 
Deplorable Event. - Monday, June 15th, 1 o'clock, P.M.; was requested to proceed to Medford, for the purpose of giving professional advice regarding the treatment of a valuable cow, said to be afflicted with "horn-ail." The animal was owned by Mr. E., a man well known to our citizens as an industrious expressman, and one who could not afford to lose an animal which contributed largely for the support of his family.

'The history of the case may be briefly condensed, as follows: The patient, at that period, was the mother of a fine, healthy calf, three days old; had been somewhat exposed to the variable weather prevailing at the time; was first observed to have lost her cud, as the saying is, or to have ceased ruminating; her head drooped; the udder became hard and swollen; the secretion of milk small ; the breathing rapid; eyes dull. Soon after the attack she got down, and turned her head towards the left side, and would occasionally throw it recklessly about. The horns were cold, and in consequence, "the neighbors persuaded the owner that his cow was the subject of horn-ail." The horns were bored in several places, and pepper, etc., introduced within their cavities; but the suffering creature grew no better very fast. In the meantime she was "dosed and doctored."

Present symptoms at the time of my visit. - The animal lies on the right, her head turned to the left side; pulse fluttering, cannot be counted. The expiratory murmur is gurgling; in number, twenty-two. She is unconscious, insensible to manipulation, and unable to rise. The eyes have lost their brilliancy, and are amaurotic. A few tears are passing over the inner canthus, and run down the cheek. She evinces little signs of life, except by respiratory action. Traces of effused blood are seen on a small portion of protruded rectum, and the inner part of the labii of the vagina is brightly reddened. Various parts of the body differ in temperature; the frontal regions and horns very hot; lumbar regions cold; fore extremities warm; 
hind extremities cold. Abdomen slightly tympanitic.* There is no appearance of either dung or urine having been recently voided.

\section{Diognosis, $\uparrow$ Puerperal Fever.}

Prognosis, $\ddagger$ Speedy death.

I shall offer no comment on this case, but respectfully ask the reader's attention to article "horn-ail," which will be found at page 259. It may not, however, be out of place to remark, that being satisfied there was no help for the poor creature, I declined doing any thing. Under such circumstances I hold to the doctrine that "it is the province of the good physician to know when to do nothing ;" for the censurable practice so often pursued of worrying a dying creature by forcing a horrid mass of "hotch potch," down its throat, is a proceeding which a Christian community should set their faces against.

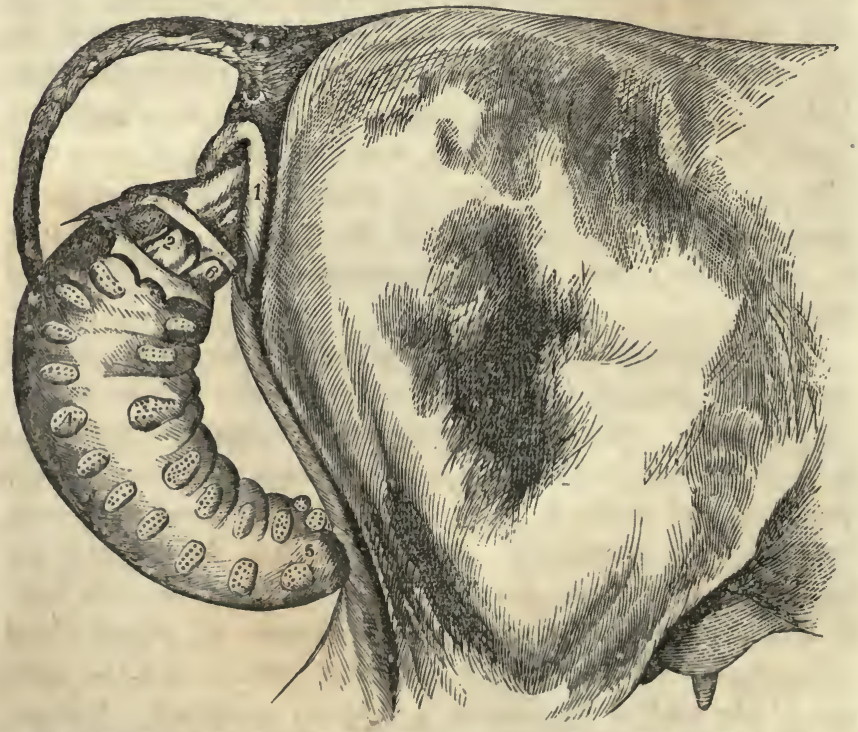

INVERSION OF TIE WOMB AFTER CALVING. For explanation see p.391.

* Tympanitis. Distended by flatus or gas.

$\dagger$ Diagnosis. The art of discriminating diseases.

$\ddagger$ Prognosis. The art of foretelling the result of diseases. 


\section{INVERSION OF THE UTERUS.}

This sad accident is generally occasioned by extra uterine expulsive action, at the moment of the birth of the calf, aided by adhesions of the placenta to the cotyledons; by which means, in the process of delivery, the uterus is actually turned inside out. The relaxation of the ligaments, which ordinarily confine the uterus to the pelvic cavity, may be one-among the various causes which tend to induce inversion. The accident, so far as my experience goes, is apt to occur in animals of an inferior class, coarse and flabbily organized, and among others in a debilitated condition. The only way to prevent a recurrence of inversion is to spay the cow.

Treatment of inversion of the uterus. - The old method of introducing the arm, in order to force back the protruded parts, is now superceded by a bulbous rod of iron (see cut of instruments), which must be applied to the fundus or base of the womb; a due amount of pressure being steadily made, an assistant manipulates the sides, and the womb is re-inverted; sometimes it-is very difficult to get the womb back, in consequence of latent uterine action; which convulsively resists our efforts, and violently sends it out again at the moment of return.

Should the convulsive action of the uterus continue any great length of time, I should etherize the animal and when fully under its influence, the reduction may again be attempted and probably consummated.

The instrument, should be kept in the womb for some time after reduction, so as to give the muscular fibres of its walls time enough to contract, and it may be necessary, to have a man in attendance for a whole day or more, in view of accomplishing this result.

So soon as the reduction is complete I should sponge the loins often with cold water, or a better plan, perhaps, would be to pack the loins after the fashion of hydropathy; the loins and abdomen will by this method receive considerable support, which will be favorable to induce contractile power in the uterus. 
Sometimes the presence of the bulbous instrument in the uterus, after reduction, tends to keep up the after pains or expulsive action, and if so it must be removed, previous to which however, some stout tape should be sent through the thick skin in the region of the prominences found on each side of the vaginal outlet, known as the tuberosity of -the ischium; this is a much better plan than that of stitching the vaginal lips. After removing the instrument, a pad may be placed on the lips of the vagina, then tie the tape sutures moderately tight; two sutures will answer, and they can be allowed to remain until all danger of re-inversion has passed. The animal should be placed in a situation where the hind parts can be elevated a few inches.

The following cases appear interesting enough to obtain a space in this work and I recommend them to the reader's perusal, they occurred in the practice of Surgeon Younghusband:

"On the morning of the $3 \mathrm{~d}$ of January, 1850, I was sent for in great haste to a cow that three days before had calved, and apparently up to this time had done well; but on that morning, on the cow-keeper attending as usual, he found the cow down, and the whole of the uterus protruding through the vagina. On my arrival I found her as described, with the uterus in a most loathsome state, from being suffered to remain unprotected among the dung and urine of the cow-house, and also the placental membranes adherent. Plenty of assistance being at hand, we had her up, well raised her hind parts, and in that position secured her, so that she could not well slip down again. Having carefully detached the placenta, I next proceeded to cleanse the parts by washing them with a mixture of weak spirit and water. Having accomplished this, I proceeded to return the part; but on minutely examining that viscus, before attempting its replacement $I$ discovered in it a large rent, through which I easily introduced my hand, and for the better satisfaction of the owner, I caused one of the bystanders to do the same, to show them that it was not through any mismanagement of mine that this untoward accident had taken place; for 
in my belief, another cow had trod upon it while she was down, and thus done the mischief. After this, I effected its return without much difficulty. Judging that I had got all the part into a right position, etc., I made made an attempt to withdraw my arm; but, in doing this, the cow immediately began to strain with such violence that it was not without the greatest difficulty that I could retain the part in statu quo.

"But, by a fortunate slip, her anterior parts were brought so near the ground that I now easily accomplished that which, for a length of time, I had found the greatest difficulty in attempting to do; viz., getting the part into a right position retaining it there, and withdrawing my arm without difficulty. The cow now straining very little or none, I applied the usual means of prevention, gave an anodyne, had her set up from the awkward position into which she had got, and waited to see the result. Retreated for a short time, leaving a watch in case any thing untoward should again take place. On my return, I found her still up, attended with no bad symptoms, very little straining, and appearing to be more comfortable than her situation would warrant. She was now offered a little food, of which she seemed to partake freely. Still I warned the owner of the danger, and told him I had not the slightest hopes of her recovery. To be brief, from that time she had a little fever medicine occasionally, and I paid her a few visits, still finding her apparently improving, and on my last visit, on the $10 \mathrm{th}$, found her in so favorable a situation that I told the owner that, being at a great distance, unless I heard more from him, I would discontinue my attendance; nor had I more occasion to repeat them. The cow did well, and has since had two more calves without needing any of my assistance.

"CASE II. - This was a cow belonging to Mr. T. Monkhouse, of Moredale, in my neighborhood, which calved apparently with the greatest ease, showing no signs of particular uneasiness; but, on paying her a visit, he found her with the uterus protruded and the placenta attached. They immediately secured the part, so as it might receive little or no injury from 
the contact of foreign bodies. In the mean time, a messenger was dispatched for me. Being at home, I was not long in being at my post. After having her put in a position which I considered favorable, I proceeded to detach the placenta, which was easily done, and the part being free from dirt, was soon ready for returning, which, from the dilated state of the parts of generation, was of all cases I ever had, the most easily accomplished. But mark the sequel; when I imagined I had made all right, the cow, appearing to suffer very little from the effects of the operation, was let up from her situation, and I had withdrawn my arm, when, behold, a portion of the small intestine made its appearance through the vulva. Judge of my consternation now, having no cause to fear such an untoward act. I told the owner how the case stood, and frankly confessed my ignorance of its cause. I now proceeded to find out the rent in the uterus, which I soon did, it being in its posterior part, and without much difficulty got the intestine returned. My next aim was to cause as much contraction of the uterus as I could, so as to bring the divided edges of the organ together. This I did by the application of tr. opii camph., and which, I am proud to say, soon gave me the required satisfaction; so much so, indeed, that before I withdrew my arm, the laceration was scarcely distinguishable to the touch. The cow in this case appearing in so easy a state, no truss was applied the first night, but a person staid with her, if possible to prevent future ills. Now, sir, I must say of all cows, this one has gone on most favorably. -To give a description of her treatment would be a waste of time and paper; since as to the medical treatment, it amounted almost to nothing. Careful nursing, with a few solitary doses of medicine, constituted the whole; and at the time of writing this, she is in as thriving a state as any of the stock on the farm. So I think I may say of this case, per se." 


\section{DISEASES OF THE UDDER AND TEATS.}

\section{MAMMITIS}

Mammitrs signifies inflammation of the udder; it usually consists of tumefaction, attended with heat and pain, and generally sets in shortly after calving. The treatment of this affection should be antiphlogistic: let the animal have a full dose of glauber salts, and apply a refrigerating lotion to the udder (cold water will answer), in view of reducing the temperature of the same. In this state of the udder scarcely any milk flows, and what comes is often bloody; soon an entire obstruction takes place, or nothing but a watery secretion can be got away. Next, the udder hardens in places, abscesses form, and then the secretory function of one or more quarters is destroyed; the animal now has the "garget," and ten chances to one if the part or parts are ever restored. The only way to prevent garget, is to let the calf suck immediately after it is born, or else introduce a tube into one or more of the teats, and thus evacuate the milk ere it coagulates.

The following article was lately furnished by the author for the Rural New Yorker, and is here introduced in view of "lighting up" the subject.

\section{INFLAMED UDDER.}

"Mr. Editor, - I notice that one of you subscribers is desirous of obtaining some information in regard to the treatment of Knots in Cows Teats (a diseased condition, known to medical men as induration), and in view of gratifying his wishes, and perhaps, at the same time, contributing an item which may result in good to the inferior animal, I send you the following:-

"The disease, at its commencement, invariably consists of an inflamed condition of the mamma or "bag," characterized by pain, heat, swelling, and more or less febrile symptoms. It is precisely the same disease which many nursing women are 
prone to, and suffer from, and its terminations, when not arrested in the early stage, are exactly the same; viz., suppuration, formation of an abscess, induration, or hardening of the walls of the bag. In the human female the suppurative stage is known to nurses as "broken breast ;" and the state of induration or hardening, which follows, or may exist independent of an abscess, is commonly called "caked" breast; hence the term caked udder. Such is the character of this disease as it occurs among cows in the United States. In Europe it occasionally assumes a more malignant form, and it often becomes necessary to extirpate the whole gland!

"Treatment of Marnmitis or Inflamed Udder. - The disease should be attended to in its early stage, and the milk must be evacuated, so that it shall not accumulate nor coagulate. In order to do this a metallic tube may be inserted into the teat, and allowed to remain there, so that the milk shall flow as fast as it is secreted. The inflamed part must be bathed with cold water several times during the day, to which add a few drops of tincture of arnica, and if the part be very painful, an infusion of hops may be used. Afterwards anoint the parts with a small quantity of glycerine.

"The animal must be kept on a very light diet (scalded shorts are good), and if she be fat, or the least constipation of bowels exist, I should give one pound of epsom salts, dissolved in warm water, to which may be added a small quantity of molasses, and a tea-spoonful of ginger.

"Supposing the case to be in the suppurative stage, and it is evident that pus or "matter" is forming within the "bag," or its walls, it may be poulticed with flax-seed, or rubbed twice, daily, with some stimulating liniment, say linseed oil, two ounces; spirits of hartshorn, one drachm. So soon as the matter burrows to the surface, and a soft spot can be detected, it should have a free opening made into it by means of a thumb lancet; the matter must then be squeezed out, and into the cavity syringe some salt and water, or a little tincture of aloes. In the suppurative stage I generally order a generous diet.

"In the indurated stage the treatment consists in exciting ab- 
sorption of the parts, and in this view I recommend iodide of potassium, known as "hydriodate of potassa ;" it is one of the most efficient remedies for the absorption of abnormal growths that $I$ have ever used, and it is highly recommended in our text books by men well acquainted with its modus operandi.

"The dose of hydriodate of potassa is twenty grains per day, to be pulverized and dissolved in water. Being inodorous and almost tasteless, there is no trouble about the patient drinking it. The medicine may be continued until the enlargement disappears, when the dose may be gradually lessened. If I were called upon to treat a chronic case of long standing, I should, in addition to the above, besmear the parts daily with a portion of the following: iodide of potassium, one drachm; glycerine, seven drachms. Mix. Yours, etc.,

"G. H. D."

\section{STRICTURE IN COWS TEATS.}

I was lately consulted in reference to the case of a very valuable, imported cow, that had obstruction in the off posterior teat. She had given birth about a week previous to twin calves. The obstruction appeared to be located about half way up the teat. I fomented the parts with an infusion of lobelia, after which the tube was easily introduced.

\section{OBSTRUCTION AT THE ENDS OF THE TEATS.}

It occasionally happens that a fungous or warty excrescence makes its appearance at the end and centre of the teat, which obstructs the flow of milk, and is very annoying and painful to the animal. This'should be removed by the scalpel, taking care to dissect away every portion of the morbid growth. The part is then to be sprinkled with powdered bloodroot, in order to prevent union of the edges of the outlet of the teat; the milk tube, well oiled, must now and then be introduced.

\section{OBSTRUCTION IN THE TEATS.}

A simple obstruction in the teats is frequently occasioned by imperfect union of the lining membrane. This is easily 
remedied by introducing a tube constructed for the purpose (see cut, page 3), which should be well lubricated with olive oil, and allowed to remain in the lactiferous channel for several hours daily, or until all danger of re-adhesion has passed away.

The lactiferous outlet is sometimes obstructed by false membranes running across its channel; these must be annihilated by the introduction of the tube.

\section{TUMORS IN THE TEAT.}

Tumors are occasionally found in the teats; their presence is determined by bulbous enlargement, which on manipulation appear very evident; the methodis medendi in such cases, is to introduce a tube well smeared with iodine ointment, and repeat the operation two or three times daily until the milk passes freely.

\section{INJURIES TO THE TEATS.}

I have met with several cases of injury to the teats in the form of an incision, which occurred accidentally on the animal rising from the ground, cutting or lacerating the same with its own hoofs. When the accident is discovered shortly after it happened, the parts may be brought together by uninterrupted suture; the seam is then coated with collodion, and the milk must be evacuated wholly by the tube until the parts have united. Sometimes the union is not complete, but a small fistulous opening is left, through which the milk is constantly dribbling. The only way to remedy this is to convert the fistula into a simple flesh-wound; this is done by means of a sharp-pointed knife which removes the thin callus forming the interior of the fistula, the raw edges are then to be brought together by suture, and collodion and the tube used as before.

SORE TEATS.

First, wash with warm water and castile soap; then lubricate the parts with Equal parts. 


\section{CHAPPED TEATS AND CHAFED UDDER.}

Foment the parts daily with an infusion of camomile flowers for at least fifteen minutes at a time; then wipe dry and use the lime liniment. These temporary, or what might with more propriety be termed local maladies, will, if the system be free from morbid matter, generally yield to local remedies. If, however, no change for the better can be observed, the following aperient should be given :-

Fluid Extract of Goldenseal, ........................ 3 drachms.

Powdered Yrandrake, $\ldots \ldots \ldots \ldots \ldots \ldots \ldots \ldots \ldots \ldots \ldots \ldots, \frac{1}{2}$ an ounce.

Powdered Ginger,............................ tea-spoonful.

Dissolve in warm water, one quart, and drench the animal with the same. In the event of the above remedies failing to give relief, anoint the parts twice daily with a portion of the following:-

\section{INVERSION OF THE VAGLNA.}

Inversion of the vagina generally occurs in the latter months of pregnancy, at a time when the digestive organs are somewhat impaired, either actually or sympathetically; in either condition the food is very apt to be imperfectly re-masticated, and ferments; this gives rise to the formation of gas within the alimentary canal, and occasions tumefaction of the compartments of the stomach and large intestines. In this state they take up more room than can be spared for their occupancy, hence the pressure in a posterior direction, which forces the vagina out of its location. When this difficulty occurs in a cow on the eve of parturition, there will be some danger of inversion of the uterus, unless the reduction is effected before delivery, therefore I should endeavor to make room in the abdominal cavity, by putting a stop to the fermentation which is going on in the stomach; in this view I recommend that the animal have the following drench :-

\footnotetext{
Hyposulphite of Soda,.............................. ounce.

Powdered Goldenseal, ...................................4 drachm.
}

Water, .................................................. 
Having administered this drench, procure a soft sponge and foment the part - if it be much inflamed and painful - with a tepid infusion of hops; if the inversion be of recent origin and not much congested, cold water may be used instead. After a while pressure and manipulation may accomplish the reduction; yet it is apt to re-appear and continue to do so until the animal has got rid of her burden. The reduction, however, must be effected if possible, every time the protrusion makes its appearance, or the cow will suffer from retention of urine.

It is very evident to me that very many cases of inversion of the vagina are caused by indigestion; therefore great care should be exercised in feeding cows during the last months of pregnancy.

\section{LACERATION OF THE VAGINA.}

This is an accident of very frequent occurrence among cows yet seldom proves fatal, it often occurs from the rough manner sometimes practised, of bringing the feet forward, therefore great care is necessary in conducting an artificial labor to a successful termination. The following case of extensive laceration of the vagina of a cow, goes to show the potency of nature in the cure of disease and injuries:-

"Mr. J. W. Maw, veterinary student, has sent us the following particulars relating to a case of wilful laceration of the vagina, and contiguous parts of a cow:-

"Mr. Crosby, who is in practice at Thornton Pickering, Yorkshire, as a veterinary surgeon, was called a short time ago to attend a milch cow which presented symptoms of colic. On his visiting her, he observed a piece of stick about three inches long protruding from the vagina, and on removing it he found that it was about a yard in length, and had been thurst throug.a the vagina and likewise the rectum into the abdomen.

"Previous to its removal the cow did not evince such symptoms as one would have been led to expect in an animal suffering from such a severe injury. There was but little external hemorrhage, the symptoms upon the whole rather indicating 
that internal hemorrhage was going on. Anodynes were administered, and quietude enjoined.

"No inflammatory symptoms supervened, and in the course of ten days or a fortnight the animal had recovered.

"The atrocious act is supposed to have been perpetrated by some gypsies, who were located near the place at the time, from their going in the following morning to beg the carcase, thinking probably, that the poor animal was dead." - Veteri-. narian.

\section{RUPTURE OF THE UTERUS.}

Rupture of the uterus appears to be a very formidable accident, yet many animals recover from the same without any medical treatment. In rents of this kind, some persons resort to sutures, but really they are not admissible; they are only in the way and prevent perfect contraction of the uterus. A large rent, say one foot in length, in the uncontracted uterus is diminished to very small proportions when the uterus contracts to its ordinary size, and this very soon heals without the aid of man, provided proper attention be given the animal. (See quotations in the preceding article.) A rupture of this description usually occurs either from violence done the parts, in extracting the foetus, or, by the violent throes of the fœetus itself or else by excessive uterine action.

\section{ABORTION IN COWS.}

The cow is the most liable of all domestic animals to abortion, and those that have once been the subjects of this mishap are liable to a recurrence of the same. Mr. Youatt, in his work on cattle, furnishes some very useful information on this subject; still the direct causes of abortion are like many other enzoötic and epizoötic affections, involved in obscurity.

That it occasionaly rages as an enzoötic pest, is clearly shown by the records of the past, and by what occurred a short time ago among the dairy cows of a milking establishment, at 
Concord in this State, without mentioning other cases, which of late have been chronicled in our agricultural periodicals.

It occasionally appears as an insolated evil; an Alderny cow the property of Mr. Burnet of Southboro, has in the course of three years, aborted four times; at the time of writing this article my attention is called to her, I recommend that she shall be spayed; the owner consents, and of course she will, hereafter, become a more useful animal in supporting other offspring than her own. I call this an isolated case, because Mr. B., informs me that his other cows have not aborted. She inherits a tendency to abort.

A theory has been broached, by some writer that, severe winters succeeded by warm springs, hilly pasturage, the practice of allowing young stock, and one and two-years-old bulls to run with the breeding cows, is likely to end in abortion. This is sheer nonsence, and is not entitled to the least consideration; and relying on the intelligence of my readers, I refrain from offering any argument in view of controverting evident absurdities.

The fact is, some cows will abort, no matter what may be the nature of the pasturage, or the condition of the atmosphere, and, so will women miscarry occasonally, in spite of their own precautions and the advice of their physicians to prevent it.

It is evident therefore, that there exists in the animal economy of some subjects, peculiarities of constitution termed idiocyncracies, which under certain circumstances, and on the application of the cause, - indirect, - develop the latent pathological fire, and thus they abort.

When abortion prevails among a whole herd of cows, on one man's farm, I should consider it as enzoötic, arising spontaneously, afterwards propagated by infection or, by sympathetic influence; Youatt gives a quotation which favors these views. "In the Leipsic Agricultural Gazette, is is stated, that, "by an unheard-of fatality, the abortion of cows in that district was almost general, and that after the most anxious search, no assignable cause for it could be discovered, nor would any medicine or medical treatment arrest the plague." " 
I shall now, in a brief manner, throw out a few hints for the consideration of dairymen and breeders, in view of the adoption of preventative measures, for since neither "medicine nor medical treatment" can arrest the plague, our only hopes of stopping abortions, which in this country are alarmingly on the increase, lies in the practice of preventative measures.

A very objectionable, and, I may add ruinous practice pervails at some milking establishments, of keeping the cows impregnated all the time, the mother no sooner gets through the pains and perils of parturition, than she is again, oftimes, compelled to submit to a re-impregnation; this is what $I$ call an excessive use of the reproductive organs, which must eventually impair their integrity.

It is well known to all physiologists, and I presume that the reader must have some knowledge of the facts; viz., that the uterine organs, like those of digestion and respiration, can be overtaxed, and disease in some form or other is very apt to occur in overworked organs. If actual disease does not set in, debility of function, or organ, must eventually ensue.

The uterus, like various other organs of the animal economy, must have periods of rest or the day of reckoning will surely arrive.

An excessive use of the reproductive organs generally, if not always, impairs the integrity of the nutritive organs, and vice versa; hence, if a cow is kept pregnant all the time for the unwise purpose of making her yield a constant supply of milk, it should not appear strange if she fall off in the quantity of milk, appear unthrifty, be off her feed, and have a glairy discharge from the vagina; these are the symptoms which usually precede abortion.

I lately visited an imported cow, the property of a gentleman in this State, who informed me that she had aborted three times at about the seventh month of her pregnancy, and she was generally put to the bull shortly after the mishap. I told him that this bad practice was the sole predisposing cause of the trouble; for the short space of time which occurred between the premature expulsion of the foetus, and re-impregnation, was not 
sufficient for the entire recovery of tone in the sexual organs; hence, so long as this practice continued, his cow would never go her full time. I strongly urge the necessity of spaying such an animal. She ought, at least, to be separated from the breeding cows, and her fotal calf, membranes, and placenta, should be burnt in the open air, for there is no safety in burying them a few inches under the earth's surface.

It is very probable that many cases of abortion occur through a deranged condition of the digestive organs; therefore the means most likely to prove effectual in keeping the stomach in a healthy state should be adopted.

What an immense amount of labor the digestive organs have to perform! They have to be almost constantly engaged in converting the elements of good and bad food into chyme and chyle, and they must not slacken much, else where are sixteen quarts, more or less, per day of milk to come from? How is the foetus in utero to be nourished, and the wear and tear of the cow's organism to be provided for when the stomach is not in working order?

The practice of milking cows to within a short period of parturition, is highly injurious, yet some persons with whom I have had conversations on this subject, contend that, in some cases, it is impossible to "dry the cow." I advised them to reduce the animals food to less than one-half, or even one-fourth if necessary; in fact, there would be no harm in withholding food altogether for a short time, and in substituting for food a dose or two of aperient medicine. This course must necessarily soon lessen the amount of blood in the system, and as the milk is concocted from the blood it will decrease in the same ratio, or rather be essentially lessened; and in view of reducing the quantity of milk, I also urge the necessity of keeping the cow on a small quantity of water. This practice may not on all occasions succeed in arresting the lacteal secretion, still it is the only rational way of accomplishing the object.

Abortion is sometimes attributed to a debilitated state of the animal; this also arises from a derangement of the stom- 
ach ; then an opposite mode of treatment must be pursued, such as a change of food to that of a more nutritious character, and the frequent administration of small doses of ' ginger and goldenseal.

Breeding cows require a great deal of care and some watching; careful selection of the right kind of food for the necessary wants of the animal and her foetus in utero is indispensable; neither the one nor the other can be expected to enjoy good health on a diet of slops, swill, brewer's grains, cornstalks, rotten potatoes, frozen turnips, damaged meal, musty hay, or sour apples, etc.

Care is also requisite in providing for the animal's wants in regard to "watering." This is a subject of great importance yet very few husbandmen give it that attention which its importance demands. The horrible stagnated stuff found in some pastures and water-troughs, which the thirsty creatures are compelled from sheer necessity to imbibe, is surely operative in producing very many unnecessary diseases, derangements, and abortions.

Some Watching is Necessary. - A cow likely to abort, is generally "off her feed," does not ruminate according to her accustomed activity; she fails to yield the daily quantum of milk; her condition is noticed to be unthrifty, and on inspecting the vagina it is observed to be the seat of a glairy discharge. Such an animal should be immediately isolated from the rest of the herd, and proceeded with as above directed.

It is said that a very common cause of abortion is sympathetic influence. (See "sympathy," page 255.

There is another matter of some importance to be considered in view of prevention: $I$ allude to breeding, and $I$ refer the reader to an article under that caption, page 147. It is my opinion that thousands of the abortions which occur among our domesticated animals in this country, are for the benefit of the several races, present and to follow. For, if the offspring of cows, whose systems have been debilitated by a too early use of the sexual organs; and those of other parents, laboring inder organic disease, malformation, and stunted growth; 
together with the apology of offspring of cows doomed to drag out a miserable existence in some horrible "swill-milk establishment," where death runs riot, or runs into the milk-pail to kill off unnursed infants; these being permitted to come into the world with their inherited imperfections, and being suffered to grow up and become parents, issuing a worse edition than the original copy in turn - these bad specimens, not of nature's handiwork, but of man's ignorance and folly, or wilful transgression of the law of nature, being permitted to live, they would be so many libels on creative power; and in order to remove them from the face of the earth, and put a check on the monstrous evil, a friendly pestilence must eventually ensue.

This would be a mournful event; for many valuable animals might, by infection or contagion, be involved in the general ruin; therefore nature adopts the lesser evil; applies the law of destruction prior to the birth of monstrosity.

The laws of reproduction and destruction are nicely and wisely balanced; "thus far shalt thou go, and no farther." The offspring of weak, emaciated, ill-formed, scrofulous, consumptive, and otherwise defective animals, should never be used for breeding purposes; in fact, they are not even fit for the butcher.

Finally, I would advise breeders to let the female get her growth, ere she is forced into copulation; for prior to maturity, all the energies of her system are concentrated upon the perfection and integrity of her organism, and until that important period arrives, the reproductive system cannot be exercised without running great risk of violating one of the fundamental laws of nature. (See article on breeding, page 147.)

I have now directed the reader's attention to most of the causes likely to influence or induce abortion, and I leave the rest, if any there be, to be discovered by their own experience. It is impossible for me to furnish definite instructions as regards the treatment of individual cases, either prior or subsequent to abortion, as each require a certain course, according to the condition and prevailing symptoms; yet, if I have succeeded 
in pointing out only a few of the errors which prevail in our present faulty system of breeding and management, and have been practical enough to secure the reader's attention in a perusal of this article, I have accomplished more than I expected at the time of its composition.

\section{INFLAMMATORY AFFECTION OF THE HIND LIMBS AFTER CALVING.}

Some cows, after calving, suffer from an inflammatory affection of the hind limbs, which renders them lame, or they are unable to use the parts with that promptitude which characterizes the physiological condition, or state of health.

The limbs are generally hot, and in certain localities, are swollen, and the general health of the animal seems to be impaired, yet there is no great danger attending the condition; the tumefaction appears to consist of a local effusion - dropsy - of serum into the cellular tissue, which readily disappears through the local application of cold water, and the action of the calf on the teats.

The attention of reterinarians has been directed to this affection by Lecouturier in the following paragraph, translated by Mr. Gamgee:-

"A few days after parturition, and always when it has been normal, a difficulty in the movements of the hind quarters is to be observed; the hocks become sensitive; the anterior surface swells up; the synovial capsule is disturbed; great pain is felt at the slightest touch, accompanied with heat. Then the appetite is lost ; the secretion of milk diminished; pulse quick and strong; and a certain amount of fever sets in. The patient eannot lie down, and still is not safe on its legs. The writer never saw the affection but on recently calved cows; never after the ninth day, and almost always from the fourth to the seventh. This disease affects generally the good mother, and is of a most benignant nature. A friction of turpentine and alcohol is sufficient to restore to health in most eases; 0 therwise, brandy and soap. When the fever is strong, a dose of nitre with digitalis is useful. 
"This disturbance is always of a benignant nature, and is coincident with parturition, as the parturient fever, and a serous diarrlıa, which occurs from the second to the third day after calving, easily checked, and never lasting more than twentyfour hours."

\section{DISEASES OF THE URINARY ORGANS.}

\section{DESCRIPTION OF THE URINARY SYSTPM.}

THE primary organs of the urinary system are the kidneys - two avoid conglomorate bodies of a purple color, located in the lumbar region, or loins, separated from each other by the inferior part of the spinal column; they are generally imbedded in adipose tissue denominated suet.

The kidneys are the great emunctories of the body, are constantly engaged in secreting waste and morbid fluids from the blood, and we find them much larger in cattle than in horses. When the function of any other excretory organ is impaired, an extra amount of work is in store for them to perform. In health their function never ceases, a constant secretion of urine is going on all the time; whether the animal be awake or asleep it matters not, there is no rest for the kidneys. On cutting through the kidneys, it is found to be composed of two substances, termed cortical and medullary.

The kidneys are supplied with blood by the emulgent arteries; they are of large calibre, and furnish a large quantity of blood from which the urine is secreted. Within the centre of each kidney is a receptacle known as the pelvis, which terminates in a funnel-shaped outlet, the commencement of the ureter.

The emulgent arteries which supply the kidneys with arterial blood, are derived from the posterior aorta; they subdivide and ramify into the substance of the gland, and end in a very complex network. The emulgent veins are much larger than the 
arteries; they accompany the latter, and finally converge into one trunk and terminate in the posterior vena cava. The nerves of the kidneys are derived from the renal plexus.

\section{THE URETERS.}

Each kidney is connected with the bladder by a common duct or tube, known as the ureter; these ducts are much stronger and larger than those found in the horse; they are composed of two tunics, the external one is both fibrous and muscular in a longitudinal direction, which permits it to contract and extend in exact ratio as the bladder contracts when empty and expands when filled. The internal membrane is of mucous texture, and is constantly lubricated with a mucous secretion which defends it against the irritating qualities of the urine.

\section{THE BLADDER.}

The bladder of an ox is much larger than that of the horse; it is a musculo-membranous sac, or bag, and is located within the pelvis, bounded above by the rectum, and below by the internal surface of the pubic bones. In the cow we find the bladder located between the rectum and the uterine organs. The bladder has a transverse ligament inserted into the lateral parts of the pelvis; it has three coats; one is derived from the peritoneum, or lining membrane of the abdominal cavity which gives the bladder an external covering - the middle coat of the bladder is composed of muscular fibres, which run in longitudinal and circular directions. The internal membrane or coat is more highly organized than the others; it is furnished with excretory outlets, from which issues a mucous secret? $\mathrm{a}$ for its own protection. The bladder is divided into fundus, body, and cervix. The fundus is that prominent part which faces anteriorly or towards the intestines, and when the bladder is full of urine, it protrudes into the abdominal cavity. The body is the bulky or capacious part generally more rounded wlyen full, than in the horse's bladder. The cervix is the neck or contracted part of the bladder; it is surrounded by muscu- 
lar fibres that involuntarily contract, so as to close the passage, except in the act of urinating. Some anatomists consider this muscle as a distinct one in the horse, and have given to it the name of sphincter, but in oxen it does not seem to be a dis tinct muscle, neither does it contract with that force or per sistency which is known to occur in the case of a horse:

\section{THE URETHRA.}

The urethra arises from the neck of the bladder, extends from it to the end of the penis; it is much smaller in calibre than in the horse; it affords a passage for the urine and seminal fluid.

Interiorly it is composed of mucous membrane, which is a prolongation of that found within the bladder.

\section{HAMATURIA.}

Hæmaturia signifies voiding of blood with the urine. In cattle raising districts, this disease, or rather the symptoms of one, is generally known by the term, "red water," although a very marked difference exists, between hæmaturia, and mere discoloration, or reddened appearance of the urine; for in the former case, blood globules are invariably present and their presence can be determined by procuring a sample of the urine; after letting it stand for a short time, the blood coagulæ may be detected by the naked eye, at the bottom of the vessel in which the urine is caught.

Causes of Hamaturia, - its character and symptoms. - The voiding of blood with the urine is generally supposed to be occasioned by some violence, such as local injury in the lumbar region, calculi within the ureters or the bladder; from local hemorrhage, occasioned by congestion, or inflammation of some portion of the urniary organs. Congestion is apt to occur in over-fed animals, and perhaps is an effort of nature to phlebotomize the subject and reduce the amount of circulating fluid, and thus lessen the liability to accumulate adipose tissue.

If such be the case (the patient being in a state of plethora), no immediate danger is to be apprehended; especially is this 
the case when the hemorrhage is merely passive, unaccompanied by symptoms of pain either at the time, or between the periods of urinating. A case of this character might very properly be termed congestive hæmaturia, and may be treated on the same principles which prevail in the practice of intelligent physicians in the management of other local congestions. Nephritis (inflammation of the kidneys), may occasion hæmaturia; and is almost always accompanied by sure and umistakable symptoms; viz., those of pain and irritation, either in the act, or else before or after urinating. It may be difficult to determine what is the exciting cause of this inflammatory con- dition; it may be purely idiopathic, or may arise from the irritation consequent on the passage of urinary calculi, through the parts involved, and notwithstanding there are certain diagnostic symptoms attending both varieties, still the medical attendant (who has just seen the case for the first time, may find it hazardous to venture an opinion on its exact pathology; yet, he shall not be at fault in treating the case as a local, inflammatory affection. If it can be shown that the animal has been dosed with strong diuretics, and no hemorrhage had existed prior to their administration, but is now quite profuse, we may safely conclude that the hemorrhage is occasioned by the local stimulus. It may therefore be laid down as a general rule, that all cases of hæmaturia, attended with symptoms of pain, are occasioned by the irritation of some foreign body acting on some part of the secretory surface of the urinary apparatus; or else, is the result of some external violence, and it is the business of the person who prescribes to carefully consider these matters, in view of forming a correct diagnosis.

Hæmaturia does occasionally occur in nursing women, of a plethoric diathesis; at the period of weaning the infant, the woman notices on urinating, that the fluid is tinged with blood, but, as the act is unaccompanied by pain, and nothing of the kind being felt in the region of the kidneys, she feels no alarm about it, and scarcely if ever, consults a medical man on the subject. In the course of a few days, all things being favorable, the urine assumes its natural appearance; therefore, if 18 
hæmaturia shall appear in a cow at the period of "drying her up," as the saying is, or if a cow shall be observed to pass blood in the urine, at the time of weaning the calf, and neither one nor the other manifest any discernible symptoms of pain, nor any perceivable manifestations of derangement in the vital functions, there will be nø necessity to resort to any very active mode of medication, and an intelligent physician would merely recommend a mild laxative, light diet, and a little nursing. A few doses of liquor acetate ammonia might be indicated as a febrifuge; this may be given from a bottle.

Should the owner of the animal be unable to obtain the services of a professional man, let him prepare some flaxseed tea * (a quart), then add half an ounce of powdered bloodroot, after which let the animal have six drachms of tincture of matico, diluted in a small quantity of water, night and morning.

Should the disease be traced to the presence of urinary calculi a lithontriptic will be indicated, which is prepared as follows :-

Muriatic Acid, ....................................2 ounces.

Water, ........................................ quarts.

Fluid Extract of Bloodroot, $\ldots \ldots \ldots \ldots \ldots \ldots \ldots \ldots \ldots \ldots, \ldots \ldots$ ounces. Mix.

The dose is one-eighth of the above quantity per day (see urinary calculi).

\section{INFLAMMATION OF THE KIDNEYS.}

Symptoms. - Cattle affected with inflammation of the kianeys, will be observed to have some slight roaching of the back, that is to say, instead of the back or spinal column being straight or slightly concave, as it ought to be, it now presents a convexity, or in other words is arched in an upward or superior direction. The arching of the back is occasioned by tonic spasms of the psoas and iliac muscles, located above the kidneys in the lumbar region. These muscles are known to butchers as "tenderloin."

On making pressure over the region of the kidneys, the animal will be observed to flinch; the parts appearing very tender and hot. The animal is generally dull, the muzzle dry, 
a chilliness of the horns and external surface is observed; showing very clearly that there is an unequal circulation of the blood. There is generally some difficulty in passing the urine, the animal strains in the act of passing it, and it is redder than usual. The symptoms vary as the disease progresses, but the above are the principal ones on which the diagnosis must be founded.

Treatment. - Drench the animal with sixteen ounces of glauber salts dissolved in a quart of warm water; then apply warm water bandages to the region of the loins, which may be retained in situ, by encircling the body with a bandage. An emollient clyster of slippery elm should occasionally be thrown into the rectum, and the patient should be drenched with four ounces of the liquor acetate of ammonia every six hours, until an improvement takes place. Then give tincture of matico in in half-ounce doses, night and morning, until the patient is better.

\section{URINARY CALCULI.}

Cattle are occasionally the subjects of urinary calculi, yet there are not many cases of the kind on record, and during a practice of fourteen years in this State, the author has never been called upon to prescribe for, nor treat, a case of this character. This testimony is diametrically opposed to that of Youatt and others. Youatt contends that "concretions are oftener found in the urinary passages of cattle than of the horse." This testimony is not in accordance with the experience of our "American cousins." In England, however, cattle may inherit some peculiarity of constitution, which causes a tendency to the formation of concretions, or perhaps the water they drink may be impregnated with alkalies, so as to induce an alkaline diathesis. Urinary calculi are generally composed of carbonate and phosphate of lime, carbonate of magnesia, and some animal matter.

Should calculi be present in either the kidneys or ureters, they are sure to occasion some degree of pain. The urine will be reddened, and sometimes blood corpuscles can be detected in the same; after a while, some muco-purulent fluid 
will be discharged with the urine. In this stage, it might be advisable to give the animal one ounce of acetic acid, in sixteen ounces of water, per day, to be continued a week or so. Should the general health be impaired, let the animal have a few doses of the following:-

Balmony, or Snakehead,.................................4 ounces.

Carbonate of Soda,..................................2 ounces.

Powder of Slippery Elm,.............................. 8 ounces. Mix.

Divide the above into eight parts, and give one every night in the food.

If the urine has a bad odor, let the animal have half an ounce of hyposulphite of soda every day for a week. This article can be dissolved in the ordinary drink.

\section{CALCULI IN THE BLADDER.}

A stone once having formed in the bladder, will defy all our attempts to dissolve or decompose it; yet if any one wishes to try the experiment, they can resort to the use of muriatic acid, sufficiently diluted with water, to render it harmless to the animal tissues with which it may come in contact. The stone can, however, be removed by the operation of lithotomy, which will require the services of a skilful surgeon. In such a case, the owner may possibly decide upon slaughtering the animal, perhaps this is the best thing he can do.

Symptoms of Stone in the Bladder. - There are various symptoms of deranged health which often attend stone in the bladder; yet, as they frequently accompany other diseases, and throw no special light on this, I shall take no notice of them, but offer something brief, yet more reliable.

The presence of a stone in the bladder will generally occasion some interruption to that free and uniform flow of urine, which takes place in a healthy animal without any symptoms of stone in the bladder; consequently, if in the act of urination the flow of fluid is suddenly stopped, to commence again a few moments afterwards; at the same moment a. slight trembling of the hind limbs is observed, and the animal strains, ineffectually, to urinate, only passing a few drops, and this state of 
things has existed for some time past, we may safely infer that a stone exists in the bladder.

\section{BLACK WATER.}

A discharge from the urethral outlet, of fluid quite black in color, very frequently indicates a grave form of disease existing in the liver; should black colored matter be detected in the urine, the probabilities are that the animal will die; for the disease which gives rise to the abnormal discharge is probably organic.

In some cases black water is occasioned by engorgement of the liver, spleen, or kidneys, and when an animal dies of these engorgments, we find the capillary veins much distended; and these engorgments frequently occur also in many of the diseases of an epizoötic or malignant character. Such condition or congestion, is owing to a loss of equilibrium in the circulation; the arteries are very impressible to excitation, and hold out their physiological actions the longest; the veins being more distensible than arteries, the blood is forced into the venous radicles faster than they can absorb it; hence the free egress of blood is retarded; the result is, an accumulation of blood distending the organs or veins, producing engorgements and a darkened color of the blood and tissues. The blood assumes a darkened color partly from delay, and partly from deficient pulmonary absorption and aeration. The causes of these local congestions are not always to be determined, yet they almost always receive their chief force from a morbid habit pervading the general system, at least this is the case when no local disease exists to account for them.

Treatment of Black Water. - The principal object in the treatment of black watcr, is to equalize the circulation and decarbonize the blood; diffusible stimulants and nauseants, fulfil the first indication, and ammonia the latter; therefore I use the following:-

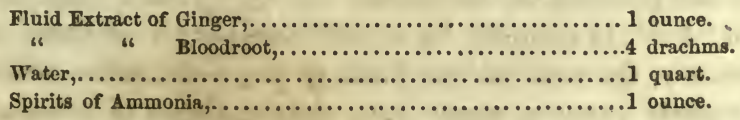

$18^{*}$ 
Mix the ingredients in the above order. Give one-eighth of the above quantity twice daily. Friction on the external surface with a good stiff brush, will prove also beneficial.

If the darkened color of the urine is owing to functional derangement of the liver, which may be known by the brown and yellow color of the membranes of the mouth, I should use the following:-

Powdered Podophyllum, ..........................1 ounce.

" Hyposulphite of Soda,.....................2 ounces.

Mix, and divide the mass into six parts; give one, night and morning, in a pint of water. Grass, if it can be obtained, is the best food for such a patient.

\section{RED WATER.}

The changes which occur in the color of urine are the results of various causes. In a preceeding article the reader is informed that hæmaturia, - voiding of blood with urine, - is traceable to certain direct causes, hence the difficulty is of an acute character.

Now suppose we take a well animal as a subject for experiment; we administer repeated doses of sweet spirits of nitre, or tincture of juniper; the first thing we notice is, the urine is augmented, or rather more profuse than usual, and of a pale color; continue the medicaments over a given period and the urine assumes a darker color, first yellow, next brown or coffee colrr, purple, or even black; this shows conclusively that the color of the urine can be altered by the use of medicinal agents; therefore, if a reddened appearance of the urine follow the exhibition of strong diuretics, the cause is plain enough and the cure is effected by discontinuing the diuretic medicine, and in restoring the equilibrium of action which should exist among the various excretory organs. Various kinds of food are also operative in producing changes in the color and quantity of the urinary secretion; beets and carrots when "fed" in quantity for a sufficient length of time, alter essentially, the color of the fluids of the body, urine included. As regards quantity, musty oats, and an excess of stimulating 
food are notorious causes, in explanation of augmented and discolored urinary secretion.

Discoloration of the urine, which some of our Western farmers term "red water," is usually occasioned by derangement of the liver, and other parts of the digestive apparatus; the urine, however, is more likely to have a tinge of brown or yellow than red, and therefore several writers, Mr. Youatt included, have termed such cases "chronic red water," and they all agree that such an affection is not primarily, one of the kidneys, but of the liver, and I presume that the "red water," which prevails among cattle in the West, owes its origin to the same causes as above; for example: A friend informs me that he lost a valuable cow, "which died of red water," and that the urine was of a "yellow-brown color," indicating very clearly that the animal labored under an affection of the liver, and in view of dispelling all doubt on the subject, I here introduce a short paragraph from my correspondent's letter:-

"On skinning the animal $I$ found that the parts beneath (subcellular tissues) had a yellow appearance. On cutting open the abdomen, I noticed that the liver was of a very dark color, and appeared to be filled with black blood ; the gall bladder was very large and appeared darker than usual ; the manyplies (manyplus) was full of caked food, and there were no appearances of disease in any other parts."

Of course it will be perceived that my correspondent was far from being an adept in the art of autopsy, however, the appearances which he has described, lead us to the necessary conclusion that the so-called red water (which he contends caused the death of his cow) was the result of functional, perhaps organic, disease of the liver.

Mr. Youatt, when discussing the theory of the pathology of chronic red water, offers the following: "Chronic red water is more prevalent than that which is acute, and in its first stage is far more a disease of the digestive organs and especially of the liver than of the kidney.

"The urine is observed to be of a brown color, or brown 
tinged with yellow; the beast feeds nearly as well as before, but ruminates rather more lazily. In a few days a natural diarrhœe comes on, and the animal is well at once; or a purgative drench is administered and a cure is presently effected. This occurs frequently in cows and calves of weak constitution.

"At other times there is manifest indisposition; the animal is dull, heavy, languid - the ears droop, the back is bowed, she separates from the herd, she refuses her food, she ceases to ruminate. Presently she gets better; she rejoins her companions; but this is only for a little while. The urine, which at first was brown, with a tinge of yellow, has now red mingled with brown, or it is of the color of porter. It is increased in quantity; it is discharged sometimes with ease, at other times with considerable straining - in little jets, and with additional bowing of the back. The milk diminishes; it acquires a slight tinge of yellow or brown, the taste becomes unpleasant, it spoils all that it is mingled with. The pulse is accelerated; it reaches to 60 or 70. If blood is drawn, the serum which separates from it is brown. The skin is yellow, but of a darker yellow than in jaundice, it has a tinge of brown. The conjunctiva is also yellow, inclining to brown. The urine becomes of a darker hue, it is almost black. The animal usually shrinks when the loins are pressed upon; occasionally there is much tenderness, but oftener the beast scarcely shrinks more than he is accustomed to do when laboring under almost every disease. The belly is not so much tucked up as drawn together at the sides. There is considerable loss of condition; the legs and ears get cold; the animal is less inclined to move ; there is evident general debility. In every stage there is costiveness, and that exceedingly difficult to overcome, but on close inquiry, it is ascertained that there was diarrhœa at the beginning, and which was violent and fetid, and which suddenly stopped."

Testimony of this description emanating from reliable authority, is entitled to our consideration, and it should teach us to seek for the cause of discolored urine beyond the region of the kidneys, except in those cases which are evidently the re- 
sults of the action of diuretics or stimulants in the form of improper food. It will generally be found that discolorations in the urine are the symptoms of a disease located elsewhere, hence the disease should be treated instead of the symptoms.

If the disease appears to be located in the liver, indicated by a yellow tinge of the visible surfaces, dark colored fæces, yellow tinge of the urine; the animal being dull and sleepy, showing symptoms of febrile action, it may be proper to administer a dose of purgative medicine, combined with some agent, calculated to restore the physiological action of the liver, and I therefore recommend the following :-

Epsom Salts, ...................................12 ounces,

Podophyllum Peltatum (mandrake),................... 2 drachms.

Dissolve the salts in tepid water, one pint, then add the podophyllum, and then administer the same by means of a "drenching horn," or bottle.

In administering medicine to cattle, our object is to get it beyond the rumen or paunch into the digestive compartment of their complex stomach, and in aiming to do this we pour the medicine down the œsophagus slowly.

After the bowels have responded to the action of the medicine, it may be proper to administer alteratives, which are known to change morbid action; powdered sulphur and mandrake may be given in small doses, not sufficient of either to keep up the cathartic action of the salts, but merely to keep the bowels in a soluble condition for a day or two, and if there be any danger of superpurgation, neither mandrake nor sulphur are indicated. In such case I should give an occasional dose, 2 drachms, of powdered goldenseal (hydrastis canadensis), and the same quantity of carbonate of soda. The patient should be fed sparingly, and if the season permit, a run in the pasture will prove beneficial. 
THE HEART, ITS FUNCTION AND DISEASES.

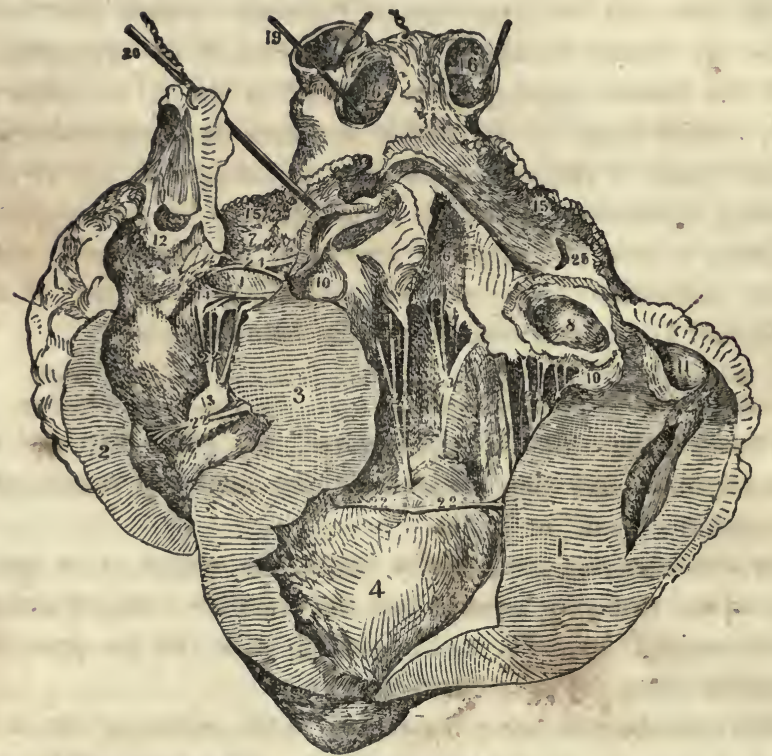

VIEW OF THE INTERIOR OF A BULLOCK'S HEART. For explanation see p. 392.

THE heart is a wonderful and powerful piece of muscular mechanism; its function is of the involuntary order, so that regular contractions and expansions, or beatings, occur in the normal state, without the knowledge and consent of the animal; these contractions and expansions, however, can be modified by means of various medicinal agents which act upon the nervous system, thus producing a sort of mixed action - voluntary and involuntary. For example; all medicines known as sedatives operate so as to depress the heart's action, and lessen for a given period the number of its pulsations; while on the other hand stimulants augment the action of the heart, and increase the number of its pulsations.

The average weight of the heart of an ox is eight pounds, yet it is frequently the seat of fatty degeneration, when its weight and bulk is then materially increased. 
The heart is anatomically divided into four cavities, two of which being in a superior and anterior direction; and in consequence of bearing some resemblance to the ears of a dog, are termed auricles. These cavities known as right and left (or rather anterior and posterior), are divided by a wall or septum, known as the septum auriculorum.

The right auricle is the receptacle for venous blood, and three venous trunks terminate in it; viz., the anterior vena cava, which returns the venous blood from the anterior extremities, head and neck - next, the vena cava posterior, which returns the venous blood from the posterior parts, and lastly the coronary vein; the latter returns blood which has circulated through the heart itself for its own nourishment. A considerable quantity of dark venous blood is generally found in this auricle after death, and it opens into the right, or anterior ventricle, by an aperture denominated the auriculo-ventricular opening, yet in consequence of a valvular contrivance within the ventricle, the blood cannot recede into the auricle.

- Internally, the right auricle is lined by a glistening vascular membrane having on various parts of its surface small muscular eminences, termed musculi pectinati; the small cavities which occur, in consequence of this arrangement, are termed cul-de-sacs. The right, or venous ventricle, is also lined by a nicely organized membrane and has beneath it several muscular prominences named carna columna which give origin to as many tendinous slips, these are known as corda tendina, they are inserted into a fibrous membrane in the region of the auriculo-ventricular opening, and then get the name (membrane included) valvula tricuspis. The lateral contractions of this ventricle are aided by small.tendinous cords having muscular origins from the wall and septum. The venous blood passes from this cavity into the pulmonary tissues of oxygenation, through the pulmonary artery, which emerges from the superior part of the ventricle. At the commencement of the pulmonary artery are found three valves termed semilunar, their function is to guard against a retrogade movement of the 
blood, so that it has no other channel than this which leads to the lungs.

The left auricle, has scarcely any anatomical or structural differences than those observed in the right, although its cavity is smaller, and its walls are somewhat thicker than those found on the right, it receives the blood from the lungs, after purification, by means of the pulmonary veins, which have four openings into this cavity, two proceeding from the right, and two from the left lobes. The left, or arterial ventricle is the reservoir for arterial blood; which is destined to re-animate, replenish, and perpetuate the vital economy; having a vastly more important function to perform (which requires augmented muscular mechanism), than its duplicate found on the right side; the thickness of its walls, must therefore necessarily, exceed those of the right; this is found to be the case, so that the outer wall of this is about three times as thick as that found on the other side, and this guide is useful to us, in determining, at sight, after the heart is detached from the body, which is the left ventricle and vice versa.

The channel of communication between the left auricle and ventricle is named as is the case on the opposite side, auriculoventricular opening; it is furnished however with only two, instead of three, valvular openings termed valvula bicuspis or mitralis.

This ventricle is one of importance for our consideration from the fact of the great aorta - the plastic hose, which seldom if ever, requires cobbling or repair-here originating. Its margin or outlet, is guarded by a complete set of valves, three in number, termed semilunar, similar to those found at the origin of the pulmonary artery. This ventricle is divided from the one on the opposite side by a muscular and tendinous partition termed septum ventriculorum.

Form, situation, and attachment of the heart. - Its form describes that simulating a cone having a body, base, and apex; its base being in a superior direction, it follows as a matter of course, that its apex has an inferior insertion downwards and backwards. 
Situation. - The heart lies in the region occupied by the fourth, fifth, and sixth dorsal vertebræ, right in the central region known as the cavity of the chest. Its apex is inclined to the left side.

It appears that in the ox, the heart differs in construction from that of the horse, in the following peculiarities. There is a bone found in the heart, termed, os cordis, the function of which has never been explained; yet it is evidently intended for some useful purpose, perhaps to give strength and durability to the sanguinous force-pump. Next we notice some difference in the internal mechanism of the right ventricle; there are several fleshy bands running across from side to side which prevents abnormal dilatation, for taken as a whole, the venous system of the bovine species is more developed than in the horse, the veins are larger and more numerous, and more blood is constantly accumulating in the right auricle and ventricle hence the need of additional muscular mechanism.

\section{THE HEART'S FUNCTION.}

The blood having gone the rounds of the circulation, enters the anterior or right cavity - auricle - it then passes into the venous or right ventricle; by the contraction of this ventricle the blood is forced through the pulmonary arteries into the lungs, there having undergone certain changes (which have been alluded to in another part of this work), it returns by the pulmonary veins to the left auricle, from thence it descends into the left ventricle. The contractions of the left ventricle force the blood into the great aorta - anterior and posterior - which gives rise to a numerous 'set of arteries, through which channels the blood reaches the extreme parts of the system.

\section{DISEASES OF THE HEART.}

Diseases of the heart in cattle are very common, yet they. frequently elude detection simply because the symptoms are rery obscure. Mr. Gamgee contends that the most common cause of diseases of the heart in cattle, is the passage of needles 
and other foreign bodies from the reticulum through the diaphragm; at the same time he alludes to many drawings in his possession of polypi in the heart, growing from the auriculoventricular valves; also to drawings of deposits beneath the endocardium - lining of the heart's cavity - of tumors also. outside the heart, consisting in masses of cysts, and due to the development of hydatids of the echinacoccus veterinorum.

\section{DILATATION OF THE HEART.}

The heart is often the seat of dilatation, or amplifications of one or more cavities, with attenuation of the walls of the same. This dilatation is supposed to arise from the mechanical effect of over distention.

The causes of dilatation are: deficient power in the heart in proportion to that of the system; this may be acquired or it may be congenital; all obstructions also to the circulation, whether situated in the orifices of the heart, or in the aortic or pulmonary systems, may induce this dilatation.

Symptoms of dilatation of the heart. - The pulsations are feeble and oppressed, and on moving the animal about he becomes distressed; the pulse is soft and feeble; languor in the arterial circulation, as shown by the congested state of the mucous surfaces. The respiration is somewhat affected, not primarily, but through the intervention of irregular nervous action. The jugulars are engorged, and various parts and organs of the body are congested, and the surface and extremities are below the natural temperature.

Treatment of dilatation. - The principal object should be to improve the general health, by alteratives and tonics; the surface of the body should be kept warm, and often rubbed, so as to excite capillary action, this will also have the effect of relieving the venous congestions. Any hygienic measures regarding both diet and management, which common sense may suggest, will certainly do good; pure air, for example, is absolutely needed to vitalize the blood as it tardily courses the veins; without such there is very little chance of restoring the animal. 
The alteratives and tonics may be prepared as follows:-

Powdered Iodide of Potassium,.................... $1 \frac{1}{2}$ scruples.

" Goldenseal,............................... drachm.

Dissolve the potassium in a pint of water, then add the goldenseal. This may be given daily for a week or more.

\section{THE PERICARDIUM AND ITS DISEASES.}

The pericardium is a membranous bag that surrounds the heart; it is known to butchers as the heart-bag, and is attached to the sternum, diaphragm, and to the roots of the large bloodvessels at the base of the heart. It is composed of two layers united by cellular tissue; the external one is composed of fibrous tissue, the internal one is a smooth serous membrane, similar to that which lines the cavity of the chest. This serous membrane is studded by numerous vessels called exhalents, from these issue a vapor of fluid, the purpose of which is to guard against friction. The insertions of the pericardium are such that it confines the heart in its proper situation, and aids in sustaining a reciprocal action between the heart ard lungs. It is often the seat of a disease known as Pericarditis.

\section{PERICARDITIS.}

This disease consists of inflammation of the pericardium, the causes of which are supposed to be nearly the same as those of pleurisy or inflammation of other serous membranes; viz., sudden impressions of cold on the external surface, violence, etc. A special cause has also been assigned for this disease; viz., the penetration of the pericardium by foreign bodies, such as nails, needles, wire, etc., coming from the interior of the stomach, working their way through it into the former.

Symptoms of pericarditis. - There is considerable increase in the force of the heart's pulsation; the jugular veins are engorged - larger than usual - and an undulating movement is observed in them. There will be acute inflammatory fever, generally preceded by rigors, shivering, and coldness, the visible surfaces of the nostrils and eyes are highly reddened in the early stages, and rumination has ceased with loss of appetite: 
the animal occasionally directs its head near the region of the heart, and if pressure be made on the sternum - breast bone -it elicits distressing symptoms. As the disease progresses the jugulars increase in volume, the pulse becomes feeble, and an œdematous, or dropsical state of the lower parts of the thorax sets in; this latter feature indicates that a considerable quantity of fluid is present, both in the pericardium and thorax. In this stage the case is incurable.

In the early stage of pericarditis, the treatment should be about the same as that recommended for acute pulmonic, and pleuritic affections. Iodide of potassium, in doses of twentyfive grains per diem, may prove serviceable, and some form of diuretic medicine may also be exhibited to increase the action of the kidneys ; so soon as the patient shows signs of amendment, tincture of matico, in ounce doses, may be given twice daily until the patient has fairly recovered.

The London Veterinarian publishes, the following case, furnished by surgeon Lepper :-

"I herewith send you what I think is a rare specimen of a diseased heart, with its investment, which was taken from a cow of the short-horn breed, about seven years old, the property of Mr. Bliss, of Windmill Hill, Waddesdon.

"On the fourth day after calving she was noticed to fail in her appetite, and her milk also became greatly diminished in quantity. In walking across the yard she staggered and fell. She laid for some considerable time, when with difficulty she got up and walked to a shed, where she soon laid down again. It was in this condition that I first saw her. The expression of her countenance did not materially differ from that of a healthy animal. The bowels were regular in their action; the pulse did not exceed fifty beats in the minute, and was soft and full. On the left side of the chest there was an emphysematous swelling, extending over four or five of the middle ribs and about eight or ten inches wide. On auscultating the chest I could not discover any unusual sound in the respiratory action; the breathing also was regular. The jugular veins were filled to repletion, so as to be observable when standing 
by the side of the animal; a state of things which $I$ have invaribly found to exist in effusion into the pericardium, and especially if much fluid is present. I felt satisfied that this was a case of this description, and consequently formed an unfavorable opinion'as to the issue. To relieve the distended vessels, I took away eight or ten pounds of blood, and gave a slight purgative, which appeared to aftord temporary relief.

"For two or three days the appetite improved, and the cow appeared to move with greater freedom and less pain. On the sixth day after my first visit she suddenly relapsed, and died on the seventh.

"This animal had for some time past wasted in flesh, but as her general appearance was healthy, little notice was taken of it. It is surprising that she should have gone on so well as she did with so extensive disease of the heart, As to the nature of the affection I shall offer no remarks, but leave this to be explained by you."

The following remarks are added by the editor of the above named journal. "This was but another of several specimens which we have received from time to time, in which the external surface of the heart was covered with layers of effused and partially organized fibrine. The pericardium was thickened to three times its natural substance, and within it was contained several ounces of colorless serous fluid. The effused fibrine hung in grapelike appendages from the base of the heart, each of which had a floculent condition. These bodies were devoid of color, and had altogether such an appearance as would lead us to doubt whether the effusions resulted from active inflammation. The muscular substance of the organ and its internal lining membrane were alike free from organic change. A similar specimen was, a few years since, laid by us before the Pathological Society, and will be found published in the record of its proceedings."

The following case which occurred in the practice of $\mathrm{Mr}$. Williams, may also prove interesting and instructive to the reader.

"On the 16th of June, I was requested by Mr. Thomas $19 *$ 
Tatum, Gwernafield, to attend,a cow of his. Her history he gave as follows:-

"She has been unwell since she calved, three weeks ago. The foetal membranes were not expelled for a fortnight after the event, and they came away piecemeal in a state of putresence. Her appetite has been very capricious all along, and her bowels rather costive. A discharge of white matter has taken place from the vagina for the last week or so. She gives but little milk. The breathing is tranquil, and she does not cough. She has a peculiar stare in the countenance, and takes a great deal of notice of every thing. On inspection I found her as the owner had stated; the symptoms, to a casual observer, being any thing but indicative of extensive organic changes, but more of general debility after parturition; she was rather emaciated. On closer examination, I found the mucous membranes to be rather pallid; the mouth cool and moist ; the temperature of the body but slightly below the natural standard, and equal over all parts of the body; the pulse very weak, beating 96 in the minute, and regular; the breathing only very slightly hurried. After advancing thus far in. my examination, I must confess that the case fairly puzzled $m e$, and I was inclined to look on it as one of general debility and leucorrhœa. But as the discharge from the vagina was very slight, I thought it could not be the sole cause of the loss of appetite and other symptoms present. I now auscultated the chest, and on applying my ear, the respiratory murmur was heard distinct and natural, but I thought a little increased at the anterior portion of both sides. On auscultating the region of the heart, I failed to detect the sounds of that organ, and on still further examination, both the sounds and the impulse were indetectible. This struck me as being curious, but on account of the regularity of the pulse $I$ did not consider either the heart or its membranes to be the seat of disease, and treated the case as one of general debility, loss of appetite and leucorrhoea. The animal lingered for about four weeks more, the symptoms remaining nearly the same as at the time when I first examined her, with the exception of increased emaciation. 
"The post-mortem revealed anæmia, the tissues being exceedingly pale and sodden, the blood in the vessels scanty and pale, and scarcely staining the fingers. The abdominal viscera were healthy with the exception of the liver which was congested. The gall-bladder was distended with dirty, lemon-colered bile, of thin consistence, and seemingly containing a large amount of mucus. On opening the cavity of the thorax, the pericardium was seen distended to an enormous extent, filling the floor of the cavity, and adherent to the sternum and pleura costalis by a thick layer of exuded lymph, this having no appearance of organization, but seemingly consisting of a shapeless basis-substance, easily separated from the parts it was in contact with. The cavity of the pericardium contained at its inferior part, about two pints of a fetid, wheylike fluid. With the exception of that part which contained this fluid, the cavity was obliterated by exudation, matter about two inches in thickness surrounding and glueing together the visceral'and parietal surfaces of the pericardium. The heart itself was flably, pale, and its cavities contained a small amount of blood, of the same thin consistence as that in other parts of the body. The endocardium was healthy. The lungs presented no appearance of disease ; they were pale, excepting in the parts lying undermost after death. The pleuræ, excepting where they were involved in the pericardiac disease, presented no abnormal appearance. The thoracic and abdominal cavities contained a little fluid.

"Feflecting on the appearance presented by the pericardium, by its being adherent through the accompanying pleuritis to the walls of the thorax and sternum, and by the heart itself being thus in a manner bound down and fastened by a thick layer of plaster, and elastic material existing between it and the ribs, I was satisfied that the absence of the sounds of impulse was due to these pathological changes, and not as I had foolishly supposed to general debility. But before giving publicity to this opinion I thought it better to wait for more proof.

"September 4th, 1857, I was called to attend a cow, the property of W. Gregg, Esq., Syntroll, Mold. I had attended her in May previous, for ' retention 'of the fœtal membrane.' She 
seemed to be very languid and depressed for some days before and after the removal of these; but as she fed pretty well, I was not requested to prescribe for her. She had given milk freely all the summer, but had not appeared so lively as she ought to be ; she seemed as well as usual on the evening of the $3 d$ of September. On the morning of the 4th her quantity of milk was diminished. On examination I found her wet and cold from the rain of the previous night, standing 'all of a heap;' head depressed and ears pendulous; mouth and nose cold, breathing tranquil, the bowels costive, pulse 100, very feeble but regular; the mucous membranes slightly tinged yellow. Auscultation failed to detect the sounds of the heart, and the palpitation was absent. I pronounced the case to be one of pericarditis, and that exudation had taken place to some extent, also that congestion of the liver existed, this being secondary, and owing to the feebleness of the circulation.

"The treatment consisted in the administration of purgatives and stimulants. Counter-irritants were also applied to the sides, and as the case advanced tonics were given. But nothing seemed to affect the pulse: it remained feeble throughout, and it was only a few days before death that irregularity was detected.

"On Friday, September 18th, diarrhœa set in, and on the 21 st, œdematous swellings appeared in different parts of the body, but more especially on the dewlap and fore parts. On the 23d she dropped down and died without a struggle.

"All throughout, this animal exhibited the same watchful state as observed in Case $I$, and the appetite was very capricious indeed. One day she would feed pretty well, then again she would not touch any thing for days. The bowels were very irregular, and on account of rumination being suspended, the food passed through her in a half-masticated state.

"'The post-mortem, four hours after death, revealed general anæmia of the subcutaneous and muscular tissues, these being seemingly in a broken-down condition. The blood in the veins was pale and thin. The abomasum, small intestines, and liver, were congested; but even here the blood was of the same 
watery character as in other parts. The gall bladder was distended with thin, lemon-colored bile. The thoracic cavity contained rather a large amount of clear serum. The pericardium was distended by a layer of lymph, about two inches in thickness glueing together its two surfaces, and containing near the apex of the heart nearly a pint of dirty, whey-colored fluid, of a fetid odor. The lymph was easily removed from the heart, and between it and the muscular tissue of the organ, was a layer of cartilaginous substance, about a quarter of an inch in thickness covered by a serous glistening membrane. Toward the apex of the heart this had formed bands of connection between the two surfaces of the pericardium, but in all other parts it was confined to the visceral pericardium only. The lungs were slightly congested. The pleuræ was as described in the former case."

\section{HYPERTROPHY OF THE HEART.}

Hypertrophy signifies augmentation - thickening of the muscular substance of an organ, resulting from increased nutrition. It generally occurs in animals of the sanguine temperament, of vigorous health, their muscles being much harder and firmer than usual; in such animals the blood is rich, and nutrition is very active. I have often visited our market in this city, for the purpose of inspecting the hearts of slaughtered oxen, and I have observed that hypertrophy generally occurs in the left ventricle; sometimes its walls are thickened, the cavity retaining its natural dimensions; occasionally the cavity is dilated and the wall thickened, but in the majority of cases the walls are thickened and the cavity diminished; this constitutes the disease known as true or concentric hypertrophy - enlargement.

This disease when moderate and uncomplicated, is not productive of much inconvenience to the bovine species, whose motions are slow, yet occurring in a horse it would produce much inconvenience, and render the animal almost useless for speed. 
Symptoms of hypertrophy. - A person unacquainted with the heart's sounds, will find it impossible to diagnose a disease of this character, in fact, such a disease will sometimes defy the scrutiny of experts. A deadened sound is always heard when the ear of a person is applied to the region of the heart, yet this depends somewhat on the form of the disease, its complications, the nature and intensity of the exciting causes and the condition of the patient. On applying the finger to the pulse at the angle of the jaw, or on the temporal artery it will appear that the circulation is embarrassed.

Treatment. - No rules can be laid down for the treatment of this affection, and the only agent of any value is iodine, or, iodide of potassium. It is possible, however, that in a case of this character, the butcher may prove to be the best doctor.

\section{ENDOCARDITIS.}

Endocarditis is an inflammatory affection located in the membrane within the heart. It is a rare disease among cattle, yet very frequently occurs among horses.

Symptoms. - Like all inflammatory conditions, this is attended with heat about the base of the horns ; lot and feverish mouth, vitiation of the secretions, cessation of rumination; some degree of suffering of a peculiar character not noticed in any other affection. 'The pulse is violent, abrupt, strong, full, and may range up to eighty; every motion the animal makes accelerates the respiration; yet the lungs show no signs of disease. On examining the heart after death, its internal membrane is thickened and appears of a dark purple color; clots of extravasated blood, are also present on its internal surface.

Treatment. - Administer a cathartic drench, about sixteen ounces of glauber salts in a couple of quarts of tepid water; then give half an ounce of powdered nitrate of potassa in a littl? water, every four hours, until the force of the pulse is essentially lowered; in the mean time administer an occasional clyster of salt and warm water. 
This disease has, occasionally, a rheumatic origin; so that if an animal be taken suddenly with inflammatory muscular lameness assuming the form of rheumatism, shifting from one limb to others, and then it leaves the regions of its first attack and goes to the heart, I should resort to wine of colchicum in the proportion of one or two drachms per day, in addition to the above remedies.

The heart is subject to various other diseases, among them sarcomatous growths projecting from the auriculo-ventricular valves: fatty, and true degeneration of the heart; cysts and abcesses in the substance of the heart; ossifications, etc., etc. These and kindred diseases always terminate fatally, therefore I shall not trouble the reader with any further remarks on these subjects.

\section{$+$ \\ DISEASES OF THE EYE AND ITS MEMBRANES.}

DESCRIPTION OF THE EYE.

The eyes of oxen are frequently the seat of various forms of disease, hence it is necessary that the farmer should know something of their wonderful mechanism; I therefore propose to give a description of the same.

The eye is protected by a bony casing known as the orbit, which appears to be much stronger than that found in the horse; in the interior part we find a large quantity of fatty matter which acts as a soft cushion for the eye to repose on, and at the same time as the fatty matter accumulates, it gives prominence to the eye and increases the range of vision.

\section{HUMORS OF THE EYE.}

The humors of the eye are named aqueous, chrystalline, and vitreous - three in number. The aqueous humor fills the interval between the cornea and chrystalline lens, and is sur- 
rounded by a capsule of its own, on the inner surface of which is secreted the aqueous humor; the uses of this limpid fluid appears to be, to transmit the rays of light and permit free motions of the iris; the fluid is frequently evacuated and reproduced.

Chrystalline Lens. - These are situated in a concavity behind the aqueous humor, and anterior to the vitreous, opposite to the pupil ; in appearance it resembles a chrystal, or lens of magnifying glass, and is composed of concentric lamellæ, and these of radii. Its form is spherical, yet the posterior surface is more convex than the anterior. Like the other humors of the eye it is enveloped in a capsule, and the disease known as cataract, consists of altered structure, in the lens or its capsule ; sometimes both are involved. Acids, alcohol, and boiling water convert it into an opaque, solid body, resembling the white of an egg when boiled. The function of the chrystalline lens is to concentrate the rays of light so as to form a distinct image on the interior of the eye.

Vitreous Humor. - This jellylike substance derives its name from its glassy appearance; it occupies the posterior concavity of the globe of the eye, known as the "dark-chamber." It fills the membranes, aids to maintain the form of the eye, and keeps the chrystalline lens at a proper, and physiological distance from the retina. Anatomists have hitherto failed in detecting any signs of vascularity in the vitreous humor.

\section{COATS OF THE EYE.}

1st. Tunica Conjunctiva. - This membrane is very highly organized, lines the eyelids, and is reflected over the anterior part of the eye-ball; it covers the region known as the pupil, yet is pervious to the rays of light. Previous, however, to being reflected over the globe, it gives a covering to the membrana nictitans, carunculæ lacrymale, and puncta lachrymalia.

2nd. Tunica Sclerotica. - This tunic is made up of fibres, which are very dense, yet elastic; it constitutes what is commonly known as the "white of the eye," extends from the 
junction of the optic nerve with the globe, to the cornea, and more than any other tunic of the eye tends to preserve its form. It also affords attachment for most of the muscles of the eye, the retractor and four recti.

$3 d$. Cornea. - This is a dense and compact membrane, yet composed of laminated structure, which accounts for the opacity or "filmy" obscurity so often encountered in veterinary practice; for, in a physiological condition of the eye, the laminæ are compact, like a house newly shingled; but, in consequence of untoward circumstances, a leak occurs, a watery exudation then sets in. The cornea may be considered as the shield that protects the eye, yet in consequence of its transparency, it is also operative in the production of vision.

4th. Iris. - This is the movable curtain of the eye, adapts the eye to vision, possesses the property of contraction and expansion; in its centre is a perforation commonly known as the pupil. The dimension of the pupil depends entirely on its contraction and dilatation; in a very dark barn (provided the eye be in a healthy condition), the pupil will be very much dilated; in a barn well lighted the pupil will be quite small. The iris is a fibro-muscular membrane, abundantly supplied with blood-vessels and nerves, and coated with a substance known as uvea which is derived from the pigment. The arteries of the iris come from the ciliary, its nerves are derived from the ciliary.

5th. Choroid Coat. - This coat or membrane lies beneath the sclerotica ; it extends from the optic foramen to the ciliary edge of the cornea; both of its surfaces are coated with pigment, which absorb the rays of light; the outer coating is entịrely black; the inner one is a mixture of black and green, which lines the posterior half of the dark ehamber.

6th. The Retina. - This is the third or inner coat of the eye; it is a delicate, transparent membrane, highly vascular; the principal part of it, probably, consists of an expansion of the optic nerve; it is the part on which the object of vision is depicted. It is supplied with blood by branches from the central artery of the retina. 


\section{MUSCLES OF THE EYF AND EYELIDS.}

The first muscle which attracts our attention on removing the palpebral integument, is the orbicularis palpebrarum; so named from the spherical or circular arrangement of its muscular fibres. It is inserted into the orbital portion of the ungis and os frontis, to the palpebral ligament, and to the skin of the lids. Its use is to shut the eyelids.

Levator palpebra Superioris. - The action of this muscle is to corrugate and draw the lid upwards; it is located above the orbit and is attached to the forehead by means of an aponeurotic expansion, and is inserted into the upper eyelid, its muscular fibres being blended with those of the preceding muscle. Its action is to raise the upper eyelid, in which action it is aided by the levator palpebræ, internus.

Next we find four muscles known as recti; viz., Levator oculi, depressor oculi, abductor oculi, adductor oculi; they are inscrted into the cavity of the orbit, and external part of the sclerotica at points equi-distant from each other. The action of these four muscles are as follows: The levator raises the eyehall in a superior direction; the depressor, as its name indicates, depresses the eyeball; the abductor turns the eyeball from the axis of the body outwards; and the adductor rotates the eyeball inwards, or towards the axis of the body.

The three remaining muscles, making seven proper, to the eye, are named, obliquus superiora et inferiora, and retractor oculi. The obliquus superioria, is found in the upper part of the inner cavity of the orbit; is-attached to the margin of the optic foramen; at the inner canthus of the eye, it passes through a fibro-cartilaginous pulleylikè arrangement, by which means the eyeball is rotated in an oblique direction upwards and outwards.

Obliquus Superioria.-This muscle is found beneath the eyeball, in the front and lower part of the orbit, it is attached to the os unguis, and to the lower and outer part of the sclerotica at its junction with the transparent part of the globe. Its action is antagonistic to that of the preceding muscle. 
The seventh and last muscle to be described, is the retractor; it is one of the most admirably arranged muscles in the whole animal economy; in figure it resembles a hollow cone; its apex turned backwards; its base pointing forwards, the inner edge surrounding the optic foramen, and at the same time offering protection to the optic nerve. Around its sides, equidistant, are found the four recti muscles, making a very complex and wonderful piece of mechanism. The action of this muscle is to draw the eye backwards within the orbit.

I shall now make some brief yet instructive allusions in relation to the appendages of the eye. The appendages romprise the eyelids, eyelashes, tarsal cartilages, meibomian glands, membrana nictitans, lachrymal glands, caruncula lachrymalis, puncta lachrymalia, lachrymal sac, and ductus ad nasum.

Eyelids. - The upper and lower eyelids may be considered as the movable blinds of the eye; the upper is the most capable of corrugation, and borders the greatest surface of the eyeball; it is readily resolved into wrinkles. At the junctures of the aperture which separates the eyelids, are the canthi or angles of the eye. The loose portion of integument entering into the composition of the upper lid, is derived from the skin covering the frontal region; and that of the lower lid is derived from the face. The lids, internally, form two cavities, thus adapting themselves to the convexity of the globe; their internal surfaces are lined with the tunica conjunctiva. The borders of the eyelids have two margins; on the outer one we find eyelashes; between the latter and the internal margin, we find the orifices of the ciliary glands through which issue a secretion, for the lubrication of the surrounding parts. The edge, or surface between the two margins just alluded to, conduct the tears into the puncta lachrymalis.

Fyelashes. - The eyelashes (cilia), are so familiar to the reader, and their function is so apparent, that $I$ need not trouble them with any remarks about them, only to observe, that by their advantageous arrangement, the rays of light, come from whatever direction they may, are somewhat intercepted, and they also operate as feeler's to the sceing as well as the sight- 
less animal, and warn him of his proximity with bodies that he cannot immediately perceive.

Tarsal Cartilages. - These fibro-cartilaginous substances, are found at the ciliary margins of the upper and lower lids; they possess firm and thick ciliary margins, yet grow thin as they recede from the cilia ; in consequence of their close connection with the rim of the orbit, they are called by some anatomists, "tarsal ligaments," their function is to give some degree of firmness to the eyelids, or the soft parts of the same, and they also preserve the physiological curvature of the eyelash.

Ciliary or Meibomian Glands. - On inverting the eyelids of a horse, and carefully running the eye over the borders of the lids, within the grooves, occurring in the concave part of the tarsal cartilages, we perceive through a very fine tunic or membrane, a number of opaque sacs, having a minature canal, capable of penetration by a small body equal in calibre to the point of a common needle. They are evidently glandular bodies, and therefore have excretory ducts, which pour out the necessary lubricating material to prevent the agglutination of the lids.

Membrana Nictitans. - This cartilaginous body, so shaped as to adapt itself to the convexity of the eyeball, and the concarity of the eyelid, is found at the inferior canthus. In horses it is known as the "haw," and in certain districts where the light of veterinary science never shines, a simple tumefaction of the nictitans is known under the unmeaning epithet of " hooks," and, unfortunately, the poor uncomplaining brute has to submit to an operation more barbarous than that performed with the scalping knife of the merciless Indian, who glories in the possession of a white man's scalp. The function of this membrane is to aid in the removal of foreign bodies from the globe of the eye, hence, it answers the purpose of a third eyelid.

Lachrymal Gland. - This gland lies underneath the process of bone known as the orbital arch; it is covered by the lining membranc of the orbit. It is a gland of the conglomerate elass, being composed of many lobules; these lobules are com- 
posed of granules, from which spring the excretory ducts, and they, by inter-union, from a set of tubes which terminate on the conjunctiva of the upper lid. The office of this gland is to secrete the tears, which run into the ducts, and are then poured on the conjunctiva.

Caruncula Lachrymalis - At the inferior canthus of the. eye, between the eyeball and eyelids, is seen a small black tubercle, called the caruncula lachrymalis; it is not a secretory organ, but appears to be placed there for the mechanical purpose of directing the tears into the puncta lachrymalis.

Lachrymal Puncta and Conduits. - The puncta are two small orifices, seen in the inner margins of the lids at the root of the caruncle; they are the openings of two canals found within the substance of the lids, termed lachrymal conduits; they terminate in the lachrymal sac.

Lachrymal Sac. - The lachrymal sac is a funnel shaped membranous bag, lodged in close proximity with the lachrymal foramen. This sac serves as a reservoir, into which the tears flow from the lachrymal conduits; the lachrymal sac terminates in the ductus ad nasum.

Ductus ad Nasum. - The office of this duct is to convey away the tears as fast as they are collected within the lachrymal sac; the duct terminates at the inner and inferior part of the nustril. It is formed by a prolongation of the membrane which enters into the composition of the lachrymal sac.

\section{GLASS EYE. - (Gutta Serena.)}

Glass eye - gutta serena or amaurosis - is an abnormal condition, which consists of dilatation of the pupil uninfluenced by the ordinary stimuli, light and darkness, and occurs in consequence of accidental or permanent paralysis of the optic nerve and its ultimate expansion, the retina.

Animals of an excitalle nerrous temperament often become the subjects of this afliction, as a temporary pathological con_ dition; yet that form of amaurosis occurring among fat or plethoric subjects whose digestive organs are either deranged 
or occupied with a mass of imperfectly digested food, the patients bordering on that peculiar condition known, as it occurs in the equine species as "stomach staggers," can easily be explained on the universal law of sympathy which pervades the animal organism.

I may, however, assign an indirect cause for its occurrence in the eyes of excitable and nervous animals; for this very condition, apparently, and truly pathological, which gives rise to the excitability, perhaps goes far to show that the brain is the seat of functional derangement, and this functional dificulty may have its origin in a deranged condition of the stomach or liver.

Amaurosis can be easily produced by administering a few doses of extract of belladonna. This is a mere artificial state of the retina (pupil), which only continues while the animal is under the influence of the narcotic. This amaurotic state of the eye is also observed, during certain stages of the etherization, and disappears as soon as the animal has recovered from the effects of the same.

Our principal authority on the subject of amaurosis is Percival; he contends that it may proceed firom some disease of the retina itself, or from some abnormal condition of the optic nerve or brain ; or it may prove, as he says, the last link of a series of morbid phenomena, originating in some remote part of the body, operating sympathetically on the nervous system and through it, extending to the eye.

We occasionally meet with eases which may be termed sympathetic amaurosis ; occasioned by congestion, tumors, or hydrocephalus (serum within the verticles of the brain), each one of these pathological conditions requires special treatment, with very little chances of success.

Symptomatic amaurosis may be the sequence of cranial fracture and consequent depression; here the skill of a surgeon is called into requisition; he must trephine in the uninjured region of the cranium, in order to elevate the depressed and fractured parts and thus remove the pressure.

Amaurosis is frequentiy associated with the anæmia; now 
anæmia is a condition of the body which indicates deficiency or impairment of the integrity of the blood. The remedy is good carbonaceous food, and a few doses of the following, to be mixed with the food:-

Phosphate of Lime 6 ounces.

Powdered Ginger, 2 ounces.

Poplar Bark

.4 ounces.

Mix, and divide the mass into eight parts. Give one part every night. Amaurosis arising from over distention or a disordered condition of the stomach, ceases so soon as the cause is removed.

\section{OPHTHALMIA.}

Oplithalmia, or inflammation of the eye, is quite a common affection among neat stock. It frequently occurs without any assignable cause, except the concentration of morbid action, or morbid material, in the tissual membranes. It is always attended with more or less pain, tenderness, and tumefaction, and the tears being secreted faster than they can be carried through the ductus ad nasum, flow over the lower lid. This simple diseased condition differs from what is known as specific, or periodical ophthalmia; there is no constitutional disturbance to be noticed, nor symptomatic fever, and the affection appears to be confined to the conjunctivial membrane only.

The treatment should commence by giving the animal a dose of glauber salts; which consists of twelve ounces of salts dissolved in one quart of tepid water; the action of this medicine will be to remove morbid matter from the system. The eye should be carefully fomented with a warm infusion of hops; after which, lay a piece of wetted rag over the eye and fasten it to the horns. I could name many favorite local application.s - lotions - for the disease in this stage, but, in my opinion, cold water surpasses them all. The food should consist of scalded shorts; the animal to be kept quiet in comfortable quarters.

FOREIGN BODIES IN THE EYE.

If an animal should suffer in consequence of irritation and 
tumefaction of the lids of one eye, and a little pus, or matter, can be detected, the probability is that some foreign body, such as a piece of hay, straw, or dirt, has insinuated itself between the ball and eyelid, and has become lodged there; in a case of this character, the lids must be carefully inverted, one after the other, and examined.

The removal of the foreign body is equivalent to a cure, for very little, if any, after treatment is needed, with the exception of cleansing the eye with cold water.

\section{SPECIFIC OR PERIODICAL OPHTHALMIA.}

This dangerous form of disease is termed periodical, because having once made its appearance, there is a liability of a recurrence; it is not, however, so prevalent among cattle as among horses. It is a disease which, finally, is sure and certain to end in cataract, or disorganization of the eye; in this stage, perhaps the butcher would be the best doctor.

It may be proper, however, to gire the reader some idea of the nature and symptoms of this malady, so that common ophthalmia may not be confounded with nor mistaken for it. It has been observed, in the preceding article, that common ophthalmia was confined to the membranes of the eye; the disease now under consideration, makes its ravages on the inner structures of the eye, the external covering being only sympathetically involved. On parting the swollen lids, and if the cornea be not too opaque, we shall find that the aqueous humor is thick and muddy, the iris, lens, and other internal parts are altered in texture and structure, in fact, the eye has all the appearance of being ruined, which is probably the case.

The remote causes of this disease are constitutional predisposition.

There are several other affections of the eyes of oxen and cows, but as they are incurable, the subjects must be referred to the butcher.

CANCER IN CATTLE.

Cancer is a peculiar malignant growth, affecting one or more 
parts of the body. It probably owes its origin to some peculiarity of constitution. It is usually divided into two stages; the first is that of scirrhous, or hardening of the soft parts; the second is that of open cancer, or ulceration; in this stage, a foul fungous sore is observed, having an irregular surface of varied hue, with elevated, everted, and rough margins.

A writer in the Eclectic Journal offers the following as the pathology of cancer:-

"According to the researches of the most eminent physiologists, malignant growths are composed of two parts, granules or cèlls, with cell germs and granules within them, nourished with fat cells and globules, and of fibrous tissue or stroma, in which the former parts are embedded. Malignant growths are composed chiefly of albumen, supplied with blood vessels, but differ in their essential elements, viz., in their chemical and microscopic, from healthy tissue. The development of this disease is evidently a perversion of the ordinary process of nutrition. The lymph or blastema which exudes through the capillaries, either in the ordinary course of nutrition, or through some accidental inflammation, appears to have its vitality perverted; so that instead of forming itself into one of the proper tissues of the body, it forms the irregular abnormal cells, which constitute this species of growth. These abnormal cells are deposited in distinct masses, or else spread through the tissue of the organ or part, which it ultimately supersedes When once formed, they increase in size by the constant formation of new cells, which are supplied with fresh material from the blood. In the course of time, the older portions of cancerous growth lose their vitality, soften down, their outer surface ulcerates, and a sanious discharge follows."

Treatment of Cancer. - The popular method of treating this dreadful malady, is to dissect out the diseased parts, but this rarely succeeds, for the disease generally has an origin beyond the reach of our scalpel. The only remedies of any value, in curable cases, are bloodroot and iodide of potassium. The parts should be sprinkled often with powdered bloodroot, and the patient should have twenty grains per day of iodide of potassium. 
The following ease appeared in the Veterinarian, and is selected for the instruction of the reader: -

"About two years since, we were called in to attend a cow, the property of a gentleman residing in our neighborhood. On examination we perceived a cauliflower excrescence growing from the membrana nietitans, about the size of a strawberry, fiom which issued an ichorous discharge that excoriated the adjacent parts, and which bled on the slightest touch. We at once decided upon taking it out, and this was accordingly done, the parts. being subsequently touched with argent. nitrat. After this, the cow appeared to go on well for about twelve months, without any re-appearance of the cancerous growth. At the conclusion of that time, we were again sent for, and found the cornea had become of a bottle-green color, and that the sight of the eye was completely gone. About three months after this, a fungoid growth sprouted from the cornea, which increased in size very rapidly, but was repressed by the applieation of a little burnt alum. Shortly after this, the eye receded considerably into the socket, and eventually it sloughed entirely away. Some weeks afterwards, she became partially paralyzed, and was unable to masticate. The lower lip was pendulous; the ear hung down by the side of the neck on the affected side; difficulty of deglutition was experieneed, and the saliva flowed from the mouth, mingled with the partially masticated food. Attenuation of the paralyzed muscles quickly followed, and much general emaciation of the frame. The owner being desirous of obtaining another calf from her, she was kept alive with gruel; but, as it was soon seen she could not live, so as to give birth to a calf, she was destroyed. This being a fortnight before her time, the calf was immediately taken out, and it seemed likely to live and do well. It, however, lived only three days; the immediate cause of death being injudicious feeding." 


\section{HERNIA, OR RUPTURES.}

Hernia signifies rupture, or unnatural protrusion of a portion of the intestines or the omentum.

In consequence of the rough encounters which horned creatures frequently engage in, they are liable to suffer from the consequences of external violence, and a pregnant cow with a distended abdomen is more apt to be injured. in this way than the male. Still an accident of this kind will occasionally occur without the intervention of external injuries, for the cow is often the subject of dropsy of the womb, and in such condition the abdomen is distended to an enormous capacity. 'The only thing that can be done in a case of this character, is to rupture the fotal membranes by means of a blunt instrument, introduced through the neck of the uterus; this will not only evacuate the fluid; but also bring on premature labor, and thus the lives of both mother and calf may be saved, provided, however, the calf be full grown.

\section{FORMS OF RUPTURE.}

- There are various forms of rupture; a calf is occasionally born with a tumor or enlargement in the region of the navel; this is known as congenital umbilical hernia. It is termed congenital in consequence of being present at birth, and umbilical because it is found in the umbilical region. This form of hernia is not a very serious matter and very rarely requires an operation; my usual course is to apply some cotton batting, wet with an astringent (infusion of bayberry bark), and over the same a bandage, which must be passed twice around the body; yet if the part is bathed occasionally with infusion of bayberry, the bandage and batting can be dispensed with.

The reason why a case of this kind is not a serious affair, is because there is no rupture of the walls of the abdomen, but a mere purse or dilated state of the common integuments exists. which if necessary can be sloughed off by the application of a common pair of clams. 


\section{INGUINAL HERNIA.}

When rupture in the groin appears at birth, it is congenital, and consists of a portion of intestine, which has found its way through the inguinal canal - the channel through which the testicle descends into the scrotum. This can readily be reduced by raising the animal by its hind legs, and giving it a few jerks upward. If the intestine slips down again, and the case requires it, I should castrate the animal and put a stitch or two in the external ring, or else castrate by the clam method, which will produce considerable swelling and block up the passage so that the bowel cannot descend. The clams may be removed at the end of twelve hours.

\section{STRANGULATED HERNIA.}

The intestine will occasionally descend into the scrotum, and become strangulate, so that it cannot be returned. . In a case of this character, the operator must dilate the ring (through which the intestine descended), by means of a probe-pointed bistoury ; having returned the bowel let the animal be castrated and then apply the clams.

Strangulated hernia occurring in any other part of the body, must be treated as follows: If the protruded bowel is tumefied in consequence of gas within, it may be punctured in one or two places by means of a suture needle; this will allow the gas to escape; then efforts should be made to return the protrusion; failing to accomplish this object in consequence of stricture or thickening of the walls of the abdomen, I should introduce the bistoury, and dilate the wound. The reader will infer, and rightly so, that $I$ am alluding to a case in which there is an accidental external wound, otherwise it would constitute what is called ventral hernia.

\section{VENTRAL HERNTA.}

This form of hernia consists of an escape of a portion of the intestines through a rent in the abdominal muscles, creating 
a tumor beneath the common integument. This tumor may exist for some time without affecting the animal's health, but when it increases in size, so as to be bulky, or becomes strangulated, an operation must immediately be performed. In performing the operation, however, it must be borne in mind that the protruded bowel has pushed before it a portion of the peritoneum (the lining membrane of the cavity of the abdomen). Therefore the intestine is contained in a sac, which - should also be returned along with the intestine, into the abdominal cavity.

The mode of operation in cases of ventral hernia, is to cast and etherize the animal; a semilunar incision is then made orer the tumor, the convex border of the flap being downwards; the panniculus carnosus (subcutaneous muscle), or superficial fascia, is also divided; a probe-pointed bistoury is then introduced between the bowel and edge of the wound. This must be dilated or made sufficiently large to allow the return of the intestine. The rent in the muscles is then to be strongly sutured, and one end of the suture should be left long enough to hang out of the wound; the integuments are then to be brought together in the same manner, after which dress the wound with tincture of aloes. In the course of eight or ten days a pull may be made on the ends of the deep-seated sutures, to see if they are ready to come away, yet it is best not to remove them until they are quite loose.

It is impossible in a work of this character to furnish the reader with all the information necessary to meet the emergencies which may occur in the various forms of hernia; for their management and treatment require more than ordinary skill, and many persons who consider themselves competent to prescribe for the ordinary diseases of cattle, are willing to acknowledge themselves at fault when consulted on the subject of rupture ; and lest my own remarks on this subject may prove of little avail in furnishing the husbandman, in the hour of need, the necessary instruction, I introduce the two following cases, selected from the London Veterinarian.

Mr. James Stowar furnishes the following case of strangulated hernia :- 
"On the 17th of Sept., 1850, I was called to the farm of Ashogle, to see a cow which had been injured by the horns of another; but as I had left home that afternoon for a distance, and did not return until late next day, I did not see the cow until the 19th. I found her with a hernial tumor protruding from the right iliac, which remained covered within the skin, so large that a bushel measure would not have contained it. She yas evidently in much pain while standing, and would stand only a very short time. I was told that she had eaten a good deal since the accident, and, as a stoppage of the dung was observed, they had given her a pound of epsom salts. Her abdomen was enormously distended, notwithstanding the largeness of the hernial tumor. The non-escape of the fæces was proof positive, under the circumstances, of the hernia being strangulated.

"I had her laid on the left side, as carefully as possible, and, after every attempt to return the hernia by external manipula tion had failed, I cut into the sac, and attempted to knead in, inch by inch, the gorged intestines; but in this also I failed. The hernial opening was large enough to admit three of my fingers, so that it was not want of room in that, but in the abdominal cavity, which was so fully distended by the intestines forming the hernia, that caused the difficulty. I had her laid upon her back, with her hind legs drawn up, so as to throw the contents of the abdomen as much as possible upon the diaphragm. Even then, however, I could not succeed; I therefore with a sharp-pointed scalpel cut into the intestine, and emptied it entirely of its semi-fluid contents, stitched up the wound, and washed it carefully, and so ultimately accomplished the reduction. With a strong cord I closed the hernial opening, as well as the one $I$ had made through the skin, nine inches farther up; I then turned her on her left side, and in a few minutes the fæces began to escape by their proper channel. I gave linseed oil twenty ounces, and tincture of opium one ounce. Next morning I found her up, stepping through the shed, inclined to eat, her bowels acting freely. I had her tightly bandaged, to support the abdomen, and made an open- 
ing to allow the escape of discharge at the bottom of the sac. I saw her daily for a week, and prescribed according to the state in which I found her. On the whole, her health proved good, and her wounds healed pleasantly. She was fourteen years old, and, like most cows, had a large belly. She fattened well, and was sold for the shambles in April. The butcher told the farmer that he found a large abscess in her side when he cut her up."

The following case of ventral hernia is from the London Veterinarian, by G. Lewis :-

"In September last, I was requested to examine a heifer, which was said to have a 'swelling on her right side.'

"I found her with a pendulous bag, hanging very low on the right flank, and of an immense size. Upon a close examination of the parts, I ascertained that the enlargement was produced by an escape of the intestines through a rent in the abdominal muscles. I informed the owner that nothing short of an operation could be productive of benefit to the animal, and $I$ also pointed out to him the nature of the case, and its probable results.

"According to the arrangement, the heifer was sent to me on September 6th, when, after due preparation by medicine, etc., I had her cast and secured, and then carefully made an opening through the skin and panniculus muscle, immediately over the laceration in the other muscles, but a little longer than it. I thus exposed the rent which existed in the external and also the internal oblique. The edges of the aperture were very uneven and much thickened; and I may state in this place, that the enlargement had been observed a month prior to this date. A large portion of the intestines were found to have escaped into the sac formed by the panniculus and common integument; besides which, a considerable quantity of serous fluid existed beneath the skin, and externally to the panniculus, which had doubtless been thrown out by the injured vessels.

"The intestines being returned into the abdominal cavity, the edges of the laceration were brought together with strong metallic sutures, and properly secured. The external wound was then closed; and before allowing the animal to rise, I 
passed a seton through the most depending portion of the integumental sac, with a view to give a gradual and continuous exit to the serous effusion. A compress was also placed upon the part to remove as much of the pressure of the viscera as possible, after which the animal was allowed to rise.

"For several days the bowels remained obstinately constipated, and some symptomatic fever was also present; but by proper measures these unfavorable symptoms were soon removed. The animal was allowed only linseed tea and thin gruel for a few days. Subsequently a large amount of serous fluid was discharged through the openings made for the introduction of the seton; it, however, soon ceased. The sutures also came away in due course, leaving but little appearance of the original injury."

\section{DISEASES OF THE BONES.}

\section{BONÉ DISORDER.}

DURING the past few years I have noticed a number of articles in our agricultural periodicals, referring to a disease named by the writers "Bone Disorder." The name, as the reader will perceive, does not throw the least ray of light on the pathology of the malady ; in fact, it savors strongly of the so-called "horn-ail," "tail-ail," - terms which apply to symptoms rather than to any real disorder. One writer informs us that when an animal becomes the subject of bone disorder, "the bones threaten to cave in - have wasted away." If they do threaten to cave in, the best method I am acquainted with to insure an opposite tendency, is to promote the healthy functions of the body, and thus keep disease and the cattle separate.

If the bones waste away and then assume their original shape by merely feeding bone meal, as the writers contend, then the bones of cattle must possess some peculiarities that I have never, in my-professional capacity, been able to discover. 


\section{SPECIMENS OF DISEASED BONES.}

For explanations see p. 394 .
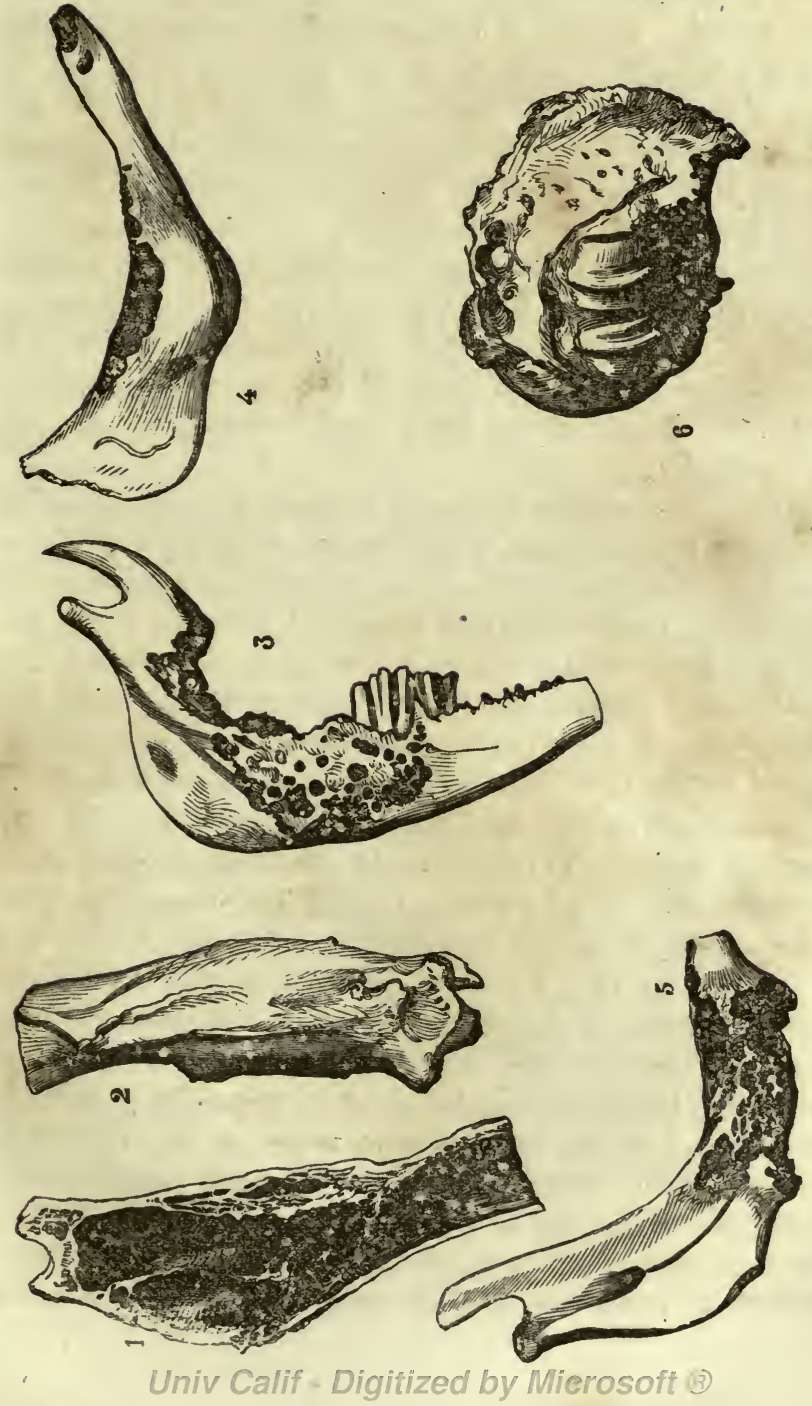
If the animals recover (we are told they do), then it might be inferred that the bones possess properties analogous to that of the soft tissues, - an inference which the reader knows is not correct. I would observe, however, that all parts of the animal organism undergo a very perceptible augmentation, and decrease or waste. 'Thus, up to the period of adult life, all parts of the animal frame increase in bulk, and give to the animal that rotund and symmetrical appearance which attracts the eye of all those who love to admire the works of nature; but at last old age comes on, which is attended by a gradual waste or shrinkage; this occurs, however, more in the muscles than in the bones; yet the latter undergo some condensation which may possibly lessen their volume; this, however, is a physiological result, - the work of uncompromising nature, over which human agency (bone meal included) has not the least control.

Whenever the bones do become diseased, it is the result of hereditary predisposition, of local injury, or of impaired digestion. So far as my inquiries have extended, in relation to the character of the so-called bone disorder, I infer that it is a disease of a debilitating character, originating in most cases in the digestive and nutritive organs, affecting not only the bones but various other tissues of the body, and therefore the only rational plan of treatment consists in improving the general health of the animal. The ways and means of accomplishing this very desirable result, are as' various as the causes which occasion the derangements. If it be evident (as the bone disorder theorists contend) that the animal organism, in such cases, is deficient in phosphate of lime, I have no objection to offer against the popular custom of giving the patient a few doses of bone meal ; for whenever there shall be a deficiency of carbon in the system, bone meal may be useful in supporting pulmonary combustion, and thus insure healthy action of the organs and functions of the animal economy; yet $I$ would suggest to the intelligent reader, that as bruised oats, ground corn, and linseed meal contain a large amount of phosphates, they should be selected in preference to bone meal, which $I$ think is more 
valuable as a remedial agent for a carnivorous than for a herbivorous animal.

As I understand the complex theory of digestion, the value of food or remedial agents is in exact ratio to their adaptation for assimilation; so that if their elements are only held in union by an uncomplex chemical affinity, as is the case with all vegetable productions known as food, their solution is easily and promptly effected by the ordinary process of insalivation, mastication, and remastication; but bone meal (a popular remedy) is actually an animal production, - vegetable matter animalized, - and in order to convert the same into the component parts of the cow's structure, it will perhaps require more chemico-vital force to effect the solution, than when oatmeal, etc., are used, the chemical affinity here being weaker than is the case with bones.

In the treatment of any and every disease, it is usual to endeavor to ascertain the direct causes, and if possible effect their removal, and whatever seems to be indicated we are justified in supplying; so that if phosphates are indicated, they may be prescribed; yet in cases of emaciation, when weakness and debility preside, I should prefer to use nutritious food, tonics, and stimulants, instead of bone meal. Why not add the bone meal to the barnyard manure? In this way the animal would get the benefit of it in the form of fodder.

In reference to a deficiency of phosphate of lime in the milk, which the writers alluded to have noticed, I remark that it may, in part, arise from functional derangement in the digestive organs (in such cases a large quantity of phosphate, etc., is expelled from the system in the excrement), or the fodder itself may be deficient in its usual yield of phosphate of lime. We then have an evidence of vegetable disease, for $I$ believe that the phosphate of lime is as necessary for the growth and integrity of the plant as it seems to be for the same purposes in the animal kingdom.

But I believe that the plant eannot lack phosphates without there being a corresponding deficiency in several other constitu- 
ents which go to form the healthy vegetable. So that in such cases the disease is general, not local; the plant is not fibre sick, nor the cow bone sick, but in both cases - the food of each being unnutritious - debility is the disease.

It is well known that successive cultivation exhausts the soil, and uses up the constituents necessary for the growth and maturity of grains and fodder. Yet the pastures and ploughed land might be made to yield good crops and rich harvests, by depositing in the soil - in the form of animal excrement, straw, wood, ashes, lime, charcoal, etc. - as much as we take out of it. The soil cannot create any thing of itself, therefore an increase in crops can only be obtained by adding more of certain agents to the soil than we take out of it.

"In Flanders, the yearly loss of the necessary matters in the soil is completely restored by covering the fields with ashes of wood or bones, which may or may not have been lixiviated. The great importance of manuring with ashes has been long recognized by agriculturists as the result of experience. So great a value, indeed, is attached to this material, in the vicinity of Marburg, and in the Wetterau - two well-known agricultural districts, - that it is transported, as a manure, from the distance of eighteen or twenty-four miles. Its use will be at once perceived, when it is considered that the ashes, after being washed with water, contain silicate of potash exactly in the same proportion as in the straw, and that their only other constituents are salts of phosphoric acid."

It is well known that phosphate of lime, potass, silica, carbonate of lime, magnesia, and soda, are discharged in the excrement and urine of the cow; and this happens when they are not adapted to assimilation, as well as when present in excess. Supposing the cow's bones to be "weak," it is possible that the gelatinous elements preponderate over those of lime, soda, and magnesia.

It is a fact well known to husbandmen, that some breeding cows do not come up to the standard of health, or fair condition, although they are fed from the cream of the crib, on the 
best kind of fodder. The inference is, that the digestive or. gans are not in working condition; therefore, in such cases, the food operates as an exciting cause of disease.

The effects of cheap and damaged food are too well known; poor food is dear at any price which may be asked for it; it may not furnish sufficient carbon; if so, the animal is deprived of the power of reproducing itself, and must eventually suffer (see article on feeding).

These preliminary remarks are introductory to the following on diseases of the bones; but before $I$ allude to them $I$ have a few brief remarks to offer on the

\section{MECHANISM AND STRUCTURE OF BONES.}

Bones have many things in common with the soft tissues and organs; for example : arteries, veins, nerves, lymphatics, and a connecting cellular web. Their structure, in the embryotic state, is highly vascular, yielding, and gelatinous. 'They have, externally, a fibrous investment known as periosteum, which is well supplied with arteries, veins, nerves, and absorbents; and it is through the intervention of this fibrous tunic, that the vessels proper to bones reach their ultimate destination. On the interior surface of hollow bones, we find a membrane of similar structure, only more delicately organized. The cavity of the shaft bones is usually occupied by a quantity of adipose matter, known as marrow; this is enclosed in laminated cells, and is supposed to be a sort of aliment in reserve, to provide against accidental emergencies of non-nutrition.

\section{COMPOSITION OF BONES.}

Bones consist of two constituents; viz., animal basis and calcareous matter. In the healthy adult, the proportions are as follows:- 


\section{ULTIMATE CONSTITUENTS OF BONES.}

The ultimate constituents of bones are gelatine, animal matter, carbonate, phosphate, and fluate of lime, phosphates of soda and magnesia. Their growth, like that of shells, is effected by the addition of new tissue to that already formed. Bones which have a central cavity are protected internally by cartilaginous fibres or unions; hence they expand or burst, so soon as their cartilaginous braces are decomposed by a diseased condition of the parts.

\section{DILATATION OF THE JAW BONES.}

This disease seems to be more prevalent among horses than cattle. In equine practice it is termed "big-head ;" in bovine practice we call it spina ventosa, ${ }^{*}$ bony tumor, etc.; but perhaps "dilatation of bone" will give the reader a better idea of the character of the disease than any other term. On inspecting the jaw bones of cattle, the subjects of dilatation, we find the greatest enlargement at the angle of the lower jaw. On cutting into the same its cavity is occupied by a preparation resembling soft cheese. On removing this it is discovered that the cartilaginous braces, which hold the sides of the bone together, are decomposed; hence the dilatation. This foreign material often degenerates into true pus, and burrows through the bones toward the surface. In this condition a fluctuating tumor can be felt at the angle of the jaw.

Sometimes the bones of the jaw appear to have lost their cohesive firmness and vitality; they then border on a state known as necrosis. Now if a portion of bone in this condition be macerated, for only a short time, in a weak solution of muriatic acid, it can be rolled up like a piece of paper, showing that it is deficient in calcareous matter; but if it takes a day or more to put the bone in this condition, the experi-

* Spina ventosa. - $\mathbf{A}$ bony tumor, in which the interior of the bone is absorbed, leaving a mere shell of bone, divided into cells, containing purulent, cheesy matter. (See cut of bones, page 245). 
ment would not be of much value, as all bones can be more or less softened by means of weak acids.

Having ascertained that the osseous structure is deficient of earthy matter, and that the animal matter preponderates, we are then in possession of facts which can be used to great advantage in preventing the malady, and perhaps treating it in its early stage. The remedies are phosphate of lime, vegetable tonics, and stimulants. I use them in the following form :

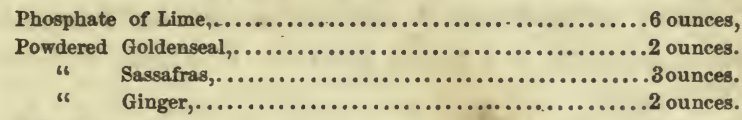

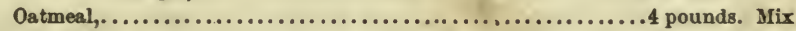

This is to be divided into sixteen parts, one of which may be incorporated with the food every night.

I recommend the medicine in this form because it is calculated to give tone to the function of nutrition. It is well known that the maintenance of the functions of animal life are almost entirely dependent on the due performance of the nutritive operations, and therefore the integrity and properties of all the hard as well as the soft tissues depend on their regular nutrition by a due supply of perfectly elaborated blood. This cannot be effected unless the functions of circulation, respiration, and secretion are performed with regularity.

Circulation is necessary to convey a supply of nutritious fluid, and respiration and secretion separate the blood from its impurities.

Therefore, in cases of this character, I adrise stock owners to endeavor to improve the general health of the patient by means just suggested, and also that they should see that the animal gets that kind of food which is rich in phosphates.

It is very difficult to define the causes of this disease. It may originate in a peculiar, morbid habit of body, or it may be the sequence of faulty nutrition or hereditary predisposition.

When an animal labors under any morbid habit of body, he is in a state far removed from that of health, and various parts of the body become affected by the change; and even should the power of forming good healthy blood remain, the organic 
force by which the constituents of blood are transformed into osseous structure, must necessarily be enfeebled by the morbid habit, so that the power to produce metamorphoses is necessarily diminished. It is my opinion that big-head usually commences in the fibrous tissues which are found in the internal surface of bones. A very peculiar feature of these fibrous tunics is, that when they once become diseased they run rapidly to purulency ; and this accounts for the large amount of purulent matter often found in the cavities of jaw bones, when buried or exposed to a drying process. It is then, however, in a spongy state.

A very distinguished French writer contends that "fibrous tunics or tissues hardly ever contribute to the formation of pus." 'This is evidently an error ; for when the periosteum, covering of bones, - which covers the fang of a tooth, and gives a lining to the cavity into which it is inserted, becomes inflamed, it suppurates, and the tooth has to be removed. I contend that it is the most common tissue, that excites the flow of those exudations from arterial capillaries, which becomes converted into pus; hence in this way I account for the collections of pus often found on and under fibrous ligamentary tissues, and coverings of muscles, also upon and beneath the periosteum, and in the vicinity of fibrous tissues in other parts of the system.

The surgical treatment of a case of this kind, is to liberate the pent-up pus or matter. With this object in view I cast the subject, and after having brought him under the influence of ether, I make an incision through the integuments, etc., and expose the bone; then by means of a pair of common bone forceps, I make an opening into the same, liberate the imprisoned matter, and inject the cavity with pryroligneous acid. Having removed as much as possible of the morbid matter, I then cram the cavity with equal parts of powdered bloodroot and bayberry bark. The external wound must not be closed by suture, but left open so as to allow of a free discharge from the parts, for the healing process must begin at the upper part of the cavity, and the integument should be the last to heal. 
I continue to throw into the cavity, by means of a giass syringe, a small quantity of pryroligneous acid daily, until the discharge ceases. Then the parts are to be dressed with common tincture of aloes.

After an operation of this character there will remain some enlargement of the tissual structures about the parts. This can gradually be reduced by a few applications of a portion of the following :-

Iodide of Potassium, .............................1 drachm.

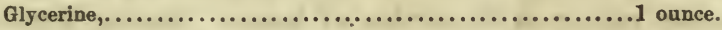

Mix, and keep the preparation in a glass vial, well corked.

ABSCESS BENEATH THE PERIOSTEUM, AT THE ANGLE OF THE JAW.

This is a very frequent and formidable disease among cattle, and is oftimes occasioned by blows inflicted purposely or accidentally on a region known as the angle of the jaw. It is a formidable disease because it frequently ends in caries or ulceration of the jaw bone (see page 245). It originates in an inflammatory condition of the periosteum, accompanied by a gradual enlargement at the angle of the jaw. It is very painful, the animal being very unwilling to have the part handled.

The pain is occasioned by distention of the periosteum, and this is sometimes found to be indurated or thickened. The animal does not eat as well as usual, in consequence of the pain occasioned by the act of mastication, and he generally labors under some degree, more or less severe, of febrile excitement. Ordinarily it is a very easy matter to detect the presence of pus in any of the superficial regions; but in this, lucated directly on the bone and covered by a fibrous membrane which only admits of a limited amount of distention, it is very difficult for an unskilful person to discover it; yet if the above symptoms are observed, I should decide that there is pus beneath the periosteum.

Treatment. - No treatment is of any advantage except that of making a free opening through the skin, muscle, and periosteum, and thus insuring a complete discharge of the morbid 
matter; and the sooner this is done the better, for it will relieve the animal of much suffering and prevent ulceration of the jaw bone. Very little after treatment is required. It is only necessary to cleanse the part daily, and dress with tincture of matico.

EXOSTOSIS, OR DEPOSIT OF CAICAREOUS MATTER ON THE SURFACE OF BONES.

Exostosis signifies an unnatural growth of bone, or deposit of calcareous matter on the surface of bones. Among horses this disease occurs in the form of splent, spavin, and ringbone. It is very seldom that cattle are treated for this affection; for the deformity is so slight, and the lameness so obscure, in consequence of the slow motions of the animal, that very little notice is taken of it. The proper mode of treatment is to apply, daily, a small quantity of Iodide of Glycerine, prepared as follows :-

Iodine 1 drachm.

Glycerine, 1 ounce.

Mix, apply by means of a small piece of sponge. This is to be applied daily for a period of two weeks, after which use acetic acid, one part; water, six parts. With a portion of this, sponge the enlargement until pain and lameness disappear.

CARIES, OR ULCERATION OF BONES.

The cut at page 245 , will give the reader a better idea of the appearance of ulcerated bones, than a description. It is a very common disease among cattle, and is preceded by inflammation and suppuration. It sometimes proceeds from a blow received at the angle of the jaw; generally, however, it is a constitutional disease of a malignant character.

Treatment. - In the first stages of this disease, the part being hot, painful, and tender, I should foment with warm vinegar, which will tend to hasten suppuration; then having ascertained that there is some pus or matter locally imprisoned, the part must be freely punctured, the pus evacuated, and the cavity injected with pure pyroligneous acid. 
Supposing or rather suspecting the discase to be constitutional, I should administer the following:-

Iodide of potassium, .................................1 ounce.

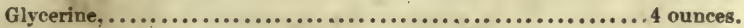

Tineture of goldenseal, ..................................2 ounces.

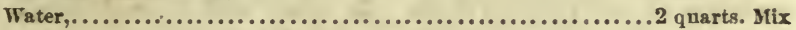

The dose is one sixteenth part of the above quantity; to be administered daily.

\section{PRELIMINARY TO HORN-AIL.}

Many very valuable animals die prematurely, under treatment, in consequence of mistaking symptoms for the disease.

Before I discuss horn-ail, I propose to offer a few brief remarks on the subject of sympathy, so that the unprofessional reader may be prepared to comprehend the why and wherefore of sympathetic diseases, as they occur in neat stock during the j)ogress of primary affections.

\section{ON SYMPATHY AND THE SYMPATHETIC RELATIONS} WHICH EXIST IN THE ANIMAL ECONOMY.

Sympathy. - The animal structures are so sympathetically related to each other, and so dependent are various organs and finctions on an equilibrium of vital action, based on the law of sympathy, that the animal economy, as a whole, may be said to comprose a vast machine, the integrity of which depends on the firee and full play of all parts composing its intricate mechanism.

The media by which sympathy is aroused and maintained, are the nerves. These originate from the brain and medulla spinalis (or spinal marrow). Ten pairs of nerves radiate directly from the brain, termed cerebral ; thirty-nine pairs from the spinal marrow, termed spinal. They are named after that of the region in which they are found; hence we have seven pairs of nerves issuing from the cervical region (neck), eighteen from the dorsal (back), five from the lumbar region, and five sacral, within the pelvis, four coccygeal; making in all forty-nine pairs cerebro-spinal nerves. They are distributed from . 
each side of the spine to various parts of the body, and their terminations are called "sentient," this being the seat of sensation.

The most important nerve, however, for our consideration, is the sympathetic. It is supposed by some writers to be in itself a complete nervous system. It originates in a branch issuing from the base of the brain, and communicates with every other nervous filament of the body. The connection takes place in the following manner: The sympathetic nerve has at various points a number of gangliform plexuses; from these, thread-like filaments arise, which radiate and connect with similar ganglions found on the cerebral and spinal nerves. On these divergent filaments we have other ganglionic structures, which send branches to the liver, spleen, kidneys, etc.

The sympathetic nerves of one side amalgamate with those of the opposite, and this is their mode of communication.

The nerves of the sympathetic system possess a certain degree of power in exciting muscular contractions, as well as sympathetic actions, in the various parts to which they are distributed. Carpenter has observed, that by " irritating a branch of the sympathetic nerve immediately after the death of an animal, contractions may be excited in any part of the alimentary canal, from the pharyn $\mathrm{x}$ to the rectum, according to the trunks which are irritated; in the heart, after its ordinary movements have ceased, in the aorta, vena cava, and thoracic duct, in the ductus choledochus, uterus, fallopian tubes, vas deferens, and vesiculæ seminales, etc. It is probable that the sympathetic system not only thus brings the organic functions into relation with the animal, but that it also tends to harmonize the former with each other, so as to bring the various acts of secretion, nutrition, etc., into mutual conformity."

There are several orders of sympathetic nerves; sonse pass into the parenchyma of the organic viscera; and others are distributed on the outer coats of arteries, continuing throughout their minute capillary structures into the papillæ. By this arrangement the harmony between the internal, external, and remote parts is perpetuated.

Correct knowledge regarding the sympathetic relations pe- 
culiar to animal organization, seems absolutely necessary in oriler to correct the erroneous impressions that some persons have formed of the nature and seat of disease incidental to horses and cattle, and in this view I offer these preliminary remarks as introductory to the subjects of "horn and tail ails" (imaginary diseases, which oftentimes, perhaps always, are the result of a fertile imagination, or rather a sequence of that faulty mode of reasoning which confounds effects with causes). Any person conversant with the sympathetic relations existing in the animal economy, can readily discover the difference between a pathological condition and the local or general symptoms which usually accompany it. An animal, for example, is attacked with acute disease of the liver; he evinces signs of pain from pressure on the right or off side, in the region of the liver, and possibly the lameness is of so grave a character as to mislead the non-medical observer, and he necessarily concludes that the subject is lame, "and nothing more," he prescribes an external remedy accordingly, which is neither calculated to cure nor palliate the liver difficulty. Thus for want of the necessary knowledge. the symptoms are mistaken for the disease.

In derangement of the digestire organs, more particularly of the stomach, the brain is usually sympathetically affected. The symptoms of disturbance in that organ or its functions, may escape the attention of the "cow-leach," yet they are always present, and range from what has been observed as "dullness," up to somnolency, accompanied by ather morbid phenomena well understood by the physician.

A knowledge of these and other sympathetic relations existing throughout the animal economy, enables us to understand what occasions vomiting in a man, when a blow of sufficient force is received on the skull. The blow arouses a certain set of involuntary operations which the subject is unable to control, as in the cases of vomiting, etc. It explains, also, why giddiness or vertiginous symptoms usually follow when a blow is received on the region of the stomach; how the impregnated uterus influences the mammæ and stomach, causing increase of function and volume in the former, and morning nausea in the 
latter; how a diseased condition of the internal mucous membrane reacts on the common integument, and vice versa. Even in the osseous structures, the law of sympathy prevails. A disease in the upper extremity of the bone gives rise to sympathetic pain at the opposite extremity. (Consult Hooper and Cooper on the hip-joint lameness). And as regards the muscles and tendons, there exists a very marked sympathy, although in the mind of pathologists this is not strange, for anatomically considered, the tendons are neither more nor less than tendinous terminations of muscles.

Puncture of a tendon is often followed by great derangement of the nervous system, and other pathological conditions, not unfrequently ending in trismus - lockjaw. This is owing to the same law of sympathetic association just alluded to. There is, therefore, a tendency in certain organs to become deranged or diseased in consequence of a malady locating in others, although they may not always be indentical in function.

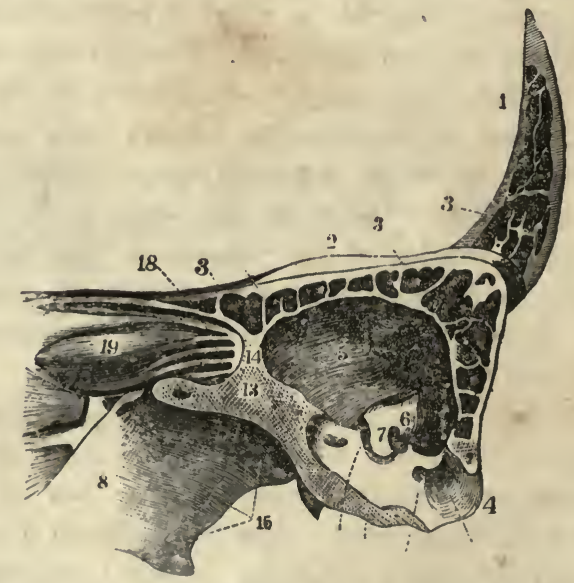

STIRUCTURE OF THE HEAD AND HORNS.

For explanation see p. 393. 


\section{HORN-AL.}

Persons who are in the habit of prescribing for sick brutes, and have never made themselves acquainted with the sympathetic relations existing in the animal economy, to which I have referred, are liable to commit errors in diagnosing disease, and when questioned regarding the seat of the same, their opinion generally is, that the suffering animal has either the horn-ail or tail-ail. The idea, in almost all cases, is so supremely absurd, that, if any thing other than a living animal were the subject of the barbarities, which according to mistaken notions of cure are sure to follow, I should feel disposed to burlesque the whole procedure regarding both horn-ail and its treatment.

In my opinion, horn-ail, in ninety-nine cases out of one hundred, exists only in the imagination of those persons who allow error to overcome their better judgment, or else they have not given the subject a passing thought; therefore, they are incompetent to even guess at the true nature of the malady, with any chances of correctness. No allusion, that I am aware of, has ever been made by the author's of standard works or text books on veterinary science, to horn-ail, and if educated veterinary surgeons were as numerous here as in England or France, and they had the same means to reach the ears and the understandings of our husbandmen, the latter would soon be convinced of the absurdity which is here described, and consequently be induced to protect their animals from that species of cruel quackery, or ignorance, which would refer all their aches and diseases to horns or tails, and which sanctions the boring of the former, and curtailing or docking the latter.

The pathological conditions on which the absurd theory of horn-ail seems to be founded, are heat or coldness of the horns. These are the principal, and, in fact, only symptoms which the unlearned expounders of a popular malady have given us; but every one ought to be aware that variations in the temperature of a part so inferiorly organized as the horns are, is no criterion as regards the nature of the disease which occasions in this vicinity merely an increase or decrease of temperature. 
The actual disease which occasions a loss or increase of temperature of the external surface of the body, horns included, may be, and often is, located in either the brain, stomach, or buwels, and at other times is the result of local congestions of the lungs and other parts - mere effects - the results of preexisting disease; therefore, I contend that the term horn-ail, when used to express the condition of parts sympathetically affected or aroused, throws no light on the true nature of the disease under which the animal labors.

I shall contend that neither the augmentation nor decrease in the temperature of the horns constitutes actual disease of the same; but may indicate a loss of equilibrium in the circulation of blood. If the horns are at fever-heat, and the surface of the body be cool, we know that the brain or its membranes may be actively or passively congested; on the other hand, should the horns and the extremities be cold, it goes to prove that the animal is the subject of internal congestion or disease. But why locate it in the horns, when in the animal economy are found so many hundred parts, sections, and divisions of parts, more important, sensitive, and of vastly more consequence to the preservation of vital inttgrity, than the horns? The variations in the temperature of the horns and other parts of the body, which the horn-ail theorists neglect to notice, enter into a class of symptoms from and by means of which an educated surgeon makes up an intelligent and correct diagnosis, and, consequently are only of value, in point of fact, in so far as they go to show the actual state of the whole animal mechanism.

The proposition admits of the following appropriate and convincing illustration: A man is attacked with acute disease of the liver, and almost always experiences a pain in the right shoulder, a purely sympathetic affection. Now it would be very ridiculous for a physician to overlook the diseased condition of the liver, and merely prescribe for the sympathetic shoulder-lameness, and call it "shoulder-ail." Such ignorance is calamitous, but does not often occur when the educated physician is employed; otherwise it does, and many such cases are quite fresh in my memory. Now, instead of prescribing 
local agents, as some have done, in view of mitigating sympathetic local pain, would it not be more in accordance with reason and seience to administer medicinal agents, such as are calculated to restore the liver to a natural physiological condition?

A man who thus ignorantly prescribes, falls irto the same error with him who would refer all diseases of neat stock to their horns or tails, merely because the parts are not in their natural physiological condition, owing, as I have said, to actual disease seated ilsewhere. Thus the symptoms are mistaken for the disease, and the treatment, in so far as boring, sawing off horns, and curtailing the caudal appendage is concerned, is highly injurious, barbarous, and, in these enlightened times, deplorable.

It requires no argument to convince many men that hornail is a very prevalent disease, for the false doctrine has been promulgated, and has received attention from men whose domains extend from Maine to California. The error has been sown broadeast, and has acquired such hold on the milds of some that it will take many years to root out the evil. One writer on this subject, believing that horn-ail is $\bullet$ sort of national disease, recommends the barn-yard faculty (for no regular physician will heed his advice) to carry gimlets in their pockets, so that they may be armed and equipped to encounter and subdue that which is more imaginary than real.

I have made examinations of the bodies of cattle, subsequent to death, said to have died of horn-ail. Among them were evident traces of softening of the brain; and this is a feature of disease very often present, as I shall attempt to show, in many of the so called cases of horn-ail. Softening of the brain is a disease of so grave a character, that any morbid symptoms attending the same, as local heat or coldness of horns, might compare in the ratio of a molehill placed besicle a mountain.

Softening of the brain is the ultimatum of a grave disease occurring in that organ. And if the owners of live stock are disposed to believe that horn difficulty is the most preponderant and alarming, and they can sleep soundly in the belief that no danger threatens, then, "If ignorance is bliss, 'tis folly 
to be wise." I cannot endorse this sentiment, however ; for in this day of intellectual maturity, no one has a right to be a dunce in his chosen profession, nor a fool, to thwart the intentions of those who would substitute light for darkness.

Softening of the brain is always preceded by acute, and, subsequently, chronic inflammation of the same or its investing tunics, and constitutes the last stage of disease; so that the days of such a subject are numbered, and the man of gimlet and ignorance, armed with his munitions of warfare, treats the disease at long odds; he pockets the fees but loses the case. His patient, on which a too confiding owner has foolishly permitted him to practice his cruelty and legerdemain, dies, and he knows not the why nor the wherefore.

But in order to convince the reader of the follies of the above practice, I offer the following illustration, from a reliable source. The case was diagnosed and treated as horn-ail. I quote from the "Southern Planter:" -

"After death, examined the head. Crest between horns perfectly hollow. All the little divisions and offshoots of bone which are usually found in the cavity, were removed, in a greater or less degree, and there were only the white of egg matter and pus; the horns also entirely hollow, one of them filled with nearly a pint of lymphy and purulent matter; the cavity extending to the orbit of the eye, thence communicating with the nostrils, especially on one side. The brain, which lies in very near contact with this cavity of the crest (which we may as well call the 'frontal sinus), was softened and fallen, in one hemisphere, into a thick mush; a small part only of this half was of healthy consistency, preserving its form or vessels entire. The other half (hemisphere) was not softened, but the vessels were very full of blood, and the membranes exhibited signs of intense inflammation. No other region or organs examined."

In regard to this quotation I remark: It is very natural that the frontal sinuses should be hollow; for if they were solid, the weight of the head would be enormous; and I can readily perceive the wisdom of the divine Artist, in thus adapting the parts for the convenience of the animal, and relieving 
him of what, had it been otherwise, must have been a burden, and would have required powerful muscles to support the head.

The bones about the head are divided into two plates, separated by numerous vacuities or cells; but, unlike those of the horse, they extend through the whole of the bone̊, nay penetrate even through the parietal and occipital bones (see cut p. 258).

Hence it happens that the frontal sinuses (so these cavities are called in cattle, as well as the horse) extend from the angle of the eye to the very foramen through which the brain escapes from the skull, nay, to the very tip of the horn. Hence the parts may be said to be hollow; and it is well that every farmer should know this, for some suppose them solid, and are very much surprised to find them hollow. On making a section of the horn, from tip to base, it will be found partly hollow, " having sinuses that extend almost to its tip."

The lymphy and purulent matter found within the frontal sinuses and those of the horn, together with the softening of one hemisphere of the brain, proved that the parts were all involved in disease; but then the disease never had its origin in the horn. The brain, or perhaps its membranes, were the primary seat of the affection, and, after softening, decomposing, involved the surrounding parts in ruin. "The other half of the brain was not softened, but the vessels were full of blood, and the membranes exhibited signs of intense inflammation." Probably this was the state of affairs in the diseased hemisphere, in its early stage, and some physical impediments to the return of blood from the brain had induced cerebral apoplexy. The animal was in a plethoric state, "very fat." There was too great redundancy of blood - just the subject for such disease. Softening of the brain, I think, would be a better designation of the disease than " horn-ail."

The editor of the Planter, in a subsequent number of his journal, remarks, "The notion that this disease originates in the horn itself, seems to us to be an error, resulting from that backward mode of reasoning which confounds symptoms with disease. The disorder in that organ, 'the horn,' should rather 
seem to be secondary. No less erroneous do we deem the opinion held by some, that the horn becomes frost-bitten, and then putrefies. Though its whole inner surface is exceedingly vascular, yet it is perfectly protected by the almost insensible horny" covering in which it is cased throughout, except only a very minute ring at its base, whose pulsations are the most accurate index of the pulse; and that ring, hardly wider than a thread, cannot be affected by cold. When it is considered that the horn is a substance of lower vitality than the hoof, which never becomes frost-bitten, even though chilled by an iron shoe, reason should teach us that it cannot be injured by cold."

A similar case occurred in the experience of the editor of the Planter, which "ran to a speedy and fatal termination." Upon dissection of the head, the left hemisphere of the brain was found completely "broken down," or disorganized; the base of the left horn was slightly implicated.

The introduction of a gimlet, therefore, into the horns of cattle thus affected, and afterwards cramming in pepper, turpentine, and other foreign bodies, cannot passibly reach the disease nor benefit the animal, but is apt to do much harm. For, puncture of the lining membrane of the frontal sinuses, which generally takes place when the instrument is introduced near the base of the horn, is attended with danger, both as regards inflammation and hemorrhage. And it is just as unwise to fill the parts with pepper, turpentine, etc., in view of cure, as it would be if one of our own race were concerned.

I now have an impression that the reader, like myself, has come to the conclusion that, in the generality of cases occurring among neat stock, of disease christened horn and tail-ails, is located elsewhere. Yet some persons contend that the practice which I denominate as unscientific and barbarous, saves some of the afflicted animals! I have doubts about the treatment saving them. They may survive it; for it is well knowr that both men and animals often recover after an unfavorable prognosis is made, and they will also survive very severe injuries, fractures, punctures, and formidable wounds, etc. So that health returns, in such cases, in spite of the violence opposed to 
it. Hence, if an animal should be restored to health, after having been compelled to submit to the fashionable barbarities of horn-boring, that is no proof of the utility of the mears used.

If we could only collect all the facts in the case of an animal said to be the subject of horn-ail, we should probably discover that in four cases out of five, the animal's stomach was the seat of the original difficulty, for the stomach is more frequently deranged than any other organ of the body, and it often occurs in this $\cdot$ way: A man has a cow, an ox, or a lot of cattle, which he intends to bring to market, in view of exchanging them for dollars and cents. He puts them through (as the moderns have it) the fattening process, furnishing them with a superabundance of earbon, in the form of meal and other nitrogenous equivalents. The result is, an accumulation of adipose tissue; the animal becomes fat, and consequently plethoric. The accumulation of fat offers an impediment to the free and full play of the heart, lungs, and diaphragm; and, should the subject be a pregnant cow, she is liable, a few hours after the period of parturition, to be attacked with milk or puerperal fever, or convulsions. Therefore, the liability to disease in more important structures than the horns, is a matter that I seriously urge our itinerant cattle doctors to consider.

Neat stock are often the subjects of catarrh, or "hoose," as it is termed, nasal gleet, etc. In either case, a profuse discharge occurs from the surface of the nasal membrane, extending to the frontal sinuses, up to the very tip of some horns. This is often called horn-ail, and the gimlet is brought into requisition, and on withdrawing it, some of the "matter" may possibly escape from the orifice. Hence the gimlet is said to do good. This I deny; for the more rational way of favoring the discharge of the matter, would be to steam the nostrils, and. adopt such other means as the nature of the case may seem to require.

Even granting what some contend for; viz., that an abscess occasionally forms in one of the nasal cavities, then it would not be proper to bore the horns, for the pus must necessarily be enclosed within a sac, which the gimlet may rupture. Then 
the morbid matter escapes into the frontal sinuses, and is apt to set up diseased action on the tissue with which it comes in contact. If it be ever necessary to puncture an abscess of this character, it should be done by way of the nostrils.

Even should the animal labor under any disease located within the horns, the introduction of a gimlet would be a very unsafe remedy, as all veterinary surgeons are ready to testify. It is a dangerous business to puncture a membrane so highly organized as that found within the frontal sinuses, ${ }^{*}$ especially when so rude an instrument as a gimlet is used. The instrument must lacerate the parts, and induce severe inflammation and suppuration; consequently, it is better calculated to produce disease in this region than to cure one existing there.

I have examined many animals after their horns have been bored, and have always found an undue degree of heat in the cranial region; throbbing pulsations about the base of the horn, and a general disturbance of the functions; sometimes an accumulation of pus within the cavity. Then, again, internal hemorrhage, effusion, etc., of blood, are apt to occur after boring the horns; and every intelligent physician would be unwilling to incur the risk attending it. Many a valuable animal has been lost by hemorrhage, following fracture, puncture, and sawing off the horns.

Horn-ail is said to be so prevalent among neat stock, that the farmer (in the imaginative mood) fears it as he would the plague. And the only remedy for this lamentable state of ignorance, is for farmers to use their reason, godlike and rational, and avail themselves of the experience of those competent to diagnose disease by its concomitant and persistent symptoms.

We are now in possession of facts showing that the introduction of a foreign body - a gimlet - may induce a formidable discase; therefore, it should never be used.

* The gimlet, before it enters the lining membrane of the parts (termed schnicderian), must necessarily puncture a highly vascular membrane (termed periosteum); the external covering of the bony column, and inflammation and suppuration may be the consequence, ending in altered structuro. 
Among the diseases mistaken for horn-ail, I name indigestion ; and this disease is almost as prevalent among neat stock as it proves to be among the members of the human family in this country. Loss of cud, or a cessation of rumination, is one of the principal symptoms of acute indigestion. I made an autopsy, in a case of this character, only a short time ago, and found the abomasum, or fourth compartment of the stomach, enormously distended with food ; and on removing the same the mucous membrane readily peeled off. I particularly pointed out the pathological appearances as they occurred, to the owner of the animal ; but as he had made up his mind and the neighbors confirmed his opinion, that the animal was the subject of horn-ail, he still believes that the trouble first commenced in the horns, which had been bored in several places!

I am not contending that the vascular membrane within and without the osseous structure of the horns and contiguous parts, enjoys immunity from disease ; it is subject to it, as are other parts precisely identical in function and structure. But $I$ am exposing a false theory, which confounds functional and organic diseases with their symptoms or manifestations.

A local disease of the horns is not unusual. For example: A blow in the region of the base of the horn often occasions a local affection; and this is not to be wondered at when we know that the parts in this region are merely defended by a thin cuticular envelope, and therefore it offers but little protection to the sub-tissues. This region is denominated by brutal men the "tender spot;" and in view of subduing a restive animal they aim their bludgeons in this direction with terrible effect. Local injuries of this character, and those occurring in the savage encounters which horned animals frequently engage in, the boring of their horns, and sawing them off, etc., etc., are accidents and processes more or less operative in exciting a local affection.

A local disease of this character admits of the following demonstration; viz., percussion. Percussion is the art of striking various parts of the body with a view of ascertaining the seat of disease. Every substance, when thrown into 
sonorous vibration, produces a sound, the tone of which is peculiar to itself, and every change which takes place in the composition of that substance, or in the arrangement of its component parts, is accompanied by a corresponding change in its tone. If we strike a solid body, it emits a solid sound; strike an empty one, and it emits a hollow sound. In like manner, if we strike a healthy horn, we get a sound of hollowness. When the horn and frontal sinuses are occupied by matter, we elicit a dull sound without vibration. The difference between the sound elicited from an empty barrel and that from a full one, or the sound from a solid post and that from a hollow one, when struck with a hammer, is not more remarkable than in the-cases of healthy and diseased horns. By the same. means we diagnose diseases of the chest. We are, therefore enabled, with absolute certainty, to determine the presence of pus within the horns. And keeping in view the history of the case which it is our business to inquire into, we can gener ally tell whether or not such abscesses result from local injury or disease within the parts, or if it be the sequence of some other disease, and thus regulate our treatment accordingly.

In regard to the treatment of an abscess located in the regior. of the base of the horns, the proper method is to trephine the skull, which operation can only be performed by a veterinary surgeon.

\section{TAIL-AIL.}

In view of sustaining the respectability of veterinary science and my own professional reputation, I would inform the reader that tail-ail is an imaginary disease, appearing only in localities which the apostles of true veterinary science have never visited. The supposed affection is said to induce partial or complete paralysis of the hinder extremities, and, contrary to the principles of science and the testimony of several veterinary writers, this condition is often termed tail-ail. The faulty theory is:- a soft spot is found at the end of the tail (this is a feature of every healthy cow's tail, when it has not been docked), which takes the strength out of her back, and produces paralysis. The remedy is, either to amputate the 
caudal appendage, or slit open the soft spot, and stuff in tar, pepper, salt, or whatever remedy neighbor so and so recommends. It seems a pity that the poor animals I am now writing about, cannot, like their masters, receive the benefits resulting from the investigations of scientific men, in improved methods of treating disease. However, it is gratifying to know that the errors of the past are fast "dying out," and that the days of ignorance are numbered.

The tail is sometimes the seat of a local affection arising from blows, etc., or it may be the seat of a cutaneous disease; but neither one nor the other can be of so grave a character as to produce paralysis of the posterior limbs. The soft extremity of the tail may also occasionally become congested, or else œdematous (dropsical). But these states of the part would not justify a man in cutting off the tail, for the limbs are often found in the same condition, and no one would ever think of lopping them off; for the remedy would be worse than the disease, and, so far as the tail is concerned in being the seat of local congestion, or œdema, there is no disease at all, and therefore does not require local treatment. But I am not discussing the probabilities of diseases of the tail. This is not my purpose. I only aim to show the folly of making the cow's tail the indicator of the various diseases of her body, and also that of confounding a disease of the nervous system with a slight congestion of the tail ; and farther, the folly of arguing that the cow's strength is taken out of her back, etc., because the end of her tail is soft.

If the tails of neat stock, or those of any other animals, become diseased, in the name of humanity let them be prescribed for. But I do hope that those who read this article will never be caught prying into the end of the above useful appendage for the purpose of demonstrating that which never existed.

Almost all animals said to have the tail-ail, are laboring under various forms of disease remote from the tail, and however diligent men may be in performing their barbarous operations on the same, the disease under which the animal $23 *$ 
suffers, perhaps located either in the brain, spinal marrow, liver, or pancreas, entirely unsuspected, may progress to a fatal termination, while an uneducated cow-leech is amusing himself by taking unwarrantable liberties with the uncomplaining animal's tail. I am often told that animals after being thus operated on get well. Very likely. Some animals will endure the most cruel torture, and I once saw a cow in apparent health who a fortnight previous drank a pint of white paint. Such cases I look upon as nothing more nor less than lucky escapes. I shall close this article by introducing a selection from "Youatt on Cattle."

Mr. Youatt, when treating of palsy, thus alludes to tail-ill, or tail-slip: "In many parts of the kingdom, palsy is traced to a most ridiculous cause. The original evil is said to be in the tail ; and all maladies of this kind, involving the partial or total loss of motion in the hind limbs of the animal, are classed under the name of tail-ill, or tail-slip. Our friend, Mr. Dick, of Edinburgh, has taken up this subject in a very interesting point of view, in the fourteenth number of the Journal of Agriculture; and the public are much indebted to him for dispelling a false, injurious, and cruel superstition. The farmer and the cow-leech believe that the mischief passes along the cow's tail to the back, and that it is on account of something wrong in the tail that she loses the use of her legs; and then some set to work and cut the cow's tail off, while others, less cruel or more scientific, make an incision into the under surface, and allow the wound to bleed freely, and then fill it up with a mixture of tar and salt, and we know not what.

“. . . Mr. Dick, with a kind consideration for which he deserves much credit, condescends to reason the case with these foolish people; and what he says is so much to the purpose, that we cannot refrain from introducing it here: 'The disease, in ordinary cases, is said to consist in a softening about the extremity of the tail, and is to be distinguished by the point of the tail being easily doubled back upon itself, and having, at this doubling, a soft and rather crepitating kind of feel. But what is the real state of the case? The tail is lengthened out 
to the extent of about three feet, and is formed like a common whip. Towards the extremity, the bones terminate gradually, becoming insensibly smaller as they proceed downwards; at this part is said to be found a soft place - the tail-slip. Beyond this again, a firm cartilaginous portion is found, covered with hair to brush off the flies within its reach. Now, why have we the long columns of bones, - the termination with a sofk space of a few inches, - this thickened, hard, cartilaginous part at the very extremity, and that extremity covered with hair, but with a view to form a whip, to drive off with the greatest possible effect the insects which wound and torment the animal?

After such testimony as the above, I firmly believe that the readers of this work will never be caught in the foolish act of locating paralysis at the extremity of the caudal appendage.

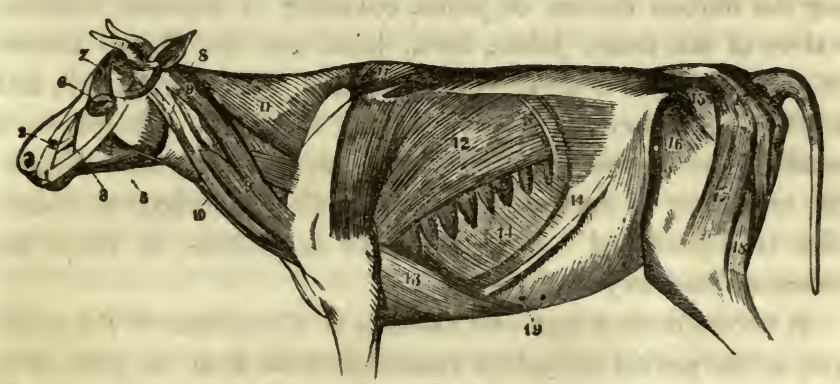

A VIEW OF SOME OF THE SUPERFICIAL MUSCLES.

For explanation see p. 392. 


\section{RHEUMATISM, ACUTE AND CHRONIC.}

\section{ACUTE RHEUMATISM.}

Animals that are unnecessarily exposed to the influences of tempestuous weather, particularly after calving, or those located in a cold, damp, or swampy region, provided they are the subjects of a rheumatic predisposition, are very apt to suffer from an attack of this painful malady. Therefore it may be truly said that the same causes which are operative in the system of the human subject to produce an inflammatory affection of this character, act precisely the same in all animals.

In plain language, rheumatism is rheumatism, in whaterer specimen of animality it may be found: it is usually accompanied by pain, heat, and tumefaction in the region of joints; sometimes it is located in muscles; then, again, we find it affecting the fibrous tissues of joints, covering of muscles, tendons, valves of the heart, joints, back, loins, and the fibrous tissues of the body. It is always characterized by a strong, full, and unyielding pulse. It always leaves the parts affected in a condition predisposed to subsequent attacks, and, according to the testimony of eminent pathologists, this pathological condition is reproduced in offspring, and constitutes in them the inherent tendency to the disease.

It occurs among men and animals at all seasons of the year; yet, at the period of sudden transition from heat to cold, it is most prevalent. Animals that are heated by exercise and then suffered to "cool off" without ordinary care, are very apt to become the subjects of this malady; so that prevention, to a certain extent, is within the province of all rational beings; and in the exercise of preventive measures, we may, in common parlance, "stave off," for a time, an acute disease, although it be hereditary. Rheumatism, like gout, is hereditary; no educated physician ever opposes this proposition; it developes itself in the predisposed. The indirect cause is obstructed perspiration. Keep the animal comfortably warm and avoid 
undue exposure, and then we have a remedy against the development of hereditary rheumatism.

Cattle, calves, and horses sometimes suffer from rheumatic inflammation in the fibrous sheathing envelopes of the muscles of the neck, constituting what is popularly known as the chords. When thus affected, the animal is very stiff, remains as much as possible in one position, and is unwilling to bend his neck either one way or the other, or to elevate or depress his head. There is always more or less fever, with a strong, full pulse. Sometimes, as in lumbago in the human subject (this is only another name for rheumatism), it affects the muscles of the back and loins, causing stiffness, tenderness, and pain, which are especially evinced on moving or turning the animal. These rheumatic affections are very readily produced in predisposed subjects, by exposure to rain and cold, especially when accompanied by overheating or exhaustion.

"Rheumatism sometimes occurs in horses and cattle, as a prominent symptom of that epizoötic affection which usually receives the much-abused title of influenza. In such cases, the rheumatism is of a somewhat more subacute or chronic character than common, and is accompanied by that low, debilitating fever so often the concomitant of epizoötic maladies. It usually affects all parts of the body susceptible of the rheumatic inflammation, is attended particularly by those symptoms which indicate disease of the heart and pericardium, as an intermittent pulse, etc., and often terminates fatally by effusions into the pleura or pericardium, thus causing death by arresting the motions of the heart.".

The reader has now before him some of the most important features of acute rheumatism, and I shall now allude to the treatment.

The remedies used by different practitioners are:- colchicum, calomel, opium, Dover powder, tartar emetic, cimicfuga, racemosa, hellebore, aconite, iodine, nitrate of potassa, acetate of ammonia. Each article has its advocates, and at certain stages is indicated. I have great faith in colchicum, yet have often succeeded in producing a favorable termination in the 
use of guiacum, nitrate of potassa, and liquor acetate of ammonia.

The theory of treatment of acute rheumatism, contemplates antiphlogistics, to be continued so long as inflammatory symptoms shall be severe; yet, we must exercise ordinary discretion in the use of antiphlogistic remedies; for, should we continue them until all inflammatory symptoms have subsided, we may purge, nauseate, and bleed our patients into the vicinity of death's door, without accomplishing our object.

The old-fashioned method of combating an inflammatory diathesis, in the use of lancet and drastic cathartics, is fast dying out, or at least a very marked change for the better is observed; and practitioners now depend more on sedatives, diuretics, febrifuges, and nauseants, than on the above. One of the principal objects in the treatment of acute rheumatisn is to excite diaphoresis; and in this view I recommend a solution of acetate of ammonia, known as Liquor Ammonia Acetatis. This is an excellent febrifuge and diaphoretic, and may be given in broken doses to the amount of eight ounces per day. One or two drachms of nitrate of potassa (common salt petre) may also be given in the form of drink; yet, in order to insure diaphoresis, and to prevent these agents passing off by the kidneys, the heat of the body must be augmented by clothing.

Practitioners of human surgery are often in the habit of using nitre, in much larger doses than $I$ have dared to administer, yet, in some cases, with marked benefit to the patient.*

* Nitrate of Potassa. - In a case of synovial rheumatism, this remedy was given by a Boston physician, in a single dose of one ounce, dissolved in a pint and a half of barley water. This was followed by one grain of opium. In fifteen hours the pulse was found reduced, and the pain absolutely gone; and in a few days the tongue was clean, and the swelling entirely abated. The remedy caused neither emesis nor catharsis, but passed off by the kidneys. . In another case of acute synovial attack, following chronic rheumatism, the same dose was prescribed without any good effect, causing active catharsis. Again, half an ounce of nitrate of potassa, largely diluted, was given every two to four hours, until the patient took three ounces in eighteen hours, with two doses of opium of one grain each, with entire relicf to the pain and fever. When 
A few doses of nitre will probably moderate the heart's action, and relieve the pain. Should it fail to do so, I should give a couple of drachms of fluid extract of Indian hemp, and repeat the dose at intervals of two hours, until some symptoms of improvement are observed. Should I fail, in the exhibition of the above remedies, to lessen the heart's action, and the pulse be fifty or more per minute, the breathing hurried, and the pain tormenting, I should then drench the animal with a full dose of glauber salts.

The bicarbonate of soda is a very valuable adjunct in the treatment of acute rheumatism, because, in seven cases out of ten, the whole system is in an acid condition; and if we can (in the language of the chemist) saturate it with alkali, or, in other words, establish an alkaline condition, our patient is then on the high road to health.

Now, in case a cathartic be indicated, we must consider the condition of the patient. He may be suffering excruciating torment, from inflammation of the pleura, pericardium, or synovial membranes; and if so, our object must be to mitigate pain, in the use of Indian hemp, or some other narcotic. Should the patient, therefore, exhibit lameness in one or more of the extremities, and the joints of the hind or fore limbs become swollen

the potassa was reduced to drachm doses, nausea and vomiting followed, which were relieved by vesication with aqua-ammonia, the blister being sprinkled with half a grain of morphine. The patient recovered. Another physician had used the remedy to the extent of half an ounce in twenty-four hours, for three successive days. He found that if the salt be given well diluted, it will purge, and vice versa. The physicians of the Massachusetts General Hospital had used the remedy, one ounce in twenty-four hours, without good effects, and its use was abandoned. It appears to be conceded, that it is safe to give the remedy in this quantity, although symptoms of gastritis sometimes followed its use; but it was always largely diluted, and generally in demulcent liquids. We are in the habit of giving it in rheumatism and other inflammatory affections, in doses of twenty to thirty grains, every two or three hours, during the period of excitement or exacerbation, combined with tartar emetic; but have been deterred from the exhibition of the larger doses above mentioned, from fear of its toxical effect. We have found this combination particularly useful in pneumonia. - Memphis Med. Recorder. 
and painful, a local application may be of some service, and in this view I recommend the following :-

Cod Liver Oil, ......................................

Tincture of Lobelia, ............................1 ounce.

Glycerine..........................................2 ounces.

Chloroform, ..................................... ounces.

Mix, apply a portion to the affected limb or joint, twice daily.

In an inflammatory state of the joints, it is customary to apply cooling applications, yet the practice is open to the following objection; viz., it may augment the acute symptoms in and around the joints, while it lessens them on the surface; nevertheless, if an action of the cutaneous vessels can be maintained, refrigerating lotions cannot do harm.

So soon as the inflammatory symptoms have subsided, and all danger of internal disease seems to have disappeared, we must commence a different plan of treatment. I then give tonics, not only to promote the convalescence of the patient, but also in order to prevent the disease assuming a chronic type, which is very apt to be the case when the prostrating plan of treatment has been too long continued, or practised with undue severity. From among the following agents the practitioner can select a suitable tonic: Sulphate of iron, cascarilla bark, gentian, quill bark, quinine, goldenseal, camomile flowers, to either of which a small portion of ginger may be added provided a stimulant be indicated.

\section{CHRONIC RHEUMATISM.}

Chronic rheumatism is generally a sequel to the acute, yet if the subject be closely watched, a train of phenomena may be observed very similar to those attending the acute stage, yet differing in its gradual accession, obscure state of the phenomena, and less functional and structural changes.

At times, chronic rheumatism is nothing more than a modified and protracted state of the acute stage; it is migratory, like the former, attacking this, that, or other tissues, without reference to its original locality. For example: a horse may, after brisk driving and subsequent exposure, become lame in 
the region of the fore extremities; this lameness may, perhaps, be defined as subacute or chronic rheumatism, from the fact that there is no increase in arterial nor respiratory actions; but the first thing we observe is, that the subject is laboring under hypertrophy of the heart, perhaps carditis, or endo-carditis; and this is proof positive of the migratory character of rheumatism.

But why should rheumatism attack the heart? This is quite an interesting question, and thus I answer it: The physiology of the heart instructs us that its motions are governed by the impression made upon the susceptible nervous tissues. Its responses are physiological when the whole system is unembarrassed ; it is the centre, not only of circulation, but of sympathy, and responds to the impressions made upon the general system; so that if any disturbance shall occur in the animal economy, in the form of fever, spasm, etc., or the animal be affrighted, punished, or exposed to sudden variations in temperature, the heart is one of the organs first deranged. Rheumatism, therefore, being migratory, is apt, in travelling from tissue to tissue, to locate on a deranged organ, especially when that organ is one so easily excited as the heart.

\section{CAUSES OF RHEUMATISM.}

The special cause of rheumatism is hereditary predisposition. In certain families morbid tendencies are transmitted from parents to offspring, and display themselves in the development of parental defect and deformity. There are, also, general exciting causes, suclı as exposure after perspiring freely, damp and cold stables; errors in diet or in stable and barn management, overwork, etc.

Principal Symptoms of Chronic Rheumatism. - The subject is generally observed to travel with a limited or stiffened gait, when first taken out of the stable. He appears "stiffened up," as the saying is, yet "limbers up" as he proceeds. This depends, however, somewhat on the temperature of the atmosphere; for the animal is nothing less than a walking barometer, 
and the slightest alteration in the weather affects him very sensibly.

The disease may manifest itself in the diffuse form, affecting the body as well as the limbs and feet, which gives to the animal a sort of wiry, spare appearance; yet, otherwise he appears well, and can play his part at the game of food as well as any creature. In the absence of all inflammatory symptoms, this peculiar and almost ruined condition is designated by some as general founder ; and as no one has ever drawn a line of demarcation between what is known to medical men as chronic rheumatism, and what the rest of the world denominate chronic founder, we shall consider that chronic rheumatism is founder, and vice versa.

Passing from the diffuse form, this chronic affection may locate in the muscles of the trunk. Then it gets the name of "body founder." The animal is then unable to move the body in lateral directions, without showing an awkward stiffness ; and on being made to turn a corner, when going at a smart gait, a stiffness, apparently in the spinal regions, is generally perceived.

At times it locates in the pectoral region, and, in consequence either of long-continued pain (which is known to exhaust muscular rotundity) or innutrition, the parts present a shrunken or hollow aspect. In the absence of acute symptoms, this is the veritable "chest founder" of horses and cattle.

A disease of this character, long confined to one or both shoulders, is often followed by a similar wasting of the spinatus muscles, and is often termed, when occurring in horses, "sweeney." The same condition of parts, however, may be the consequence of diseased feet; for we often observe an atrophy or wasting of the above muscles in animals that have long been the subjects of chronic laminitis, and altered structures about the feet. The term founder is often applied to a ruined state of these parts. Chronic rheumatism is more apt to localize itself than the acute kind, and once located it is not so easily removed, although the animal may receive benefit from the ordinary means, such as warm clothing and stimulating embro- 
cations, yet, when exposed to wet or cold, he again relapses into his former condition, travelling stiff and lame as ever. The stiffness and lameness, if there be any, attending chronic rheumatism, disappears, to a certain extent, after a brisk trot, whereas, acute rheumatism is generally aggravated by exercise.

Chronic rheumatism may, however, appear in one spot today, and to-morrow manifest itself in another, yet the affected parts exhibit none of the heat nor tenderness, difficult respiration, wiry pulse, nor functional disturbance which attends the acute stage; so that the difference between the acute and chronic conditions of this affection is very marked.

Treatment of Chronic Rheumatism. - Local treatment consists in the application of vapor, warm blankets, and leggings, and stimulating liniments, the patient to be located in a warm yet ventilated stable.

The following is probably one of the best local applications :-

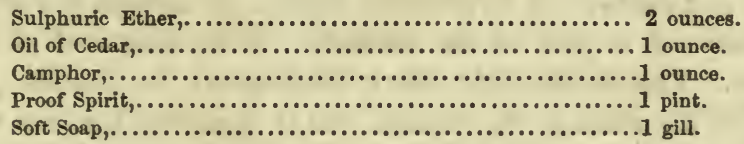

Dissolve the oil of cedar in the sulphuric ether; then dissolve the camphor first and soap afterwards in the proof spirit, and mix.

Apply a portion of the above to the affected parts, night and morning, so long as the case seems to require it.

Constitutional Treatment. - The constitutional remedies are various, those entitled to our greatest confidence are :-

First. - Medicines which act upon the cutaneous vessels.

Secondly. - Medicines récognized as pure tonics, which impart tone and activity to organs without inducing subsequent prostration.

Thirdly.-Medicines known as general stimulants, that excite without depression.

As an example of the above, I offer the following formulæ:- 
Thayer's Fluid Extract of Black Cohosh, diaphoretic,.........2 ounces.

" " " Gentian, pure tonic,..............2 ounces.

" " " Jamaica Ginger, stimulant,..........1 ounce.

Syrup of Garlic, antispasmedic,....................... ounces.

One-fourth of this mixture may be given, night and mornw $r$. in the form of drench.

Other medicines are in high repute, such, for example, as hydriodate of potassa, nitrate of potassa, phosphate of ammonia, camphor, capsicum, tincture of white mustard seed, etc.

\section{THE LIVER AND ITS DISEASES.}

\section{DESCRIPTION OF THE LIVER.}

The liver is the largest gland in the body; unlike the liver of a horse, it has a large reservoir for the reception of the bile, called the gall bladder. In form it is irregular, being convex anteriorly, or towards the diaphragm, with which it is in contact, and concave on its posterior surface, or towards and in the vicinity of a part of the stomach. It is composed of two lobes. That on the right side is the largest; the central portion of the gland is the thickest, and it gradually becomes thin towards its borders. The mass consists of a vast number of minute lobules, varying in size and form, containing a network of biliary ducts connected with their main trunks, and a large number of biliary cells; and each is connected in like manner with three bloodvessels; namely, the hepatic, or nutrient artery of the liver; the vena portæ, which returns the venous blood after it has circulated through the intestines; the hepatic vein, which carries back the blood received from both the other sources. It will be seen, therefore, that the venous blood, which is brought to the liver by the vena portæ, is intended for the elimination of bile. Therefore, this vessel seems to act in the double capacity of vein and artery; for, as a vein it receives blood from the abdominal viscera; as an artery it ramifies through the liver, forms a capillary network, and then secretes the bile. From this capillary network, which can be traced to the centre of the minute lobules, the hepatic vein takes its 
origin, collecting the blood from the capillary network. It then unites with other radicles to form the main trunk, by which it is delivered into the vena cava (see heart and its functions).

The branches of the hepatic artery are principally distributed upon the walls of the hepatic ducts, and upon the trunks and branches of the portal and hepatic veins, supplying these and the contiguous parts with the necessary amount of arterial blood for their nourishment, as well as that of the whole gland.

The investing membrane of the liver, from which prolongations extend into its substance, is termed Glisson's capsule.

The liver derives its nerves and nervo-vital power, from the great sympathetic and eighth pair.

The liver is confined to its situation by ligaments, which get the name of broad, lateral, coronary, and round. The round ligament is the remains of the umbilical vein of the foetus. The others are continuations or duplicatures of the peritoneum.

\section{SECRETION OF BILE, ITS USES, ETC.}

The bile is secreted from the capillaries of the hepatic artery, by minute glands found on the surface of the biliary ducts. It then passes through the biliary pores and branches of the hepatic duct. By this duct it is conveyed to the ductus communis choledochus, ${ }^{*}$ from whence, in part, it passes by the cystic duct to the gall bladder. When needed in the duodenum, it returns by the cystic duct, and mixes in the ductus communis choledochus with fresh bile from the hepatic duct, and then passes into the duodenum. The bile having entered the intestine mixes with the aliment and pancreatic juice. The pancreatic juice changes the digested aliment into a brown mass, termed chyme, and then emulsifies it. After being emulsified, a portion of the chyle is taken up by the lacteals and enters the receptaculum chyli.

In a healthy state of the system, should any bile escape with

* Union of the eystic and hepatic ducts. 
the chyle, it is absorbed by the mesenteric glands, and returns to the liver by the vena portæ.

\section{GALL BLADDER.}

The gall bladder is a pear-shaped bag connected with the concave and posterior surface of the liver, by the above vessels and cellular membrane; it has four coats termed peritoneal, cellular, muscular, and villous. The villous coat is the internal one, and is thrown into numorous minute folds, arranged in a reticular form, filled with small ducts or follicles, and glands. The latter secrete a fluid for the protection of the internal surface.

\section{INFLAMMATION OF THE LIVER.}

Cattle and young stock, when fed too high, or when allowed to luxuriate in a rich meadow, are often attacked with an acute disease of the liver. The principal symptoms of this malady are yellowness of the membrane which lines the eyelids, and covers that part known as the "white of the eye." The visible surfaces of the mouth are also of a yellow tinge. In addition to the above symptoms, the animal is feverish, thirsty; mouth and base of the horns hot; pulse accelerated; breathing rather laborious ; rumination is suspended, and the animal is said to have "lost its cud." Some fulness will also generally be observed on the right side, in the region of the liver, and the animal will occasionally turn its head in that direction, as if it were the seat of pain, which is probably the case; yet the most reliable symptoms, in a disease of this character, are a yellow tinge of the visible surfaces, accompanied by febrile symptoms.

Treatment of Inflammation of the Liver. - The most rational method of treating this disease, is to endeavor to mitigate the inflammatory diathesis, and restore the normal function of the liver. In view of accomplishing these desirable results, $\mathbf{I}$ recommend the following prescription :-

Glauber Salts,...................................16 ounces.

Powdered Mandrake, .............................2 drachms. 
The salts should be dissolved in one quart of tepid water; then add the mandrake, and drench the animal by means of a common porter bottle. This drench should be poured down the œsophagus, in a gradual manner, so as to prevent its being received into the rumen, or paunch.

The patient should, if possible, be dieted on green fodder; if such cannot be procured, some sliced cabbages, turnips, or carrots may be substituted. A teaspoonful of mandrake should be given daily in the food, until the visible surfaces assume their natural color. A curable case will generally yield under the above treatment.

This disease sometimes runs into a chronic type, and is known by the yellow color of visible surfaces; dull, sleepy appearance of the subject, and absence of those acute symptoms which are invariably present in the inflammatory stage. A chronic disease of this character may exist for months and even years without interfering very essentially with the general health; finally, however, the liver undergoes alterations in structure, becomes hardened or indurated, or else it becomes tuberculous, or is the seat of hydatids, and the fluke-worm is often found in the ducts.

\section{Treatment of Chronic Disease of the Liver:-Take}

Powdered Iodide of Potassium,....................2 drachms.

"Goldenseal,.........................4 ounces. Mix.

Divide the mass into six equal parts, and give one in a little water every morning on an empty stomach.

The medicine may be continued for some length of time without the least danger. If this treatment does not benefit the animal, the case is probably incurable.

HYDATIDS.

Hydatids, commonly known as "flukes," consist of a sac or vesicle filled with fluid. To the naked eye it appears as a simple enveloping cyst ; but on examining it more closely, by means of the microscope, it shows many tunics or coats, and these are the rudimentary cells in various stages of growth. According to Carpenter, these rudimentary developrnents pro- 
ject more and more into the parent cell, and at last become detached from its wall, and lie loosely within it. Shortly before this separation, however, the young hydatid is seen to contain smaller cells, which increase in size along with it. This increase continues until the new brood thus formed entirely fills the cavity of the parent, and a farther increase causes the rupture of the sac and the escape of the progeny; and these in their turn undergo the same evolution, becoming parent hydatids in distinct cysts, and setting free their contained cells as a subsequent generation. These cystic entozoa are never found in the alimentary canal, but are always embedded in the liver, brain, or glands of organs. They obtain their food by absorption from the inner surface of the investing membrane. Hydatids infest the various organs of the bodies of all mammalia, and, although they are said to possess an independent existence while residents of the organ or organs which they inhabit, they die immediately when removed from their chosen habitation.

" * The principal genera of cystic entozoa are - cysticercus, conurus, echinococcus; to which may be added acephalocystis. Several species of cysticercus are enumerated, but the most common are cysticercus tenicollis and cysticercus cellulosus. 'The former (tænia hydatagenia, hydatis globosa) is met with frequently in the peritoneum and pleura of ruminating animals and pigs. It is often generated in the disease called rot, where another entozoon, the distoma or fluke worm, is met with in the biliary ducts (liver). The cysticercus cellulosis is found generally lodged in the tissues of the muscles; it occurs sometimes in man, but more frequently in animals, particularly in the hog, where it causes the disease denominated measles. Of the genus cœnurus (hydatis polycephalus), the species cerebralis is found in the brain of the sheep, oxen, and other ruminating animals. These hydatids on the brain of sheep cause the disease called sturdy, or giddiness. The hydatids belonging to the genus echinococcus are considered by some as varieties of the acephalocyst. They are commonly called

* Pan, in the London Field. 
granular hydatids, from the presence of numerous granules which float in the fluid of the cyst, or adhere to its walls. There are two species of echinococcus; one, echinococcus hominis, hàs been met with in the brain and abdomen of man, in a few instances; the other, echinococcus veterinorum, occurs in the hog and other animals.

"The following is from the pen of Mr. John Gamgee, Edinburgh, on sturdy in sheep, in which much useful information relative to parasites is given.

"'The more inquiries made, the more accurate will the conclusion arrived at by scientific men appear, that dogs and sheep must live together for certain parasites to extend their ravages with effect. On all the sheep farms I visited last summer, sturdy was complained of, and on all such farms there were dogs. Such was the case at Cairnton, Mill of Kincarnardine, on Glendye, and in other localities. Mr. Falconer, of Balnakettle, a gentleman of great experience, and other farmers, assured me that there has been more giddiness in sheep within the last two or three years than they had ever witnessed before, and the losses in consequence are sometimes greater than by that fatal malady, "braxy." This clearly does not depend on a large number of dogs being kept; but there are many conditions affecting the propagation of parasites, and if destructive agencies were not as universal as the productive, much more effectually would vermin and parasites multiply and spread their baneful influence, to the detriment of mankind. It is accidental circumstances that affect the development of diseases of animals. If every germ produced by a single tape-worm in a limited period of time were to take effect, it would be quite sufficient to exterminate the flocks of Great Britain; but, I repeat, the laws established to procure the multiplication of any animal are counteracted by an infinity of uncontrolled, but perhaps not uncontrollable, agencies. The latent vitality of the eggs of such parasites is extremely ditficult to destroy, and, to use the words of one of Kucherimelster's reviewers, after months of exposure to warmth and moisture, the pulpy and putrid debris of segments of the tænia solium yield 
ova which show no sign of any approach of degeneration or decay. And the writer of this review has been struck by the remarkable way in which the size and structure of these ova allow them to elude all precautions that may be taken against their mechanical dispersion. In spite of every attempt to insure their destruction, by steeping the specimen glasses he may have used in strong acids, and by afterwards bathing them in the flame of a spirit-lamp, he has once or twice found the characteristic ova appear most unaccountably in healthy and diseased tissues of secretions of the human body, which he has subsequently examined with these glasses. The dissolution of the parent tissues ultimately sets free the eggs contained in their interior, to be carried by the winds and waves wherever accident may determine. How vast a number of them miscarry, is evident when we attempt to take the census of a single tapeworm. Or, imagine the million of eggs such a parent foists upon society during the years it may inhabit a given animal. What becomes of these abortive germs, how long they retain any vitality, and what are the circumstances that may rob them of it, are questions we cannot answer, save by the conjecture that their albuminous and fatty materials are either applied to the soil in a decomposed form, or are consumed as food by various of the minute intervertebrata that throng the surface of the earth and the waters. But the more fortunate minority of these eggs, the destiny of which is to eat instead of being eaten, after many and long wanderings of this passive nature, are at length engulfed by some unconscious animal in company with its food, and through its alimentary canal attain the locality of their second form of existence. During this passive emigration, the worm has retained its previous size (1-700th of an inch) and shape. But its thick wall bursts and sets free the inclosed embryo, which is an ovoid body, of nearly equal size, armed with six hooklets at one extremity. Impelled by instinct to begin its active migration, the embryo pierces the first portion of its path, by bringing together the anterior pair of hooks so as to form with them a kind of wedgeshaped stiletto, and now drags itself forward in the same 
direction by means of the succeeding pairs of hooks, which it uses like a person who, in attempting to get out of a bowwindow, thrusts limself forward by his elbows. In this way the minute embryo penetrates the body it inhabits, and only increases its efforts on reaching the place its instinct recognizes as suitable for its abode, prior to the next series of changes it has to undergo. Streaks of re-active inflammation and exudation generally indicate the minute channel by which the embryo thus traverses the wall of the digestive canal, in its course to the liver or other organs. The migration of a tænia is probably a passive process. Various facts suggest it to be so- ' a true locomotion, effected under the impulse of an instinct, and by means of certain special organs. The germs of parasites are evidently carried through the system in the stream of circulating blood, and they do not always travel themselves through the interstices of tissues.'

"Sturdy was long considered as dependent on a simple accumulation of water on the brain, generally affecting one side. Lœeke had observed, in 1780, that the water-bladders on the brain of giddy sheep were animals; and Fabricus (Harvey's master) was the first to assert the same respecting the cysticercus of the pig. Albildguard, the founder of the Copenhagen Veterinary School, observed that a tape-worm (the bothriocephalus latus) which existed in the abdominal cavity of the stickle-back, and in the intestinal canal of certain water birds, never had eggs in the former but only in the latter situation; and that from the first-mentioned creature it passed into the second, he ascertained by direct experiments with ducks, which he fed on banstickles. Gœtze, in 1782, had perceived the great resemblance between the head of the hydatid of the liver of mice and rats, the cysticercus fasciolaris, and of the tape-worm of the cat, tænia crassicollis. The cercariæ was first studied by Müller, and lastly by Bejanus, in 1818, who recognized them as parasitic, in certain snails, inclosed in bags. M. Wagner and Von Siebold and Steenstrup fancied they had discovered the change cercariæ underwent to become true fluke-worms. Ehrenbreg, in 1852, disputed Steenstrup's ac- 
cepted metamorphoses, and only gives the resemblance of the tailless cercariœ, with a trematode worm. Dr. Kuchenmeister, of Zittau, instituted ingenious experiments to settle these hypotheses. He made dogs and cats swallow hydatids, which dereloped into tape-worms in the intestines. From the hydatids of the liver of cats and mice, the tænia crassicollis in the intestines of the cat arose; and from the cysticercus of the hare and rabbit, the tænia serrata in the intestine of the dog; so that if the water-bladder is lost, the head of the worm attaches itself to the head of the mucous membrane, the rings constituting the body of the tape-worms, including the organs of reproduction, and they are thus formed. By repeated experiments made by several eminent zoölogists, the deductions were confirmed."

The liver is sometimes enormously enlarged, in consequence of the presence of a numerous progeny of the fluke-worm. The following case, contributed for The Veterinarian, by Surgeon J. B. Gregory, will serve to illustrate this matter. The morbid parts referred to were sent by Mr. Gregory to the editor of The Veterinarian, who makes the remarks enclosed in brackets.

"The morbid parts I send were taken from a well-bred, short-horned cow, six years old, estimated to weigh, when fat, one hundred twenty-five stones of eight pounds. She was purchased in August last, with a warranty to calve in November following. On September 2d, her owner called on me, and wished me to give her some medicine, as he thought she was not quite recovered from the effects of being driven sixteen miles. The medicine I sent had a beneficial effect, as the cow's appetite returned, and she appeared to be quite well again. After this I heard no more of her until the sixth of January lašt, -when I was requested to go and give my opinion as to her being in calf, it being two months beyond the time she was expected to calve. I found that her appetite and rumination were natural, the pulse regular, and the kidneys and bowels acting well. There was, however, a peculiar expression of her countenance, that told of continuous pain; her eyes, also, were 
sunk in their orbits, and she had a frequent and troublesome cough. Her skin, likewise, had lost its pliancy, and she was sadly out of condition, but no yellowness of the mouth or eyes was present. I first examined her abdomen externally, by percussing the right side, with a view of determining her pregnancy; but the body my hand came in contact with was too large for, and had not the feel of, a fœtus. As the cow had occasionally been observed to strain, I was now induced to examine her per vaginum, when $I$ found the os uteri to be indurated and unyielding. I could also distinctly feel a round and hard substance, about the size of a large cricket ball, and which I supposed to be the right ovary; the other one, however, I could not find. I told the owner that the cow was not in calf, unless it were extra uterine, and that in all probability the mass we could feel from the outside was a tumor within the abdomen. I also added that medicine could do no good in such a case. He at once decided on having her killed, which afforded me the opportunity of making a post mortem examination. All the viscera were healthy, with the exception of those I send. The liver, as you will see, is the organ principally affected. It weighed, when first removed, one hundred and forty-six pounds. Its great size led to its encroaching on the space occupied by the other viscera, all of which were more or less compressed. It did not adhere to the side of the abdomen, but was firmly attached to the diaphragm, and also, in places, to the intestines. In my examination I had the assistance of Mr. Hearn, M. R. C. V. S., who was recently your pupil, and who has, I believe, also written to you on the subject. The cause of the enlargement of the liver is evident enough, being produced by hydatids, but I leave to you to describe the variety to which they belong. I have attended post mortem examinations of many cattle since 1828 , but never met with any thing like this before.

["The description given by Mr. Gregory leaves us but little to say respecting this extraordinary enlargement of the liver, as stated by him. The sole cause of its increase in size was due to the presence of an immense number of hydatids in the sub- 
stance of the organ. These entozoa belonged to the variety designated the acephalocystis endogena, and each cyst contained within it a considerable quantity of the so-called echinococci. In the 'Transactions of the Veterinary Medical Association, for 1842-3,' a similar case is recorded as occurring in a pig, which is illustrated by a colored plate, and which may be said to depict equally as well the condition of the liver of the animal in question."]

\section{JAUNDICE, OR YELLOWS.}

This disease is of very common occurrence among horned creatures; the stall-fed animal is probably more subject to it than those otherwise fed. From this the reader will infer that it is more likely to occur in the winter or spring than at any other season, which is the case. In order to prove this, let any one visit our markets, and note the color of the rat of beef, and he will notice the yellow appearance of almost all the beef offered for sale. There may be some exceptions, yet this feature of fat is a sure sign that the animals while living were not entirely free from functional derangement of the liver. This peculiar color, however, is very rarely, if ever, found to pervade the brain, humors of the eye, or the milk during lactation.

Occasionally, a yellow tinge of the visible surfaces - membranes of the mouth, nose, and eyes - appears very suddenly, and is supposed to originate from sympathetic action of the brain upon the liver; yet it may arise in the same sudden manner, in consequence of gastro-intestinal irritation, produced by the introduction of poisonous plants and rough food, such as cornstalks and sugar-cane, into the stomach. Jaundice, in a very protracted form, often owes its origin to the presence of biliaiy calculi - so say the authorities; but I have examined many gall bladders after death, yet have never succeeded in finding any; and I have inquired of our slaughterers in this State, and am informed that they never observed any stones in the gall bladder; yet, in various alkaline districts of this country, I presume biliary calculi may be as common as in the chalky regions of the old world. 
According to concurrent testimony, the presence of biliary calculi, in the gall bladder of an ox, does not interfere much with the general health; but they oceasion a jaundiced appearance, a general eye-sore, which renders yellow beef unacceptable to the palate of an epicure, and the shrewd butcher declines to deal in any thing yellow, except pure dust.

I know of no symptoms by which the presence of biliary calculi can be detected prior to death.

The two following paragraphs occur in "Youatt on Cattle," and may throw some light on the subject :-

"Sometimes, they [calculi] enter the duct (the cyst) which conveys the bile to the intestines. They are likely to do this on account of their swimming on the surface of the fluid which the bladder contains. The cystic duct is large at its union with the bladder; it is a continuation of the neck of the bladder, and the gall-stone may be easily pressed into the commencement of the tube; but it has scarcely entered it before its passage is obstructed by the folds of the inner coat of the duct. These assume a semilunar form, with the edges projecting towards the bladder, and they act as partial valves, retarding the progress of the bile, so that it may not all be pressed out at once, but gradually escape as the process of digestion may require.

"The gall-stone being thus impacted, violent spasmodic action takes place in the muscles of the duct, occasioned by the irritation of its continued pressure. It is fortunate, however, that, although the muscles of these ducts act with some power, the obstruction is usually, with no great difficulty, overcome. The duct distends; as it distends these valvular folds lie closer to the sides, and no longer oppose the passage of the calculus, which is pressed on until it reaches the common duct. The calibre of this tube is larger, and, unless the calculus is of considerable bulk, no farther difficulty occurs until it reaches the opening into the duodenum, which being situated in the centre of a muscular prominence, acting as a valve, and preventing the passage of all matters, whether fluid or solid, from the int stine into the ducts, a new dif- 
ficulty is opposed to the progress of the gall-stones, and there is some return of pain, and in a few cases the pain is evidently more intense than in the early stage. At length, this sphincter muscle of the duodenum dilates, the calculus enters the intestinal canal, the pain ceases, and the natural color of the skin returns. In this species of jaundice, we have, in addition to the yellow skin, the heaving of the flanks, the hard, concentrated pulse, the diminished appetite, the insatiable thirst, and the other symptoms of fever. Then, too, we have the alternate cold and heat of the ears, the roughness of the coat, the urine becoming first of a transparent yellow, and then opaque red, saffron-colored, or brown, and the sediment brown. The bowels are constipated, the fæces seldom evacuated, and, when appearing, are hard and black."

Treatment of Jaundice. - Very little can be done for that form of jaundice occasioned by gall-stones, with the exception of giving a dose of glauber salts and a few bran mashes, for we have no means of dissolving the calculi, nor of removing them.

Sympathetic jaundice, or that occasioned by functional derangement of the digestive organs (including the liver), may be treated as follows:-

Powdered Mandrake 2 drachms.

" Iodide of Potassium, $\ldots \ldots \ldots \ldots \ldots \ldots \ldots \ldots \ldots \ldots$ grains.

" Goldenseal,............................... drachm.

Mix in a quart of warm water, and drench. This quantity is to be given daily, until the visible surfaces assume a more natural color. Scalded shorts seasoned with table salt is the best diet, and the patient will not require much of this, for it is very likely that the stuffing process has been practised, and if so the stomach wants some rest.

The jaundiced animal should always be turned out for exercise. It often happens, however, that he is either unwilling or too lazy to move about. If the disease occur in the grass season, let the patient have some; it is the best medicine in the world for stall-fed jaundice. 


\section{DISEASES OF THE BRAIN.}

\section{INFLAMMATION OF THE BRAIN AND ITS MEMBRANES.}

Ir makes but little difference, so far as our method of treatment is concerned, whether the brain or its membranes be the seat of inflammation; for the treatment in both cases must be the same, and the difference in a pathological point of view cannot be very great between a disease of the brain and its investing membranes, although each may have peculiarities of appearance.

The affection is generally sudden in its attack, and it is often accompanied by symptoms of phrensy, and the animal sometimes becomes frantic, and decidedly mischievous; soon, however, alterations in the structure of the parts take place, as softening, effusion, etc., and then the animal dies.

In regard to the treatment, I must confess that it is much easier to write about it than accomplish it.

In cases when delirious fits occur, accompanied by conrulsions, which make it dangerous to approach the animal, I have no remedies to offer; the case is beyond the reach of art. I may, however, add, that the terminations of this disease are different. They depend on the intensity of the malady, and the structural susceptibility.

The disease is generally treated on the antiphlogistic plan: cold water to the head, active cathartics, and counter irritation on the region of the spine. The causes of a disease of this character are often obscure, yet $I$ have known it to occur as a symptomatic affection. I examined the carcase of an ox, a short time ago, that died of what the owner termed "mad staggers." I found the brain highly congested, and several adhesions between it and its membranes; there were also large patches, intensely red, on the lining membrane of the third and fourth apartments of the stomach. I was informed by the owner that the animal died twenty-four hours from the time of its first attack. The disease probably originated on the digestive surfaces, in consequence of the irritating nature of 
the food-mouldy hay and tough cornstalks, with a sprinkling of damaged meal and brewer's grains.

The symptoms of symptomatic disease of the brain are as follows:-dullness, loss of appetite, staring of the coat; and, if the animal be a milch cow, diminution in the quantity of milk is observed; the extremities are cold, and the animal grates its teeth. The respiration is at first tranquil, and the pulse slow but full. The patient will frequently be seized with a kind of epileptic fit, which lasts but for a few minutes, during which time some of them will exhibit the most violent symptoms, such as bellowing hideously, pawing the earth, and running at any thing within their reach; they will also break out into profuse perspiration, and press their heads forcibly against the wall, even to such an extent as to break off their horns. Many are seized with violent tremblings and twitchings, and towards the latter period of the disease, the respiration becomes extremely laborious, the jaws are firmly closed, convulsions succeed each other rapidly, and death shortly closes the scene.

Treatment. - In the early stages of this affection, the animal should be drenched with the following:-

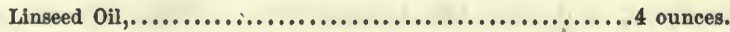

Lime Water, ...................................4 ounces.

Powdered Ginger,.............................. 4 drachms. Mix

The rectum is to be emptied, by means of clysters composed "of salt and warm water, and the whole length of the spine should be rubbed twice daily with a portion of the following :-

Linseed Oil,.......................................1 pint.

Spirits of Hartshorn. ...............................

Should the animal improve, a few doses of the following will complete the cure :-

Powdered Goldenseal,...............................2 ounces.

Carbonate of Soda,.............................. M ounce. Mix.

Divide the mass into six parts, and give one night and morning, in a pint of cold water.

STURDY, OR CEREBRAL PARASITES.

The brain, and its investing membranes, are often infested 
with a species of entozoa, termed conurus; they consist of a parent sac, or membranous tunic, from which, externally, germination takes place. This mode of multiplication of this group of parasites, differs from that which is observed in the hydatid - fluke - in which it occurs internally.

Symptoms of Sturdy. - The symptoms will depend altogether upon the number and size of the parasites. In their early state, they take up but little room, and do not occasion any very marked symptoms; yet, if the animal could only speak, we might be informed that he was the subject of headache. As the parasite or parasites increase in size, they produce pressure on the brain, which makes the animal appear giddy, confused, nervous, and desirous of separating itself from the herd; and it is in consequence of these peculiar symptoms making their appearance, when no other form of disease is present, that the term sturdy is applied, which is simply used to denote the presence of cerebral parasites.

Treatment. - When once these parasites have fairly taken up their abode in the cranial cavity of an ox, I fear there is very little help. An operation, such as that alluded to by the writer of the appended article, may, once in a while, prove successful, yet, in my opinion, the remedy is about as bad as the disease; therefore, I recommend prevention rather than attempts at cure. The preventive remedies are as follows :-

Salt, sulphur, and chârcoal, equal parts. This is a specific for all parasites. About a table-spoonful of the mixture, given occasionally in the food, will prevent the germination of many forms of parasites.

The following interesting "translations" are by Mr. Gamgee :-

"Sturdy in Cattle. - No less than seven bladders of the cœnurus were found in the left hemisphere of the cerebrum, in an old cow affected with the sturdy. Between the dura mater and the cranial parieties there were several transparent vesicles about the size of a pea, embedded in the substance of the bones. The left hemisphere of the cerebrum only weighed three drachms, and a scruple less than the right, 
although the former contained all the bladders. Hering could not find any heads of the ccnurus on the interior of the sacs, and he held them to be yet undeveloped hydatids. - Repertorium für Thoerheil, p. 21, 1855, Stuttgart.

"In the second volume of the Milan Veterinary Journal, at page 52, is a case of sturdy, reccrded by Patellani. It occurred in a two-years-old animal, that had shown, for several days, attacks of madness; and in one of these, it had broken a horn off. Patellani found her lying senseless on the ground, the head bent on one side, the forehead hot, painful on percussion, the sound produced hollow. On examination after death, the membrane of the brain was found injected, and in the right ventricle of the cerebrum, were hydatids with several heads."

"The trephine. has of late years been much recommended in cases of cerebral hydatids in cattle; and in Bavaria and Wurtemberg, it has frequently been employed, and often with good results. At the Clinique of the Munich Veterinary School, in the month of November, 1854, a year-old heifer was presented, with expansion of the right frontal bone; there were symptoms of giddiness, with turning towards the right side, dulness, etc. Ramoser found, on percussing the seat of the disease, that the sound was most hollow to the left. The case was observed for forty-three days, during which time the symptoms became more severe; the animal was trephined, and about two ounces of serum passed out, followed by the bag of the parasite. The wound would have been closed with a clay plaster, but the animal had to be slaughtered the following day. The membranes of the brain were inflamed, especially to the right, and blood was extravasated on its surface. The expansion, thinning, and even perforation of the upper part of the right lateral ventricle, showed that the bladder was lodged in the ventricle itself, as had been seen the previous year, in another case that had been operated upon. Death was then attributable to the far advanced stage of the malady, and to the abrupt collapse of the parietes of the ventricle, after contraction of the bladder."-Mïnchen Jahresber, for $1854-5$, p. 13. 
" Hydatids occur much less frequently in the brains of cattle in Great Britain, than in other countries, as Youatt has correctly said, in his treatise on the 'Diseases of the Ox.' It occurs only in the young animals. Indeed, it obeys the same laws that guide the development of the cœnurus in the sheep; and it is a well-established fact, that it is only when animals are growing, that the germs for the propagation of the bladderworms will be taken up, and carried to parts probably through the blood.

"The success attending the trephine, in cases of hydatids in the brain of the ox, is very great and encouraging; and not only have I read interesting and convincing records on this subject, but, in conversation with skilful and experienced veterinarians, I have learned that trephining is an operation often to be relied upon."

\section{SHAKING PALSY.}

Shaking palsy is a condition of the animal economy known to medical men as irregular, or abnormal, nervous action. It generally occurs in cows of the nervous temperament, whose digestive organs are deranged; and, so far as my experience goes, the disease is confined to imported stock, of the Alderney breed. I lately attended an Alderney cow, the property of Mr. Chenery, at the "Highland Stock Farm," Belmont. The patient was suddenly attacked with symptoms of irregular nervous action of the muscles of the chest and fore-legs, simulating skaking palsy. The membranes of the eyes were highly injected; pulse, jerking in unison with the irregular muscular action; external surface, extremities, and horns, quite chilly; respirations, normal; pulse, small and languid.

I gave the patient three drachms of fluid extract of goldenseal, and the same quantity of fluid extract of camomile flowers.

The spine and fore extremities were then irritated by the application of tincture of capsicum. On visiting the animal, the next day, I found her in better condition; the tremulous 
motion had somewhat subsided, and I pronounced her out of danger. She finally recovered without much subsequent treatment.

It is my opinion, that this case had its origin in derangement of the digestive organs, and constipation; for, after the exhibition of the tonics, - "bitters," - which aroused the action of the stomach, the animal passed an immense quantity of black, fotid excrement. The quantity was so great that it occasioned remarks on the subject from all who visited her.

\section{HYDROPHOBIA.}

There are generally some circumstances connected with a case of hydrophobia which afford a clue to its real nature. It often happens that evidence conclusive is furnished, that the animal has been bitten by a rabid dog. If this be the case, all doubts are at an end.

Symptoms. - In the early stages of the disease, there may be nothing in the symptoms to excite suspicion as regards the true character of the affection; they may merely denote approaching illness; but if the animal has been bitten by a rabid dog, or any other animal, and has become inoculated with the virus, which is usually communicated through the medium of the saliva, then any slight deviation from health, as shown by suspension of rumination, or by any other abnormal condition which may attract the attention of the farmer, is the precursor of the dreadful malady which is to follow. The most marked symptoms of hydrophobia are - protrusion of the eyeballs, the conjunctivial membrane is very much reddened, and, in fact, all the visible surfaces of the eyes, nostrils, and mouth are much inflamed. The animal is ripe for mischief, bellows occasionally, will paw and tear up the ground with its horns, and on the least excitement will become more dangerous than a rabid dog, - trying, however, to do injury, to friend or foe, with its horns rather than with its teeth.

The rabid cow or ox will drink water, if it can swallow; in fact, it generally suffers from intense thirst; but the fact is, the poor creature cannot swallow a drop. The least attempt 
at deglutition induces spasms of the larynx, and puts the animal into the most distressing agony. It is not the sight of water that puts a rabid animal into convulsions, as some persons suppose; for in the early stage of the disease, when the membrane of the larynx is not much affected, they will drink freely.

Treatment. - It is well known that the poison of all rabid animals resides in the saliva, consequently they cannot be handled and drenched without fear of danger; for if a small quantity of the saliva comes in contact with an abraded surface or sore, the unfortunate individual is just as much in danger as if he had been bitten. The only remedies that seem likely to be of any service, are the plantain leaf (plantago major) and lobelia.

Take four ounces of each of these herbs, and infuse them in two quarts of boiling water; wher cool, strain through a fine sieve, and administer at once. If, at the end of a few hours, the patient has not improved, it will be advisable to destroy him.

Mr. G. Lewis, V. S., of Monmouth, England, publishes the following case in the Veterinarian:-

"I was requested to see a cow, the property of an extensive farmer near this town. Upon my arrival he gave me the following history of the case :-

"On the 15th nlt., the calf from this cow, tied in an outhouse, was severely bitten in the nose and mouth by a dog, it was believed, although none was seen. But the cattle which were in the same meadow were in a very excited state, lowing and bellowing, as also the calf; and, upon the arrival of the shepherd, who hastened to the spot, he found the calf much torn, and the cow with blood upon her nose. The calf, from this period until the $27 \mathrm{th}$, could not take its milk in the natural manner, and was obliged to be drenched. But from the above date, the wounds having healed, and the animal apparently recovered from the injuries it had received, it was turned to the cow, and took its milk in the usual way, which it continued to 
do up to the 31 st, at which period the teats of the cow were bitten by the calf. From this date the calf became very ill, appeared to have sore throat, made a very peculiar noise, a kind of half bellow and roar, continued to get worse, and died on the $3 \mathrm{~d}$ inst. I did not see him, but such is the description given to me by Mr. J., and I know that it is a faithful one.

"My attention was now directed to the cow. She was observed yesterday to separate herself from the others, and to bellow occasionally. But this morning she was seen to foam greatly at the mouth, and appeared much excited. The other cattle also would not associate with her, but kept at a respectful distance, with their heads and tails erect. She was now brought to the house, at which time I first saw her.

"She was standing; the eyes were half-closed; she appeared to be in a kind of stupor, or half comatose state; extremities, natural temperature; respiration, natural. She, was looking rather thin; she was always a remarkably quiet creature, bụt now the least noise appears greatly to agitate her. The human voice, or the slightest movement, is sufficient to cause her eyes to glare, and set her bellowing, which ends in something between a growl and a roar. A person whistling, or the bark of a dog, produces fearful excitement. These paroxysms also appear to come on spontaneously. At their termination, the eyes again become half-closed, the abdominal muscles tremble, the respiration is slightly quickened, and the pulse is quick and tremulous. I remarked that some, water might be brought. Upon presenting the same she plunged her nose into the bucket, but could not swallow, and the effect was fearful to behold.

"I informed Mr. J. as to the nature of the case, stating that I had no hesitation in pronouncing it to be a case of hydrophobia. But, as he did not wish to have her destroyed, and was very anxious that $I$ should give her something, and watch the case, I merely ordered a purgative, combined with a little febrifuge medicine; at the same time pointing out the propriety of being cautious while administering the medicine, and the probable impracticability of it, which was verified. 
"Sept. 14. - All the symptoms of yesterday are aggravated intensively. The eyes have still a heavy appearance, when suddenly they appear like two brilliants. I observe that the spasm is more severe, and that she bites the woodwork of her stall.

Sept. 15. - Much worse; the cornea of the left eye, in its centre, is become opaque, and appears as though nitrate of silver had been applied to it. She sometimes lies down, but gets up again and roars. Upon a person present putting his fout near her mouth, she made an effort to seize it, uttering a growl. She died this evening.

"Post Mortem Examination, seventeen hours after death.The brain - its substance appeared healthy. The pia mater showed intense inflammation in small patches; its vessels generally were very fully congested.

"The larynx showed traces of intense inflammation, as also did the membrane lining of the trachea, throughout its entire length, and was most beautifully spotted, as was also the lungs, plura pulmonalis, pericardium, and heart. The coats of the first and third stomachs parted upon the slightest touch, in patches. The abdominal viscera, also, was similiarly spotted, as was the diaphragm, etc., although not so thickly as the respiratory organs."

\section{DISEASES OF THE SKIN.}

\section{MANGE.}

Tris disease is too well known to need ány particular description from me. It is due to the presence of parasites. Hence it can be communicated by contact or touch; and is, therefore, contagious. This latter fact suggests the propriety of removing the diseased animals from the healthy ones.

Treatment of Mange. - Let the animal have a table-spoonful of sulphur in the food, for three or four days in succession; in 
the mean time anoint the affected parts daily, with a portion of the following:-

Cod Liver Oil .6 ounces.

Sublimated Sulphur, 2 ounces.

Mix, and apply by means of a sponge.

In the course of four or five days wash the surface of the body with warm water and soap, and then give the body a thorough sponging with the following :-

Lime Water,,$\ldots \ldots \ldots \ldots \ldots \ldots \ldots \ldots \ldots \ldots \ldots \ldots \ldots \ldots \ldots \ldots$ quart.

Sublimated Sulphur,..................................2 ounces.

The above treatment generally cures the most inveterate cases.

FOUL IN THE FOOT.

In cases of this character the animal is dead lame, and often an intolerable stench arises from the parts between the claws. This is followed by the discharge of sanious, and finally, purulent matter. In this stage, astringents and antiseptics are indicated; therefore, I recommend the following:-

Tincture of Matico, 2 ounces.

Pyroligneous Acid, 1 pint.

Glycerine,

4 ounces. Mix

Saturate a small piece of sponge with a portion of the above, and introduce it between the "cleft" of the foot; the hoof and contiguous parts are then to be bathed with the preparation; and finally, in view of keeping the sponge in place, and to produce a good effect on the external parts, a narrow bandage must be applied so as to encircle the hoof. If any heat or tenderness exist, the bandage should be kept moist with cold water.

\section{WARTS.}

Warts, as they occur on cattle, are of three kinds. One makes its appearance upon the skin, and consists in part of an increased development of the epidermis or scarf skin; the next kind originates under the epidermis, and, as is grows, elevates the same; the latter, however, is nothing more than a common encysted fibrous tumor, without organization. This 
can readily be removed by cutting down upon it, and dissecting out the cyst or sac which enshrouds it. The epidermic wart, sometimes, has a very broad base, and in order to remove it a double armed ligature must be sent through it, so that it can be tied in two equal halves. Occasionally, this kind of wart is pendulous - has a contracted neck at its base. This may be encircled by a single ligature, and in the course of thirty-six hours will fall off.

The third kind of wart is a sort of funguous excrescence; not horny, nor hard, like the two former, but possessing great vascularity, and when rubbed or bruised they often bleed profusely. I lately removed one from the inferior jaw of an ox, which bled very profusely after the removal, and did not cease until a hæmostatic had been repeatedly applied. The hæmostatic was powdered matico leaves, which coagulated the albumen of the blood. There is great danger in removing warts of this kind. The following case, occurring in the practice of Surgeon Cartwright, will illustrate the proposition :-

"On the 1st of June, 1846, I removed several warts from the linea alba of a year-old heifer, belonging to Samuel Worthington, Esq., of this town. I cast her, and cut them off with the knife, and did not apply anything to the wounds, as they did not bleed an ounce. I could see one or two large bloodvessels on the surface of the wounds. We loosed her from the hobbles, and then tied her up, and the wounds soon left off bleeding. Gave her an aperient, and left her for the night.

"The next morning she was found down, and could scarcely get up from loss of blood, which continued to issue through a large band that was passed round her. I was immediately sent for; but was gone to Liverpool. They, in consequence, applied to a druggist, who sent some alum water, which stopped the blood. In a day or two I saw her; but as a scab was then forming on the wounds, I did not meddle with it; soon afterwards the parts were cicatrized.

"Observations. - There is no doubt but that, after she was left, she commenced licking the wounds, and so brought on the secondary hemorrhage. The person who looked after her 
believes that, had not something been done at the time, she would have bled to death. From this and other cases that I have seen, I think it absolutely necessary that we should guard against the animals licking themselves, and perhaps it would be quite as well to apply the cautery to the parts, after removing the warts, or subsequently."

When a large surface is occupied by warts which do not possess any definite necks, they must be cut off close to the skin, and the surfaces thus exposed should be touched with strong pyroligneous acid, and then sprinkled with powdered bloodroot.

Warts on the teats are to be removed by ligaturing them at their base, by means of saddler's silk, or horsehair. If securely tied, so as to obstruct circulation, they drop off in the course of thirty-six hours. Any sores which may occur in consequence of the removal of warts, can be healed by covering them one or twice daily with a small quantity of glycerine.

\section{GADFLIES.}

The gadfly is known to naturalists as the oestris bovis. It punctures the integument of cattle, and then deposits its ova, or eggs. In this situation the ova mature, until they are capable of enjoying an independent existence. They then make their exit through the external outlet, fall to and burrow into the ground, and remain there until the period of their metamorphosis takes place, when they assume the form of winged insects. In this form they multiply the species by the deposit of their ova. They probably occasion much irritation; and in view of getting rid of them, I usually puncture the tumor, by means of a thumb lancet, and squeeze out the parasite.

The following paragraph is from the pen of Gunther; and I urge the reader, if he be the owner of live stock, to give them an occasional dose of sulphur; for I contend that no living creature can ever be infested with parasites, when its system is saturated with sulphur.

"The gadfly not only persecutes healthy oxen, by its bites, during summer, but also deposits its eggs in their skin, which 
give rise to tumors on the back and other parts, in which the larvæ become developed. They live there on the succulent fluid which the soft parts secrete, and make their escape thence in the following spring, in order to become metamorphosed. The greater the number of tumors, the more is the strength of the animal diminished by the pain and suppuration. For this reason we should endeavor to free the animal, as soon as possible, from these larvæ pests, by frequently washing these tumors with camphorated brandy, or forcibly compressing them, which either crushes the insect or forces it to make its exit. When they have attained the size of a filbert, an incision must be made into the part, which is then to be covered with a pitch plaster. A few doses of sulphur are to be given internally. We are told that those oxen which have taken sulphur for a long period of time, are not infested by gadriies."

\section{YOKE GALLS.}

The exciting cause of yoke galls is local irritation occasioned by the yoke.

Treatment of Yoke Galls. - So soon as an abrasion is discovered on the neck, the animal should be excused from duty for a few days; the abraded part should be lubricated two or three times daily, with a small quantity of glycerine. In most cases, however, a few applications of tincture of aloes and myrrh will produce a healthy action, and thus restore the parts to soundness. Should there be no abrasion, yet some tumefaction, heat, and tenderness, a cold water bandage, renewed as occasion seems to require, will in most cases have the desired effect. Occasionally the integuments are so bruised as to induce induration - hardening. Local induration in the neck is a morbid condition of parts, known to the farriers of old as "sit-fast." The treatment consists in smearing the part with a portion of the following:-

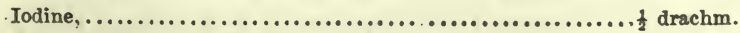

Simple Ointment, ................................... drachms.

Powdered Bloodroot,..............................

A few applications of a portion of the above, will have the 26* 
effect of removing the sit-fast, or eschar, when a healthy granulating surface will appear.

Some animals, owing to a peculiarity of constitution, will "chafe," as the saying is, in those parts which come in contact with the yoke, and no human foresight or mechanical contrivance can prevent it; therefore, in view of protecting the parts against the local irritation and its consequences, I recommend the following liquid cuticle :-

Collodion, Equal parts.

After washing the abrasion with soap and water, wipe dry, and smear it with a portion of the above invaluable liquid cuticle.

\section{THE HAIR OF CATTLE IS AN EPIDERMIC APPENDAGE.}

According to Carpenter, hair is an epidermic appendage, although not developed upon the external surface, but in the interior of a follicle * formed by a depression of the true skin. This follicle is lined by a continuation of the epidermis (scarf skin), the cells of which are developed in peculiar abundance from a spot at its deepest portion; the dense exterior of the cluster thus formed being known as the "bulb of the hair," while the softer interior is termed its pulp. Although the hairs of different animals vary in the appearances they present, we may generally distinguish two elementary principles corresponding with those which we meet with in the stem of a feather; viz., a cortical, resembling bark ;" and a medullary, resembling marrow. The fullest development 'of both sub'stances is seen in the spine hairs of the hedgehog; and in the quills of the porcupine, which are but hairs on a magnified scale. The cortical envelope of hairs is a continuation of the outer scales or layers of the epidermis that lines the follicles; whilst the medullary is derived from the deeper stratum whose cells are produced in usual abundance at its coccal (blind) extremity. And it is by the constant development of new cells at this point, that the continual growth of the hair is kept up.

* Follicle, sac or fold. 


\section{PEMPHIGUS, OR VESICULAR ERUPTION.}

In the United States, at least in this region, pemphigus is of rare occurrence, yet it has made its appearance in Texas and in the Western States. The following symptoms, which usually accompany this eruptive affection, may enable the reader to recognize it.

Symptoms. - The breathing is generally hurried and sonorous, accompanied by a slight cough ; the animal shivers, which is occasioned by deranged and irregular nervous action. The integument in the regions of the neck, shoulders, anus, loins, and haunches, is elevated by effusion into the cellular tissue ; the cuticle, or external tunic of the body, is the seat of watery bladders, varying in size from a Beverly bean to a walnut. In other parts of the skin a serous or watery fluid may be observed to dribble from the hair. The ears are drooping and moist, and their temperature is much elevated. The base of the horns are hot, and the whole external surface of the body is in the same condition. The visible surfaces, viz., those of the eyes, mouth, and nose, are highly injected with a reddened yellow tinge; the tongue is swollen or tumefied, and an abundance of saliva flows from the mouth; the pulse will often run up to 80 , yet may be imperceptible at the jaw. The spinal column presents a convexity, or is arched upwards. The urine is scanty and dark colored, and the fæces are of a lighter color than usual, showing very conclusively that the function of the liver is impaired.

As the disease advances, the serous tumors burst, exposing broad excoriated patches.

Treatment. - Let a portion of the following mixture be applied to the surface of the body, by means of a sponge :-

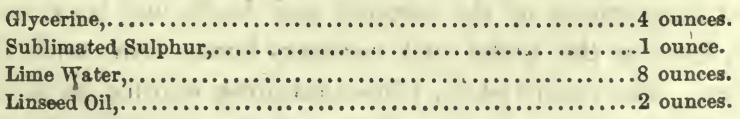

Two or three applications of a portion of the above, on successive days, will soon change the morbid habit of the skin, when the residuum may be removed by sponging the surface 
with tepid water. In the mean time let the patient have a few doses of the following:-

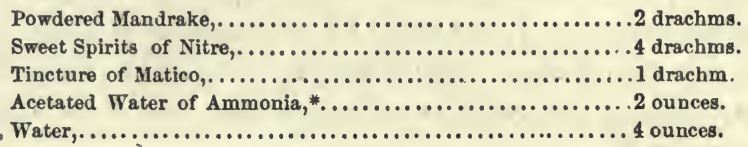

Mix, and drench the animal from a bottle, and repeat the same on the two succeeding days, if necessary. So soon as the animal improves, stop the medicine and allow a generous diet.

A few years ago a vesicular epizoötic broke out among cattle and milch cows at Stratford-on-Avon. The symptoms are thus described by J. Tombs, V. S. :-

"The symptoms were: increased pulsation, copious discharge of saliva from the mouth, respiration disturbed. These symptoms continued for two or three days, when a tremendous inflammation of the integuments and cellular tissues set in, around the coronets at the heels, and between the hoofs, causing exceeding lameness and excruciating pain. The swelling quickly extended to the fetlocks. The poor beasts lay down the greater portion of their time, - panted and perspired profusely, with occasional deep groaning. At this stage of the disease the mouth improved. When made to get up, they could hardly walk, and soon lay down again. The beating of the heart could be distinctly heard several yards off. In some, all four feet were affected; in others, the fore feet; others, the hind feet, and in some one fore foot. Suppuration took place in the integumentary and cellular membranes, five or six days subsequently to the original attack, which process afforded great relief. In the interim they became emaciated and lost their milk. In a day or two after, extensive sloughing supervened of the integuments of the coronets and heels, and between the hoofs, leaving the pedal and coronary bones bare, with deep sinuses. The putrid parts, while sloughing, emitted an unbearable stench. Granulations of new flesh soon formed, which

* This is a cooling febrifuge, and is known to physicians as "liquor ammonia acetatis." 
became prominent and luxuriant, forcing the hoofs wide apart. At this period of the complaint the urgent and painful symptoms considerably lessened; the animals could then hobble out of the yard into a grass field close by. where they were prior to the attack. 'The milk, flesh, and strength, began to return, and the lameness slowly diminished, as the thickening of the integuments and cellular membrane became absorbed. New hoofs formed, which in some grew irregularly, and caused great tenderness for some length of time." 
- 



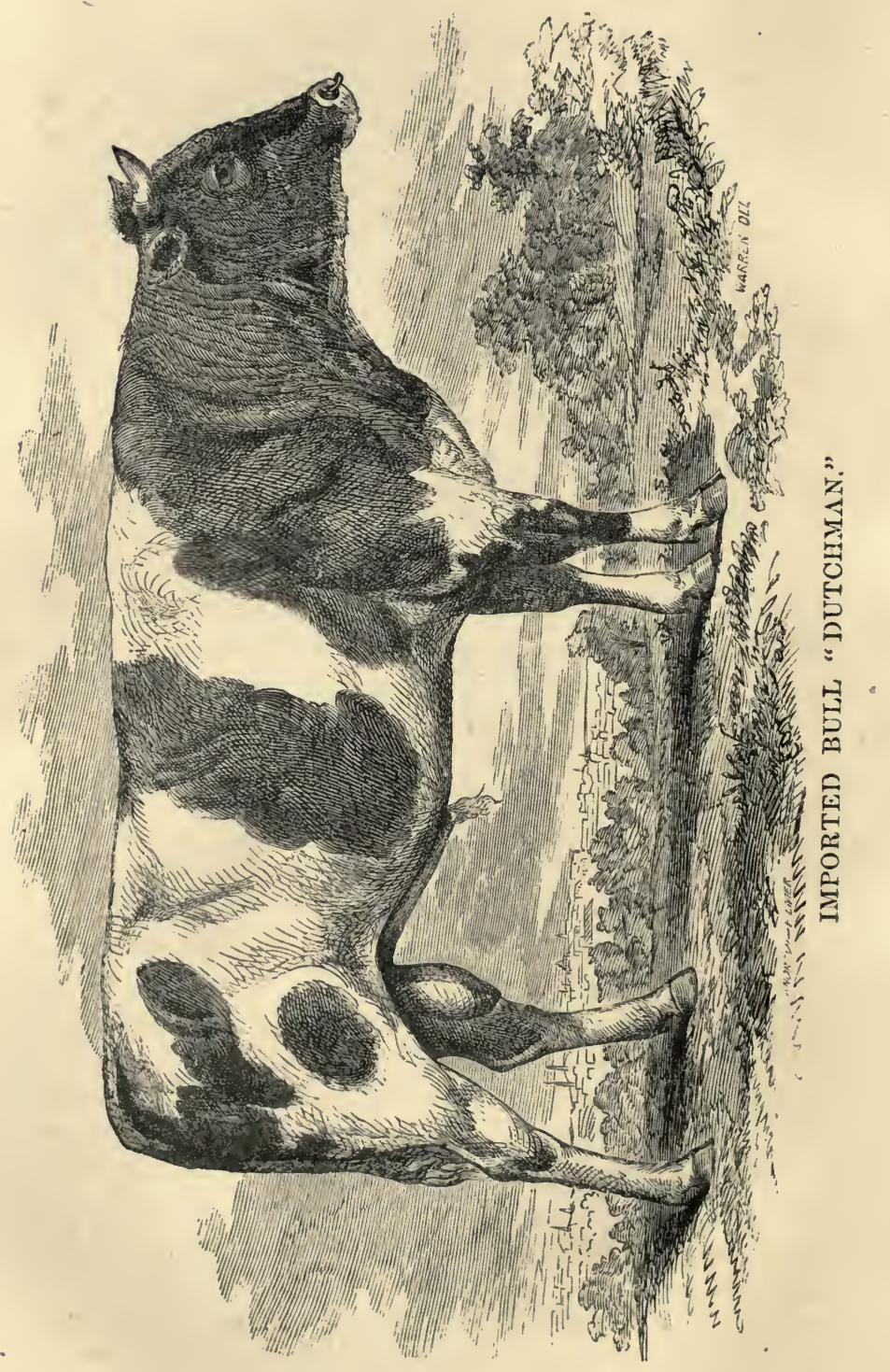




\section{GENERALITIES.}

DUTCH CATTLE - THEIR INTRODUCTION INTO MASSACHUSETTS - VALUABLE QUALITIES, ETC.

THE Dutch race of cattle have heretofore received but slight notice at the hands of either American or English authors, yet $\mathrm{I}$ hazard the prediction that the breed is destined to become pre-eminently the farorite in this country. Indeed, when we consider the enviable reputation that the dairy stock of Holland has so long maintained, it seems a matter of surprise that our breeders have not earlier considered the importance of making direct importations from that country.

At a very early period importations of Dutch cattle were made from Holland into England; and it is admitted that this blood contributed, in an important degree, to build up both the Short Horn Durham, and Ayrshire breeds. The principal characteristics of the Dutch breed of the present time confirms this, as on examination a thorough-bred Dutch cow will be found to combine, to a very remarkable extent, the best qualities of both those breeds. It will be seen that her dairy qualities are far superior to the justly celebrated Ayrshires, many of the Dutch cows producing' daily in the best season from 25 to 45 quarts of rich milk; while in size, docility, early maturity, and evident adaptation to the yoke or the shambles, they are in no way inferior to the famous Short Horn Durhams.

The early Dutch settlers in the vicinity of the Hudson river, in the State of New York, brought over some of the Dutch race of cattle; and about fifty years ago, an individual in the State of Vermont imported a bull and cows of that 
breed. It is presumed, however, they have not been bred pure up to this time, although animals are often met with in that locality showing evident traces of their Dutch origin.

I believe the only herd of thorough-bred Dutch cattle now in this country, were imported and are now owned by Winthrop W. Chenery, Esq., of Belmont (late Watertown), Massachusetts. Mr. Chenery has made three importations of cattle from Holland. The first in 1852, another in 1857, and the last the present season (1859). He has, through his agent in that country, been able to procure very superior specimens of the North Holland cattle. Mr. Chenery is firm in the belief (and I think all intelligent breeders who have examined his stock coincide in the opinion), that they are destined to supersede all other breeds, especially throughout the New England States.

The bull " Dutchman," and the cow " Purmer," whose portraits are correctly delineated in this work, are animals of Mr. Chenery's importation. He has now some twenty head of purebred Dutch stock.

I would remark, also, that the Dutch race of cattle, owing, doubtless, to a long course of careful breeding, are capable of reproducing their good qualities to an extraordinary extent, and are, therefore, invaluable to cross with our native stock. Probably no animal, in a given time, will produce such a marked change in the stock of any locality, as a thorough-bred Dutch bull. This opinion is verified in a remarkable degree by the experience and observation of Mr. Chenery. That gentleman informs me that his cow, "Lady Louise," imported in 1852, dropped in 1854 a bull calf; the sire an Ayrshire bull. The calf, in color black and white-like its dam, and a fine large animal at birth, was presented to $\mathrm{Mr}$. T. Hunt, of Framingham, Mass., on condition that it should be raised for the improvement of stock there.

In 1856,1857 , and 1858 , this bull served from seventy-five to one hundred cows annually, and, although but a half-blood himself, every calf of his get (no matter what may have been the color of its dam) has been of the Dutch color, with sym- 
metrical form and strongly marked features, bright, full eyes, and small, short, handsome horns.

Mr. Hunt is now raising some twenty head of this bull's get, including a pair of steers that took the premium at the county show last year. The bull was exhibited at the county fair, in 1857 and 1858 , and pronounced by good judges to be the best animal upon the ground.

Every calf got by "Dutchman," imported in 1857, has, also, been of black and white color, and all very extraordinary animals.

For the benefit of all persons interested in improving the breed of neat stock in this country, the author would inform the reader that the owner of the splendid animals referred to, is the proprietor of the "Highland Stock Farm," Belmont, Mass. Mr. Chenery is. a gentleman of ample fortune, and having a decided taste for that department of husbandry known as breeding, he has determined, without regard to cost, to see what improvements can be accomplished among neat stock. So far, he has been eminently successful, and the farmers in this vicinity will have many occasions for rejoicing that so enterprising and so liberal a man as Mr. Chenery, is engaged in the laudable enterprise of improving our native stock. A little of the blood of this hardy and valuable Dutch stock, infused into the veins of "natives," would very soon wipe out of existence the poor apologies for cows - things of little else than skin and bones - which are calculated to shock our ideas of the beautiful handiwork of Nature. Such are scarcely, if ever, free from disease, and it is very rare that they bring forth a calf worth saving. On the other hand, the Dutch cattle are not only beautiful (see cuts of the same), but they enjoy, after acclimation, a remarkable immunity from disease; and the calves of such, when only a few days old, even if intended for veal, are actually worth five dollars more than the progeny of ordinary cows.

It.is a magnificent sight to see so fine a lot of animals together, as can be seen at the "Highland Stock Farm." Every thing about the barn is in perfect keeping with the liberality 
of its enterprising owner. There is no bad smell about the place, a capital system of ventilation being established, which not only contributes to the health of the stock, but also makes it a pleasant place to visit. I recommend all persons in search of valuable stock to visit the "Highland Stock Farm."

\section{CASTRATION.}

I labor under an impression that the husbandmen of this country commit some awful mistakes in the theory and practice of castration. The usual practice is, to castrate the calf from one to three months after birth. This is evidently done to the manifest injury of form, size, and muscular development. The operation may tend towards fattening the animal, and improving the epicurean quality of its meat; and it may render the animal docile, and thus increase his usefulness; but his strength, stamina, and endurance are compromised by early castration.

If animals are needed as. working oxen, they should not be castrated until they have attained the age of three or four years. At these periods, the muscles of the neck and chest have undergone remarkable developments, and the animals have strength and endurance to make really valuable oxen for work ; whereas, if castrated at too early a period, the muscles of the forward parts are always defective, lank, and lean. I am aware that there are difficulties in the way of keeping bulls, up to the age here indicated; yet the experiment has been tried, in this State and elsewhere, to the entire satisfaction of the parties that made the experiments; therefore, I recommend farmers not to castrate calves intended for work-oxen, until their muscular system is well developed; and even in view of obtaining good beef, and developing the propensity to fatten, I should let the calves remain uncastrated for six months or more.

It has been urged, by some writers, that the danger of castration is less in young than adult animals. This may be correct, yet $I$ apprehend but little danger in castrating either a horse or bull, at any age, provided the creature is in the enjoyment of health, and the operation be properly performed. 


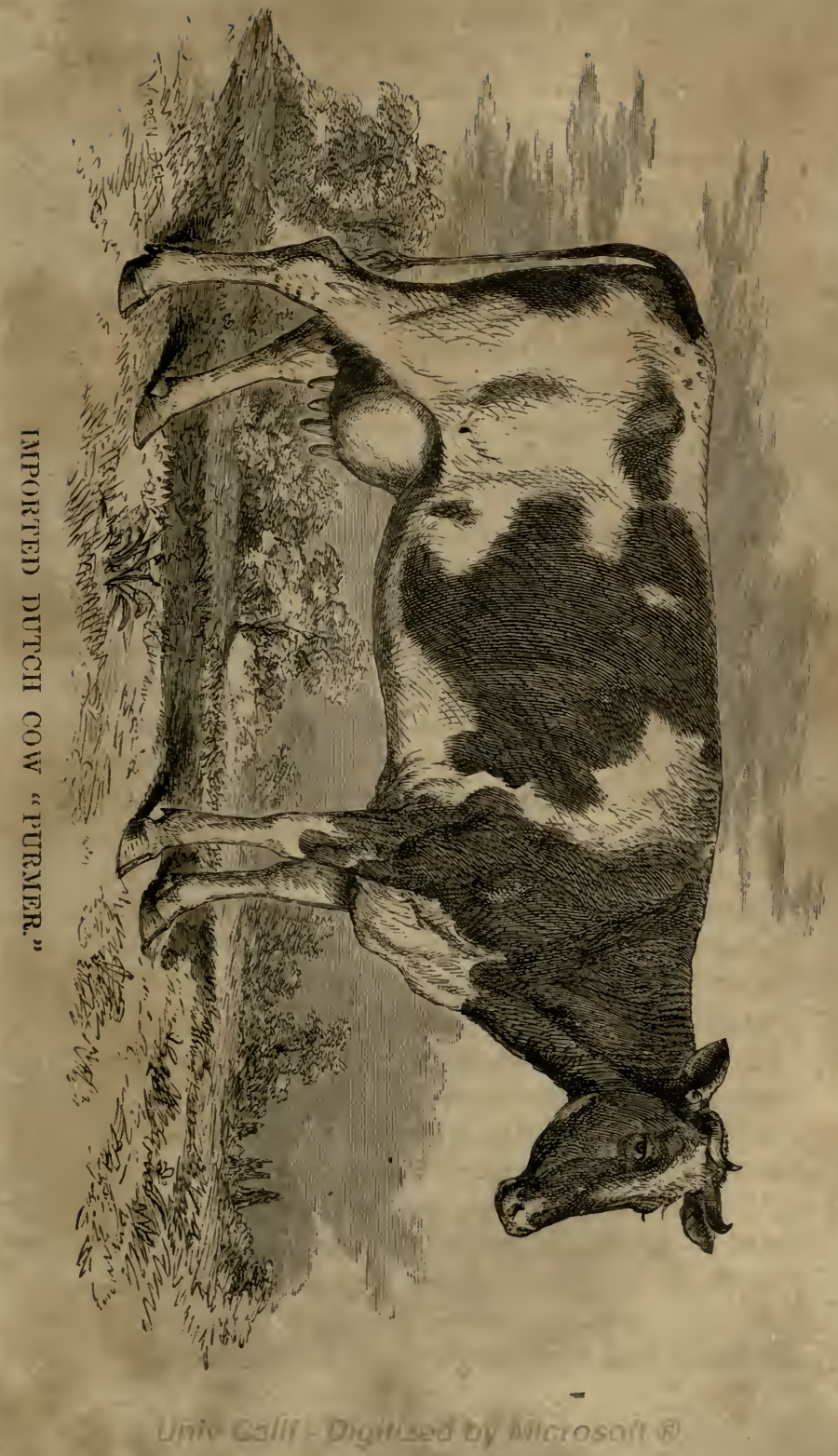


y

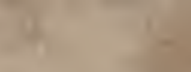

4

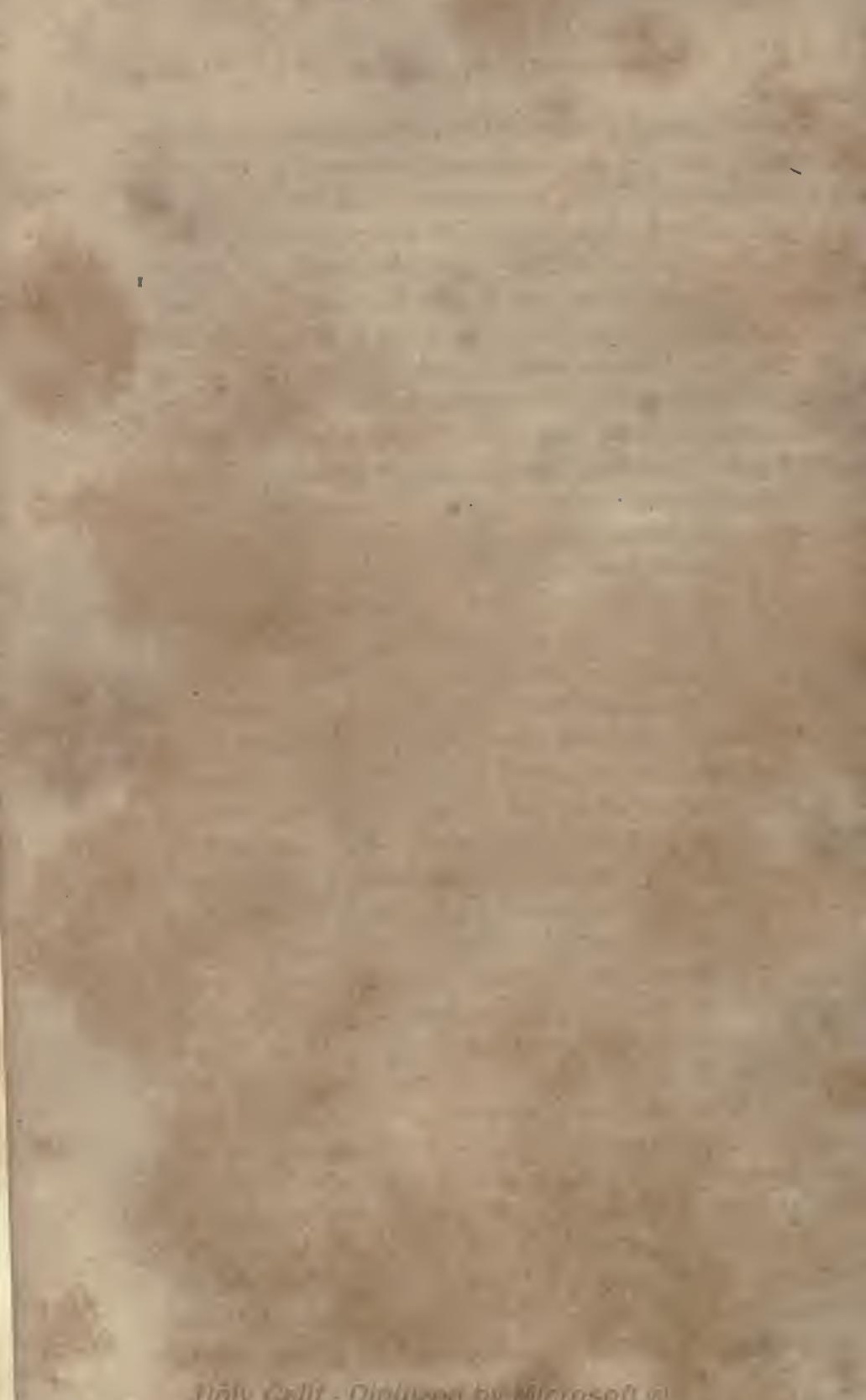

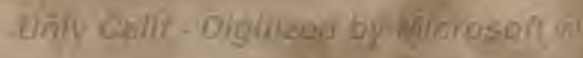


"In many parts of France the bull-calf is castrated by means of a curious species of torsion, termed bistournage. The anicnal is thrown and secured; the operator places himself behind the animal, and opposite to the tail; he seizes the testicles with both his hands, and pushes them violently upwards and downwards several times, in order to destroy their adhesion to their coverings. He continues this manipulation until he thinks that he has produced sufficient lengthening of the cords, and dilatation of the bag itself; he then pushes up the left testicle as nearly as possible to the ring, leaving the right one low in the bag; he seizes the cord of the right testicle between the finger and thumb of the left hand, about an inch above the testicle, and grasping the bottom of the scrotum with his right hand, he turns the testicle, and pushes it forcibly upwards, until he has reversed it, and its inferior extremity is uppermost. Some little practice is required in order readily to effect this. Then, the right hand holding the testicle while the left hand raises the cord, the testicle is turned round from right to left four or five or six times, until there is a degree of tension and difficulty in the turning, which indicates that the spermatic vessels are so far compressed or obliterated as to be deprived of the power of secreting or conveying the seminal fluid. The testicle is by this means brought up nearly to the abdominal ring, where it is retained by turning the scrotum over it, while the left testicle is brought down, reversed, and turned in the same manner. Last of all, in order to prevent the untwisting of the cords and the descent of the testicles, the operator grasps the bottom of the scrotum in his left hand, and holding one end of a piece of cord, eighteen inches in length, and about as large as a quill, between his teeth, and having the other end in his right hand, he makes with it several turns round the scrotum with considerable firmness below and close to the testicles, yet not so tightly as quite to stop the circulation of blood through the bag. This is taken away at the end of the second day, after which the testicles will remain fixed against the abdomen, and will gradually wither away. The animal is usually bled after the operation, and half of its allowance of food taken away." 
I lately castrated two horses, at the respective ages of twelve and seventeen years, and they have both done well; yet, if they had been "prepared," as the books recommend, I might have lost both animals; and I verily believe that the once popular method of physicking- prostrating - animals before castration, has been the cause of many unnecessary deaths.

In castrating bullocks, I apply a ligature around the whole cord, for it is not always safe to merely ligature the spermatic artery, as the reader will perceive by reading the following paragrapl.

Herring has observed, that, after tying the spermatic artery, without difficulty, in two places, and cutting between them, the spermatic cord being then cut across two inches below, arterial hemorrhage sometimes ensued. It is easy to account for blood flowing through the spermatic veins, after this operation, by a retrograde circulation in the wide vessels; but, as regards the arterial hemorrhage, Herring was in doubt, until, after several injections of the spermatic cord, he found that the spermatic artery often divides into two nearly equal branches; if but one be tied, on removing the testicles, the other division bleeds. Herring afterward injected several testicles and spermatic cords of buils, and found an extraordinarily rich net-work of veins, which differs in many points from the pampiniform plexus of the spermatic cord, in man, horse, dog, etc. In the spermatic cord of the horse, we observe the artery making a large number of curves on itself, until it reaches the testicle; and from the latter organ arise numerous veins, which coil upwards, but now join in several branches which pass up with the artery, anastomosing at intervals, and forming a net-work, the meshes of which are in the shape of parallelograms. In the bull, on the contrary, the veins are exceedingly numerous, and spin round the artery like the tendrils of a climbing plant round a wire; and this is seen high up in the abdomen; so that, in successful injections, the spermatic artery is completely hidden.

Some persons may object to the plan of applying a ligature around the whole cord, and Youatt speaks of it as a cruel operation. I cannot conceive how there can be any more 
cruelty in it, than when the "clams" are used. The pressure on the cord is the same; and all the difference is, I use saddler's silk instead of wooden clams. I have castrated a great number of animals, at all ages, by means of a ligature around the cord, and have never met with loss or accident.

Method of Castration. - There is very little danger in castrating a young calf, and it is very rare that a surgeon is ever called upon to perform the operation; yet I would advise persons who are in the habit of castrating these young animals, to make free openings into the scrotum and inner covering of the testicles. This inner covering is called tunica vaginalis. If too small an opening be made, the swollen cord will be imprisoned by the divided edges of the tunica vaginalis, which will ultimately end in hardening or schirrosity of the end of the cord, or else there will be scrotal abscess. A large opening into the scrotum and tunic is necessary, in order to postpone union of the external parts, until the tissues above and within have healed.

When castrating bullocks, I either secure them in the trevis and partly etherize them, or else cast them with the hobbles (see cut of instruments), and render them completely insensible by ether. I then grasp the scrotum, between the belly and testicle, and make an incision on one side and at the lower part of the scrotum sufficiently large to allow the testicle to escape. The testicle then hangs by the cord. A ligature is then passed around the latter, which must be tied tight enough to compress the bloodvessels and prevent after bleeding. The cord is then divided, and one end of the string may be cut very close to the knot, so that a slight pull will untie it. The other testicle is to be proceeded with in the same manner, and the operation is complete. It is proper, however, to return the cord within the inner tunic, or covering of the testicle, and one end of the ligature is left long enough to hang out of the wound.

In the course of a week, if the ligatures do not come away, a slight pull will detach them. I never make use of any dressing, except when a bad odor arises from the parts. The 
best remedy, under such circumstances, is diluted pyroligneous acid, in the following proportions :-

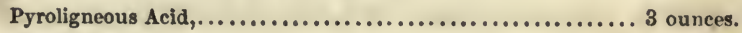

Water,.........................................15 ounces. Mix.

Let the parts be well cleansed, night and morning, with a portion of the above.

Should any undue amount of swelling ensue, the parts are to be rubbed occasionally with an ounce or two of sweet spirits of nitre.

I find that exercise operates favorably in preventing scrotal swelling, which is a condition of the parts known to surgeons as local effusion - dropsy; and, as exercise at pasture always tends to reduce these kinds of swellings, I generally, if the weather permits, place the castrated animal under the care of "Doctor Green," - a good pasture, - where the patient can vitalize its blood with pure air, promote the integrity of the whole system by voluntary exercise of the muscles, and partake of herbage calculated to benefit the whole animal economy.

\section{ENŻOOTIC MILK SICKNESS, OR TREMBLES.}

The cause or origin of enzoötic milk sickness, - commonly denominated trembles, - is a subject of much speculation. Various are the opinions and conclusions of medical and nonmedical men. It has been asserted that a creeping vine, known to luxuriate in forest regions, occasions the disease. The theory is that this vine, or vegetable parasite, is matured in the latter months of summer, or the first autumnal, at which season of the year the grass becomes dry and tough, when the cattle resort to the timbered land for sustenance, feeding upon the (supposed) vine; and as the animal is (without satisfactory evidence) susceptible to its (imaginary) influence, it often sickens and dies; yet, strange to relate, many animals located in the same regions escape the pest. And, in order to sustain this faulty theory, we are informed that the lucky creatures who live and die at a respectable bovine age, know enough to give the poisonous plant the go-by. This is nothing more than mere speculation, for the disease very frequently occurs when 
the ground is covered with snow. Dr. Graff informs us that the general appearance of the infected districts is somewhat peculiar. "The quality of the soil is, in general, of an inferior description; the growth of timber is not observed to be so luxuriant as in situations otherrwise similar, but is scrubby, and stunted in its perfect development ; in many instances, simulating what, in the West, is denominated 'barrens.' "

Now it is possible that these barrens do not furnish a sufficient amount of carbon (in the form of food) for the metamorphosis of the tissues; and if we take into consideration that the animal receives, during the day, while in search of this food, a large supply of oxygen, and at the same time the waste of the body is increased by the extra labor required to select sufficient nutriment, - it being scanty in such situations, - then it follows that this disproportion between the quantity of carbon in the food, and that of oxygen absorbed by the skin and lungs, must induce a diseased or abnormal condition. The animal is sometimes fat, at others lean. Some of the cows attacked with this disease were fat, and in apparent health, and nothing peculiar was observed until immediately preceding the outbreak of the fatal symptoms. The presence of fat is generally proof positive of an abnormal state; and, in such cases, the liver or spleen is often diseased ; the blood then becomes loaded with fat and oil, and is finally deposited in the cellular tissues. The reader will now understand how an animal accumulates fat, notwithstanding it be furnished with insufficient diet. All that I wish to contend for is, that in such cases vital resistance is compromised. We are told that, in the situation alluded to, vegetation was stunted, \&c.; and knowing that vegetables are composed of nearly the same materials which constitute animal organization, - the carbon or fat of the former being deposited in the seeds and fruits, and that of the latter in the cellular structure, - then we can arrive at but one conclusion; viz., that any location unfavorable to vegetation, is likewise ill adapted to preserve the integrity of animal life.

In connection with this, it must be remembered that, during 
the night, the soil emits excrementitious vapors, which are taken into the animal system by the process of respiration. In the act of rumination, vapor is also enclosed in the globules of saliva, and thus reaches the stomach. Many plants which, during the day, may be eaten with 'impunity by cattle, actually become poisonous during the night! This, I am aware, will meet with some opposition, to meet which I quote from Liebig:-

"How powerful, indeed, must the resistance appear which the vital force supplies to leaves charged with oil of turpentine or tannic acid, when we consider the affinity of oxygen for these compounds!

"This intensity of action, or of resistance, the plant obtains by means of the sun's light; the effect of which in chemical actions may be, and is, compared to that of a very high temperature (moderate red heat).

"During the night, an opposite process goes on in the plant; we see then that the constituents of the leaves and green parts combine with the oxygen of the air - a property which in daylight they did not possess.

"From these facts we can draw no other conclusion but this: that the intensity of the vital force diminishes with the abstraction of light; that, with the approach of night, a state of equilibrium is established, and that, in complete darkness, all those constituents of plants which, during the day, possessed the power of separating oxygen from chemical combinations, and of resisting its action, lose their power completely.

"A precisely similar phenomenon is observed in animals.

"The living animal body exhibits its peculiar manifestations of vitality only at certain temperatures. When exposed to a certain degree of cold, these vital phenomena entirely cease.

"The abstraction of heat must, therefore, be viewed as quite equivalent to a diminution of the vital energy; the resistance opposed by the vital force to external causes of disturbance must diminish, in certain temperatures, in the same ratio in which the tendency of the elements of the body to combine with the oxygen of the air increases." 
"It is obvious that the cause of the generation of force, namely, the change of matter, is diminished, because, with the abstraction of heat, as in the plant by abstraction of light, the intensity of the vital force diminishes. It is also obvious that the momentum of force in a living part depends on its proper temperature; exactly as the effect of a falling body stands in a fixed relation to certain other conditions; for example, to the velocity attained in falling.

"When the temperature sinks, the vital energy diminishes; when it again rises, the momentum of force in the living parts appears once more in all its original intensity.

"The production of force for mechanical purposes, and the temperature of the body, must, consequently, bear a fixed relation to the amount of oxygen which can be absorbed in a given time by the animal body.

"The quantities of oxygen which a whale and a carrier's horse can inspire in a given time are very unequal. The temperature, as well as the quantity of oxygen, is much greater in the horse.

"The force exerted by a whale, when struck with the harpoon, his body being supported by the surrounding medium, and the force exerted by a carrier's horse, which carries its own weight and a heavy burden for eight or ten hours, must both bear the same ratio to the oxygen consumed. If we take into consideration the time during which the force is manifested, it is obvious that the amount of force developed by the horse is far greater than in the case of the whale.

"In climbing high mountains, where, in consequence of the respiration of a highly rarefied atmosphere, much less oxygen is conveyed to the blood, in equal times, than in valleys or at the level of the sea, the change of matter diminishes in the same ratio, and with it the amount of force available for mechanical purposes. For the most part, drowsiness and want of force for mechanical exertions come on; after twenty or thirty steps, fatigue compels us to a fresh accumulation of force by means of rest (absorption of oxygen without waste of force in voluntary motions)." 
In the situations alluded to, we gencrally find poisonous and noxious plants, with an abundance of decayed vegetable matter. An English writer has said: "The farmers of England might advantageously employ a million, at least, of additional laborers in clearing their wild domains of noxious plants, ${ }^{*}$ which would amply repay them in the superior quality of their produce. They would then feel the truth of that axiom in philosophy, 'that he who can contrive to make two blades of grass, or wholesome grain, grow where one poisonous plant grew before, is a greater benefactor to the human race than all the conquerors or heroes who have ever lived." "The noxious plants found in such abundance in the Western States, are among the principal causes, either directly or indirectly, of the great mortality among men, horses, cattle, and sheep. The hay would be just as destructive as when in its green state, were it not that, in the process of drying, the volatile and poisonous properties of the buttercup, dandelion, poppy, and hundreds of similar destructive plants found in the hay, evaporate. It is evident that if animals have partaken of such plants, although death in all cases do not immediately follow, there must be a deficiency of vital resistance, or loss of equilibrium, and the animal is in a negative state. It is consequently obvious that when in such a state it is more liable to receive impressions from external agents - in short, is more subject to disease, and this disease may assume a definite form regulated by location.

It has been observed, also, that in the infected districts, the

* The Ameriean farmers are just beginning to wake up on this subject, and before long $I$ hope to see our pasture lands free from all poisonous plants. Dr. Whitlaw says, " $A$ friend of mine had two fields cleared of buttercups, dandelion, ox-eye, daisy, sorrel, hawk-weed, thistles, mullein. and a variety of other poisonous or noxious plants; they were dried, burnt, and their ashes strewed over the fields. He had them sown as nsual, and found that the crops of hay and pasturage were more than double what they had been before. I was furnished with butter for two sunmers, during the montlis of July and August. The butter kept for thirty days, and proved, at the end of that time, better than that fresh churned and brought to the Brighton or Margate markets. It would bear salting.at that season of the year." 
water is not of the best kind, neither is it very abundant; hence, in consequence of its insufficiency or unwholesome character, the equilibrium of health may become disturbed. (See article on watering.)

A loss of vital resistance may also be the result of exposure. It has been observed that cattle which have been housed regularly have escaped the attacks of this malady, and that when suffered to run at large, they were frequently seized with it.* Therefore we may conclude that the indirect causes of milk sickness, or trembles, are any thing that disturbs the general health.

Now let us suppose that one, or a combination of the preceding causes, has operated so as to produce an abnormal state in the system of a cow. She is then suffered to remain in the unlealthy district during the night. While there, exposed to the emanations from the soil, she requires the whole force of

* Loss of STock. - From every part of the country we hear of great loss of stock, principally cattle. The long-continued rainy weather, with lack of feed and shclter, has been the cause of much suffering on the part of poor dumb animals, and great loss to the stock-growers generally throughout the Willamette valley. How long will this plan of raising stock, without shelter from the cold blasts of winter, and without food, be continued in Oregon? Not long, we think, should each succeeding winter be like the past. When, in a number of the Farmer, last fall, we expressed a desire to see the wintering of stock without shelter classed as "cruelty to animals," we little thought it an attmmpt to shield them from so very severe an ordeal as many were compelled to pass through. We have been informed, that in some sections, nearly or quite one-fourth of the cattle had died in the last two months, the greater portion cows. The grass being quite short in the fall, stock was gencrally poor, and thus, with but little feed through the winter, and in many cases no shelter whatever, as the time approached for cows to "come in," their strength was gone and could not be regained.

Had many stock-raisers, last fall, sold half their stock, and with that money provided sufficient shelter for the remaining half, dollars would have been saved. Where stock is well protected from the cold and wet, they require much less food, and there is economy in it. We trust to see the day in Oregon when our stock will be so improved that the same in. vestment will be fed in half the number of mouths that are now fed. Oregon Farmer. 
her vital energies to ward off chemical decompositions, and prevent encroachment on the various functions. A contest commences between the vital force and chemical action, and, after a hard conflict, in their incessant endeavors to overcome each other, the chemical agency obtains the ascendency, and disease of a putrid type (milk fever) is the result. The disease may not immediately be recognized, for the process of decomposition may be insidious; yet the milk and flesh of such an animal may communicate the disease to man and other animals. It is well known that almost any part of animal bodies in a state of putrefaction, such as milk, cheese, muscle, pus, etc., communicate their own state of decomposition to other bodies. Many eminent medical men have lost their lives while dissecting, simply by putrefactive matter coming in contact with a slight wound or puncture. Dr. Graff made numerous experiments on dogs, with the flesh, etc., of animals which died of milk sickness. He says, "My trials with the poisoned flesh were, for the most part, made on dogs, which I confined; and I often watched the effect of the poison when administered at regular intervals. In the space of forty-eight hours from the commencement of the administration of either the butter, cheese, or flesh, I have observed unequivocal appearances of their peculiar action, while the appetite remains unimpaired until the expiration of the fourth or fifth day." From the foregoing remarks, the reader will agree with me, that the disease is of a putrid type, and has a definite character. What is the reason of this definite character? All diseases are under the control of the immutable laws of nature. They preserve their identity in the same manner that races of men preserve theirs. Milk sickness of the malignant type luxuriates in the locations referred to, for the same reasons that yellow fever is peculiar to warm climates, and consumption to cold ones ; and that different localities have distinct diseases ; for example : ship fever, jail fever, etc.

Before disease can attack, and develop itself in, the bodies of men or animals, the existing equilibrium of the vital powers must be disturbed; and the most common causes of this 
disturbance I have already alluded to. In reference to the milk, butter, cheese, etc., of infected animals, and their adaptation to develop disease in man, and in other locations than those referred to, I observe, that when a quantity, however small, of contagious matter is introduced into the stomach, if its antiseptic properties are the least deranged, the original disease (milk sickness) is produced, just as a small quantity of yeast will ferment a whole loaf. The transformation takes place through the medium of the blood, and produces a body identical with, or similar to, the exciting or contagious matter. - The quantity of the latter must constantly augment; for the state of change or decomposition which affects one particle of the blood is imparted to others. The time necessary to accomplish it, however, depends on the amount of vital resistance, and of course varies in different animals. In process of time, the whole body becomes affected, and in like manner it is communicated to other individuals; and this may take place by simply respiring the carbonic acid gas or morbific materials, from the lungs of diseased animals in the infected districts.

My principal object is to show what are the causes of this malady, so that the farmer can prevent its occurrence, for the treatment is very unsatisfactory. A writer in the Atlanta Medical Journal informs us :-

"Where stock cattle, for instance, are kept pent up until after the morning's dew, they are never affected, though they are pastured where it is known to abound. Again, if food, in the form of bundles of hay, or fodder, or sheaves of oats, has been cast on the surface of the earth where it was suspected to exist, fed to calves or a calf, during the morning, while wet with dew, the result is the death of the animal.

"Facts like these are, to my mind, evidence conclusive of its origin in the form of vapor. But let it originate from whence it may, it is only known in timbered land, and there disappears, after being once cleared, cultivated, and seeded with tame grass; which shows, again, if of a telluric source, that the toxical agent lies near the surface, and is destroyed by being slifted from its lurking place." 
Symptoms. - The principal symptoms are irregular, nervous action, trembling, tremors, spasms, and, lastly, convulsions. The other symptoms are such as are noticed in affections of a low typhoid type; the pulse is quickened, yet small; the tongue slightly swollen, and coated with a brown fur; the urine is high-colored, and the bowels are constipated ; the membranes of the eyes are reddened, and the breath has a bad odor.

Treatment. - If the bowels are constipated, I should give an aperient, composed of glauber salts, ten ounces; powdered ginger and goldenseal, of each, one drachm; tepid water, one quart. Then let the whole length of the spine be well rubbed with two or three ounces of oil of cedar. Should the breath or excrements have a very bad odor, the following must be given :-

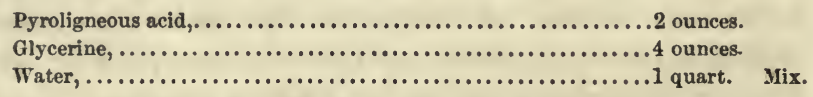

Dose. - A wine-glassful three or four times daily, until an improvement takes place.

To relieve the nervous irritation and trembling, $I$ give two drachms of tincture of Indian lemp, in a little water, twice daily.

The patient is to be kept on oatmeal gruel, the quantity to be regulated according to actual necessity. A curable case will be very likely to improve under the above treatment; if it fail, the owner will have the satisfaction of knowing that the patient was not destroyed by meddlesome medication, nor was its death occasioned by poisonous drugs, but the case was incurable.

\section{WATERING CATTLE AND FARM HORSES.}

Although few persons think it worth while to pay much attention to this department of husbandry, yet a little reflection. will convince any reasonable person of the value and importance of furnishing cattle with a constant supply of pure water. Pure, cool water, is said to be a godsend to a thirsty throat; 
and as cattle are apt to have thirsty throats, they should be permitted to enjoy a luxury which costs but a trifle, and operates very favorably in promoting their health. All classes of domestic animals have as great an aversion to impure, filthy water, as ourselves; and the former will often turn away with disgust from the filthy stuff called water, which is often found in water troughs on the roadside, and within the precincts of the barn, and in some pastures. The common, stagnated pond water, which many poor creatures are compelled to imbibe, is often the exciting cause of disease, especially in the western states, where decayed vegetable matter abounds. Pure water will never injure an animal. I do not believe the stories which are told about horses becoming foundered in consequence of drinking pure water. In a majority of cases Mr. Fastman is blamable; he has, probably, either overdriven or overworked the creature, or else has suffered it, when heated, to cool off without the necessary care and attention, which should always be observed when animals are fatigued or perspiring freely.

Hard usage, wilful neglect, and wanton cruelty, are more likely to produce disease, than the "universal beverage" so acceptable to the palate of a weary or thirsty horse. How often do we see a "let" horse come into the stable all exhausted and used-up, scarcely able to advance one limb before another ! Examine into the facts, and we shall find that the powers of the subject have, perhaps, been overtaxed. He has been driven too far, or at too rapid a rate, for the present state of his constitution to endure; and, perhaps, he has not had sufficient nourishment to repair the waste incidental to the living mechanism, under the states of rapid and protracted labor. Is not this enough to account for the used-up condition? Is it not more rational to suppose that abuse of the respiratory organs, and those of locomotion, operates far more unfarorably on the horse than water? It is. But Mr. Fastman must, if there be any blame rightly belonging to him, try to shift the same from his shoulders, and therefore he avails himself of a popular error, - "He drank too much water." Yet the individual has no means of ascertaining the precise quantity needed. 
We might say the same as regards our truck horses, whose labors are very fatiguing; they come from their work, and, as soon as unharnessed, go to the trough and imbibe from one to three buckets, without any bad effect. Some animals need more water than others; the kind of work, the temperature of the atmosphere, and the nature of the food, whether it be wet or dry, all tend to diversify an animal's wants. The domesticated horse requires a bountiful supply of good water; his body is composed of seventy-five per cent of the same, and he can no more exist without it than he can without food.

A cow or ox is probably the best judge, as regards its own wants, as to the quantity of water needed. It is not the quantity which a rational animal imbibes which does harm, but it is the quality that demands our attention.

Thirsty people drink all the cold water they need; then why deprive a cow or horse of what they actually need? Consider the condition of the inhabitants of populous cities during the summer season. Thirst amounts almost to a disease, and, in view of quenching it, the thirsty are continually imbibing water, rendered cold, hot, sour, sweet, or alkaline, just as fancy dictates, or as fashion prevails; cold ices and other fixings are called into requisition, to smother the fire of thirst that rages within; everybody partakes freely, the young and the aged, the exhausted and vigorous; the laborer, exhausted by a hard day's work, and the rich man of no work, each and all are doing their best to see the bottom of the pitcher, and to pitch their bodies into the watery element; yet, after all, how few persons complain of any bad effects from it!

Inquire into the history of some of the acute maladies that are supposed to arise from water-drinking, and it will be found that many of the sufferers have a peculiarity of constitution, which renders them amenable to the laws of primogenial disease, which, although latent under ordinary circumstances, can, by disturbing the life forces, through neglect, cruelty, and overwork, be developed at almost any time of life.

Cattle should never be allowed to drink pond water. They should either have access to a running stream, or a clean water trough. 


\section{CRACKS IN THE HEELS OF CATTLE.}

Cracked heels are generally more prevalent in the horse than cow ; yet, as I have had an opportunity of seeing and prescribing for a few cases of this character, I shall give the reader the benefit of my experience; so that when cases of this character do occur, the farmer may know what to do. Some persons suppose that uncleanliness is the sole cause of cracks. This is not the case; the subjects are predisposed to a humory condition and congestion of the feet.

Treatment of Cracks. - The part must first be sponged, or rather, washed, with tepid water, slightly alkalized with a small quantity of carbonate of soda. I prefer soda instead of soap. The latter is apt to irritate the parts; and there exists no dirt nor morbid matter which cannot be removed by an alkaline wash. After cleansing the parts, apply a portion of the following:-

Glycerine,

Powdered Phytollacca (Pokeroot), ..................... ounce.

" Alum, .............................. drachms.

Mix, and apply by means of a piece of sponge. The parts should be dressed once per day, and oftener if necessary.

The edges of the crack sometimes become inverted.' In this case, procure a small piece of linen; form it into a pad, and, after smearing its surface with a portion of the above preparation, apply it so as to press the lips of the gap together, and then bind it on.

If the disease be constitutional, which may be inferred from the fact that the animal is said to be "subject to it," in the winter, then a few doses of alterative medicine may be given. The following forms a very excellent stimulating alterative :-

Iodide of Potassium,................................. $\frac{1}{2}$ ounce.

Water, .......................................... quart.

Tincture of Sassafras, ................................4 ounces.

Mix. Give a wine-glassful every.morning, before feedingtime. 


\section{PARASITES AROUND AND WITHIN THE GLOBE OF THE EYE.}

A species of parasite, commonly known as worms, are ocr , sionally the habitants of the tissues entering into the composi tion of the coverings of the eye, and once in a while they make their appearance within the globe. The only local remedy. of any value is, infusion of lobelia, prepared as follows:-

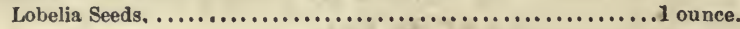

Boiling Water, ..................................

Let the mixture stand until cool, then pour off the clear liquor, and occasionally bathe the eye with a portion of the same; in the mean time let the patient have a dose or two of sulphur and sassafras, equal parts. Dose, one ounce, to be incorporated with the food.

According to Baillet, these worms belong to the genus filariæ (the same are often found in the air passages of sheep). Naturalists consider them as gregarious, being found in numbers of nine - eight females and one male. The filariæ are thus described by Mr. Gamgee.

"M. Serres has often found them under the eyelids of the ox. I had an opportunity to study their characteristics, in six females found by M. Lafosse, under the eyelid of a cow, in 1855. From that time, though some details of their organization were still wanting, I considered them as belonging to the genus filariæ, and I designated them, in my course of lectures, the filaria bovis. There can be no doubt as to the place which these worms are to occupy in our classification.

"The slender, filiform, and elongated body; the defined moutl, without papillæ; the almost terminal anus; the double ovaries, united in one common oviduct, which is situated at a little distance from the extreme end of the anterior extremity; and the embryons, which are notched in the interior of the tubes of the oviduct, all show that these nematoïdes belong to the genus filarix. The name of filaria bovis may not be a proper one, as there are other filariæ found in these animals, and, therefore, an inconvenience might arise from its 
adoption. I propose to give them the name of filaria palpebrarum, which would indicate their locality. It is probable that the worms found in the globe of the eye of the ox, are of the same genus as the one just described, and that their differ ent locality is affected by transmigration, or, perhaps, they may deposit their embryons under the eyelids."

\section{IMPROVED METHOD OF MULKING.}

The first process in the operation of milking, is to make the cow's acquaintance, and give her to understand that the milker approaches her with none other than friendly intentions; for if he swears, scolds, or kicks her, she is likely to prove refractory, and may, possibly, give the uncouth and unfeeling milker the benefit of her heels, which, in my opinion, he is justly entitled to.

Before commencing to milk the animal she should be fed, or have some kind of fodder; in the enjoyment of the mastication of the same, her attention is withdrawn from the milker's operations, and the milk is not "held up," as the saying is, but is yielded freely.

The milker should not sit off at a distance, like a coward, but his left arm should be in close contact with the leg of the cow, so that she cannot kick. If she make the attempt when the milker is in close proximity with the cow's body, the former merely gets a push instead of a blow.

Before commencing to milk, the teats are to be washed with cold water in warm weather, and warm water in winter; the object is to remove accumulated dirt, which otherwise would fall into the milk pail, to the disgust of persons who love pure milk, and hate uncleanliness. Here is a chance for improvement.

The best milker is a merciful man. The udder and teats are highly organized and very sensitive, and these facts should be taken into consideration, especially when milktng a young animal, for the parts are sometimes excessively tender, and the hard tugging and squeezing which many poor sensitive crea- 
tures have to endure at the hands of some thoughtless, hardfisted man, are really distressing to witness.

$A$ better milker than even a merciful man, is a woman. The principal part of the milking, in private establishments in foreign countries, is done by women; and in these United States, there are thousands of capable women out of employment that might be advantageously employed, in private and dairy establishments, as milkmaids. Therefore, in view of improvement in the art of milking, I advise farmers to learn their wives, daughters, and female domesties, how to strip the cows.

An indolent person - slow coach - should never be suffered to touch a cow's teat; the process, to say the least of it, is painful ; therefore, the best milker is the one that can abstract the milk in the quickest time.

Finally, milk the cow dry. The last of the milk is the most valuable, yet Mr. Hurry-up cannot spare time to attend to this matter; consequently he loses the best of the strippings and actually ruins the cow as a milker.

\section{DISEASED THYMUS GLAND.}

The thymus gland, commonly known as the sweetbread, is usually found, after adult life, in the region of the thoracic duct, just within the anterior or front part of the chest; yet the greatest activity and development of this gland is during fœetal life. This is one of the glands, which, according to Goodsir, is an involuted portion of the germinal membrane, acting as the first assimilating organ possessed by the foetus; hence, as soon as the animal is born, and the legitimate organs of digestion are called into operation, the thymus dwindles away, and, in some cases, almost disappears: Occasionally, however, it becomes enlarged, and has to be removed by a surgical operation. The following instructive case occurred in the practice of $\mathbf{W}$. Lyon, V. S. and appeared in the London Veterinarian.

"I beg to forward for your inspection a tumor, being the largest of two which were removed on the 15 th instant, 
from under the cervial vertebræ of a yearling quey, and which, although now considerably shrunk and dry, weighs forty-nine ounces, and measures twenty-three inches in its greatest circumference. It rested upon the œsophagus, trachea, bloodvessels, and sternal muscles, excepting when the animal's head was depressed; so much so, that had the same degree of pressure been made on the gullet, by a tumor existing elsewhere, as within the chest, permanent hove, etc., would have been produced.

"The operation consisted in an incision through the integuments of the off-side of the neck, over and parallel to the course of the vessels, which exposed part of the levator humeri; the next incision being made right through that muscle, in the direction of its fibres, which brought to view part of the great tumor, exposing also the sub-scapulo-hyoid muscle, which was considerably but favorably displaced by the pressure of the lesser tumor, which inclined to the off side: the remaining incisions were made with care through numerous ligamentouslike bands and cellular membrane, by which the tumor was attached to the inter-vertebral and other muscles. The lesser tumor, which was more superficial, was then removed in the same manner, after having been very useful in keeping the said sub-scalpulo-hyoid muscle out of the way. Both tumors seemed to be indifferently supplied with blood. Excepting the cutaneous veins, which yielded less than an ounce of blood, there were no bloodvessels divided; hence no artery nor vein required to be taken up. A few interrupted stitches were put in, and as the quey had necessarily to stand during the operation, there being only one man and a boy present at its commencement, orders were given to let go the under jaw, when the animal immediately sprang over a four-foot wall. I have not seen her since, but have learned that she is doing well.

"She is the property of Mr. George Reay, cattle-dealer, here, being one of the stock-cattle on his farm of Caim, parish of Tarmadice. I need make no remark on the origin, progress, structure, locality, and treatment of such tumors, such being already well known to veterinary practitioners. Farm- 
ers, however, would do well (now that the disease is very common) to feed off cattle so affected or predisposed, when it is possible to do so, and not to breed from such stock, as it is generally difficult and sometimes impossible to remove the tumors when once formed. It would also be for their interest to pay less attention to the direct treatment, by entrusting that in the hands of a practitioner, and to attend more to the negative treatment, such as blood-letting, avoiding refrigerants, such as nitrate of potash, and all other medicines that tend to diminish the fibrine of the blood, particularly all mucurial preparations, and, in general, to avoid every thing formerly used in the treatment of scrofula in the human subject. But this they will not always attend to when any thing is wrong with any of their cattle; they must not merely get direct treatment, but without due discrimination they must share and share alike."

\section{CORDS IN YOUNG CALVES.}

A disease to which the above name is given, occasionally appears among young calves. It is an inflammatory affection, and particularly manifests itself in contractions of the sinews, tendinous structures; hence the name - cords. White contends that calves are most liable to be affected by this disorder during the first days or weeks after they are dropped. If they outlive five or six weeks, they are seldom in any danger. Calves that suck their mothers are not so liable to the disease, as those which are reared by hand. The greatest number of calves that fall a sacrifice to this disease, if not the whole of them, are those which are closely confined to the house from their birth, without ever being exposed to the free, open air. It is a well-known fact, that calves which are dropped and remain in the fields are in little or no danger. - Farmer's Magazine, rol. iv. p. 59. Mr. Lawrence, in his Treatise on Cattle, observes, that "a complaint called the cords has recently destroyed a number of young calves in Scotland, both such as have been calved abroad and under shelter. Those which are brought up 
by hand are most liable, and the most dangerous period is the first week or two after birth."

As a preventive $I$ should give the new-born calf (provided he have no discharge from the bowels) a wine-glassful of castor oil; yet if the mother yield milk, and the calf immediately after birth imbibes the same, there is no need of giving any medicine. The object in giving castor oil is to purge off the meconium - first excrement. The first flow of milk, however, will meet the emergency, and it is only in cases of suspended lacteal secretion, or in cases of acute garget, when the cow cannot yield milk, that I recommend the castor oil. Should the oil purge the calf too actively, twenty drops of the oil of anise-seed or peppermint, may be given in half a pint of flour gruel.

Should the animal be dangerously attacked, and the contractions of the tendinous structures violent, let the little creature be placed in a warm bath for a few minutes; then give him a good rubbing with coarse towels, after which he will probably do well.

\section{STEAMED AND COOKED FOOD FOR STOCK.}

In view of fattening neat stock, and augmenting the quantity of milk in dairy cows, I recommend the use of steamed and cooked food.

It has been satisfactorily proved that fat cattle, of the best quality, may be produced by feeding them on boiled food.

Dr. Whitlaw says: "On one occasion, a number of cows were selected from a large stock, for the express purpose of making the trial ; they were such as appeared to be of the best kind, and those that gave the richest milk. In order to ascertain what particular food would produce the best milk, different species of grass and clover were tried separately, and the quality and flavor of the butter were found to vary very much. But what was of the most importance, many of the grasses were found to be coated with silicia, or decomposed sand, too hard and insoluble for the stomachs of cattle. In consequence 
of this the grass was cut and well steamed, and it was found to be readily digested; and the butter that was made from the milk, much firmer, better flavored, and would keep longer without salt than any other kind. Another circumstance that attended the experiment was that, in all the various grasses and grains that were intended by our Creator as food for man or beast, the various oils that enter into their composition were so powerfully assimilated or combined with the other properties of the farinaceous plants, that the oil partook of the character of essential oil, and was not so easily evaporated as that of poisonous vegetables; and experience has proved that the same quantity of grass, steamed and given to the cattle, will produce more butter than when given in its dry state. This fact being established from numerous experiments, then, there must be a great saving and superiority in this mode of feeding. The meat of such cattle is more wholesome, tender, and better flavored than when fed on the ordinary food."

"A mixed diet (boiled) is supposed to be the most economical for fattening cattle. 'A Scotchman, who fattens 150 head of Galloway cattle annually, finds it most profitable to feed with bruised flax-seed, boiled with meat or barley, oats or Indian corn, at the rate of one part flax-seed to three parts meal, by weight - the cooked compound to be afterwards mixed with cut straw or hay. From four to twelve pounds of the compound are given to each beast per day.' The editor of the Albany Cultivator adds : ' Would it not be well for some of our farmers who stall feed cattle, to try this or a similar mode? We are by no means certain that the ordinary food (meaning, probably, bad hay and cornstalks) would pay the expense of cooking; but flax-seed is known to be highly nutritious, and the cooking would not only facilitate its digestion, but it would serve, by mixing, to render the other food palatable, and, by promoting the appetite and health of the animal, would be likely to hasten its thrift." (See article on diet.)

An article on steamed food for stock, lately appeared in the columns of the Mark Lane Express. It does not sustain my theory exactly, yet the closing paragraph proves all I contend 
for at the commencement of this article. It is my opinion that . in order to test the real value of steamed over raw food, the experiments must be conducted with great care, and be continued for some time, during which it must not be expected that the animal will thrive in health and flesh, unless it have an occasional meal of its more natural food in its raw state. What I mean by the "real value" of steamed food, is its usefulness in the animal economy, as a co-agent with the unsteamed articles of fodder; and considerable discretion will be needed in making selections among articles of food; some of which might be improved, or rather, rendered more acceptable to the palate, and convenient for mastication; while others might be deteriorated by the same process. I select the following from the above source:-

"As to steaming food for cattle, there is considerable difference of opinion among theoretical writers. Among practical men there is little difference of opinion, especially where experiments have been individually undertaken. The late $\mathrm{Mr}$. Howden, of Lawhead, East-Lothian, undertook a series of experiments on feeding cattle with steamed food. Lots of cattle of similar age and breeding were selected and divided. Those cattle fed on turnips and potatoes given raw, made rather greater progress than those fed on the prepared food, equal quantities being given. The difference was slight, - still it was perceptible; the rate of progress being tested by girthing the animals; and the condition generally, by handling. The experiments were carried on for more than one season, with nearly the same result. A lot of young cattle, a year and a half old, fed on boiled beans, made very rapid progress, and left a profit beyond payment for their food consumed. They were cheap when purchased, and the value of beef-was at the time relatively high with that of lean cattle. Of course, the straw was not prepared, either by steaming or cutting into chaff. Other experiments with steamed food have been, from time to time, undertaken in that county, and with nearly the same result. In every case that came under our observation, the preparing of food by steaming and boiling was, after a time, given up. 
"In feeding dairy stock when in milk, steaming and boiling food is known to be profitable; but the health of the animal sometimes suffers, compared with that of cows kept partly on raw and partly on prepared food."

\section{CHEAP FODDER FOR COWS.}

Straw contains much farinaceous aliment. The attention of agriculturists in France has recently been directed to the discovery of a method of converting straw into a kind of bran. The discovery has been claimed by two individuals. The first is a miller, near Dijon, who, it is said, on trying the mill-stone of a new mill, discovered the possibility of converting straw into a nourishing food; the second, M. Jos. Maitre, of Villotte, near Chatillon.

This distinguished agriculturist, known for the purity and perfection of his breeds of sheep, conceived the idea of converting into farina not only the straw of wheat and other grains, but of hay, trefoil, lucern, sanfoin, etc. His efforts are said to have been perfectly successful, and his discovery arrived at, not by chance, but by long experiment and research. The aliment which he has produced is said to be a complete substitute for bran. It is given to sheep and lambs, who consume it with avidity, and may be given to all other graminivorous animals as a grateful and substantial food. We know, in this country, that the mere chopping of straw adds greatly to its powers, by facilitating mastication and digestion. We may believe that a more perfect comminution of its parts will produce a corresponding effect, and extend very widely the uses of straw and other fodder, as a means of feeding our domestic animals.

This sort of aliment is very excellent, when combined with a sufficient amount of nutrimental matter, for animals whose systems lack the requisite amount of phosphates and phosphoric acids. A milch cow, for example, whose lacteal vessels yield, in the form of milk, the above equivalents, may be benefited by an occasional feed of straw meal. 


\section{CHINESE SUGAR-CANE AS FOOD FOR STOCK.}

It is my opinion that the Chinese Sugar-cane is a valuable article as food for neat stock; but it should be fed to them before it becomes fibrous and tough.

A writer in the Chronicle and Sentinel, who appears to be better qualified to judge of the value of this kind of fodder than the author of this work, has given husbandmen the benefit of his experience, as follows :-

"Allow me a small space to 'give in' my experience as to the virtues of Chinese sugar-cane as food for stock. I wish to do so, because I have recently read several notices of the deleterious effects of the cane upon cattle, and have also learned that, in some parts of an adjoining county, it is being cut down and suffered to rot upon the ground, for fear the cattle or hogs or horses might accidentally get a bite of it ! This is the most ridiculous aspect through which I have looked at the case, and I have had my cachinatory muscles no little exercised in consequence thereof. But to the 'law and the testimony.' This is my third season of cultirating the Chinese cane. I have seven acres of it this year, five of which I planted for the express purpose of feeding it, green and dry, to horses, cattle, and hogs; and since the first of June until now, I have been feeding it daily to those animals. My calves have run daily upon two acres, sown broadeast, since that time. My cows and oxen, while sick with the 'black tongue,' were daily fed with it. My oxen, when at work, are fed upon it; horses ditto. My hogs are daily fed with the cane now, and are in fine growing order. I intend to fatten my pork upon the cane, as not only good feed, but equal to corn for the same purpose. These facts can be attested by my neighbors, for they know all about them. After three years' experience with the Chinese sugarcane, I have come to the following conclusions with regard to it ; and I give them for what they are worth, not caring a 'baw

'bee' whether or not they are endorsed by the people :-

"1. For forage, either green or dry, there is no plant so I valuable. 
“2. More grain can be made upon the same land than oats will produce, with an analytic value as food of one-third over oats.

"3. For hogs, it is next to corn, in every particular.

"4. For syrup, it is equal to any cane, and for sugar, ditto.

"This is no mere speculation; I have tried the forage, made syrup and sugar, and, for the analysis of its value as food, am indebted to Prof. Lee.

"If the Patent Office had done no other thing than import this seed, it deserves the commendation of the whole country; and while politicians are wrangling over the "tithes of anise, mint, and cummin, and neglecting the weightier matters of the law,' let the 'bone and sinew' - the producers of the country - sustain the only bureau of the federal government which benefits them by the distribution of seeds."

\section{THE VALUE OF NATURAL FOOD, IN CONTRAST WITH ARTIFICIAL FOOD}

It is well known to the husbandmen of the West, that in the rich pastures of Illinois, where the tall but original herbage of the prairies has been supplanted by a thick turf of blue grass, cattle are reared of a prodigious size. The Chicago Press, under the head of "Illinois cattle the largest in the world," gives an account of one hundred head of cattle, raised by B. F. Harris, in Champaign County, Illinois. He fed them for the New York market, and, previous to shipping them, he had them accurately weighed, which resulted in an aggregate gross weight of $118 \frac{2}{5}$ tons, or 2,373 pounds each. Twenty-five of the best and fattest weighed 33 tons 550 pounds, or an average of 2,662 pounds each. "The baby" of twenty-five, kicked the beam at 5,876 pounds. It will give some eorrect idea of the condition of these bullocks, when the fact is stated that three days were required and needed to drive them to the railroad station, fourteen miles. The average age of the one hundred is less than five years. Not one has ever been housed a day in his life. A half-dozen pairs only have been yoked, and 
a less number worked. They were pastured and herded on the prairies in summer, and in the winter fed on corn in the liock. and yarded along the skirts of the Sangamon timber.

\section{BLACK LEG}

Various are the names given to an affection of the above kind. Some persons call it inflammatory fever, gangrene, etc. Then again it gets its name from the region in which it first appeared. So if it first appears in the region of the thigh, it is called quarter ill, quarter evil, black quarter, joint murrain, etc.; hence it appears to have as many names as there are locations for it.

The Nature of Black Leg. - Youatt, and other orthodox veterinary writers, contend that this affection is a pure inflammatory fever, yet at the same time they admit that cattle of all descriptions, ages, and conditions are subject to it. Now I think it will be very difficult to prove that inflammatory fever can attain a very high grade in the system of an animal in poor condition. The very reverse is the case; for disease of a low typhoid type, and those which are known to run a rapid course, are apt to pounce upon animals having but little vital resistance - being out of condition, as the saying is.

In my opinion, this is an epizoötic affection, and, like most epizoötics, its pathology must necessarily be obscure. In applying the term black-leg, black-quarter, etc., to this affection - epizoötic or enzoötic - leads us into error in supposing that it is merely a local affection, limited to a certain part, when, in fact, it is a general affection, showing itself in various parts of the economy at the same time. For example: in the early stage, when a limb or part is swollen and distended with gas, the various organs and functions of the body are more or less disturbed; even in the early stage, the respirations are short and quick; pulse accelerated - a mere fluttering action scarcely perceptible; the coat stares; rumination is suspended; the bowels are constipated, and the nervous system is affected; for the beast staggers, and soon becomes comatose; death fre- 
quently takes place in the course of from twelve to twenty-four hours. It will be perceived, therefore, that the local affection is not proportionate, in degree or extent, to the severity and magnitude of the general symptoms; therefore it is a general disease.

The autopsy clearly indicates the ravages which this epizoötic or enzoötic makes on the general economy. Youatt informs us that "The chief appearances after death will be venous congestion every where. It affects both of the pleuræ, the whole substance of the lungs, brain, and peritoneum; the intestines and stomach are also affected." Therefore, what we perceive externally, in the form of tumors, emsphysema, ulcers, sloughing, and mortification, are only the symptoms of a general malady. Mr. Ernes informs us, through the pages of The Veterinarian, that "black-quarter" (which is the same as "black leg") is neither more nor less than that dreadful malady of horses and cattle called by the French charbon. Authrax, would, perhaps, be the better appellation, seeing its characters are a hard, circumscribed tumor, exceedingly painful, with tension and burning heat in the subcutaneous cellular tissue. This is often depressed in its centre, and sometimes preceded by a small opening.

According to authorities, "the tumor of black leg, though small at first, suddenly increases in size, sometimes to that of a child's head. Gangrene soon supervenes, beginning in the centre and extending to the circumference, which rapidly converts the whole into an eschar of a black color, similar to a piece of charcoal ; hence its name (charbon). 'The eschar is sometimes several inches in diameter, and is almost always either preceeded or accompanied by bladders, which form a sort of areola around it. There is also always an odematous swelling, more or less considerable, owing to an emphysematous state, and an infiltration of serum or sero-gelatine into the cellular tissue, which crackles on pressure, caused by the presence of gases. The danger and rapidity of the disease are such, that, when an animal is attacked, after a violent access of fever, it falls a sacrifice to it in a few hours, rarely exceeding twenty-four or 
thirty-six. All animals are subject to it, but the herbivora more so than others. It is either epizoötic or enzoötic; the first is the most destructive."

I now consider the point settled regarding the nature of the disease; viz., it is an epizoötic or enzoötic affection, and, of course, is subject to the same laws which govern diseases of this type. This will explain the otherwise unaccountable variations which are observed in the symptoms of the affection when prevailing in different localities, and it also enables us to account for the great losses which Messrs. Shortfeed and Orerfeed are continually encountering. The fact is, all overfed animals may be ranked as gluttons, and all half-starved animals furnish a savory morsel for the great epizoötic pathological glutton, which, like the epidemic one that, hovering around the city of New Orleans, a few year's ago, destroyed several thousands of its inhabitants ere it touched a single sober citizen.

When this disease rages in a single locality, it is supposed to have a spontaneous origin. Then the term enzoötic is applied to it; and if it prevail among the cattle of an extensive region, then it is called epizö̈tic.

Causes of Blqck Leg, etc. - The causes of this affection are as obscure as those of cholera, influenza, potato rot, etc. They seem to appear independent of local causes, occur at uncertain intervals, prevail for indefinite periods, and run their course in a short space of time. It is supposed by some persons that a disease of this character and nature is propagated by contagion or infection. How far it is engendered in these ways, I am not prepared to decide. There must, however, have been a time when the disease did not exist, but must have arisen from a concurrence of natural causes; and if these were allequate to its production at an anterior period, they must be so at the present time. I shall, therefore, abandon all further speculation in this direction as unprofitable, for there is evidently no direct cause, but various are the predisposing, exciting, indirect, and morbid causes. The only way that I know of to prevent this malady is to keep the cattle in a physiological condition, by paying proper attention to breeding, feeding, rearing, and 
housing. For animals in a perfectly healthy state are certain to enjoy immunity from this and other diseases.

I have lately noticed several articles in agricultural papers on the prevention of black leg, which in the name of commion humanity I am compelled to notice. The one I have thought proper to select reads as follows:-

"Preventive. - Take spring calves in the month of October"; cut a small incision in the hollow above the foot. On the top of the flesh a small blue vein appears; take a crooked instrument, in the shape of an awl, and put the point under the vein, raise it up so that it can be cut, and take about an eighth of an inch out of the vein. Don't sew up the incision. It must be done on all the four feet.

"I have cut many hundreds, and have known of thousands being cut, and never knew of one dying with the above disease after being cut."

Now I am not disposed to scold, or find fault, nor question the intentions of men who recommend or practice such outrageous barbarities under the guise of doctoring sick animals, but I wish to remind the intelligent reader that cattle have nerves to feel and are as keenly sensible to pain as we are, therefore, all unnecessary operations, even should they have received the seal of antiquity, ought to be avoided. This is the age of progression. The lamp of veterinary science is illuminating the mystified halo which has hitherto surrounded our barn-yard practice; and before the barbarities of by-gone clays are practised on our domestic animals, let us be satisfied that we are using rational means for the recovery of the sick. such as science and common sense confirms. Just as rational would it be, if it were at all rational, to take an infant and divide one of the posterior veins of both feet, in view of preventing disease common to adult life, which, after all, might never occur, the little creature not being predisposed thicreto.

Let any one just study the anatomical structure of the foot of an $o x$, and he will iearn that the vein which we are recommended to sever and amputate from, is called the coronary, and 
is engaged in returning blood from the vast venous plexuses of the foot, which requires to come in contact with the lungs, for purification and oxygenization. Any impediments, such as severing a vein, which interrupts the free circulation or return of blood to the heart and lungs, cannot be beneficial, but otherwise.

It will be seen that the vein is nothing more than an elastic hollow tube, a mere vehicle, through which the blood courses; therefore, it cannot be supposed to have any specific power over other parts of the organization, in warding off disease.

I shall not trouble the reader with any farther remarks on the subject of irrational and barbarous prevention ; for I presume that the introduction of the above paragraph will answer all the purposes intended.

Among physicians, the disease is known as homatosepsis; and our experience is, that it usually occurs among young stock, and generally in well-bred animals in high condition, or in native stock in low condition; yet it may occur in the system of any bovine, as the result of sudden change in the quality of the food.

Treatment of Black Leg. - It is an unfortunate occurrence that this disease should ever have been classed as an inflammatory affection, for the error has led to a system of practice disastrous as the cattle plague. The following paragraph from Youatt, will serve to show the orthodox method of treating inflammatory fever, and will also explain the reason why a great proportion of the animals treated die.

"The very name of the disease - inflammatory fever - indicates the mode of treatment. In a case of excessive vascular action, the first and most important step is copious depletion. As much blood must be taken as the animal will bear to lose; and the stream must flow on until the animal staggers or threatens to fall. Here, more than in any other disease, there must be no foolish directions about quantities. As much blood must be taken away as can be got; for it is only by the bold and persevering use of depletory measures that a malady cam be subdued that runs its course so rapidly. 
"Purging must immediately follow. The epsom salts are here, as in most inflammatory diseases, the best purgative. A pound and a half, dissolved in water or gruel, and poured down the throat as gently as possible, should be our first dose; and no aromatic should accompany it. If this does not operate in the course of six hours, another pound should be given; and after that, half pound doses every six hours, until the effect is produced."

It is a wonder to me how any creature can survive such barbarous treatment as this; yet, even at the present day, just such doctrines are taught in the schools, and practised on cattle, to the disgrace of science, and shame on those men who perpetrate the wickedness.

Blood-letting and purging can have no good effect on a dis- ease like this, so prostrating, and which runs its course to mortification so rapidly. Such a wretched system of practice has always failed, and ever will fail.

That form of treatment which reason and experience suggests, is the best; for example: it would naturally occur to the mind free from the prejudice of veterinary orthodoxy, that a disease which runs into sloughing and mortification, in a few short hours, must require life-sustaining agents; hence I recommend a very different mode of treatment from that heretofore practised.

I commence the treatment thus:-

Spirits of Hartshorn, ..............................4 drachms.

Tar-water,.......................................... quart.

Tincture of Bloodroot,..............................

Mix the hartshorn and tar-water first ; then add the bloodroot. Drench (dose No. 1). The object in giving the hartshorn is to decarbonize the blood, and impart healthy stimulus to the nutrient system of bloodvessels and nerves; and this agent will do it.

Should the animal slow any lameness in the back or hind quarters, apply the following:-

Oil of Cedar,......................................2 ounces.

Sulphuric Ether, ................................ 2 ounces.

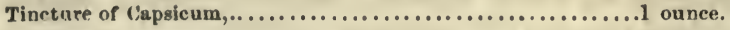

Cod Liver Oil, .....................................6 ounces. 
Mode of Preparation. - First, mix the two oils; then add the ether, and shake them thoroughly; lastly, add the tincture.

The olject in applying this preparation is to arouse capillary action, and thus prevent the engorgements, which, according to the best authorities, are everywhere found.

Four hours after administering "Dose No. 1," drench the patient with the following:-

Liquid Tar .1 ounce.

Glycerine,. .4 ounces.

Thin Gruel, ......................................1 quart.

If the urgency of the case demands it, this dose may be repeated, at intervals of four hours, until symptoms of improvement are observed.

The tar is a powerful antiseptic, and prevents decomposition, emphysema, and mortification.

All sores and ulcers must be dressed with pyroligneous acid, and kept constantly sprinkled with powdered bloodroot. All abscesses must be punctured with a thumb lancet; their contents evacuated by pressure, and syringing them with soapsuds, and their cavities must be crammed with fine salt. Should any sores or ulcers be observed about the muzzle, mouth, or throat, tincture of matico is the remedy, or liquid tar; one ounce of the same may be introduced into the mouth of the patient; it will surely do good.

If the patient be weak and debilitated, tonics are indicated; goldenseal, in two drachm doses, may be incorporated in the food, in direct ratio to the urgency of the case.

\section{BLACK TONGUE.}

This epizoötic has of late raged very extensively in North and South Carolina, Georgia, and Florida.

"The Mobile Mcrcury records the death of two persons near that place, from drinking milk from diseased cows, besides the deaths of several others from the same cause at a distance. It appears that domestic cattle are not alone the sufferers, but that in Florida, particularly, the deer are perishing from the same disease in large numbers, and, according to a letter in the $S a$ - 
vannah Republican, dogs, and the buzzards in Burke County, Georgia, that have eaten the flesh of cattle that have died of the black tongue, have perished from the effects of such poisonous diet. The cause of this malignant disease does not seem to have been yet ascertained, though by many it is attributed to the rust, which, in various parts of the Southern States, as elsewhere, has affected the grain crops, and, it is said, in some places, the grass also. The cattle are attacked by stiffiess, and walk as though foundered, while froth is discharged in large quantities from the mouth; they can eat nothing, fall away rapidly, and the tongue and gums become dreadfully swollen, and turn black, and death speedily releases them from their agony."

Treatment of Black Tongue. - The rapid progress which usually attends this dreadful epizoötic calls for prompt and energetic treatment. It is evidently a congestive disease, and very apt to run into the typhoid stage and end in sudden death. The moment an animal is suspected to be the subject of this malady, he should be drenched with table salt, twelve ounces; warm water, one quart; to which add tincture of eapsicum, two ounces. This medicine will act as a powerful antiseptic and stimulating tonic, thus preserving the animal tissues against putrescence; and at the same time it relieves the venous congestion. If, on applying the liand to any part of the body, a crackling sound is elicited, the animal is then said to be emphysematous, which signifies an accumulation of gas beneath the skin. The patient should then be immediately drenched with two ounces of pyroligneous acid, twenty-eight drops of pure oil of sassafras, linseed tea one quart. Mix the oil with the latter, then add the acid. After having drenched the animal, apply a portion of the following to the tumefactions, or emphysematous region :-

Soft Soap, .4 ounces.

Oil of Sassafras, $\frac{1}{2}$ ounce.

\section{Dissolve the sassafras in two ounces of alcohol.}

Tincture of Capsicum,..............................2 ounces.

Tincture of Peruvian Bark, .........................

Mix, and rub the external surface with a portion of the same. 
The swollen tongue should be frequently covered with fine salt; and the moment there appears any improvement, tonic medicines should be given. One ounce of the fluid extract of camomile flowers may be given, twice daily. This remedy will give tone to the system and restore the appetite:

The Wilmington (Delaware) Herald says : the disease called "black tongue," which has been causing such wide-spread destruction among the cattle, particularly cows, in the States South, has reached that place, and one or two cows have died with it, and others are infected. A particular watch has been, in consequence, kept upon the markets by the municipal authorities.

It is about time that the stock-raisers in this country should endeavor to use their influence and means for the purpose of establishing veterinary schools, or rather, in view of sustaining those now incorporated; for should this country ever be visited by any of those dreadful epizoötics which occasionally rage in Europe, a vast amount of property will be sacrificed. Very few persons in the United States know anything about the nature or treatment of " black tongue," or indeed any of the infectious and contagious epizoötics; and if they should make their appearance among live stock, death will run riot, just because of our ignorance and neglect in educating men for the business.

I do hope that a change in the sentiments of stock-owners will ere long take place, and that they may be led to see the necessity of having an efficient corps of reterinary surgeons, properly qualified, to render valuable service in the time of need. In times of health, prepare to guard against sickness and death.

\section{ORGANIC COMPOSITION OF THE BODY.}

On inspecting the animal body, or rather, a part of it, under the livid rays of a powerful microscope, we find that it is composed of laminated cells of different degrees of compactness. The inlets and outlets of this vast piece of animal 
mechanism, vary in calibre in exact ratio to the compactness of this, that, and other parts and organs. Hence we find that the cornea of the eye - a dense substance - is entirely composed of lamina, - a succession of plates in close contact with each other. On the other hand, a tissue less dense, like that composing the muscles, is said to be more cellular than laminal. These portions of the organism constitute what physiologists term the solids. However dense may be their structure, both laminæ and cells have openings through which liquids pass and enter.

The body, as a whole, is composed of four elements ; namely, carbon, hydrogen, oxygen, and nitrogen. These four primary animal formations coalesce, in persistent proportions, and thus constitute the animal organization, - the solids of the body. The four primary elements above named resolve themselves by varied proportions, into constituent molecules; thus, as a primary proposition, we have gelatine, or jelly, a substance which can be extracted by the ordinary process of boiling the tendons, bones, capsules of joints, dura mater, cellular tissue, or any other part of the animal organization. In fact, the whole laminated and tendinous structures of the body are chiefly composed of this gelatinous material.

The presence of gelatine in the animal tissues may be demonstrated as follows; namely, it is soluble in water, but not in alcohol; it liquifies by heat, and at a very low temperature it becomes solid, and yet again can be liquified by heat. Gelatine is composed of thirteen equivalents of carbon, ten of hydrogen, two of nitrogen, and five of oxygen. Its power of forming a jelly is (on cooling) such, that a solution of one part in one hundred of water, will become a consistent solid.

Next we have albumen, a substance identical with the white of eggs. In a fluid state, it coagulates at about $165^{\circ}$ of Fahrenheit. Alcohol, various acids, and astringents, also coagulate it. It abounds in the vegetable as well as animal kingdom. In the former, it abounds in seeds, roots, stalks, and leaves. The body of an adult contains more albumen than that of a young animal. Under the combined action of 
warmth and moisture, it readily decomposes and yields a disagreeable effluvia. It is composed of seventeen equivalents of carbon, six of oxygen, thirteen of hydrogen, and two of nitrogen.

Next we have fibrine. This is one of the principal constituents of all the muscles, heart, etc. It is also an important constituent of the blood, and may be separated from the albumen and serum of the latter, by simply agitating the whole in water. It then assumes a light-colored, and solid, filamentary form. Therefore fibrine may be said to be insoluble in water. Its equivalents are: carbon, eighteen; oxygen, five; hydrogen, fourteen ; nitrogen, three.

There are various auxiliary constituents which enter into the staminal formation of tissues, although those just alluded to are the primary elements of organization.

\section{FRACTURED BONES.}

Fracture of bones, occurring among neat stock, is generally considered as a justifiable cáuse for their destruction. But I object to this summary mode of disposing of unfortunate, yet valuable, animals; for the truth is, many are killed that might be saved.

The trouble of managing, and the expense of treating cases of fracture, often deter husbandmen from performing a duty incumbent on them in view of protecting their property, and acting the part of "good Samaritan;" but the facts are, the trouble and expense are mere trifles when the usefulness of a valuable animal is involved.

The remedy in case of a simple fracture of bones, under the improved system of practice, is neither tedious nor expensive. The bones unite very readily, if kept in contact, and the unity is secured by means of starched bandages. Where there is any laceration of the soft parts, and the bone is broken into several pieces, the better way is to put an end to the sufferings of the creature, for recovery is impossible.

The following case will give some idea of the method 
of treating simple fractures. An animal under treatment for fracture, may be placed in the trevis, if necessary; but I prefer to let the patient have its liberty in a box stall.

The limb opposite to the fractured one, will have to sustain more weight than usual; therefore, I try to prevent swelling and stiffness by occasional hand rubbing, or by bathing it once or twice daily, with a portion of the following:-

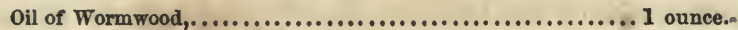

Alcohol, ...........................................2 ounces.

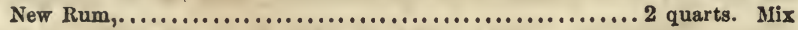

\section{FRACTURE OF THE RADIUS OF A CALF CURED.}

This was a case of simple fracture of the radius-bone above the knee - of a calf about six months old, the property of a gentleman residing in Brookline.* The accident was occasioned in consequence of the animal getting his leg entan- gled in a fold of chain, the latter being used for the purpose of confining him, in the day time, to a grazing spot.

The fracture was crosswise of the long diameter of the bone in the central region; viz., midway between its superior and inferior extremities. No laceration of the soft tissues; nor comminution of bone. The diagnostic symptom was crepitis - crackling noise.

Treatment. - The bones were brought in apposition, and secured by means of slips of pasteboard and starched bandages; and in order to keep them from slipping downwards, they were sewed to a broad belt, which passed over the inferior cervial region, in the form of a figure 8 . The animal did not appear to like this contrivance, or else he liked to lick the starch, for he soon commenced to nibble the wick-yarn with which it was marled on, and so loosened the bandage that in the course of a few hours it slipped below the carpus. So soon as this occurred, I was again summoned to visit the patient. I now procured some thick tar, and with it, smeared the limb to the extent which was to be covered by

* From the author's case book. 
bandage; the bandage was composed of common sheeting, three inches wide, three yards long, and this was also well tarred, and after being neatly applied, was secured by means of the many-tailed, tarred bandage. This had the desired effect; for, however well the animal might have liked the taste of starch, he apparently had no relish for tar. The bandage remained undisturbed.

The accident happened on the 18th day of August, 1857. On the 4th day of October, the osseous union was complete; the bandage had been removed some time prior to the latter date, yet the condensed tar was allowed to remain on the skin for some time. At the present time, his limb is just as symmetrical as the other, and no one but a skilful surgeon would ever discover that the bone had been fractured.

\section{LIGHT IN BARNS.}

Barns should be so constructed, by the insertion of windows in various parts of the building, that they shall be as "light as day." A "dark" barn is only a suitable black hole for some vicious animal; it is the very worst location for any thing that breathes. Sir A. Nylie (who was long at the head of the medical staff in the Russian army) states that the cases of disease on the dark side of an extensive barrack, at St. Petersburg, have been uniformly, for many years, in the proportion of three to one to those on the side exposed to a strong and uniform light. Humboldt has also remarked, that among bipeds, the residents of South America, who wear very little clothing, thus allowing the cutaneous, as well as the orbital surfaces to receive a free ray of light, enjoyed immunity from various diseases which prevailed extensively among the inhabitants of dark rooms and underground locations; and so excellent an authority as Linnæus contends that the constant exposure to solar light is one of the causes which render a summer journey through high northern latitudes so peculiarly healthful and invigorating.

Dr. Edwards has also remarked, that persons who live in caves or cellars, or in very dark or narrow streets, are apt to 30 * 
produce deformed children; and that men who work in mines are liable to disease and deformity.

Light, therefore, is a condition of vital activity; and in view only of preserving the sight of animals, it is absolutely necessary that, while they are in the barn, their optics shall have free access to the sun's rays.

If a cow were in the same condition as a polype, with no organ of vision, who shuns light, a dark barn might prove to be its earthly paradise; but as the cow has special organs of vision, evidently susceptible to the influence of light, and the integrity of its organism or a part of the same, depending entirely on the admission of light, it is absolutely necessary that barns should be constructed accordingly.

\section{DIARRHCEA IN CALVES.}

Diarrhœa is a very prevalent disease among calves. The suckling calf is liable to be the subject of this affection, whenever the general health of the parent is impaired. In such cases the mother is to be treated instead of the calf; she, probably, is the subject of a deranged condition of the digestive organs, which can easily be remedied by the administration of a few doses of the following :-

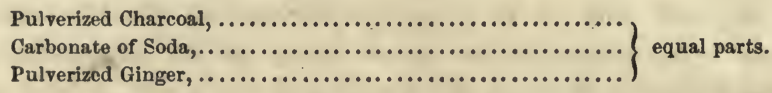

Dose. - Two ounces, daily, to be incorporated with the food, or it can be given as a drench, by adding a pint of scalded milk.

The disease occasionally occurs in consequence of weaning the calf (in view of husbanding the cow's milk), and feeding the juvenile on improper food. This kind of diarrhœa must be treated as follows: let the calf have two ounces of phosphate of lime, two drachms of carbonate of soda, and a quart of scalded milk; mix the same, and administer by means of a drenching horn, or bottle. It may be divided into "broken" doses, or may be given at once, as a single dose.

If the above remedies fail in arresting the diarrhœa, I should 
give three drachms of tincture of matico, every four hours, until the patient showed some signs of improvement.

\section{SPRAINS, OR STRAINS.}

Sprains, or strains, are generally occasioned by unnatural distention of parts, or rupture of cellular structure, which connects muscles or tendons. They are generally accompanied by heat, tenderness, and lameness. Working oxen are more liable to sprain than cows, because, when used in the yoke for draught, they are as liable to strain or rupture parts as horses, by sudden exertions, or violent efforts of the muscles to guard against a sudden slip and fall. The slightest strain will sometimes occasion lameness, because the parts concerned are composed of minute fibres and cells, delicately organized ; and a portion or the whole of such minute tissues are easily injured. In bad cases of strain, considerable tumefaction or swelling is observed. This is occasioned by the presence of serum, or water, in the cellular tissue beneath the skin. If proper means are adôpted, this fluid can be taken up by the absorbent vessels, so as to leave no enlargement; but if the case be badly treated, the enlargement becomes organized into a permanent, hard mass, which is known to medical men as induration.

Treatment of Strain. - The very best and cheapest remedies in the early stages of strain are rest and cold water. This very soon lessens the vascular excitement; and, if there is no laceration, the animal will soon get well. It will be necessary to shower the sprained spot two or three times per day, until the acute symptoms have subsided. Then a common bandage may be applied. This should be wet with vinegar occasionally. Should the strained part be very painful, I would foment with infusion of hops, - a handful of hops to a quart of boiling water, - to be applied when cool. If this does not relieve the pain, let the part be occasionally sponged with a small quantity of sulphuric ether, or chloroform. 


\section{FARCY.}

This disease is very rare among neat stock, and those cases which have been recorded appear to have taken place when there has been no known communication with an infected animal; consequently, this affection has sometimes a spontaneous origin. The animals thus affected were of the lymphatic temperament.

This disease first appears in the form of slight elevations, running in lines, called corded lymphatics, known also as "farcy buds." These finally break and form ulcers, which discharge unliealthy matter. From the comimencement of the disease the animal is continually losing flesh, and, on moving about, shows symptoms of pain, indicating that the deep-seated, as well as the superficial absorbents, are affeeted. When this disease arises spontaneously, it is probably owing to some morbid habit of body, occurring in an animal inheriting some predisposition to suppuration of the absorbents.

Treatment. - When the tumors acquire magnitude and feel soft, they should be opened with a thumb lancet; then, after sponging and cleansing, wet them with pyroligneous acid, and cover the exposed surface with powdered bloodroot. The constitutional treatment, however, is most important; for, unless we can counteract the morbid tendency, and improve the general health, there are very little hopes of recovery. The constitutional remedies are as follows:-

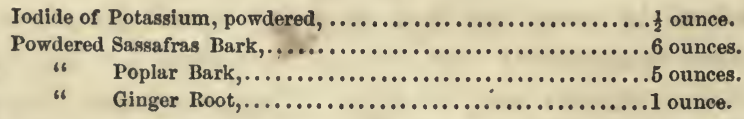

Thoroughly mix the above, and divide it into twelve equal parts. Dose, one part every morning, in food or gruel. Every night let the patient have four ounces of cod-liver oil. Should the bowels become too lax, discontinue the oil.

Let the animal have whatever kind of food it seems inclined to eat. 'There may, however, be loss of appetite. If this be the case, I should bottle down a few quarts of oatmeal gruel as often as necessary, and give a drachm of powdered goldenseal, night and morning. 


\section{SPLENIC APOPLEXY.}

A past student of mine informs me that he lately attended an ox, the property of a gentleman residing in the town of Palmyra, Maine. The animal was suddenly seized with abdominal pains, of a colicy character, in consequence of which his services were secured. On visiting the patient, he found him laboring under the following symptoms:- Pulse quickened and wiry; the visible surfaces of the mouth, nose, and eyes were reddened; horns and extremities chilly; excrement soft, slimy, and slightly tinged with blood. The animal appeared to suffer from abdominal weakness, was very unwilling to move, and stood with its back slightly arched. He applied external irritants, gave diffusable stimulants, and friction was applied to all parts of the body ; but it was of no use ; the extremities still continued cold. At the expiration of fourteen hours from the period of attack, the animal died. The autopsy revealed rupture of the spleen and a highly congested state of the bowels.

I have just had the pleasure of perusing an article on splenic apoplexy, published in the Edinburg Veterinary Review, which I think is calculated to throw some light on a subject but little understood. The article referred to reads as follows:-

"Splenic Apoplexy. - This disease broke out in the winter of 1857-58, on a farm characterized by its extreme richness of soil, in the north of Northumberland. Last January, the malady reappeared, and did not cease until twenty-three head of cattle had been seized.

"Splenic apoplexy is a malady that has hitherto not been observed in the north of Britain, and its occurrence recently is evidently to be attributed to the special method of farming and feeding stock where it has for the last two years proved so destructive.

"The farm is a peculiarly dry and healthy one. About 300 head of cattle are annually fattened on it. One lot were made ready by Christmas, and sold as fat beef in Newcastle; a 
second lot kept rather back until January, when they were allowed an abundance of turnips, especially swedes, meals, and the best oat straw. The cattle affected are three-year-olds; and it would appear that those fed on the Swedish turnips, especially from one field, have suffered most; but some fed on yellow or white turnips have been affected, and we would regard the meals, and perhaps the oat straw, as more likely to have produced the disorder. According to Delafond's researches, leguminosæ, or forage very rich in nutritive principles and deficient in water, from artificial pastures, are frequent causes of splenic apoplexy. The farmer in Northumberland suspected the artificial manures last year, and therefore dressed his land chiefly with home manure; but the properties of the last crop have proved as deleterious as those of the preceding one.

"The malady stopped suddenly, about the middle of February, and this was probably due to the cattle suffering only when the system was taxed by change from rather moderate to very high feeding. It is an interesting fact, that, in cows, the disorder only affects those which are approaching the period when the secretion of milk is stopped, and when there is a tendency to lay on flesh. Being then liable to plethora, cows fed on food capable of producing splenic apoplexy die from it. Change of diet proved of no avail at the farm above referred to, and common salt had been recommended as a preventative. But, as Delafond has shown, it is not a remedy in such cases, - rather the reverse, - and thus it proved in the case referred to. The malady stopped spontaneously, and the point now to settle is prevention of the disease during future seasons.

"For the benefit of our readers, who may not know the symptoms of splenic apoplexy, we may mention that often there are premonitory signs - the animals apparently enjoying the best health early in the morning may be dead some time before noon. Sometimes there are symptoms of excitement; the eyes are prominent and the visible mucous membranes injected. Symptoms of uneasiness suddenly manifest them- 
selves, and colicy pains indicate abdominal disorder. The urine voided is high colored and red, and there may also be blood in the frecs. The back becomes arched, and the animal fixes itself, hanging on to any thing by which it may be tied in the stall, or pressing back into a corner of the stable or shed in which it may be. The pulse is quick and hard, then feeble and small; the breathing is accelerated and short. The animal soon drops, and is seized with. convulsive twitchings. In addition to the discharge of fæces and urine tinged with blood, there is a red, frothy liquid which escapes from the nostrils; the animal bellows and moans, and soon dies.

\section{BRONCHOCELE.}

Bronchocele is a disease known in common parlance as swelling in the throats of cattle. When it occurs among members of the human family, it is denominated goitre; yet, it is my opinion that bronchocele occurring among cattle, and goitre in man, are very different affections. For example: Bronchocele occurring in cattle is curable, and, so far as I have been able to ascertain, is confined to the thyroid glands, although in a protracted state of the malady the surrounding tissues may become so involved as to render the case incurable. Goitre, as I understand it, is a diffuse tumor occupying the anterior part of the neck, occurring principally among the inhabitants of the Alps, and considered incurable. Medicine and external applications seem to have little if any effect on it, and its removal by operation is generally fatal. The following cases are offered in support of my argument as to curability :-

A couple of cows, the property of Mr. Humphrey, of Brookline, Mass., were observed to be the subjects of an enlargement in the thyroid region, which gradually increased up to the size of a man's fist. At this period, I was requested to see them. The animals were natives; their ages seren and eight; in fair condition, and yielding the usual quantity of milk. The only fault the owner had to complain of, was, that 
their appetites were not so good as usual, and he merely consulted me for the purpose of ascertaining what could be done for the thyroid tumors. On making careful examination of both animals, there was very little of abnormal action to be perceived, either internally or externally; the pulse was regular; respirations normal ; the surface of the body comfortably warm ; coat, glossy; nothing unusual about the fæces nor urine; and all I could say about the cases was, that they were mild forms of hypertrophy of the thyroid glands - enlargement without change of structure. The tumor, in one animal, occupied the right side of the thyroid region; in the other, it was found in the left; both immovable, yet having no morbid adhesions to skin nor sub-tissue.

Treatment of the above Cases. - The owner being unwilling to incur the expense of professional attention, and desiring to treat them himself, under advice, I accordingly prescribed as follows :-

Each animal to have daily ten grains of iodide of potassium in half a gill of water. The tumor to be anointed daily with a portion of the following:-

Simple Ointment,....................................2 ounces.

Iodide of Potassium,..............................2 drachms. Mix.

During a period of seven days each animal got seventy grains of iodide of potassium, and by inunction received one drachm each.

According to the testimony of Mr. Humphrey, the remedy was effective; for at the end of two weeks the tumors had disappeared, and the animals were on the high road to health.

\section{ANALYSES OF COWS' MUK.}

The following analyses of cows' milk was made by a scientific chemist, for a report lately made by the Academy of Medicine in the City of New York. It would seem, by this table, that the variation in quality between summer and winter milk is not so great as might have been expected. 


\section{ANALYSES OF COWS' MILK.}

\begin{tabular}{|c|c|c|c|c|}
\hline & 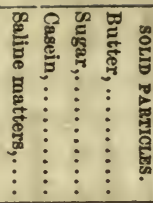 & & 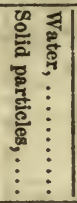 & (1) \\
\hline $\begin{array}{l}\vec{w} \\
\vec{i} \\
\text { is }\end{array}$ & 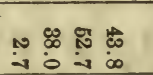 & $\begin{array}{l} \\
\text { है। } \\
0 \mid\end{array}$ & 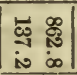 & POGGAILE. \\
\hline $\begin{array}{c}\text { 点 } \\
\text { i } \\
\end{array}$ & 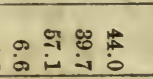 & $\begin{array}{l} \\
\varnothing \\
0\end{array}$ & 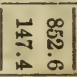 & $\begin{array}{l}\text { Mr. Suydam's cow, kept for use of his family. } \\
\text { DOREMUS. }\end{array}$ \\
\hline $\begin{array}{c}\text { 点 } \\
\text { is }\end{array}$ & 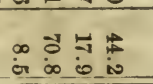 & 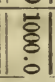 & 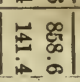 & $\begin{array}{l}\text { Swill-fed cows from Sixteenth st. distillery stables. } \\
\text { BT } \\
\text { DOREMUS. }\end{array}$ \\
\hline | & 苾 & है। & 萑 & $\begin{array}{l}\text { From one of the fattest cows in Sixteenth street } \\
\text { distillery stables. }\end{array}$ \\
\hline 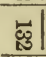 & 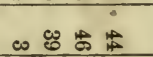 & है। & $\overrightarrow{\mathbb{S}_{3}} \stackrel{\infty}{\&}$ & $\begin{array}{l}\text { From a grass-fed cow on a farm in Westchester } \\
\text { County. }\end{array}$ \\
\hline $\overrightarrow{\mathscr{E}}$ & 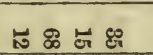 & है & $\begin{array}{cc}\infty \\
\& & 0-1 \\
\end{array}$ & $\begin{array}{l}\text { From Williamsburg distillery stables. Mixed } \\
\text { milk of four cows, milked while I was waiting. }\end{array}$ \\
\hline के & 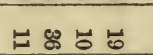 & है & के & $\begin{array}{l}\text { From same stables, obtained from one while on } \\
\text { his route, delivering to his customers. }\end{array}$ \\
\hline 苞 & 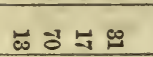 & ह & 芯 & $\begin{array}{l}\text { From same stables, the mixed milk from several } \\
\text { large cooling cans, immediately after milking. }\end{array}$ \\
\hline $0^{-1}$ & $\breve{0} \infty$ & है। & -i \& & $\begin{array}{l}\text { From same stables, obtained from a man while } \\
\text { on his route, delivering to his customers. }\end{array}$ \\
\hline 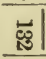 & 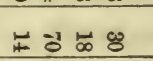 & \& & $\overrightarrow{\mathrm{W}} \stackrel{\infty}{\infty}$ & $\begin{array}{l}\text { From distillery stables } 39 \text { th st. and } 10 \text { th av., from } \\
\text { the cooling cans, immediately after milking }\end{array}$ \\
\hline 事 & 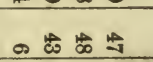 & है। & 点总 & $\begin{array}{l}\text { Country milk from T. Decker, milk dealer in E. } \\
27 \text { th st., obtained while delivering to customers. }\end{array}$ \\
\hline 芯 & 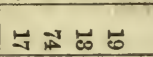 & है। & ț. & $\begin{array}{l}\text { From a sick cow, in the Williamsburgh distillery } \\
\text { stables. }\end{array}$ \\
\hline$\breve{E}$ & 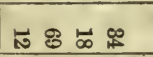 & है। & 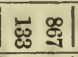 & $\begin{array}{l}\text { From } 16 \text { th st. \& } 10 \text { th av. distillery stables, mixed } \\
\text { milk of four cows, milked while I was waiting. }\end{array}$ \\
\hline$\Rightarrow$ & 훙ㅎㅇ & \&े & $\Rightarrow \mathbb{1}$ & $\begin{array}{l}\text { From same stables, obtained from a man while } \\
\text { on his route, delivering to his customers. }\end{array}$ \\
\hline$\breve{\omega \omega}$ & $\rightarrow$ I & है। & డ & $\begin{array}{l}\text { From D. Baldwin, a milk dealer, obtained while } \\
\text { delivering to his customers. Country milk. }\end{array}$ \\
\hline 点 & 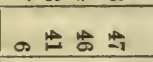 & \&े & 若 8 & $\begin{array}{l}\text { From J. Willets \& Son, obtained while delivering } \\
\text { to their customers. Country milk. }\end{array}$ \\
\hline$=1$ & or 4 出 -1 & हे & 넌 & $\begin{array}{l}\text { From John T. Norton. Farmington, Ct., mixed } \\
\text { milk from six pure Alderney cows. }\end{array}$ \\
\hline$\breve{\omega}$ & or से 曹 & हैँ & $\stackrel{\varpi}{\omega}$ & $\begin{array}{l}\text { Gail Borden, mixed milk from a large number of } \\
\text { cows, before condensed. G. B. }\end{array}$ \\
\hline t: & 。鹿总店 & $\overline{8}$ & 究 & Gail Borden, condensed milk. \\
\hline $\mathscr{E}$ & N & हे & \&్టి \& & $\begin{array}{l}\text { Cream from John T. Norton, Farmington, Con- } \\
\text { necticut. }\end{array}$ \\
\hline हे & 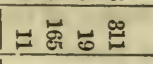 & हे & \& & $\begin{array}{l}\text { Cream from Husted's distillery stables, Brooklyn, } \\
\text { New York. }\end{array}$ \\
\hline 밍 & था जि & हैँ & शै: & Cream from Gail Borden, milk marked G. B. \\
\hline
\end{tabular}


ANALYSES OF WOMEN'S MILK, BY SAMUEL R. PERCY

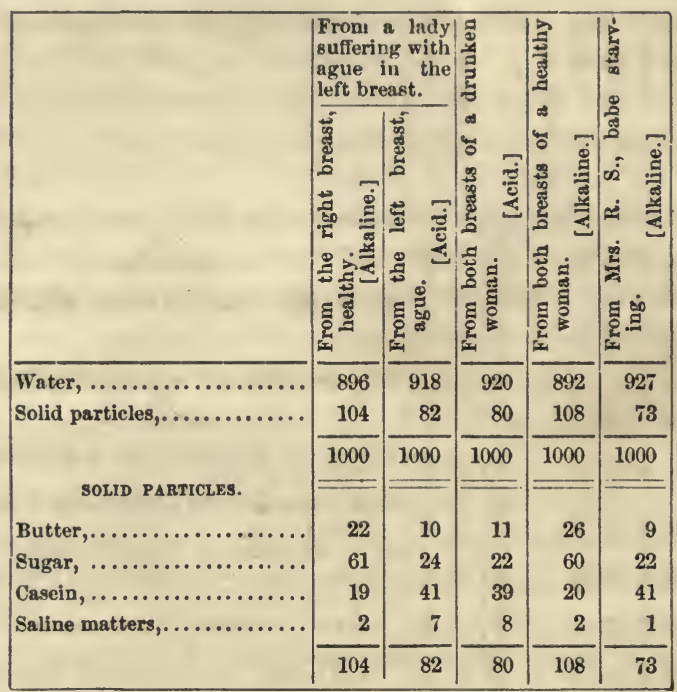

It will be observed, by the above tables, that the milk of a woman and that of a cow do not differ very essentially.

\section{THE EFFECTS OF IMPURE MILK.}

Milk obtained from diseased animals operates unfavorably on the systems of those who partake of it. * I have an impression,

* Deleterious Effects of Swill-Milk. - At the late regular meeting of the Acalemy of Medicine, a report was presented on behalf of the Committee to whom had been referred the matter of preparing a reply to Mayor 'Tiemann's inquiry as to the effect on the human system of the milk of swill-fed cows. The report was read by Dr. Samnel R. Percy. Aecompanying it, was an elaborate statement of the investigations in reference to this subject, in which Dr. Percy has been personally engaged for several months, and which he has pursued with great intelligence and assiduity. This statement shows that the condition in which swill-fed cows are kept, gives undeniable evidence of the poisonous effects of their milk. Their stables, instead of giving forth the healthy aroma of country-fed cattle, are pervaded by a sickening stench. The cows themselves are the victims of disease engendered by the food 
that the milk obtained from a cow located in a city, downcellar location, is just about as good for the purposes of nutrition, as a dose of poison. The.latter may not kill the imbiber outright; just so of diseased milk; it reverses the order of physiology, and places the subject in the vicinity of "death's door."

I am not prepared, at the present moment, to show the pathological effects of diseased milk on the system of man. Yet the following article, selected from The Boston Medical and Surgical Journal, seems apropos:-

"Dr. Parks has had an opportunity of comparing two specimens of human milk under the microscope. An apparently healthy American mother gave up nursing her child, for the double reason of an inflammation of the breast, and because the infant did not thrive upon her milk. A wet nurse whose milk was of the same age was obtained, when immediately the child began to improve, and soon became plump and hearty. After a few weeks, the mammary abscess having departed, the milk of the mother and that of the nurse were examined under a

on which they live. Eighteen pounds of corn and a little straw, given daily, is abundant to keep a cow in good flesh. But to obtain the same quantity of nutritive aliment from swill, 130 gallons of it must be taken daily ; that is, $\mathbf{4 0}$ gallons to supply the nitrogen ; 30 , to supply the oleaginous matter; and 60 , to supply the hydro-carbonate. In taking so much swill, a cow will consume daily one quart of vinegar. In the course of the doctor's experiments, he found that this milk gave a strong acid reaction; and, from a series of results derived from personal observation, he had discovered that the milk of unhealthy women, living in damp cellars and eating bad food, or hahitually intemperate, exhibited the same characteristic. Having thus established, prima facie, his case against swillmilk, the Dr. proceeded to furnish instances in which young children, born of healthy parents and healthy when born, or brought in a healthr condition from the country to the eity, had incurred disease by the use of swill-milk, and recovered when it was withheld from them. He exhibited numerous analyses of different kinds of milk, and various microscopic drawings of swill-milk, showing, in every case, conferves and sporads. These were examined with much interest. The Academy resolved to send an engrossed copy to Mayor Tiemann, and return a vote of thanks to the Committee, who were then discharged. - New York Times. 
microscope. No difference was perceptible in the proportion of milk globules in the two specimens; but the globules in the nurse's milk were some two or three times the size of those of the mother's. This corresponds to what some observers have stated with regard to human milk - that its nutritive properties depend as well upon the size, as upon the number, of its corpuscles."

\section{THE COMPOSITION OF MLK AT VARIOUS TIMES OF} THE DAY.

"Professor Boedeker has analyzed the milk of a healthy cow, at various times of the day, with the view of determining the changes in the relative amount of its constituents. He found that the solids of the evening's milk (13 per cent) exceeded those of the morning's milk (10 per cent); while the water contained in the fluid was diminished from 89 per cent to 86 per cent. The fatty matters gradually increase as the day progresses. In the morning, they amount to 2.17 per cent, at noon to 2.63 per cent, and in the evening to 5.42 per cent. This fact is important in a practical point of view; for while 16 ounces of morning's milk will yield nearly half an ounce of butter, about double this quantity can be obtained from the evening's milk. The casein is also increased in the evening's milk, from 2.24 to 2.70 per cent; but the albumen is diminished from 0.44 per cent to 0.31 per cent. Sugar is least abundant at midnight (4.19 per cent), and most plenty at noon (4.72 per cent). The percentage of the salts undergoes almost no change at any time of the day." - Henle's Zeitschr. fur Rationelle Medicin. - Edinburgh Medical Journal.

MILK WHICH DOES NOT YIELD BUTTER, AND THE REMEDY.

The author's attention was lately called to a couple of native cows, aged five and six years, the property of Mr. H., West Roxbury. The animals appeared to be in the very best condition; had good appetites, and remasticated their food; in fact, I could not perceive any thing about the animals that 
would indicate the least deviation from health; and the only trouble was, the milk did not yield butter. I ordered a small quantity of milk to be drawn from each cow, and, on inspecting it, it appeared to have a light blue tinge, resembling milk when artificially watered. On letting it stand for a short time, there appeared to be a deficiency of the oleaginous or butter-making qualities. The only way I could account for this peculiar condition of the milk was, that it arose in consequence of faulty alimentation. I therefore prescribed a change of diet, from hay, meal, and turnips, to grass and oatmeal. Next day, I furnished the owner a package of medicine composed of the following agents:-

Powdered Poplar Bark,............................6 ounces.

" Phosphate of Lime.........................6 ounces.

" Ginger,...............................

A tablespoonful of this mixture was given to each cow in the food. By the time it was all used, there was no farther trouble. It is probable that these animals might have recovered merely through change of diet, without any medicine; yet as medicine of the above kind is always favorable to health, I do not hesitate to recommend it.

I find in the London Veterinarian a brief translation of a very singular occurrence, which may, perhaps, prove of some value to some of my readers.

"A letter from a farmer states that he had fourteen cows in full milk, from which he obtained very little butter, and that of a bad quality. Guided by the statements of M. Deneubourg, which had appeared in the Annales Vétérinaires, he had separately tested the milk of his cows, and found that the bad quality of it was owing to one cow only, and that the milk of the others yielded good and abundant butter. It was therefore clearly established that the loss he had so long sustained was to be attributed to this cow only. $\mathrm{He}$ at once administered the remedy recommended by $M$. Deneubourg, which effected a speedy cure."

$31 *$. 


\section{SPAYING COWS.}

Before I commence to point out the method of spaying; it may be proper to allude briefly to the female organs of generation.

Uterus, or Womb. - This is a hollow, musculo-membranous organ, united to the front part of the vagina, and terminating beneath the anus, in what is known as the lips of the puden-. dum. The womb is destined for the reception of the foetus. It is situated within the cavity of the pelvis, between the region of the bladder and that of the rectum, and is an organ capable of extraordinary distention.

The womb is divided into body, horns, neck, and mouth. The body is the oblong, cylindrical part, growing out of the front part of the vagina, in the centre of which it terminates, internally, by the mouth of the womb, termed by physicians the os uteri. The front part of the body of the womb, by branching into two divisions, forms the horns; they diverge laterally sideways - towards the front part of the pelvis, and finally terminate in oval extremities, fallopian tubes, and lastly, the testes, or ovaries. The part termed the neck protrudes backward into the vagina, and is only perceptible when the parts are unimpregnated.

The uterus and ovaries are partly covered, and confined to the sides of the pelvis, by a portion of the peritoneun, called broad or lateral ligaments, which also enclose within its folds the fallopian tubes.

The ovaries are two soft bodies, about the size of a walnut, and resembling somewhat in form the testicles of the male. They are filled with little vesicles, or bladders, which can be seen through the surface texture, containing a small quantity of a whitish yellow fluid. These yellow bodies, or spots, termed corpora. lutea, are supposed to contain the ova. The cicatrices, or marks left in the region where the vesicles have burst, denote the number of times the animal has been impregnated. The contents of the ovarian yesicles, from one or both testicles, 
are discharged into the uterus, through the fallopian tubes, and the same is vitalized by the male semen in the act of copulation. So it will be perceived that the uterus has two inlets, coming from the ovaries, and one outlet, which is the lips of the vagina.

The arteries which supply the uterine organs with blood, are named vaginal, uterine, and spermatic. The vaginal is derived from the internal iliac; the uterine, from the external iliac; and the spermatic comes directly from the great aorta.

This brief description of the form, function, and location of the uterine organs, may possibly prove of some value to the husbandmen of this country, who are not expected to be posted on the subject, and cannot spare the time to familiarize themselves with the technicalities of the schools, yet have intelligence enough to comprehend plain matters of fact.

On the Selection of Animals for Spaying. - If the animal be intended for milking purposes, a good milker must be selected, for the operation will not transform a poor milker into a good one. She must necessarily be in possession of those constitutional peculiarities which have been observed to prevail in animals renowned as first-class milkers. The operation will, without doubt, improve the quality of the milk, yet may not, under all circumstances, increase the quantity, although the French dairymen contend that "the cow will be found to give as much milk after eighteen months as immediately after the operation; and there was found, in quantity, in favor of the spayed cows, a great difference." About three years ago, I spayed a cow, the property of a gentleman residing in Southboro. She continued during this period to yield her usual quantity of milk, yet gradually accumulated fat, so that she was known in the neighborhood as the "fat cow." When in this condition, the daily yield of milk gradually decreased, and the owner at last sold her to the butcher. I learned from parties who bought the meat, that it was of superior quality even to that of an ox or steer, and commanded a higher price. Among other animals that I have spayed, several have run to fat, as the saying is, and at the end of from eighteen months 
to three years, fell into the hands of the butcher as first rate beef.

I am, therefore, inclined to think that if animals are predisposed to fatten easily, they will not remain uniform milkers beyond the above period; yet, from a report made by the Rlieims Academy, I learn that this liability to fatten was not observed in the environs of Paris, where, in some milking establishments, one hundred and fifty cows are kept, all spayed except fifteen or twenty. It may happen, however, that in consequence of their not being permitted to go to pasture, and their artificial food, not of the best quality, and perhaps scanty, they do not have enough adipose matter to spare and store away in the fat-cells, as is the case with stall-fed animals in private establishments, where only one or two are kept.

In view, therefore, of securing a permanent milker, I should select a cow of compact muscular organization (native breed), having little, if any, predisposition to accumulate fat; she must be a good milker, and the mother of at least three calves. The best period for spaying is in the spring, when the unimpregnated animal is in her full flow of milk.

If the object of spaying be to furnish the market with fat, tender, juicy meat, then I should select animals, barren or otherwise, that keep in good condition on a small quantity of food. The operation may be performed at any period, from the age of three months to nine or more years.

Mode of Operation. - The principal authority on the modus operandi of spaying is M. Morin, a celebrated French veterinary surgeon. I am not in the habit of performing the operation according to his directions, yet the reader may desire to know how it has been performed in a country where the results have been so remarkably successful. Therefore I introduce the following quotations:-

Morin's Method of Spaying. - "Having covered the head of the cow to be operated on, we place her against a wall provided with five rings, firmly fastened and placed as follows: the first corresponds to the top of the withers, the second to the lower anterior part of the breast; the third is placed a little 
distance from the angle of the shoulder; the fourth is opposite to the anterior and superior part of the lower region, and the fifth, which is behind, answers to the under part of the buttocks. We place a strong assistant between the wall and the head of the animal, who firmly holds the horn in the left hand, and with his right the muzzle, which he elevates a little. This done, we pass through and fasten the end of a long, strong, platted cord in the ring, to the lower part of the breast; we bring the free end of the cord along the left flank, and pass it through the ring which is below and in front of the withers; we bring it down along the breast, behind the shoulders and the angle of the fore leg, to pass it through the third ring; from there we pass it through the ring which is at the top of the back; then it must be passed around against the outer angle of the left hip, and we fasten it, after having drawn it tightly to the posterior ring, by a simple bow knot.

"The cow being firmly fixed to the wall, we place a cord, fastened by a slip-noose, around the hocks, to keep them together in such a manner that the animal cannot kick the operator. The free end of the cord, and the tail, are held by an assistant.

"The cow, thus secured, cannot, during the operation, move forward nor lie down; and the veterinary surgeon has all the ease desirable, and is protected from accident.

"M. Leorant advises that an assistant should hold a plank or bar of wood obliquely under the teats and before its limbs, to ward off the kicks; but this method is not always without danger, both to the operator and the animal, because, at the commencement, - that is, when the surgeon makes the incision through the hide and the muscles, - the cow makes such sudden movements, and tries so frequently to strike with its left hind foot, that it may happen that, upon every movement, the plank or the bar may be struck against the operator's legs.

"On the other hand, although the defence may be firmly held by the assistant, yet it may happen that, in spite of his exertions, he sometimes may be thrown against the operator, 
'by the movements she may attempt, and there may be an uncontrollable displacement of the plank or bar ; and then it may happen that she becomes wounded, and at the same time prevents the operation; while, by the mode we point out, there is no fear of accident, either to the operator or the beast.

"In case of the want of well provided rings, we may use a strong palisade, a solid fence, or two, trees at suitable distances apart. Across, we fix two strong boards of wood, separated from each other, according to the size of the cow.

"There is another means of confining them that we have employed for some time past, where the cows were very strong and irritable, more simple than the preceding, less fatiguing to the animal, less troublesome to the operator, and which answers perfectly. It consists -

"First. In leaving the cow almost free, covering her eyes, lolding her head by two strong assistants, one of whom seizes the nose with his hand, and strongly pinches the nostrils whenever the animal makes any strong movement during the operation.

"Second. In causing another assistant to hold the two hind legs, kept together by means of a cord passed above and beneath the hocks. This assistant also holds the tail, and pulls it whenever the animal seeks to change its place.

"The cow being conveniently disposed of, and the instruments and appliances (such as curved scissors, upon a table, a convex-edged bistoury, a straight one, and one buttoned at the point, suture-needle filled with double thread of desired length, pledgets of lint of appropriate size and length, a mass of tow in pledgets, being collected in a shallow basket held by an assistant), we place ourselves opposite to the left flank, our back turned a little towards the head of the animal; we cut off the hair which covers the hide in the middle of the flanks, at an equal distance between the back and hip, for the space of thirteen or fourteen centimetres in circumference. This done, we take the convex bistoury, and place it open between our teeth, the edge out, the point to the left; then, with both 
lands, we seize the hide in the middle of the flank, and form of it a wrinkle of the requisite elevation, and running lengthwise of the body.

"We then direct an assistant to seize, with his right hand, the right side of this wrinkle. We then take the bistoury, and cut the wrinkle at one stroke through the middle. The wrinkle having been suffered to go down, a separation of the hide is presented of sufficient length to enable us to introduce the hand. Thereupon we separate the edges of the hide with the thumb and fore finger of the left hand, and, in like manner, we cut through the abdominal muscles, the iliac (rather obliquely) and the lumbar (cross), for a distance of a centimetre from the lower extremity of the incision made in the hide. This done, armed with the straight bistoury, we make a puncture of the peritoneum, at the upper extremity of the wound; we then introduce the buttoned bistoury, and move it obliquely from above to the lower part, up to the termination of the incision made in the abdominal muscles. The flank being opened, we introduce the right hand into the abdomen, and direct it along the right side of the cavity of the pelvis, behind the paunch and underneath the rectum, where we find the horns of the uterus. After we have ascertained the position of these viscera, we search for the ovaries, which are at the extremity of the cornua, or horns (fallopian tubes), and when we have found them, we seize them between the thumb and fore finger, detach them completely from the ligaments that keep them in their place, pull lightly, separating the cord and the vessels (uterine or fallopian tubes) at their place of union with the ovarium, by means of the nails of the thumb and fore finger, which presents itself at the point of touch; in fact, we break the cord, and bring away the ovarium.

"We then introduce the hand again in the abdominal cavity, and proceed in the same manner to extract the other ovarium.

"This operation terminated, by the assistance of a needle we place a suture of three or four double threads, waxed, at an equal distance, and at two centimetres or a little less from the lips of the wound; passing it through the divided tissues 
we move from the left hand with the piece of thread; having reached that point, we fasten with a double knot. We place the seam in the intervals of the thread from the right, and, as we approach the lips of the wound, we fasten by a simple knot, being careful not to close too tightly the lower part of the seam, so that the suppuration, which may be established in the wound, may be able to escape.

"The operation effected, we cover up the wound with a pledget of lint, kept in its place by three or four threads passed through the stitches, and all is completed.

"It happens, sometimes, that in cutting the muscles of which we have before spoken, we cut one or two of the arteries, which bleed so much that there is necessity for a ligature before opening the peritoneal sac; because, if this precaution be omitted, blood will escape into the abdomen, and may occasion the most serious consequences."

Improved Method of Spaying. - I cast the cow, by means of the hobbles (see cut of instruments), on her right side. I then apply to the nostrils a sponge, saturated with concentrated sulphuric ether. After having rendered the animal completely unconscious, I slacken the casting rope, so as to free the limbs, and prevent any pressure on the walls of the abdomen. By so doing, I secure room enough to introduce a hand and arm, for the purpose of searching for the ovaries.

The first stage of the operation consists in pinching up a fold of the skin on the left side, midway between the prominent bone of the haunch, or pelvis, and the last, or posterior rib, about four inches below the transverse processes of the lumbar (back) vertebræ. (See cut preceding article "Gut-tie.") Having divided the integuments, to the extent of about five or six inches, I make a similar incision through the abdominal muscles, until the peritoneum (lining membrane of the abdominal cavity) is exposed. This membrane is then punctured by means of a beak-pointed bistoury, into which puncture 1 insinuate a knife having a probe point, and then divide the peritoneum to the extent of the external incision.

The second stage of the operation commences with the 
introduction of the operator's right arm, he kneeling down in close contact with the cow's back. The hand is then passed within the brim or cavity of the pelvis. Having found the deepseated or right ovary, it must be removed by laceration. I find that the best and most expeditious way is, to slip the other hand into the abdominal cavity; then with the right $I$ seize the broad ligament at the base of the ovary; my left then clasps the ovary, and in this way, by using trifling force, the ovary is detached or torn away. The left ovary is then to be sought for, and an assistant depresses the edges of the incision. At the same time the operator, having a firm hold on the ovary, brings it into view, so that it can be removed by means of a pair of blunt-pointed scissors.

The third stage of the operation is the process of uniting the abdominal muscles, by means of stitches or sutures. A curved needle, armed with four or five threads of shoemaker's twine, well beeswaxed, is to be passed through the abdominal muscles, without penetrating the peritoneum (lining membrane of the abdominal cavity), at interrupted distances of one inch, more or less. Each suture is to be securely tied; one end of the same is to be cut close to the knot, the other is left long enough to protrude through the integumental incision. The skin, or integument, is then to be closed by means of ligature or metallic wire, leaving a small orifice at the inferior or lower region of the external incision, for the escape of morbid matter. This completes the operation. In the course of a week or ten days the deep-seated ligatures may be pulled away, and when the integument is well united, the external stitches may also be removed. The wound is healed by nature, and scarcely, if ever, requires any sort of dressing.

Since writing the preceding, I have received the two following letters :-

"Newton Centre, June, 1859.

Dr. DAdD. Dear Sir:-In reply to your inquiry respecting my cow, I would remark that this is the third summer since you performed the operation of spaying; and she 
has continued to give milk ever since, varying from seven to sixteen quarts per day, according to the season. At the present time she averages about ten quarts per day. The quality of the milk is superior, and peculiarly adapted as a diet for young children. Several cases have occurred under my own observation, where children accustomed to use common cow's milk, and seeming to be suffering from some unknown cause, have improved immediately on the use of the milk from the spayed cow. This fact being established, a good reason is given why every family having children, and keeping cows, should have the operation performed upon one of them.

"My cow begins to increase in flesh, and I presume the quantity of milk will decrease proportionately. But I see no reason why she should not continue to give milk a year or two longer, at the end of which time she will be in a superior condition for beef, and as such will command the highest market price. "Yours truly,

J_."

A gentleman of Brookline, Mass., writes me as follows :-

"Boston, June 9th, 1859.

"Dr. DADD : - My native cow, "Bessie," upon which you performed the operation of spaying in June last, just one year since, has produced since that time an uninterrupted flow of milk, of the finest flavor and richest quality, from nine to fifteen quarts daily, according to the season of the year and the quality of the food given her; and, strange to say, my fear that she would gradually but certainly grow fat, and her milk proportionately decrease, has not been realized, as she is now leaner than when the operation was performed, notwithstanding that she has been fed in the most liberal manner.

"Where families have young children, and keep but one cow, I consider it a duty they owe to their children to have her spayed; as such milk, from the nature of things, must be more nutritious. As far as one year's experience goes, I should say it is very desirable for any family keeping but one cow, to keep her in this condition.

$$
\text { "Yours, etc., }
$$

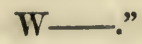




\section{HAIR BALLS.}

In consequence of the propensity which some animals have of licking their own bodies, or those of their associates, they manage to swallow large quantities of hair, which, being indigestible, accumulates in a compartment of the stomach in the form of a dense ball, which is occasionally regurgitated. I know of no remedy calculated to obviate the difficulty, except those agents which preserve the tone of the stomach, bitters and alkalies; for the creature which prefers to swallow hair, in preference to the ordinary agents known as food, is evidently the subject of a morbid appetite, and prevention in such cases is the better part of cure. Many valuable animals are lost in consequence of these hair-ball accumulations.

I am informed that in the city of Louisville, Kentucky, a "singular mortality among the city cows running upon the Common, has prevailed in that city in the early part of this winter, the cause of which has been pretty satisfactorily traced to their eating hair that remained in the grass where the hogs' hair from the slaughter-houses had been spread, to be washed by rains and dried in the sun. The effect upon the earth, after the hair was removed, was to fertilize it, and cause the grass to grow luxuriantly, which attracted cattle; and, while cropping the grass, they took in considerable quantities of fine hair, the natural tendency of which is to become felted together and massed into one or more hard balls, which were, in the days of New England witchcraft, called "witch balls," and not a few people at this day believe that such is their origin. These balls sometimes accumulate material until they are bigger than ordinary sized goose eggs. It is not surprising that death ensues from the irritation of such an indigestible mass in the stomach of an ox or cow, and it is also not surprising that many deaths of cattle cannot be accounted for by their owners. But the certainty that such causes do produce death, should act as a caution to cattle owners. Some years ago, the same cause existing at Louisville killed a number of cows at Terre Haute, Indiana, and, upon opening the stomachs, it 
was found that not only one or two balls had formed, but a mass of them, that nearly filled the whole cavity of the stomach."

\section{EFFECTS OF SALT ON ANIMALS.}

The experience of the husbandmen of this and other countries, is, that no animal can live without salt, and the inhabitants of the Celestial Empire are of the same opinion in regard to man. They being more experienced than we in this matter, have demonstrated, beyond the possibility of a doubt, that to deprive a man of this necessary condiment, for any great length of time, is equivalent to a sentence of death. Hence, in the Chinese Empire, many persons convicted as felons are doomed to a deprivation of salt, and it has been observed that such unfortunates are finally so infested with intestinal parasites, that they succumb to the most horrible of all deaths - they die by inches.

A short time ago, a contributor to the "Water Cure Journal" concocted a readable, yet one sided, argument in view of demonstrating the poisonous effects of salt. He pitches into the time-honored custom of salting food, after the following fashion :-

"But, says one, salt is good for cattle. Let us see. Suppose that a eow that has never taken any poison should have salt mixed with her food. Her system, never having been injured by poison, will be keenly alive to so destructive a poison as salt, and her vital powers will be vigorously aroused to expel it, which will cause her to eat more than usual. A reaction will follow that will restore the equilibrium, if it be allowed to do so ; and until it shall, she will not need and consequently will not relish food, unless salt or some other poison be added to it, which will again arouse her powers; but not so intensely, for her vital energies were injured by the previous preternatural excitement. After awhile, salt will be insufficient to arouse her debilitated powers, and then, as our allopathic friends would say, she will need something stronger to improve her 
poor appetite. Cattle are benefited about as much by taking salt, as men are by taking tea, coffee, liquor, tobacco, opium, spices, and salt-one and all causing temporary excitement and permanent debility, disease and premature death. The use of salt can be defended only on allopathic principles, which require one to be stimulated with poison so long as life shall last, always increasing the stimulant, poison, according to the sluggishness of the system. If this will not cause premature death, we know not what can.

"Nothing can be more unnatural than to mix poison with food, and yet nothing is more common."

The writer probably proposes to furnish, in the form of " simon pure," a universal panacea for the cure of all diseases. Water is unquestionably one of the indispensables in the treatment of various forms of disease; but, that it is indicated in every form, I do most emphatically deny; and I consider the promulgation of such a theory as fatal to the success of hydropathy. The writer is down on drug-doctors, butchers, bakers, and, in fact, every other individual in any way engaged in catering for the wants of the "inner man." According to his mode of reasoning, about every thing a man eats is poison. He informs us that "salt is the most injurious poison in common use." This is just what a wiseacre of a physician once affirmed of tea, in the presence of an aged lady who had drank it all her lifetime. She observed that it was a "very slow poison; for she had partaken of it for ninety-nine years, and now could play rough and tumble with him, without asking 6odds." " I do not understand what the writer's definitions of poisons are; but when he undertakes to show that salt is poisonous, and operates injuriously on a class of animals that come under the especial jurisdiction of veterinary science, I, as one of its votaries, enter my protest against unsupported facts.

Mr. Morton, the author of a valuable text book on " Pharmacy," lecturer on Veterinary Materia Medica, at the "Royal Veterinary College," speaks of salt as one of the bounties of creation. "The diffusion of so valuable, indeed indispensable, 
an agent to man, evidences both the wisdom and design of Him who, having made all things, pronounced them 'very good.' On all the ruminata, the influence of this agent (salt) is marked; nor are the carnivora less benefited by it. In fact, it appears to be the natural stimulus to the digestive organs of all animals." Mr. Morton's opinion is worth more than that of a hundred speculators, ashamed to sign their own name, but who screen themselves under initials. There exists no analogy, as the writer would have us believe, between a natural stimulus and a manufactured one; the former induces no subsequent depression of vitality, but preserves its identity; the converse is the case in the use of the latter.

Mr. Youatt, whose opinion is also entitled to the greatest respect, states that "there is no remedy for the rot in sheep, that is of the slightest avail, in which salt is not the principal agent."

Animals that are permitted to roam in the salt marshes are generally the most healthy; they consume a large amount of saline material. The antiseptic properties of salt are too well known and appreciated by our husbandmen ever to be disregarded; and the farmer might as well think of dispensing with food altogether, as to think of failing to season fodder with salt. No animal can long exist without it; in the stomach it operates favorably, on the liver it has a physiological action, and it also prevents the food from running into fermentation.

The idea of salt being a "destructive poison," is so very absurd that it does not seem to require refutation; and it is only in consequence of finding such matters occupying the pages of a respectable journal, that $I$ have been induced to notice them. 


\section{FLUID EXTRACTS}

\section{OF MEDICINAL PREPARATIONS USEFUL IN CATTLE PRACTICE.}

(NEW REMEDIES.)

During the past few years I have employed extensively, the fluid extracts of vegetable medicinal agents, and $I$ am satisfied that they possess many advantages over other vegetable preparations. They appear to possess uniformity of strength, are very convenient to administer, and produce their peculiar effects in small doses, and when the bottles are properly corked, the contents will keep for any length of time. These remedies can be procured in almost every large town in the United States, and I advise husbandmen to keep a few of the most useful on hand. From the following list a selection of necessary and useful articles can be made. They are all safe and efficient, and will never be likely to do any harm, when used with discretion.

Fluid Extract of Bloodroot. - This article is used in chronic pulmonary affections and consumption. It is a nauseating stimulant, and, in consequence of its nauseating properties, it promotes diaphoresis. It should be given in some kind of mucilage. Dose, thirty drops, twice daily. When prescribed for consumptive patients, it may be given in three ounces of cod-liver oil.

Fluid Extract of Cayenne. - This is a very useful preparation, destitute of the very irritating properties which follow the exhibition of the crude powder. It is a powerful and pure stimulant, useful in all diseases attended by prostration or loss of strength. It is also a remedy of great value in typhoid affections, putrid sore throat, and in all diseases of a low type, or where there is a tendency in any part of the system to mortification. Dose, from twenty to sixty drops, diluted with half a pint of water. 
Fluid Extract of Chamomile. - I have found this medicine of great value in chronic diseases of digestive origin. It is used principally for its tonic properties, hence is indicated in all cases of debility, convalescence after an acute attack, and in view of restoring the appetite, when the animal is said to have lost its cud. Dose, from one to three fluid drachms, undiluted.

Fluid Extract of Cubebs. - This preparation is a reliable one in the treatment of chronic catarrh, nasal gleet, purulent ophthalmia, diarrhœa in cattle, and scouring in calves.

Dose, one to two fluid drachms; for a calf, half a drachm, twice daily. This medicine should be given in a small quantity of mucilage or honey.

Fluid Extract of Ginger. - This is a valuable carminative and stimulant. Its properties, however, are too well known to need description here. It is used in doses of from one to two drachms, in a pint of hot water, for gastric distress, flatulency, or tympanites.

Fluid Extract of Hops. - The properties of this extract are narcotic and sedative, hence $I$ recommend it as a substitute for the famous narcotic, opium, also for the popular sedative, hellebore, etc. Dr. Matou has observed that, besides allaying pain and producing sleep, it reduces the frequency of the pulse. The pulse has been reduced from ninety-six to sixty, in the course of a few hours after the exhibition of a few doses of a preparation of hops. I have found it exceedingly efficacious in allaying pain in diseases of an acute character. A couple of ounces, mixed with a quart of tepid water, makes an excellent fomentation for painful swellings of joints. Dose, as a narcotic and sedative, from one to two drachms, twice or thrice a day.

Fluid Extract of Mandrake. - This is a substitute for the now unpopular remedy, calomel. It is supposed to act 
upon the system like mercury, yet does not create a medicinal disease, nor does it tend to convert the patient into a walking barometer, as is often the case when the preparations of mercury are administered.

In cases of functional derangement of the liver, a condition of the animal which may be known by a yellow tinge of the membrane of the mouth, etc., I administer it as an alterative. Dose, a tablespoonful every other day, until the bowels respond to its action.

A full dose. - One ounce will generally operate as a cathartic, but as it is apt to produce griping pains, I prefer glauber salts when a cathartic is indicated.

Fluid Extract of Matico. - This is a reliable agent in the treatment of chronic indigestion. It is an excellent tonic and aromatic, and will increase the appetite and promote digestion. Dose, from one to three drachms, morning and evening. The powdered leaves are used for the purpose of arresting internal and external hemorrhages. Dose, for internal hemorrhages, one drachm. Externally, it may be applied ad libitum.

Fluid Extract of Scullcap. - A valuable nervine and antispasmodic. Its remedial power depends chiefly on its essential oil, which the extract contains in solution. It is indicated in all diseases of a spasmodic character. Dose, from one to three fluid drachms.

\section{REMARKS ON CLYSTERS}

In the treatment of diseases of cattle, I recommend the more general use of clysters; for I find that they generally have a very good effect, and seldom, if ever, do harm. They not only serve to evacuate the contents of the rectum and large intestines, but also to introduce nourishment into the system when the animal is unable to take any by the mouth.

In diseases of the brain, and other anterior parts of the 
body, of an acute character, a good stimulating and laxative clyster relieves the parts inflamed, and tends, to a certain extent, in equalizing the circulation.

The bowels being the seat of inflammatory action, clysters of tepid water are therefore indicated; they act as aqueous relaxents and local fomentators; consequently, when administered with discretion, are always salutary.

\section{FORMULA OF CLYSTERS.}

\section{Emolient Clyster.}

Take of powdered slippery elm, one ounce; tepid water, sufficient to form a thin mucilage.

As a substitute for slippery elm, use flaxseed, powdered marshmallow-root, gum arabic, or Iceland moss. This form of clyster is indicated in all cases of inflammation of the intestinal canal.

\section{Laxative Clyster.}

Powdered Mandrake,..............................2 ounces.

Soap-suds,.......................................

\section{Another.}

Croton Farina. 2 scruples.

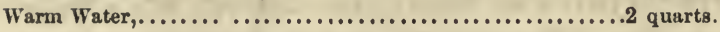

A laxative clyster must necessarily be administered when the faces appear hard and blackened.

\section{Anodyne Clyster.}

Tincture of Indian Hemp, ........................1 ounce.

Warm Water,.................................. quarts.

This clyster is used in cases of painful spasm of the bowels, gut-tie, etc.

Stimulating Clyster.

Pure Jamaica Ginger, ................................

Warm Water,..................................... quarts.

This clyster is indicated in cases of torpidity of the bowels; it excites in them physiological action, and tends to restore their lost function. 


\section{Diuretic Clyster.}

Oil of Cedar .1 ounce.

Infusion of Flaxseed. 2 quarts.

This form of clyster is used with decided advantage in all chronic diseases of the urinary organs, red-water, etc.

\section{Astringent Clyster.}

Powdered Bayberry Bark 1 ounce.

o Charcoal,.................................2 ounces.

Carbonate of Soda, 4 drachms.

Thin Flour Gruel, .2 quarts.

Useful in diarrhoea, and scours in calves. To be injected into the rectum, in small quantities, and often.

\section{Nourishing Clyster.}

Milk porridge is probably the best form of nourishing clyster which can be used. This should be thrown into the rectum, a quart at a time, several times during the day.

The following article, on the absorption of medicinal substances, is worthy the reader's attention.

M. Briquet has paid much attention to the study of the absorption of medicinal substances introduced into the large intestines by means of clysters, and the following is the result of his conclusions:-

"1. The fluid constituting the injection may easily reach as far as the cœcum, and consequently, may be brought into contact with a very large extent of absorbing surface. 2. The mucous membrane and the fluids that bathe its surface do not exert any chemical action upon the substances so introduced into the large intestine, where all that is absorbed is that which was previously in a state of solution. 3. When a clyster of the soluble salts of quinine, in doses less than 15 grains, is administered, rather more than a third of the quantity so ad. ministered is eliminated, and has consequently been absorbed. 4. When larger doses are administered, they are ill-supported, and only a fifth or a sixth of the quantity is absorbed. 5 . In whatever dose the quinine may have been given, it generally gives rise to cerebral symptoms, only very slowly, and to a slight degree. 6. Traces of elimination, and consequently of 
absorption, are only met with an hour after the administration of the clyster, and even then the elimination is usually short two or three days at the utmost. 7. The greater or less dilution, within certain limits, the more or less viscous nature of the liquid, or the addition of the salts of morphine to the chinchona alkaloids, do not exert any sensible modification of the absorption. 8. Absorption takes place more readily in the young than in the adult, and is performed with difficulty in the aged of either sex.

" 9 . The salts of quinine, administered in clysters, in doses of less than 15 grains, exert the same effect as when given in moderate doses by the mouth, and may be very well substituted for these. 10. But this is not the case with large doses, which are never absorbed in sufficient quantities to produce energetic effects. 11. The large intestine will rarely tolerate a larger dose than 30 grains of the sulphate.

"12. These conclusions more or less exactly apply to the various substances administered by clysters. 13. The apyretic is notably more favorable to the absorption of medicinal substances than the pyretic condition. 14. The typhoid condition favors such absorption less than other states of phlegmasia. Nevertheless, it is more energetic than hitherto supposed, being only about a tenth inferior to the absorption taking place in the pyretic condition. 15. In diabetes, the absorption of medicinal substances appears to be very feeble in the intestine. 16. In certain diseases, the tolerance or intolerance of medicinal substances may depend upon a special susceptibility rather than upon variations in absorption. Thus, in hysteria, the tolerance of opium nowise depends upon an absence of absorption, but results from a special susceptibility. 17. The rapidity with which medicinal substances, such as salts of quinine, are eliminated, is in a direct ratio with the quantity of urine passed. This rapidity is the exact measure of time which the economy takes to rid itself of the greater part of fixed substances taken medicinally. 18. The absorption of medicinal substances, analogous to the salts of quinine, is far more rapid in the young. 19. It is less active in females 
than in males, in the proportion of a sixth to an eighth. 20. Abstraeting from a medicinal effect the portion due to the quantity of the substance absorbed, and the remainder gives the measure of the susceptibility of being influenced by the medicinal substance. - Buletin de Acad., tom. xxii, pp. 237, 1273; and Medieal Times Gazetre.

\section{MISCELLANEOUS RECIPES.}

\section{Tonic and Alterative Drench.}

Infusion of Camomile, 1 quart.

Powdered Kandrake, 1 drechne.

Mix, and drench by means of a bottle.

The above is a very excellent preparation for various chronic diseases of the digestive organs, liver included. It acts as a tonic and alterative, and in cases of want of condition or unthriftiness, and in many cases of cutaneous diseze, it is an. invaluable preparation.

\section{A Valaable Disinfectant.}

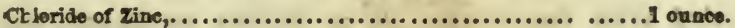

Rain Water, .......................................1 gallon. Mix.

This remedy absorbs or neutralizes unwholesome odors that accompany epizoötic and infectious affections. It is a very excellent remedy for disinfeeting stables in which glanders or farcy may have prevailed. Every thing within the stable should be washed with it. When an unpleasant smell exists, hang cloths about the stable saturated with the solution.

\section{Refrigerating and Sedative Lotion.}

Hydrochlorate of Ammonia (Sal Ammoniach................. eunce.

Nitrate of Potases, .................................... ounce.

Water, .......................................................1 quart.

Alcohel, ...................................................... t pint.

A cloth may be dipped into this mixture, and loosely tied over the inflamed parts. So soon as it beeomes dry, it should be again swetted. Having continued the application of the 
above until the heat and tenderness have disappeared, the tumefaction, if any remain, will generally disappear by making a few applications of the following:-

Glycerine, 1 ounce.

Iodide of Potassium, ........................... drachms.

Mix. Smear the tumor with a portion of this, twice daily.

In chronic cases of long standing, the oil of cantharides is, probably, the best remedy, several applications of which may be needed before the tumor disappears.

\section{To Protect Animals against Flies.}

Take four ounces of walnut leaves, and four quarts of boiling water; when cool, strain and add a gill of tincture of aloes. This may be applied to the body, lightly, by means of a sponge, as often as necessary.

\section{Tincture of Matico.}

To one pound of matico leaves add one quart of Bourbon whiskey; macerate for fourteen days, and pour off the clear liquor. Matico is said to possess marvellous medicinal properties. It is a fine carminative stomachic. Hence I recommend it in cases of derangement of the digestive organs, especially if attended with flatulency. It is slightly astringent, and also possesses the property of coagulating the blood; consequently is a good remedy in hemorrhages of any and every kind. I have used it with excellent results in sore throat, catarrh, nasal gleet, and diarrhœa. The dose is one ounce, two or three times per day. It should be diluted with a small quantity of water.

The leaves, powdered, arrest local hemorrhage, and aid in the healing of wounds.

Matico is obtained from the interior of Peru. Dr. Royle states that - "Its properties, by analysis, appear to depend chiefly on its resin and volatile oil, its aqueous extract having only a slightly bitter and astringent taste.

"It has also been prescribed in discharges of blood from the urethra and rectum, as well as in uterine hemorrhage, and has 
been used as an injection in leucorrhœa, and as an external application to piles, both as an ointment and as a lotion."

Liniment for Acute Lameness.

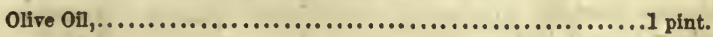

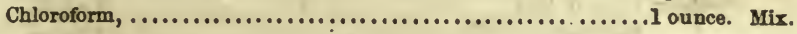

Liniment for Indolent Swelling in the Region of Joints.

Glycerine,..............................................4 ounces.

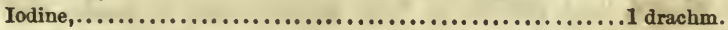

Spirits of Ammonia, ................................

A portion of this may be rubbed over the swollen part, morning and evening.

\section{Parturient Drench after Protracted Labor.}

Tincture of Matico, ....................................1 ounce.

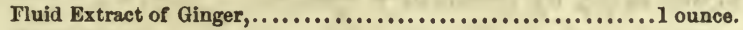

Warm Water, ....................................

Antidote for the Bite of Venomous Reptiles.

Bathe the part with a strong infusion of lobelia, or plantain. leaves.

\section{Fever Drench.}

Liquor Acetate of Ammonia, .4 ounces.

Water,............................................ quart.

This is an excellent febrifuge for cows, when thirst is urgent and the appetite is impaired.

\section{Remedy for Scouring in Calves.}

Phosphate of Lime,..............................1 ounce.

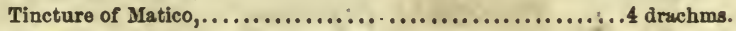

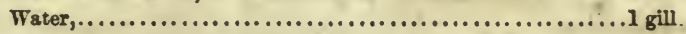

Drench, and repeat the dose if necessary.

\section{Remedy for the Cure of Itch and Mange.}

Take one part of quicklime, two parts of sublimated sulphur, and ten parts of water; boil them until they are perfectly united. The mixture should be constantly stirred with a wooden spoon or piece of wood. When cool, pour off the clear liquor, and rub a portion of the same into the skin, by 
means of a sponge. Two or three applications will cure the most inveterate cases.

\section{Ointment for Cutaneous Eruptions.}

Sublimated Sulphur, ...................................2 ounces.

Powdered Slippery Elm, ................................

" Bloodroot,.................................1 ounce.

Glycerine sufficient to make the mass of the consistence of ointment.

The eruptions should be smeared once daily, with a portion 'of the above, and before a new application is made, the old should be washed off.

\section{Liniment for Burns, or Stings of Insects.}

Snlphuric Ether, ...................................2 drachms.

Glycerine, ..........................................2 ounces.

Cod-liver Oil, ....................................2 ounces.

Mix, and apply by means of a sponge.

\section{Remedy for Cutaneous Parasites.}

Pure benzole is a specific for parasites. It is a sure cure, and a few applications will rid the animal of all cutaneous pests.

\section{Iodide of Ammonium.}

Take of Iodine, two drachms; Iodide of Potassium, three drachms ; Spirits of Hartshorn, four ounces; Glycerine, four ounces; Tincture of Spanish-Flies, two ounces. This is a valuable preparation for the treatment of deposits on bones; it is invaluable in the treatment of splents, spavin, ringbone, etc.

\section{Tincture of Capsicum.}

Powdered Capsicum .2 ounces.

Water and Alcohol, of each,..........................

Macerate for fourteen days, then pour off the clear liquor. This is a very powerful stimulant, and is indicated in all diseases of a low type, or when the stomach is in a deranged condition. When applied externally it is a good counter-irritant. The dose, as an internal remedy, is from one to four drachms, diluted with water. 


\section{Tincture of Lobelia.}

Lobelia Seeds, .....................................4 ounces

Water and Alcohol, of each, ........................

- Macerate for fourteen days, and then pour off the clear liquor. Dose, as an anti-spasmodic, two drachms, diluted with warm water. So soon as the animal begins to "slaver" at the mouth this medicine must be discontinued.

\section{Liquor Acetate of Ammonia.}

Take of acetic acid, one part; water, seven parts ; carbonate of ammonia sufficient to saturate the acid.

This preparation is made as follows:- Pour the acid and water into a large wedgewood mortar, then add small pieçes of carbonate of ammonia, and pulverize the same in the fluid by means of the pestle; an effervescence immediately commences. Keep on adding ammonia, and pulverize and agitate the same untileffervescenceceases; then pour off the clear liquor into a stoppered bottle, and it is then fit for use. Dose, as a febrifuge and decarbonizer of the blood, four ounces, diluted with a pint of water.

\section{Tincture of Bloodroot.}

Powdered Bloodroot,

Water and Alcohol, of each,...........................

Macerate for fourteen days, and pour off the clear liquor.

This is an excellent remedy as a dressing for canker and footrot. When diluted with water, in the proportion of two ounces of the tincture to sixteen ounces of water, it is the very best remedy that can be applied for opacity or whiteness of the cornea of the eye. In curable cases it is a remedy which was never known to fail.

\section{Tincture of Goldenseal.}

Powdered Goldenseal, .5 ounces.

Water and Alcohol, of each,..........................

Steep for fourteen days, and pour off the clear liquor. Dose, one ounce, to be diluted with water. This is a good tonic and alterative. (See page 426, "Modern Horse Doctor." 


\section{Caustic for Fungous Growths.}

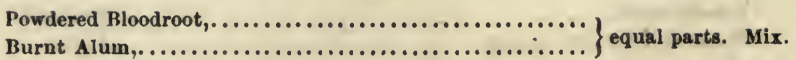

First, rub a small quantity of pyroligneous acid on the fungus, then dust the parts with a small portion of the new caustic, and repeat the application twice daily until the fungus disappears.

$$
\text { Oil of Cantharides. }
$$

Powdered Cantharides, Spanish Flies,......................1 ounce.

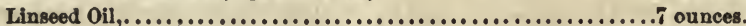

This is a sort of liquid blister, and is far preferable to the common blistering ointment. I recommend it in all cases indicating. a blister

$$
\text { A Cheap Refrigerating or Cooling Lotion. }
$$

Acetic Acid, ........................................2 ounces.

Soft Water, ......................................

This mixture may be applied with advantage to the external surface in all cases of strain, sprain, or cutaneous inflammation. In view of relieving the inflammatory action of the part, it must be diligently applied. 


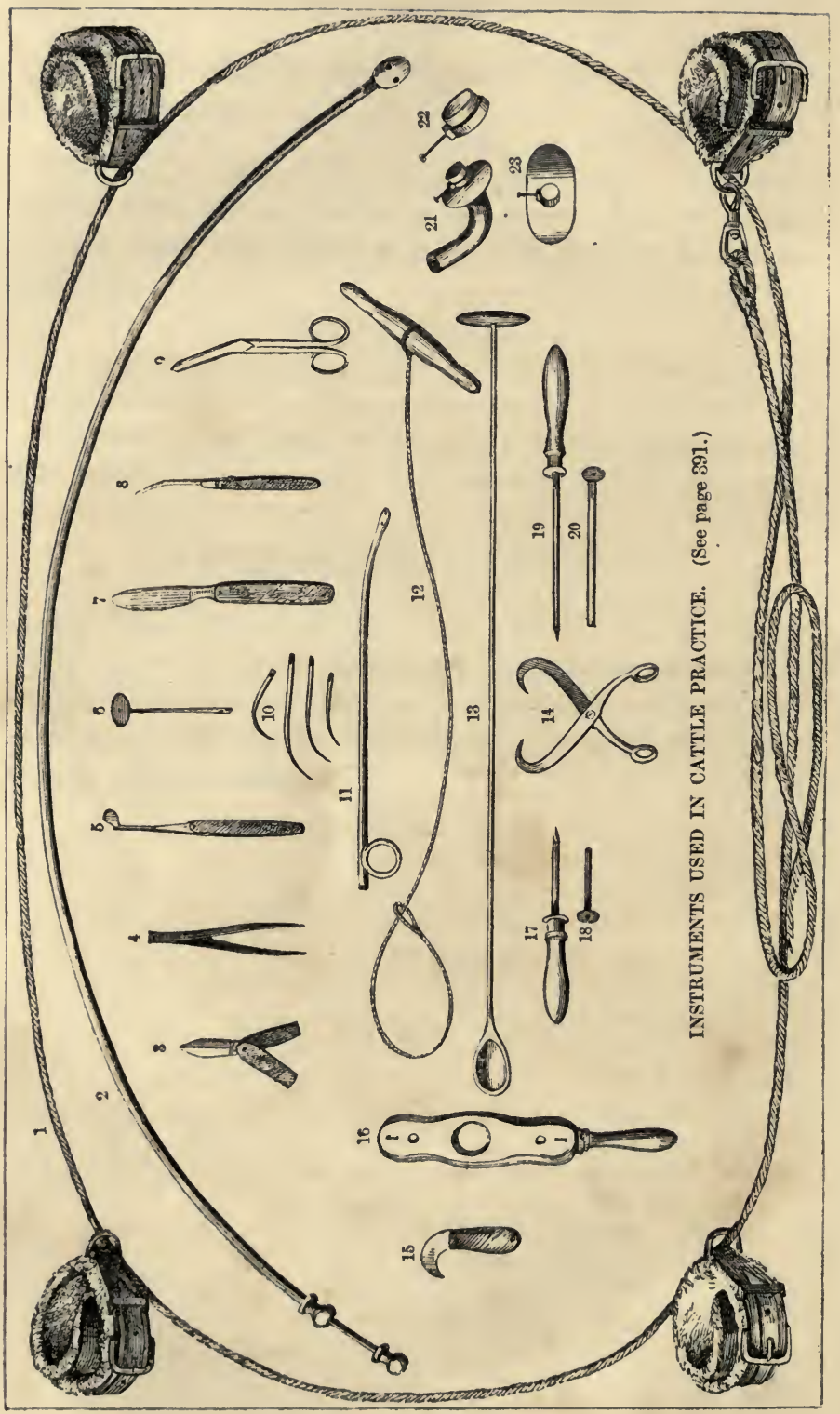




\section{EXPLANATIONS.}

\section{EXPLANATION OF CUT OF INSTRUMENTS.}

(See opposite title page.)

1. Hobbles, or Casting Apparatus.

2. Cattle Probang, used for liberating gas from the stomach, or for pushing downwards substances which may have lodged in the gullet.

3. Thumb Lancet, used for the purpose of opening an abscess, or for bleeding.

4. Dissecting, or Artery Forceps.

5. Gum Scarificator.

6. Tube for Obstructions in Cows' Teats.

7. Knife used in performing the operations of Castrating and Spaying.

8. Bistoury, used in opening the Peritoneum.

9. Curved Surgical Scissors.

10. A Set of Suture Needles.

11. Female Catheter, for evacuating the bladder of urine.

12. Midwifery Tractor, and Slip-Noose.

13. Instrument for reducing an inverted womb.

14. Midwifery Clasp-Hooks, used for the extraction of the foetus.

15. Crainotomy and Embryotomy Knife.

16. Mouth-Gag, used in connection with the Probang.

17. Trocar, used for puncturing the chest in dropsy.

18. This is the Canula, which slips over the Trocar, and conducts the water from the chest when the cutting instrument-Trocar - is removed.

19 and 20 are Trocar and Canula for puncturing the paunch in cases of "hoove," or tympanites.

21. Tracheotomy Tube, used for the purpose of reliering an animal when afflicted with spasm of the larynx, etc., etc.

22 and 23. Two different views of the shield of the tracheotomy tube.

\section{INVERSION OF THE WOMB AFTER CALVING.}

1. The pudendum.

2, 6. Region of the neck of the womb. 
4. Cotylodon, or gland of the womb ; many of which are to be found on the internal surface of the womb, as shown in the cut.

5. The fundus of the uterus. This is the part to which the blunt end of the instrument is to be applied when attempting to return the inverted uterus.

The womb is inverted in the manner represented by convulsive efforts to expel the fœtus."

\section{A VIEW OF SOME OF THE SUPERFICIAL MUSCLES.}

1. Circular muscle of the lips, named orbicularis oris.

2, 2. The muscle which raises the upper lip, termed levator labii superoris.

3. A muscle at the angle of the jaw, which aids the motion of the lips, termed zygomaticus.

4. The "chewing" muscle, or masseter.

5. The muscle which depresses the lower lips, termed depressor labii inferioris.

6. The circular muscle of the eyelid, termed orbicularis palpebrarum.

7. The muscle which raises the upper eyelid, termed levator palpebrce superioris.

8. A muscle which abducts and depresses the ear, termed abducens vel deprimens aurem.

9. A muscle which raises the fore extremity.

10. A muscle which aids in the act of chewing, and also in depressing the head. It is called sterno maxillaris.

11. The triangular muscle over the region of the shoulder, termed trapezius.

12. This muscle draws the arm backwards, and aids the motions of the trunk. It is named latissimus dorsi.

13. A muscle of the chest known as pectoralis magnus.

14, 14. An abdominal muscle called external oblique.

14. A muscle of the haunch, known as the gluteus.

16. The muscles in this region aid in extending the thigh; the region is the seat of the fascia lata.

17 and 18. Muscles known as biceps and triceps.

19. An abdominal muscle, termed transverse.

\section{EXPLANATION OF CUT OF THE HEART.}

1,1 , and 3. Divided surfaces of the left ventricle.

2. One of the divided surfaces of right ventricle.

4. Large fleshy eminence or pillar within the left ventricle. 
6. Mitral valve.

15, 7, 24. The right anricular region.

8. Base of the left auricle.

10, 10. Division of the valves on the left side of the heart.

12. The vena cava, which empties the renous blood into the right a uricle.

13. Carnæ columnæ, or fleshy pillars within the right rentricle.

14. A portion of the tricuspid valve.

15. The region of the left auricle.

16, 16. Pulmonary veins, which return the blood from the lnngs to the left auricle.

17. Great aorta.

19. A probe inserted into one of the pulmonary veins. (The lower end of the probe should be seen at 6 , but the artist has failed to show it.)

20. A probe inserted into one of the pulmonary arteries; the other artery is in close contact with the former: they both carry blood to the lungs for oxygenation.

22 , which is seen under 14 , is the tendinous cords of the right ventricle.

$22,22,22$, are the transverse bands running across the ventricles.

$23,23,23$. The tendinous cords of the left rentricle.

24. Base of the right auricle.

25. A portion of the os cordis, or bone of the heart.

\section{STRUCTURE OF THE HEAD AND HORNS.}

1. The osseous, or bony structure of horn.

2. The frontal bone.

3, 3. The frontal sinus, which extends from the bones of the nose nearly up to the tip of the horn.

4. The round, or condyloid process, and the region where the spinal marrow passes from the skull.

5. The cranial cavity in which the brain is lodged.

6.' A portion of the temporal bone.

7. Inlet to the ear.

8. Internal surface of the check bone.

13, 14. Portion of the athmoid and sphenoid bones.

18. The æthmoid bone.

19. Turbinated bone 


\section{EXPLANATION OF THE PLATE OF DISEASED BONES.}

1, 2. Dilatation of the shank bone - beneath the knee of a cow. The bone is sawn through its centre for the purpose of showing the interior; which, the reader will perceive, is very much dilated, especially about the centre of the bone. Before the death of the animal this cavity was occupied by matter resenbling pus.

2. Shows the exterior of 1 .

3. This is a case of caries, or ulceration of the jaw bone.

4. This constitutes dilatation of the jaw bone, a disease similar to that shown in 1.

5. This is a specimen of malignant disease of the jaw bone known as cancer. Cancer has no respect for tissues, but involves all contiguous parts in ruin.

6. This is non-malignant tumor, and is occasioned by a disease known as ostitis A small orifice will be perceived at the upper part of the tumor through which the extensor tendons passed, and thus their free action was secured; therefore, as the disease respected the tissues in the immediate vicinity, I call it non-malignant.

\section{DESCRIPTION OF “LADY WASHINGTON."}

The mammoth cow, "Lady Washington," whose portrait is truthfully delineated in the cut, is the property of Winthrop W. Chenery, Esq., of Belmont, Mass. She was dropped Feb. 22, 1854, and is, therefore, now but five years old. Her weight is three thousand two hundred and sixty pounds! This extraordinary growth has not been attained by high feeding, as, from a calf to the age of two years, she was herded with, and fared the same as, ordinary calves and yearlings. The third and fourth summers, when the feed became short in the pasture, she had a little meal. She is of the Durham breed, from a stock known in the vicinity of Lake Champlain as the "Keyes Importation." She was raised in Pittsford, Vt. Her dam was a first rate milker, and of extraordinary size; her weight, when not quite five years old, having been two thousand pounds.

"Lady Washington" has dropped three calves - the two last having weighed, at birth, respectively, one hnndred and thirty-nine, and one hundred and thirty-two pounds. Her last calf, when five months and six days old, weighed six hundred and twenty pounds, and before reaching the age of twelve months his weight was twelve hundred pounds. She is now in calf by the imported Dutch bull, "Dutchman," from which cross ker owner anticipates highly gratifying results. 
This cow is the largest $I$ have ever had the pleasure of seeing. She is of elephantine proportions, as the reader will perceive by the contrast between her and an Ayrshire cow, which the artist has introduced for the purpose of judging of her form and size. 
.
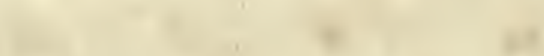

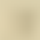

y.

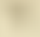

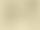

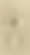

$-1$

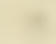

$(-1)^{4}$

Univ Calif - Digitized by Alicrosoft (i) 


\section{$\cos =x^{2}$}

wis?

(4)

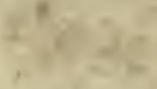

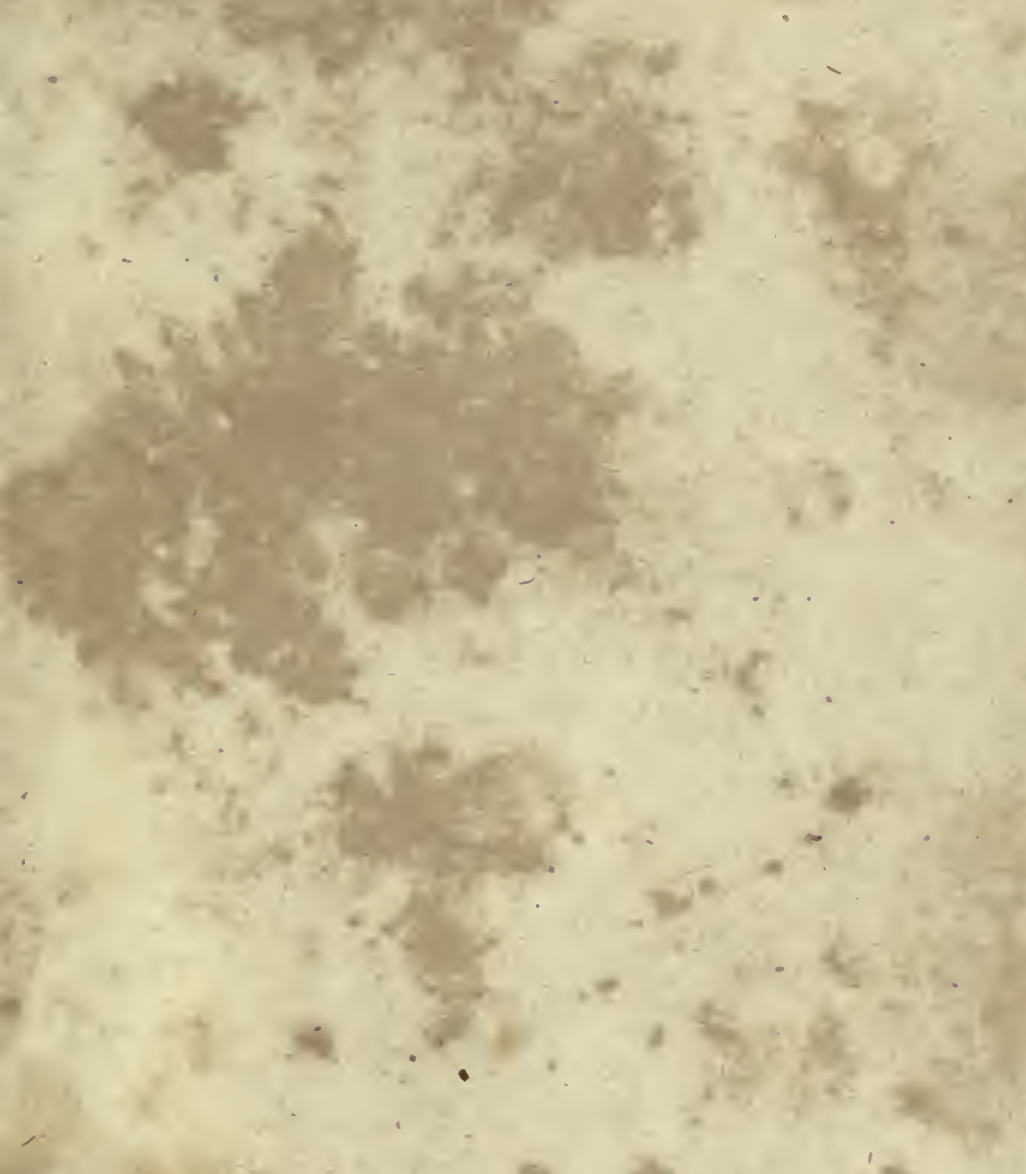

$r$

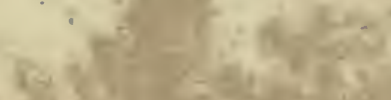

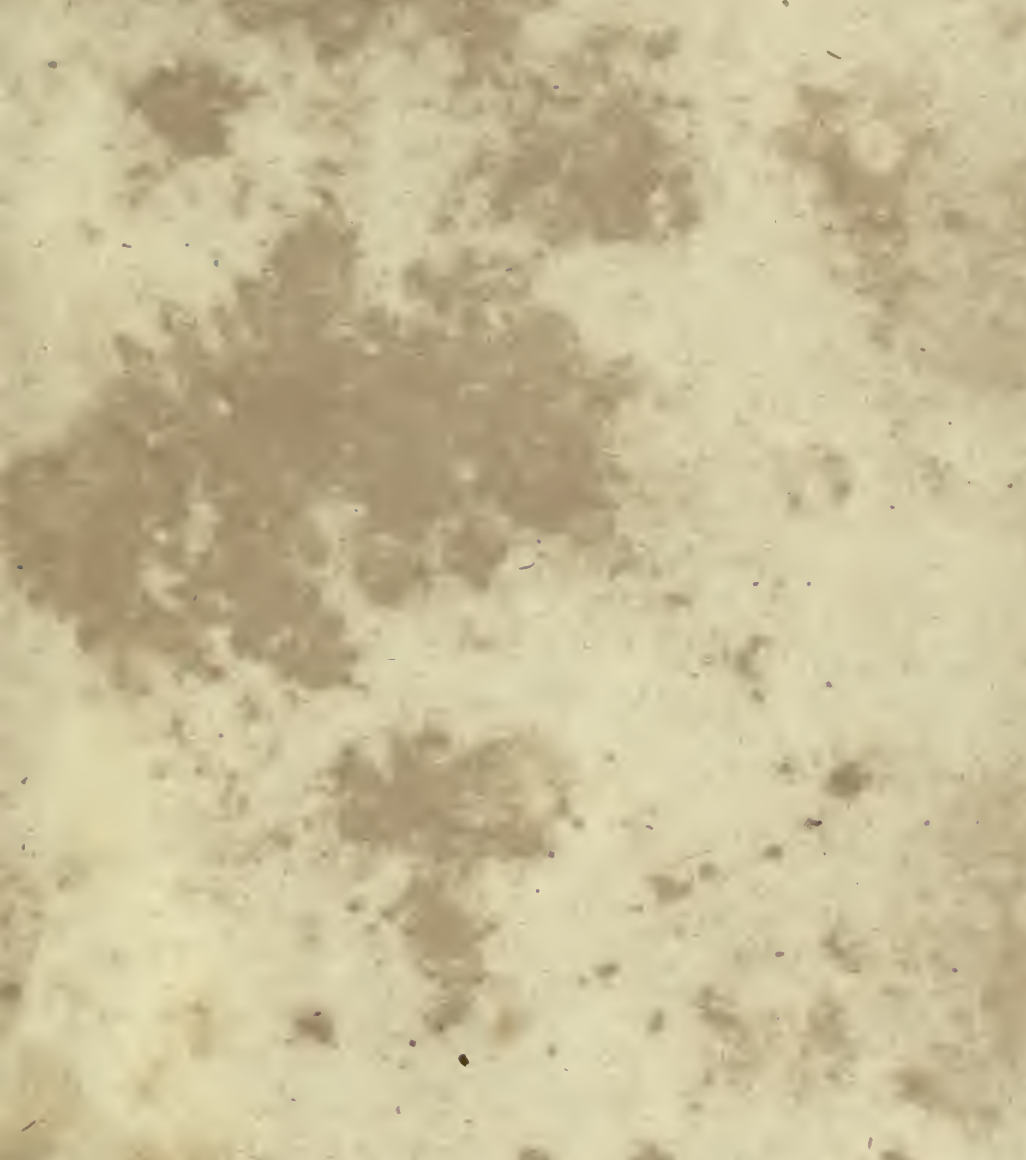

$\lim _{4} \log ^{2}$

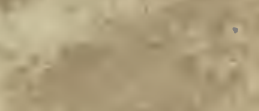

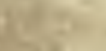

$$
4+5-4=
$$

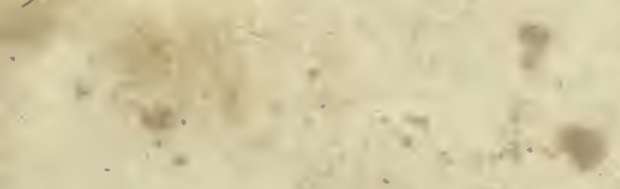

L.

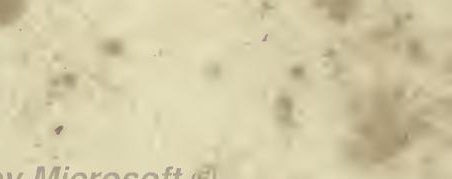

Unıv Calif - Digitized by Microsoft (하 


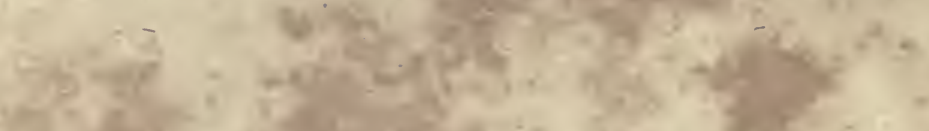

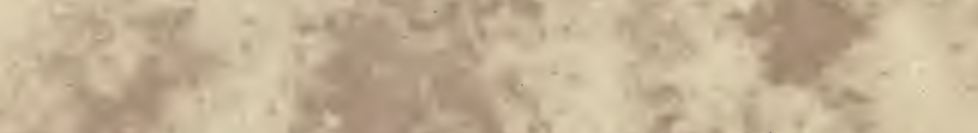

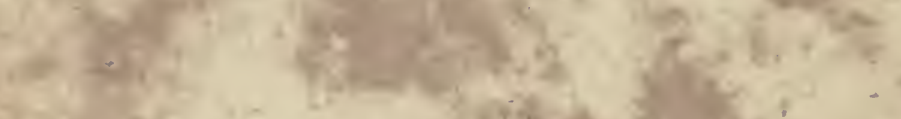

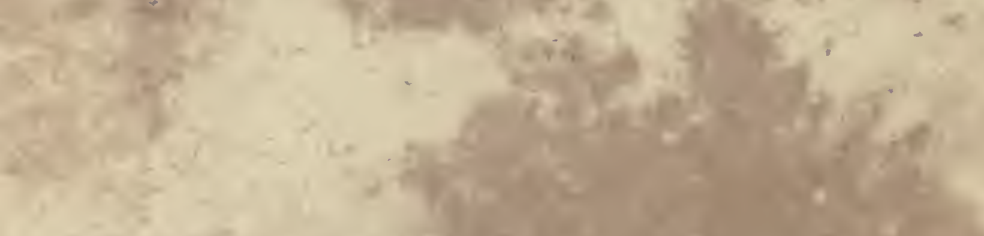

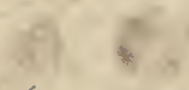

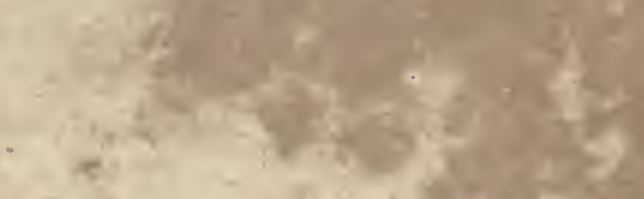

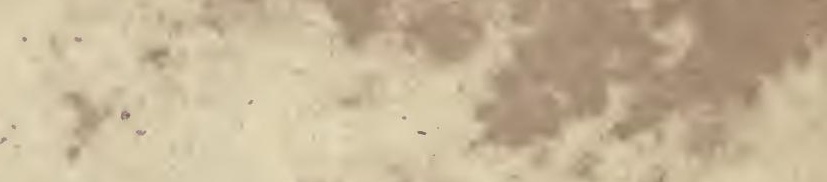
fo: if

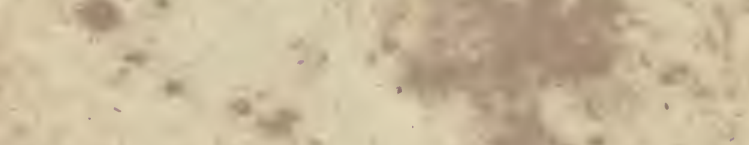
Ar y is.

$4 x^{3}>0$

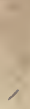
toxis 2 a. Wets

A<smiles>[AlH2]</smiles><smiles>CC1[C@@H](C)C(C)(C)[C@@H]1C</smiles><smiles>CCCC[C@H]1CCCC12CCCC2</smiles>

8

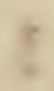

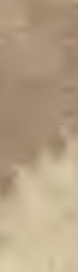


1. 


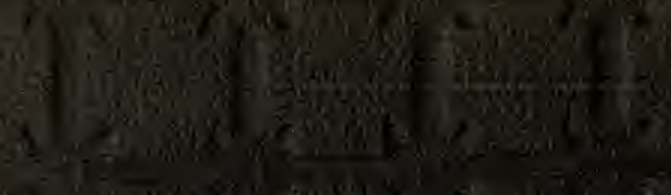

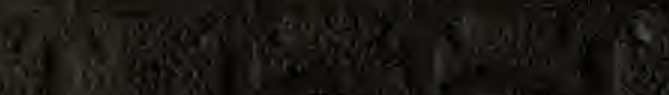

ard Whatis?

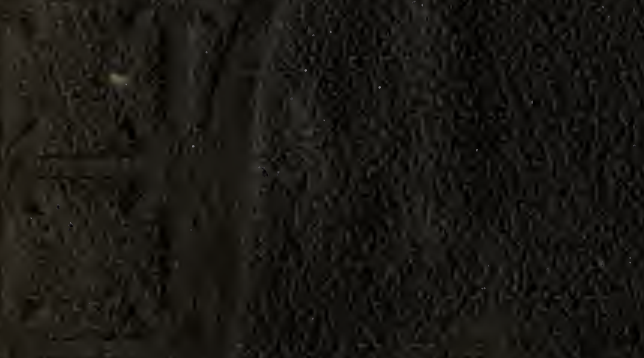

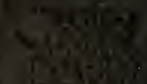

$x^{2} \times x^{2}$

3078

Divisis

ton

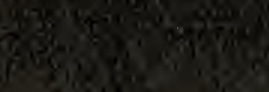

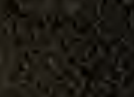

ris

$16=8$

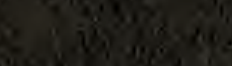

(t)

$\lim _{2} \lim ^{2}$

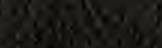

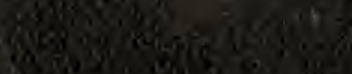

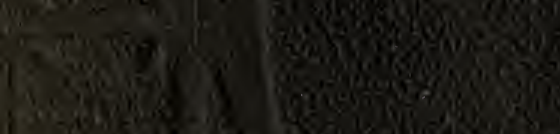

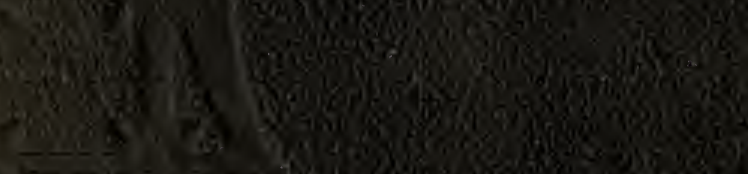
ing

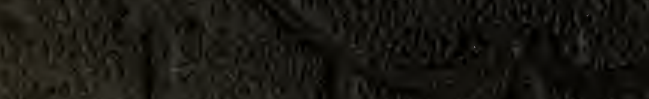

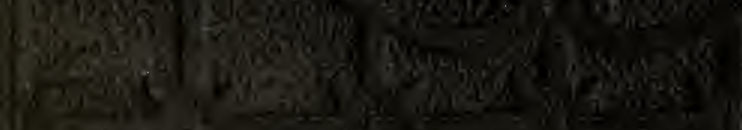

- 4 .

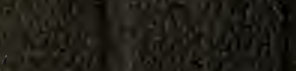

